RUTH NATALIA TERESA TURRINI

\title{
ENSINO DE ENFERMAGEM EM CENTRO CIRÚRGICO NOS CURSOS DE BACHARELADO EM ENFERMAGEM DO BRASIL
}




\title{
RUTH NATALIA TERESA TURRINI
}

\section{ENSINO DE ENFERMAGEM EM CENTRO CIRÚRGICO NOS CURSOS DE BACHARELADO EM ENFERMAGEM DO BRASIL}

\begin{abstract}
Tese apresentada à Escola de Enfermagem para inscrição no concurso para obtenção do título de Professor Livre Docente na área de Enfermagem em Centro Cirúrgico junto ao Departamento de Enfermagem Médico Cirúrgica.
\end{abstract}


AUTORIZO A REPRODUÇÃO E DIVULGAÇÃO TOTAL OU PARCIAL DESTE TRABALHO, POR QUALQUER MEIO CONVENCIONAL OU ELETRÔNICO, PARA FINS DE ESTUDO E PESQUISA, DESDE QUE CITADA A FONTE.

Assinatura:

Data:

Escola de Enfermagem da Universidade de São Paulo

Turrini, Ruth Natalia Teresa

Ensino de enfermagem em centro cirúrgico nos cursos de bacharelado em enfermagem do Brasil / Ruth Natalia Teresa Turrini - São Paulo, 2012.

$216 p$.

Tese (Livre-docência) - Escola de Enfermagem da Universidade de São Paulo. Departamento de Enfermagem Médico - cirúrgica.

1. Enfermagem em centro cirúrgico - Estudo e ensino 2. Curso de graduação 3. Ensino superior 4. Currículos e programas I. Título. 


\section{Dedicatória}

Aos meus pais que me deram condições de chegar até aqui e a todos aqueles que apostam em mim. 


\section{Agradecimentos}

Aos meus colegas de disciplina pelo apoio e incentivo.

A todas as secretarias que me atenderam prontamente. Aos meus alunos pela paciência nesse momento difícil. E

A todos aqueles que direta ou indiretamente me acompanharam nesta caminhada 
Turrini RNT. Ensino de Enfermagem em Centro Cirúrgico nos cursos de bacharelado em Enfermagem do Brasil. [tese de Livre Docência] São Paulo: Escola de Enfermagem, Universidade de São Paulo; 2012.

\section{RESUMO}

As mudanças curriculares têm alterado o foco de atenção do ensino do indivíduo para a coletividade e nesta abordagem conteúdos, como o de centro cirúrgico, tendem a ser excluídos dos currículos de graduação em enfermagem. A presente investigação tem por finalidade conhecer como é oferecido o conteúdo de centro cirúrgico no país e verificar qual a opinião dos professores ou coordenadores dos cursos de enfermagem sobre sua importância na formação do enfermeiro. Método. Estudo descritivo e exploratório de abordagem quanti-qualitativa que utilizou instrumento com perguntas fechadas e abertas, que teve algumas modificações após o pré-teste. Por meio de contato eletrônico com as instituições de ensino superior, a partir de relação obtida no site do Ministério da Educação tentou-se obter o contato dos coordenadores dos cursos de bacharelado em enfermagem, para envio do questionário por e-mail com convite para participação na pesquisa. Para a análise dos dados utilizaram-se freqüências relativas e absolutas, medidas de tendência central e variabilidade, teste de proporções, teste de diferença de médias para as variáveis quantitativas e análise de conteúdo para as variáveis qualitativas. Resultados. Dos contatos realizados houve retorno de 29,8\% (251) com 159 (19,8\%) questionários respondidos. A porcentagem de escolas participantes foi semelhante entre as regiões, exceção a região nordeste que foi inferior; $32,0 \%$ localizavam-se em capitais; $76,7 \%$ de gestão privada; carga horária do curso variou 3.500 a $5.850 \mathrm{~h} ; 44,0 \%$ duração de dez semestres. Quanto a presença do conteúdo na grade curricular, apenas um dos respondentes não oferece o conteúdo. A média da carga horária total do curso foi de 94,7h (DP $\pm 80 \mathrm{~h})$; média da carga horária teórica 56,1h (DP $\pm 29,9 \mathrm{~h})$; média da carga horária prática $42,3 \mathrm{~h}(\mathrm{DP} \pm 33,2 \mathrm{~h}) ; 67,3 \%$ têm uma disciplina específica de centro cirúrgico. Nas disciplinas específicas a carga horária teórica é maior que a prática e também maior em relação ao grupo que possui o conteúdo inserido em outras disciplinas. As denominações das disciplinas onde se insere o conteúdo de centro cirúrgico foram muito variadas e em alguns cursos o conteúdo está disperso em duas ou três disciplinas. O conteúdo administrado envolve as técnicas usuais em centro cirúrgico e a sistematização da assistência perioperatória. Os conteúdos menos administrados forma instrumentação cirúrgica, cirurgia ambulatorial e avanços tecnológicos (cerca de 50\%). Número de docentes responsáveis pelo conteúdo variou de 1 a 6 , com média de 2,5 (DP $\pm 2,2)$. Quanto a opinião sobre a importância do conteúdo na formação profissional: é essencial para a formação do enfermeiro generalista pois há demanda no mercado e poucos enfermeiros com curso de especialização na área, agrega conhecimentos de outras disciplinas (interdisciplinaridade); é transversal a outros conteúdos da ciência da enfermagem; permite ao aluno identificar o papel do enfermeiro de entro cirúrgico. Respondentes desejariam maior carga horária, pois o conteúdo é denso. Conclusões. É indiscutível a importância do conteúdo de centro cirúrgico na formação do enfermeiro, é preciso traçar diretrizes para carga horária mínima tanto teórica quanto prática e definir qual o conteúdo básico para a formação do enfermeiro generalista.

Descritores: Enfermagem Perioperatória. Educação Superior. Currículo. Bacharelado em Enfermagem 
Turrini RNT. Perioperative nursing education in the Nursing Baccalaureate Programs in Brazil [thesis]. São Paulo(SP), Brasil: Escola de Enfermagem, Universidade de São Paulo; 2012.

\begin{abstract}
Changes in curricula have altered the focus of education from individuals to the community and in this process some discipline as perioperative nursing are at risk of disappearing from the curriculum programs. The aim of this investigation it is to identify the way perioperative nursing has been taught in Brazil Nursing Colleges and to verify the opinion of professors about the importance of operating room contents to the undergraduate students. Methods. Descriptive and exploratory study with a quantitative and qualitative approach that used an instrument with open and closed questions. After pretesting, the questionnaire was sent by e-mail to the Nursing Colleges in Brazil with an invitation to participate in the study. The list of the schools was obtained from the site of the Education Ministry. Quantitative data were analyzed by relative and absolute frequencies, measures of central tendency and variability, proportion test, Mann Whitney or Kruskall Wallis tests and content analysis to the qualitative data. Results. It was received 251 (29.8\%) answers from the e-mail contact, but only $19.8 \%$ (159) fulfilled the questionnaire. The proportion of schools participating in the study was similar between Brazilian regions, except in northeast were there was fewer participation; $32.0 \%$ of the schools were located in capital cities; $76,7 \%$ were private schools; hour course ranged from 3.500 to $5.850 \mathrm{~h}$; $44.0 \%$ of the courses were 10 semesters long. Only one answered that the school don't offer a perioperative course. The mean hour of the total perioperative course was $94.7 \mathrm{~h}(\mathrm{DP} \pm 80 \mathrm{~h})$; the mean hour of clinical practice was $42.3 \mathrm{~h}(\mathrm{DP} \pm 33.2 \mathrm{~h})$ and theory has a mean of $56.1 \mathrm{~h}(\mathrm{DP} \pm 29.9 \mathrm{~h}) ; 67.3 \%$ has a perioperative nursing course in the curriculum program and the others have this content inside other courses. In perioperative course the hour theory is higher than the practice hour. Comparing to the situation when the content is offered inside an other discipline the perioperative courses have higher hour practices. These other disciplines have different names, and in some cases the content is spread inside two or three disciplines. The program contains the usual techniques of operating room practice and the nursing process. The issues less taught were surgical instrumentation, ambulatory surgery and technology advances (about 50.0\%). The number of professors involved with the course ranged from 1 to 6 , a mean of 2.5 (DP \pm 2.2 ). Opinions about the importance of perioperative nursing to the future nurses were: the content is essential to generalist nurses because hospitals need nurses to working in operating theaters and there are few specialists; it is a interdisciplinary content; it is transversal to others nursing contents; allow students to identify the role of the perioperative nurses. Professors claim for more hours to the course because there are a lot of content. Conclusions. There is no doubt about the importance of perioperative nursing contents in curriculum programs to prepare the students to the possibility of working in an operating theater. It is need recommendations about the ideal hour theory and hour clinical practice to the perioperative nursing courses and to define which is the ideal content of perioperative nursing to be included in curricula.
\end{abstract}

Descriptors. Perioperative Nursing. Education, Higher. Education Nursing Baccalaureate. Nursing. Curriculum. 


\section{LISTA DE FIGURAS}

Figura 1 - Distribuição de cursos de Enfermagem segundo tipo instituição quanto à sua administração. Brasil, 2011

Figura 2 - Distribuição de cursos de Enfermagem segundo classificação do estabelecimento de ensino. Brasil, 2011.

Figura 3 - Frequência absoluta e relativa dos cursos de Enfermagem segundo estado e região do país. Brasil, 2011.

Figura 4 - Distribuição de turmas segundo o período e tipo de administração. Brasil, 2011.

Figura 5 - Distribuição de vagas (\%) por região por período. Brasil, 2011.

Figura 6 - Mapa do Estado do Acre e cidades com curso de bacharelado presencial em Enfermagem. Brasil, 2011.

Figura 7 - Mapa do Estado do Amazonas e cidades com curso de bacharelado presencial em Enfermagem. Brasil, 2011.

Figura 8 - Mapa do Estado do Amapá e cidades com curso de bacharelado presencial em Enfermagem. Brasil, 2011.....

Figura 9 - Mapa do Estado do Pará e cidades com curso de bacharelado presencial em Enfermagem. Brasil, 2011.

Figura 10 - Mapa do Estado de Rondônia e cidades com curso de bacharelado presencial em Enfermagem. Brasil, 2011.

Figura 11 - Mapa do Estado de Roraima e cidades com curso de bacharelado presencial em Enfermagem. Brasil, 2011.

Figura 12 - Mapa do Estado de Tocantins e cidades com curso de bacharelado presencial em Enfermagem. Brasil, 2011.

Figura 13 - Mapa do Estado de Alagoas e cidades com curso de bacharelado presencial em Enfermagem. Brasil, 2011.

Figura 14 - Mapa do Estado da Bahia e cidades com curso de bacharelado presencial em Enfermagem. Brasil, 2011.

Figura 15 - Mapa do Estado do Ceará e cidades com curso de bacharelado presencial em Enfermagem. Brasil, 2011

Figura 16 - Mapa do Estado de Maranhão e cidades com curso de bacharelado presencial em Enfermagem. Brasil, 2011.

Figura 17 - Mapa do Estado da Paraíba e cidades com curso de bacharelado presencial em Enfermagem. Brasil, 2011.

Figura 18 - Mapa do Estado de Pernambuco e cidades com curso de bacharelado presencial em Enfermagem. Brasil, 2011

Figura 19 - Mapa do Estado do Piauí e cidades com curso de bacharelado presencial em Enfermagem. Brasil, 2011.

Figura 20 - Mapa do Estado do Rio Grande do Norte e cidades com curso de bacharelado presencial em Enfermagem. Brasil, 2011.

Figura 21 - Mapa do Estado do Sergipe e cidades com curso de bacharelado presencial em Enfermagem. Brasil, 2011. 
Figura 22 - Mapa do Distrito Federal. Brasil, 2011..

Figura 23 - Mapa do Estado de Goiás e cidades com curso de bacharelado presencial em Enfermagem. Brasil, 2011....

Figura 24 - Mapa do Estado de Mato Grosso e cidades com curso de bacharelado presencial em Enfermagem. Brasil, 2011.

Figura 25 - Mapa do Estado de Mato Grosso do Sul e cidades com curso de bacharelado presencial em Enfermagem. Brasil, 2011.

Figura 26 - Mapa do Estado de Espírito Santo e cidades com curso de bacharelado presencial em Enfermagem. Brasil, 2011

Figura 27 - Mapa do Estado de Minas Gerais e cidades com curso de bacharelado presencial em Enfermagem. Brasil, 2011

Figura 28 - Mapa do Estado do Rio de Janeiro e cidades com curso de bacharelado presencial em Enfermagem. Brasil, 2011

Figura 29 - Mapa do Estado de São Paulo e cidades com curso de bacharelado presencial em Enfermagem. Brasil, 2011.

Figura 30 - Mapa do Estado do Paraná e cidades com curso de bacharelado presencial em Enfermagem. Brasil, 2011.

Figura 31 - Mapa do Estado de Santa Catarina e cidades com curso de bacharelado presencial em Enfermagem. Brasil, 2011

Figura 32 - Mapa do Estado do Rio Grande do Sul e cidades com curso de bacharelado presencial em Enfermagem. Brasil, 2011.

Figura 33 - Proporção de cursos com participação no estudo segundo região do país. Brasil, 2011

Figura 34 - Proporção de cursos segundo a localização da escola por regiões, na amostra e no país. Brasil, 2011.

Figura 35 - Proporção de cursos que preencheram o questionário segundo a região e a entidade mantenedora. Brasil, 2011.

Figura 36 - Proporção de vagas dos cursos que preencheram o questionário por região por período e no país. Brasil, 2011.

Figura 37 - Distribuição de cursos por regiões e carga horária no país. Brasil, 2011.......... 113

Figura 38 - Proporção de cursos segundo o período e carga horária. Brasil, 2011 ............... 114

Figura 39 - Proporção de cursos segundo a duração em semestres. Brasil, 2011 ................. 114

Figura 40 - Distribuição da carga horária total de CC e box plot. Brasil, 2011 ..................... 115

Figura 41 - Distribuição da carga horária teórica de CC e box plot. Brasil, 2011 ................ 116

Figura 42 - Distribuição da carga horária prática de CC e Box plot. Brasil, 2011 ............... 116

Figura 43 - Distribuição da carga horária teórica de CC nos cursos com disciplina específica e box plot. Brasil, 2011

Figura 44 - Distribuição da carga horária prática de CC nos cursos com disciplina específica e box plot. Brasil, 2011

Figura 45 - Distribuição da carga horária teórica de CC e box plot nos cursos com conteúdo de CC em outras disciplinas. Brasil, 2011 
Figura 46 - Distribuição da carga horária prática de CC e box plot nos cursos com conteúdo de CC em outras disciplinas. Brasil, 2011

Figura 47 - Distribuição da carga horária total de CC e box plot nos cursos com disciplina específica. Brasil, 2011

Figura 48 - Distribuição da carga horária total de CC e box plot nos cursos com conteúdo de CC inserido em outras disciplinas. Brasil, 2011

Figura 49 - Representação do intervalo interquartil quando a carga horária teórica foi superior que a prática nas disciplinas específicas (A) e nas disciplinas inespecíficas (B) de CC. Brasil, 2011.

Figura 50 - Representação do intervalo interquartil quando a carga horária prática foi superior a teórica nas disciplinas específicas (A) e inespecíficas (B) de CC. Brasil, 2011.

Figura 51 - Distribuição de cursos de enfermagem segundo o número de docentes. Brasil, 2011 


\section{LISTA DE TABELAS}

Tabela 1 - Número de postos de trabalho de enfermeiros por 100 leitos e número de enfermeiros por 100 leitos segundo região e unidades da federação. Brasil, 2009.

Tabela 2 - Frequência de Procedimentos cirúrgicos segundo complexidade e unidade da federação e região. Brasil, 2009.

Tabela 3 - Frequência de enfermeiros e enfermeiros de centro cirúrgico, relação de enfermeiros de centro cirúrgico/ 100 procedimentos cirúrgicos por região e unidade da federação. Brasil, 2009.

Tabela 4 - Distribuição de cursos de Enfermagem segundo região do país. Brasil, 2011 _.....45

Tabela 5 - Distribuição de cursos de Enfermagem segundo o tipo de instituição e o tipo de administração da entidade mantenedora. Brasil, 2011.

Tabela 6 - Distribuição de Cursos de Bacharelado em Enfermagem segundo o tipo de administração e a região do país. Brasil, 2011.

Tabela 7 - Distribuição de Cursos de Bacharelado em Enfermagem segundo o tipo de instituição e a região do país. Brasil, 2011.

Tabela 8 - Distribuição de Curso de Enfermagem segundo carga horária do curso. Brasil, 2011.

Tabela 9 - Distribuição de Cursos de Enfermagem segundo carga horária e entidade mantenedora. Brasil, 2011

Tabela 10 - Distribuição de Cursos de Enfermagem segundo carga horária e região. Brasil, 2011.

Tabela 11 - Distribuição das turmas dos Cursos de Enfermagem segundo período e região. Brasil, 2011.

Tabela 12 - Distribuição das respostas aos e-mails enviados, segundo retorno de resposta

e retorno de questionário por unidade a federação. Brasil, 2011.

Tabela 13 - Distribuição de vagas por período dos cursos de enfermagem e dos que ministram o conteúdo de CC por unidade da federação. Brasil, 2011.

Tabela 14 - Distribuição de carga horária teórica e prática, para os cursos que oferecem uma disciplina específica de CC. Brasil, 2011.

Tabela 15 - Distribuição de disciplinas que integram CC, segundo carga horária da disciplina e a relativa ao conteúdo de CC. Brasil, 2011.

Tabela 16 - Distribuição de carga horária total para os cursos que oferecem uma disciplina específica de CC e dentro de outra disciplina. Brasil, 2011

Tabela 17 - Distribuição das cargas horárias segundo a relação entre teoria e prática. Brasil, 2011.

Tabela 18 - Distribuição de cursos de enfermagem segundo o fato da disciplina ser específica ou não e o semestre em que o conteúdo é ministrado. Brasil, 2011. 130

Tabela 19 - Frequência de temas de CC assinalados pelos respondentes. Brasil, 2011.

Tabela 20 - Distribuição de cursos segundo ter uma disciplina específica de CC e o número de docentes de CC. Brasil, 2011.

Tabela 21 - Distribuição de cursos segundo o número de docentes de CC e o tipo de gestão das escolas. Brasil, 2011. 
Tabela 22 - Distribuição de cursos segundo o número de docentes de $\mathrm{CC}$ e a região das escolas. Brasil, 2011.

Tabela 23 - Distribuição de cursos segundo o número de docentes com curso de especialização em CC. Brasil, 2011.

Tabela 24 - Frequência de cursos segundo a distribuição entre teoria e prática. Brasil, 2011.

Tabela 25 - Distribuição dos conteúdos das respostas de acordo com as categorias estabelecidas. Brasil, 2011.

Tabela 26 - Distribuição dos locais mencionados para desenvolvimento das atividades de campo. Brasil, 2011.

Tabela 27 - Distribuição das atividades desenvolvidas pelos alunos em campo de prática. Brasil, 2011.

Tabela 28 - Distribuição do número de alunos por supervisor de estágio. Brasil, 2011_......144

Tabela 29 - Distribuição dos cursos segundo tempo de estágio. Brasil, 2011.

Tabela 30 - Distribuição de opiniões emitidas sobre a importância do conteúdo para a atuação do enfermeiro. Brasil, 2011.

Tabela 31 - Distribuição de escolas que oferecem a especialização em CC, segundo o número de especializações. Brasil, 2011. 


\section{LISTA DE QUADROS}

Quadro 1 - Dados sobre população, extensão territorial densidade demográfica, número de cursos de bacharelado, vagas oferecidas e número de vagas/10.000 hab.

Acre, 2010.

Quadro 2 - Dados sobre população, extensão territorial densidade demográfica, número de cursos de bacharelado, vagas oferecidas e número de vagas/10.000 hab. Amazonas, 2010.

Quadro 3 - Dados sobre população, extensão territorial densidade demográfica, número de cursos de bacharelado, vagas oferecidas e número de vagas/10.000 hab. Amapá, 2010.

Quadro 4 - Dados sobre população, extensão territorial densidade demográfica, número de cursos de bacharelado, vagas oferecidas e número de vagas/10.000 hab. Pará, 2010.

Quadro 5 - Dados sobre população, extensão territorial densidade demográfica, número de cursos de bacharelado, vagas oferecidas e número de vagas/10.000 hab. Rondônia 2010.

Quadro 6 - Dados sobre população, extensão territorial densidade demográfica, número de cursos de bacharelado, vagas oferecidas e número de vagas/10.000 hab. Roraima, 2010.

Quadro 7 - Dados sobre população, extensão territorial densidade demográfica, número de cursos de bacharelado, vagas oferecidas e número de vagas/10.000 hab. Tocantins, 2010 .

Quadro 8 - Dados sobre população, extensão territorial densidade demográfica, número de cursos de bacharelado, vagas oferecidas e número de vagas/10.000 hab. Alagoas, 2010.

Quadro 9 - Dados sobre população, extensão territorial densidade demográfica, número de cursos de bacharelado, vagas oferecidas e número de vagas/10.000 hab. Bahia, 2010.

Quadro 10 - Dados sobre população, extensão territorial densidade demográfica, número de cursos de bacharelado, vagas oferecidas e número de vagas/10.000 hab. Ceará, 2010.

Quadro 11 - Dados sobre população, extensão territorial densidade demográfica, número de cursos de bacharelado, vagas oferecidas e número de vagas/10.000 hab. Maranhão, 2010.

Quadro 12 - Dados sobre população, extensão territorial densidade demográfica, número de cursos de bacharelado, vagas oferecidas e número de vagas/10.000 hab. Paraíba, 2010.

Quadro 13 - Dados sobre população, extensão territorial densidade demográfica, número de cursos de bacharelado, vagas oferecidas e número de vagas/10.000 hab. Pernambuco, 2010 .

Quadro 14 - Dados sobre população, extensão territorial densidade demográfica, número de cursos de bacharelado, vagas oferecidas e número de vagas/10.000 hab. Piauí, 2010.

Quadro 15 - Dados sobre população, extensão territorial densidade demográfica, número de cursos de bacharelado, vagas oferecidas e número de vagas/10.000 hab. Rio Grande do Norte, 2010. 
Quadro 16 - Dados sobre população, extensão territorial densidade demográfica, número de cursos de bacharelado, vagas oferecidas e número de vagas/10.000 hab.

Sergipe, 2010.

Quadro 17 - Dados sobre população, extensão territorial densidade demográfica, número de cursos de bacharelado, vagas oferecidas e número de vagas/10.000 hab. Brasília, 2010.

Quadro 18 - Dados sobre população, extensão territorial densidade demográfica, número de cursos de bacharelado, vagas oferecidas e número de vagas/10.000 hab. Goiás, 2010.

Quadro 19 - Dados sobre população, extensão territorial densidade demográfica, número de cursos de bacharelado, vagas oferecidas e número de vagas/10.000 hab. Mato Grosso, 2010

Quadro 20 - Dados sobre população, extensão territorial densidade demográfica, número de cursos de bacharelado, vagas oferecidas e número de vagas/10.000 hab. Mato Grosso do Sul, 2010.

Quadro 21 - Dados sobre população, extensão territorial densidade demográfica, número de cursos de bacharelado, vagas oferecidas e número de vagas/10.000 hab. Espírito Santo, 2010.

Quadro 22 - Dados sobre população, extensão territorial densidade demográfica, número de cursos de bacharelado, vagas oferecidas e número de vagas/10.000 hab. Minas Gerais, 2010.

Quadro 23 - Dados sobre população, extensão territorial densidade demográfica, número de cursos de bacharelado, vagas oferecidas e número de vagas/10.000 hab. Rio de Janeiro, 2010.

Quadro 24 - Dados sobre população, extensão territorial densidade demográfica, número de cursos de bacharelado, vagas oferecidas e número de vagas/10.000 hab. São Paulo, 2010.

Quadro 25 - Dados sobre população, extensão territorial densidade demográfica, número de cursos de bacharelado, vagas oferecidas e número de vagas/10.000 hab. Paraná, 2010.

Quadro 26 - Dados sobre população, extensão territorial densidade demográfica, número de cursos de bacharelado, vagas oferecidas e número de vagas/10.000 hab. Santa Catarina, 2010.

Quadro 27 - Dados sobre população, extensão territorial densidade demográfica, número de cursos de bacharelado, vagas oferecidas e número de vagas/10.000 hab. Rio Grande do Sul, 2010.

Quadro 28 - Medidas de tendência central e de dispersão para o número de docentes de acordo com presença de disciplina específica, tipo de gestão e região do país. Brasil, 2011.

Quadro 29 - Medidas de tendência central e de variabilidade segundo o número de docentes com curso de especialização em CC e a região. Brasil, 2011 


\section{LISTA DE ABREVIATURAS E SIGLAS}

AACN: American Association Colleges of Nursing

AC: Acre

ACORN Australian College of Operating Room Nurses

AL: Alagoas

AM: Amazonas

AORN : Association of periOperative Registered Nurses

AP: Amapá

BA: Bahia

CC: centro cirúrgico

CE: Ceará

CES: Câmara de Ensino Superior

CFE: Conselho Federal de Educação

CME: Centro de Material e Esterilização

CNE: Conselho Nacional de Educação

CNES: Cadastro nacional de Estabelecimentos de Saúde

CO: centro-oeste

COFEN: Conselho Federal de Enfermagem

COREN: Conselho Regional de Enfermagem

Datasus: Sistema Nacional de Banco de Dados do Ministério da Saúde

DF: Distrito Federal

ECC: Enfermagem em Centro Cirúrgico

ECM: Enfermagem em Centro de Material

EEUSP: Escola de Enfermagem da Universidade de São Paulo

ES: Espírito Santo

GO: Goiás

IBGE: Instituo Brasileiro de Geografia e Estatística

IES: Instituição de Ensino Superior

INEP: Instituto Nacional de Estudos e Pesquisa Educacionais Anísio Teixeira

ISC: infecção de sítio cirúrgico

LE: laboratório de enfermagem

MA: Maranhão 
MEC: Ministério da Educação

MG: Minas Gerais

MS: Mato Grosso do Sul

MT: Mato Grosso

$\mathrm{N}$ : norte

NANDA: North American Nursing Diagnoses Association

NE: nordeste

NSNA: National Student Nurses' Association

PA: Pará

PB: Paraíba

PE: Pernambuco

PE: processo de enfermagem

PI: Piauí

PNDS: Perioperative Nursing Data Set

PR: Paraná

RJ: Rio de janeiro

RN: Rio Grande do Norte

RO: Rondônia

RR: Roraima

RS: Rio Grande do Sul

S: sul

SAEP: Sistematização da Assistência Perioperatória

SC: Santa Catarina

SE: Sergipe

SE: sudeste

SESU: Secretaria da Educação Superior

SGTES: Secretaria de Gestão do Trabalho e da Educação Superior

SO: sala operatória

SOBECC: Sociedade Brasileira de Enfermeiros de Centro Cirúrgico, Recuperação Anestésica e Centro de Material e Esterilização.

SP: São Paulo

TO: Tocantins 


\section{SUMÁRIO}

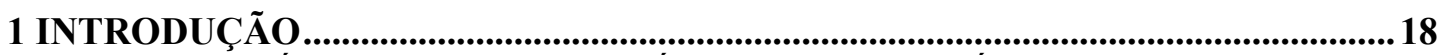

1.1 O CONTEÚDO DE CENTRO CIRÚRGICO NO CURRÍCULO DO BRASIL .........24

1.2 CONTEÚDO DE CENTRO CIRÚRGICO NO CURRÍCULO DA ESCOLA DE ENFERMAGEM DA UNIVERSIDADE DE SÃO PAULO ….......................................30

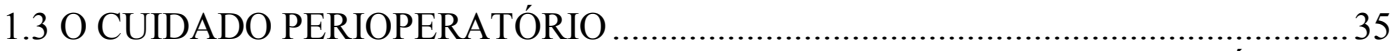

1.4 DEMANDA DE CIRURGIAS E RECURSOS DE ENFERMAGEM NO PAÍS ..........40

1.5 PANORAMA NACIONAL DAS INSTITUIÇÕES DE ENSINO SUPERIOR:

CURSO DE BACHARELADO EM ENFERMAGEM ..............................................4

2 OBJETIVO GERAL............................................................................................................97

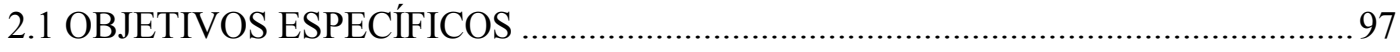

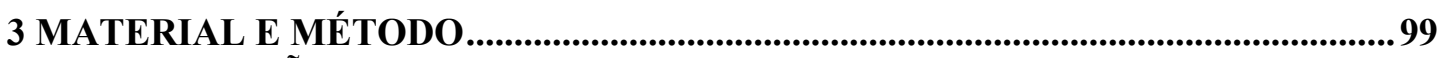

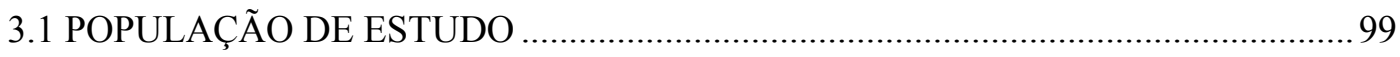

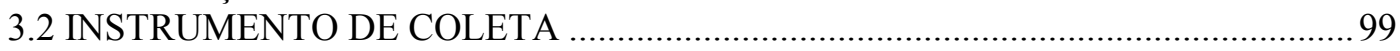

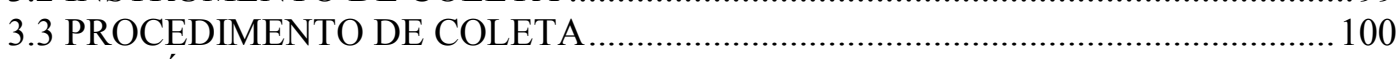

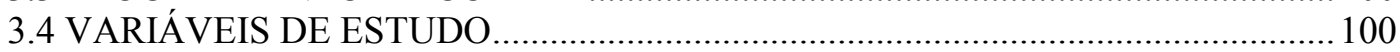

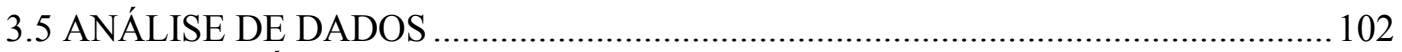

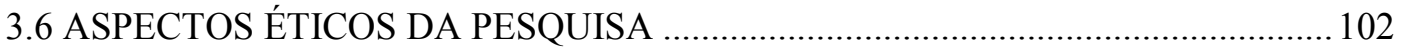

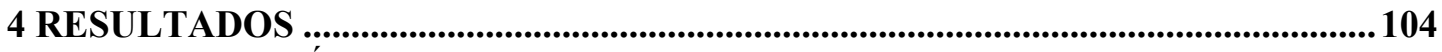

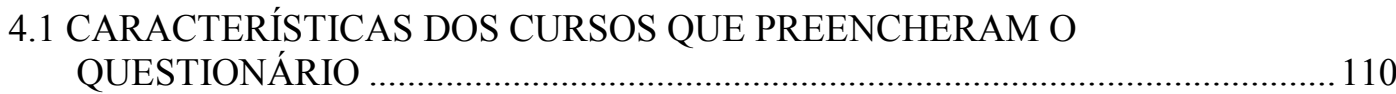

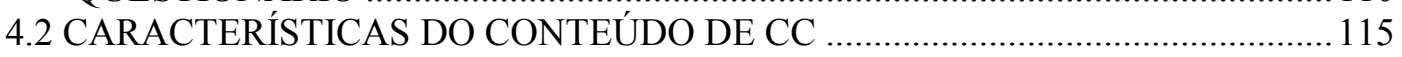

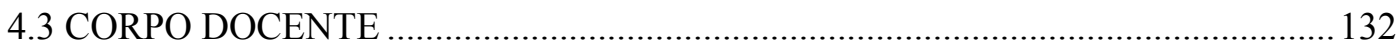

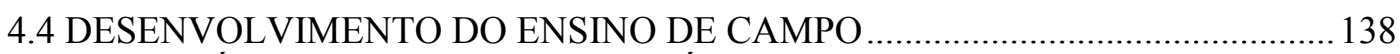

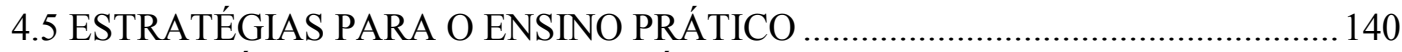

4.6 COMENTÁRIOS SOBRE O CONTEÚDO DA DISCIPLINA .................................... 145

4.7 OPINIÃO SOBRE O CONTEÚDO NA FORMAÇÃO DO ALUNO ......................... 149

4.8 IMPORTÂNCIA DO CONTEÚDO PARA A ATUAÇÃO PROFISSIONAL DO

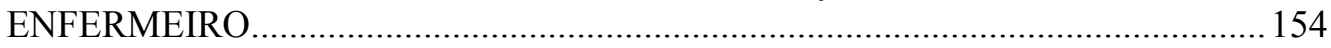

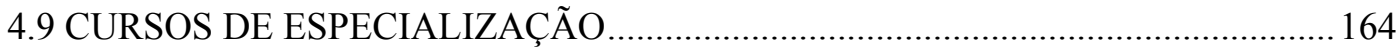

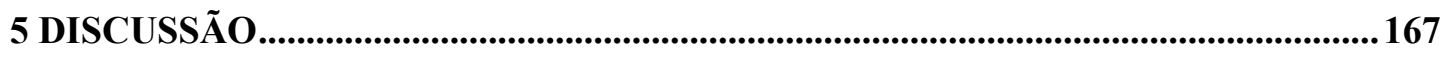

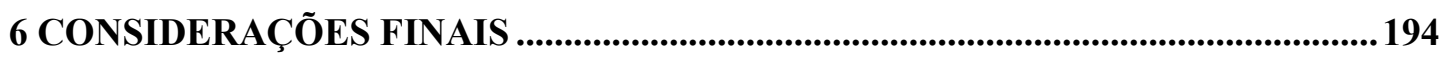

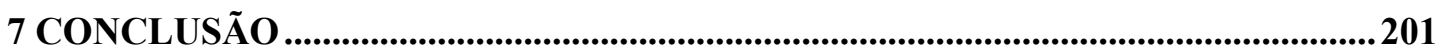

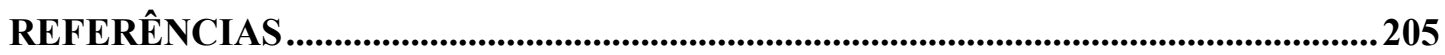

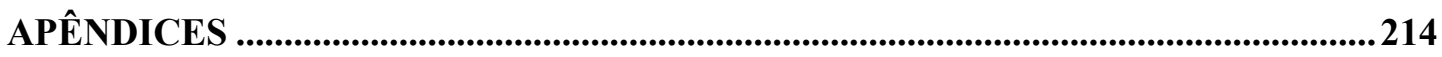




\section{Introdução}




\section{INTRODUÇÃO}

O século XIX foi marcado por diversas descobertas relacionadas à assistência a saúde com importantes avanços na área de cirurgia e microbiologia. $\mathrm{Na}$ enfermagem, Florence Nightingale deu um impulso à evolução do cuidado de enfermagem ao se preocupar com a limpeza e a ordem no ambiente onde se processava a assistência introduzindo princípios e conhecimento científico na arte de cuidar.

A enfermagem em centro cirúrgico (CC) parece ter-se iniciado em 1880 quando se estabeleceram as técnicas assépticas de Lister que permitiam a realização de cirurgias mais complexas e as "enfermeiras" eram responsáveis pelos cuidados com o instrumental. Na virada do século, com a designação de espaços restritos para a realização dos procedimentos cirúrgicos, a limpeza do ambiente, já valorizada por Florence Nightingale, passou a ser importante na prevenção de infecções e se tornou mais uma das atribuições da "enfermeira". Desta forma, progressivamente aumentava a responsabilidade das "enfermeiras", bem como a carga de trabalho, e conhecimentos específicos se desenvolviam, o que as distinguiam das enfermeiras das unidades assistenciais ${ }^{1}$.

Paralelamente, o aprendizado forçado no cuidado aos doentes nos campos de batalha impulsionava não só desenvolvimento da cirurgia, mas também a prática de enfermagem na arena cirúrgica configurando-se assim a enfermeira assistente de CC. Durante a II Guerra Mundial houve um desenvolvimento expressivo no conhecimento do cuidar cirúrgico pela necessidade de enfermeiras com conhecimento de bloco operatório, incluindo anestesia para atuar na supervisão das ações do pessoal auxiliar e para cuidar dos pacientes operados. Esta situação acelerou o desenvolvimento do conhecimento e das habilidades no cuidar do paciente cirúrgico ${ }^{2}$.

Como se percebe, a especificidade de CC foi sendo desenvolvida em campo prático pela necessidade emergente e aos poucos os enfermeiros foram incorporando conhecimento científico para dar sustentação a esse saber. 
Em 1933, a National League for Nurses estabeleceu nos Estados Unidos da América (EUA) o currículo de enfermagem que incluía disciplina de sala de operação (SO) e experiência clínica. Este modelo permaneceu vigente até 1949, até a SO se tornar repentinamente prioridade mínima ${ }^{3}$. A tendência para uma gradual e progressiva eliminação da experiência em SO nos currículos de enfermagem nas escolas americanas pode ser traçada desde a década de $50^{4}$.

No relato de experiência de uma enfermeira inglesa encontrou-se que em 1968 no segundo ano de treinamento, as estudantes de enfermagem permaneciam 14 semanas no $\mathrm{CC}$, sendo dez semanas nas salas de cirurgia geral e quatro semanas nas salas de procedimentos ortopédicos ${ }^{5}$. Com relação aos cursos de pós-graduação em CC há relatos no Canadá de seu oferecimento a partir da década de $40^{6}$.

Ao se considerar a enfermagem em CC uma especialidade técnica demais para ser incluída na formação básica do enfermeiro, muitas escolas desacreditaram a SO como um laboratório de aprendizagem, exceto para observação do procedimento cirúrgico ${ }^{7}$.

$\mathrm{Na}$ transição dos cursos de formação do enfermeiro diplomado para o bacharel em enfermagem alguns conteúdos foram excluídos por algumas escolas ao redor do planeta, de modo geral, e por motivos particulares. Um dos motivos apontados pela exclusão do conteúdo de enfermagem perioperatória dos currículos de graduação em enfermagem nas escolas americanas foi a falta de professores para ministrar esse conteúdo e de espaços adequados para a prática clínica ${ }^{8}$.

No entanto, a adoção de novas teorias para embasar a assistência de enfermagem também contribuiu para esse fato. Na Georgetown University, o CC deixou de fazer parte dos campos de estágio quando a escola adotou, em 1969, a teoria de auto-cuidado da Orem no modelo assistencial ensinado aos alunos ${ }^{9}$.

Mas afastar o aluno de graduação desse contato levou a uma redução no número de enfermeiros interessados em trabalhar em CC e, conseqüentemente, a demanda nos cursos de aperfeiçoamento nessa área de conhecimento também diminuiu.

Em 1981, a Association of PeriOperative Registered Nurses (AORN) instituiu o Projeto Alpha que tinha por missão introduzir o componente de enfermagem perioperatória nos currículos de enfermagem, pois traria os seguintes 
Ruth Natalia Teresa Turrini

benefícios: explorar sentimentos e reações do paciente e família em relação à cirurgia, participar como membro da equipe interdisciplinar; prover cuidados de enfermagem cirúrgicos de acordo com crenças religiosas e sócio-culturais; integrar o conhecimento do processo de enfermagem com anatomia, fisiologia, microbiologia e farmacologia; desenvolver habilidades de assepsia cirúrgica; implementar uma avaliação de enfermagem multissistêmica; ampliar a prática de educação do paciente e família individualizada; identificar oportunidades de pesquisa em enfermagem perioperatória; observar a resposta do paciente a anestesia; expor o estudante às atividades no ambiente cirúrgico; oferecer uma dose de "realidade" aos alunos com motivação sub-ótima ${ }^{10}$.

Alguns coordenadores de projetos pedagógicos foram relutantes em excluir a experiência de $\mathrm{CC}$ e decidiram continuar a rodiziar os alunos na SO. No entanto, os alunos eram observadores e não participantes, geralmente sem um professor presente para ajudá-los. Consequentemente, os alunos ficavam em um canto com a recomendação para não tocar em nada. Este tipo de experiência não contribuía para o desenvolvimento de habilidades no cuidado ao paciente em SO. Algumas escolas ofereceram o conteúdo na forma de curso de verão com a desvantagem de que um número limitado de estudantes se beneficiava desta oportunidade ${ }^{11}$.

Gutierrez $^{12}$ relatou em sua publicação um estudo descritivo, realizado em Denver (EUA), sobre educação em enfermagem perioperatória com 230 estudantes de cursos de enfermagem. Foi distribuído aos alunos um questionário, com um retorno de $56,0 \%$ e na análise das respostas observou-se pouca exposição dos alunos às áreas operatórias e ao processo de enfermagem; 76,9\% dos alunos permaneciam menos de cinco dias em SO durante todo o curso e metade deles desenvolveram apenas atividades de observação. A autora considerou um ou dois dias de observação limitantes por não permitirem ao aluno compreender as funções do enfermeiro na visão mais ampliada da enfermagem perioperatória.

A partir desses resultados, a autora ${ }^{12}$ criou um curso de primavera/verão com $15 \mathrm{~h}$ de atividades didáticas com teoria e laboratório e $90 \mathrm{~h}$ de prática clínica. As atividades práticas eram desenvolvidas em três dias consecutivos por semana por quatro ou cinco semanas e as atividades eram acompanhadas pelo professor, um preceptor e o enfermeiro de CC. O curso tinha por objetivos desenvolver uma 
Ruth Natalia Teresa Turrini

compreensão inicial do papel do estudante de enfermagem no $\mathrm{CC}$ relacionado à prevenção primária, secundária e terciária; utilizar o processo de enfermagem para desenvolver planos de cuidados a paciente e família no período perioperatório; demonstrar conhecimento sobre trabalho em equipe e comunicação efetiva pela participação como integrante da equipe cirúrgica na avaliação, planejamento, implementação e avaliação de cuidados perioperatórios ao paciente; demonstrar conhecimento sobre influências psicológicas, crenças de saúde e doença por meio da efetiva avaliação, planejamento e implementação de cuidados; utilizar princípios de ensino-aprendizagem para conduzir sessões educativas a paciente, família e equipe; participar como colaborador no gerenciamento de uma experiência intra e pósoperatória; demonstrar nível inicial de valorização da pesquisa em enfermagem relacionada ao ambiente perioperatório; discutir as implicações legais na prática em enfermagem perioperatória e o papel do enfermeiro. Como pré-requisito para o curso, o aluno deveria ter completado a formação básica e o módulo I de Enfermagem Médico-Cirúrgica. Também foi permitida a inscrição de enfermeiros com experiência recente no cuidado a pacientes críticos. Para facilitar a comunicação com o professor, os alunos mantinham um diário sobre as atividades desenvolvidas, conceitos e sentimentos identificados durante a experiência em prática clínica. Entre suas atividades estava a busca na literatura de temas previamente definidos, escolher um paciente para estudo de caso que seria acompanhado do pré-operatório até a alta e no seu desenvolvimento incluir a prevenção primária, secundária e terciária para que o aluno pudesse expandir seu raciocínio para além da situação crítica para situações de promoção à saúde e educação. Os alunos deviam documentar a avaliação pré-operatória, história clínica, exame físico focado nos riscos cirúrgicos e implicações para o enfermeiro, incluindo uma base teórica e referências. A parte educativa devia incluir os princípios de ensino aprendizado utilizados e quais os tópicos abordados. Na parte intra-operatória devia demonstrar a compreensão sobre a segurança do paciente, gerenciamento do ambiente cirúrgico e monitoramento fisiológico e psicológico. O aluno devia explicar os procedimentos cirúrgicos e anestésicos e discutir o papel do enfermeiro e implicações para a enfermagem. Além disso, devia apresentar o plano de cuidados, com diagnósticos de enfermagem em 
Ruth Natalia Teresa Turrini

cada fase do perioperatório discutir a evolução do paciente no pós-operatório e avaliar a efetividade da avaliação perioperatória.

Embora, um programa desenvolvido no final da década de 80, percebe-se na descrição das atividades desenvolvidas pelo aluno a integração de conteúdos de diversas disciplinas e a necessidade de um raciocínio clínico estruturado para o alcance dos resultados esperados.

A University of Florida College of Nursing, o Sands Hospital at the University of Florida e o Veteran Administration Medical Center em Gainsville, tomaram como desafio criar um curso de verão de enfermagem perioperatória mobilizados pela redução no número de enfermeiros em $\mathrm{CC}$ atribuída em parte à falta deste conteúdo na formação do enfermeiro. O curso foi criado com quatro créditos e duração de 12 semanas. A base dos objetivos do curso foram as recomendações da AORN “Competency statements in perioperative nursing” tendo por foco: as funções da equipe de cirúrgica, circulação de sala, paramentação e degermação, processo de enfermagem, técnica asséptica, fontes de contaminação e controle da esterilidade do material, equipamentos cirúrgicos, instrumentação, anestesia, comunicação no $\mathrm{CC}$, aspectos éticos do cuidar em $\mathrm{CC}$ e pesquisa em $\mathrm{CC}^{13}$. Em 1990, Janice Beitz ${ }^{10}$ criou um curso de verão que se adequasse ao currículo da Temple University (Philadelphia,USA) e consultou hospitais quanto a possibilidade de receberem estudantes de enfermagem no CC. Para se inscrever no curso, o estudante de enfermagem deveria atender a determinados critérios: ter completado todas as disciplinas básicas de enfermagem com pelo menos média B em cada uma delas e ter avaliações de desempenho em atividades clínicas que demonstrassem maturidade e conhecimento de base. O curso foi oferecido com aulas duas vezes por semana durante seis semanas, com a seguinte carga horária: $20 \mathrm{~h}$ de teoria, $15 \mathrm{~h}$ de laboratório e $23 \mathrm{~h}$ de prática clínica. Em campo de prática, os alunos elaboravam planos de assistência, circulavam sala, instrumentavam e auxiliavam a enfermeira na recuperação anestésica. Entre as avaliações positivas, os alunos referiram que puderam aprender muitas coisas, entre elas, a valorizar o enfermeiro de $\mathrm{CC}$, compreender as necessidades do paciente cirúrgico e obtiveram conhecimentos que os ajudariam nas provas para a obtenção da licença profisssional. Entre os aspectos negativos destacaram-se inabilidade para seguir um paciente da recepção a 
Ruth Natalia Teresa Turrini

alta, dificuldade em oferecer a cada aluno experiências em diferentes cirurgias devido ao agendamento oscilante, exposição do estudante na recuperação anestésica com poucos pacientes, pouco tempo para ler sobre o procedimento cirúrgico e para ficar com a enfermeira anestesista.

$\mathrm{Na}$ tentativa de atrair o interesse para a área de $\mathrm{CC}$ e retornar o conteúdo de bloco cirúrgico aos currículos de graduação, o National Committee on Education da AORN elaborou o primer Perioperative Program com estratégias para parcerias entre os hospitais e as escolas para o ensino prático, com sugestão de conteúdos e bibliografias $^{8}$.

Em 2006, a AORN ratificou uma declaração sobre a importância de atividades clínicas em CC para o aprendizado dos alunos de graduação em enfermagem, afirmando que esta formação inicial poderia despertar o interesse do futuro enfermeiro para os cursos de especialização em enfermagem perioperatória ${ }^{14}$. Em seguida, a National Student Nurses' Association também encaminhou um posicionamento a algumas entidades de classe americanas pedindo apoio para a inclusão de conteúdos teóricos e práticos relativos à enfermagem perioperatória para melhor atender as necessidades dos pacientes cirúrgicos e seus familiares, em oposição à tendência passada de remoção gradual desse conteúdo dos currículos de enfermagem $^{15}$.

Preocupada com a formação e a qualidade dos enfermeiros futuros, a AORN elaborou uma declaração de posição, o "Value of Clinical Learning Activities in the Perioperative Setting in Undergraduate Nursing Curricula", para ajudar as escolas de bacharelado em enfermagem a planejarem oportunidades de aprendizado no cuidado perioperatório que desenvolvam competências essenciais para todos os alunos de graduação em enfermagem. Essa assistência refere-se aos cuidados pré, intra e pós-operatórios de pacientes submetidos a cirurgias ou outros procedimentos invasivos ${ }^{16}$. A necessidade de re-inclusão do conteúdo de bloco cirúrgico na formação dos enfermeiros também se faz presente na Austrália. O Australian College of Operating Room Nurses (ACORN) declarou que a especialidade de CC foi uma daquelas que sofreu com a transição dos cursos de enfermagem diplomada para os de bacharelado porque a enfermagem perioperatória não foi incluída na grade curricular dos cursos de graduação. A Universidade Australiana de Notre Dame é uma das 
Ruth Natalia Teresa Turrini

poucas que tem uma disciplina de enfermagem perioperatória que segue os tópicos mandatórios da Acreditação em Enfermagem da região, e, embora, com carga teórico-prática pequena, foi considerada suficiente para que o enfermeiro possa iniciar suas atividades em CC e se interessar no futuro por um aperfeiçoamento na área $^{14}$.

Observa-se pelos relatos que o investimento no ensino no $\mathrm{CC}$ em âmbito internacional foi um movimento gerado pelos hospitais e pela AORN mais para atender uma demanda de mercado, do que uma necessidade sentida no interior da academia. Algumas IES sem este conteúdo na grade curricular, quando sensibilizadas pelo problema, passaram a oferecer cursos de verão aos alunos, mas com pequena abrangência pelo número de vagas.

\subsection{O CONTEÚDO DE CENTRO CIRÚRGICO NO CURRÍCULO DO BRASIL}

A formação do enfermeiro teve, e ainda tem, como pano de fundo a situação sócio-econômica do país, as transformações políticas e técnicas da área de educação e da saúde.

O início do século XX caracterizou-se por atividades de produção primária, endemias e epidemias de caráter infecto-contagioso que ameaçavam a população e a economia e os serviços de saúde organizavam-se voltados prioritariamente para os aspectos sanitários. Assim, a formação do enfermeiro tinha como referencial a saúde pública ${ }^{17}$. Mas o principal campo de atuação dos enfermeiros formados era o ambiente hospitalar, que se ajustava bem a aplicação do modelo nightingaleano adotado pela enfermagem brasileira, com exceção dos programas de combate a tuberculose ${ }^{18}$.

Com o início da industrialização, nas décadas de 40 a 50, as afecções prevalentes na época passaram a ser as doenças degenerativas e os acidentes de trabalho e acentuava-se o enfoque da assistência médica curativa ${ }^{17}$.

Em 49, com a expansão da assistência médico-hospitalar e a re-estruturação do ensino superior, no primeiro governo Vargas, elevado quantitativo de 
Ruth Natalia Teresa Turrini

especialidades médicas passou a compor o currículo de enfermagem com uma aproximação inicial ao campo das ciências sociais. Discutia-se amplamente a enfermagem como profissão comprometida com a ciência e a tecnologia ${ }^{18}$.

Nesse período é decretada a Lei $775 / 49^{19}$, que regularizou o ensino de enfermagem no país e logo a seguir o decreto $27.246 / 49^{20}$ regulamentou os cursos de enfermagem definindo as ciências biológicas e as disciplinas profissionalizantes, segundo o modelo clínico americano ${ }^{17}$. Pelo artigo $5^{\circ}$ deste decreto, na segunda série previa-se o conteúdo de "Técnica de Operações" e no artigo $7^{\circ}$ definia-se a prática em SO. O parágrafo único apresentava a duração mínima dos estágios de 15 dias, com no mínimo sete dias de serviço noturno, com exceção da saúde pública que os estágios deveriam ter duração mínima de três meses.

A década de 60 se caracterizou pela crise do mercado interno e externo, a inflação, o desemprego, a crise mundial de alimentos com um perfil de morbimortalidade semelhante ao anterior e mantinha-se a hegemonia da assistência curativa. Apesar desse quadro, iniciava-se o debate sobre a necessidade de aumentar a cobertura para a população desassistida (rural e periurbana) com enfoque na assistência primária a saúde ${ }^{17}$.

O parecer 271/62 $2^{21}$ do Conselho Federal de Educação determinou o segundo currículo mínimo voltado para a demanda da prática hospitalar e excluiu a obrigatoriedade da disciplina de saúde pública ${ }^{17}$. Este currículo reduziu o número de matérias obrigatórias condensando o número de especialidades, assim distribuídas: Fundamentos de Enfermagem; Enfermagem Médica; Enfermagem Cirúrgica; Enfermagem Psiquiátrica; Enfermagem Obstétrica e Ginecológica; Enfermagem Pediátrica; Ética e História da Enfermagem e Administração.

Neste documento ${ }^{21}$ também se inicia a preocupação com as características de cada região e no item IV relata-se que

O currículo de cada curso abrangerá, além do mínimo referido nos itens anteriores, uma parte complementar fixada pelo estabelecimento, conforme as suas possibilidades para atender as peculiaridades regionais, as diferenças individuais dos alunos e a expansão e atualização dos conhecimentos. 
Ruth Natalia Teresa Turrini

A Associação Brasileira solicitou uma revisão do parecer $271 / 62^{21}$ ao Conselho Federal de Educação solicitando a inclusão de ciências sociais e saúde pública. O relator se manifestou que as disciplinas não precisariam ser incluídas no currículo mínimo, pois cada escola poderia instituí-las como complementar ao curso geral, não sendo necessária a alteração do currículo ${ }^{22 \text { p.249 }}$.

A Resolução $4 / 72^{23}$ estruturou o curso em três partes: tronco pré-profisssional com matérias de primeiro ciclo comum a todos os cursos da instituição da área da saúde, o tronco profissional que levaria o aluno a graduação em enfermagem e o tronco das habilitações em Enfermagem Médico Cirúrgica, Enfermagem Obstétrica ou em Saúde Pública. O tronco profissional de acordo com o artigo $3^{\circ}$ compreendia disciplinas de Introdução a Enfermagem, Enfermagem Médico-Cirúrgica, Enfermagem Materno-Infantil, Enfermagem Psiquiátrica, Enfermagem em Doenças Transmissíveis, Exercício da Enfermagem, Didática em Enfermagem e Administração em Enfermagem, de certa forma semelhante ao parecer CFE 271/62 21 . No artigo $4^{\circ}$ definia-se que a habilitação em Enfermagem Médico-Cirúrgica incluiria Administração em Centro Cirúrgico, Enfermagem em Pronto Socorro, Unidade de Recuperação e Cuidado Intensivo. Propunha o curso no mínimo em $2.500 \mathrm{~h}$ em três anos para a formação geral do enfermeiro e em quatro anos com $3.000 \mathrm{~h}$ no caso das habilitações.

O fato da habilitação em médico-cirúrgica incluir administração em $\mathrm{CC}$, não excluiria necessariamente o conteúdo de enfermagem perioperatória da disciplina do tronco profissional, pois em nível de graduação ensina-se o processo de cuidar no CC e não o gerenciamento da unidade.

A formação positivista dada pela padronização de conhecimento persistiu até meados da década de 90, reforçando-se a necessidade do domínio sobre as técnicas avançadas em saúde e fundamentadas no saber biomédico ${ }^{18}$.

A Portaria $n^{\circ} 1721 / 94^{24}$ respaldada no parecer $n^{\circ} 314 / 94$ do então Conselho Federal de Educação, fixava em seu artigo $3^{\circ}$, parágrafo $3^{\circ}$ que o conteúdo de assistência de enfermagem deveria compor $35 \%$ da carga horária do curso, com obrigatoriedade de conteúdos teóricos e práticos e considerando o perfil epidemiológico e o quadro sanitário do país / Região / Estado, incluindo situações clínicas, cirúrgicas, psiquiátricas, gineco-obstétricas e de saúde pública. Não há uma 
Ruth Natalia Teresa Turrini

referência direta ao $\mathrm{CC}$, mas este faz parte das situações cirúrgicas. Definia-se uma duração de no mínimo quatro anos e 3.500 h. Data desse ano também a implantação do Sistema Único de Saúde no país.

A lei 9.394/96 de Diretrizes e Bases da Educação ${ }^{25}$ excluiu os currículos mínimos e estabeleceu diretrizes para reestruturar e reger o ensino superior. Mas, definia em seu artigo 43, inciso VI, que o ensino superior deveria "estimular o conhecimento dos problemas do mundo presente, em particular os nacionais e regionais, prestar serviços especializados à comunidade e estabelecer com esta uma relação de reciprocidade" e no seu artigo 53, inciso II, assegurava autonomia às universidades para "fixar os currículos de seus cursos e programas, observadas as diretrizes gerais pertinentes".

Desta forma, os estabelecimentos de ensino iniciam sua caminhada na elaboração de novas propostas, tentando atender as diretrizes gerais da lei, diferenciando-se entre si em termos de nomenclatura e organização de disciplinas e conteúdos.

O parecer $1133 / 2001^{26}$, homologado por despacho do Ministro de Estado da Educação, estabeleceu as diretrizes curriculares nacionais para a enfermagem, que além de assegurar a liberdade de composição da carga horária, entre outros propunha, "garantir uma sólida formação básica, preparando o futuro enfermeiro para enfrentar os desafios das rápidas transformações da sociedade, do mercado de trabalho e das condições de exercício profissional". Preconizou a articulação entre Educação em Ensino Superior e Saúde, determinando como elementos fundamentais para esse processo princípios e diretrizes do SUS: I - a identificação e divulgação dos fatores condicionantes e determinantes da saúde; II - a formulação de política de saúde; III - a assistência às pessoas por intermédio de ações de promoção, proteção e recuperação da saúde, com a realização integrada das ações assistenciais e das atividades preventivas.

Por este parecer, o perfil do enfermeiro deveria ser generalista, humanista, crítico e reflexivo; qualificado para o exercício de Enfermagem, com base no rigor científico e intelectual e pautado em princípios éticos; capaz de conhecer e intervir sobre os problemas/situações de saúde-doença mais prevalentes no perfil 
Ruth Natalia Teresa Turrini

epidemiológico nacional, com ênfase na sua região de atuação, identificando as dimensões bio-psico-sociais dos seus determinantes.

O programa de ensino-aprendizagem deveria estar direcionado para formar enfermeiros com competências na assistência a saúde, tomada de decisão, comunicação, administração e gerenciamento, e educação permanente.

No quesito habilidades ${ }^{26}$, o futuro enfermeiro deveria ser capaz de:

Reconhecer a saúde como direito e condições dignas de vida e atuar de forma a garantir a integralidade da assistência, entendida como conjunto articulado e contínuo das ações e serviços preventivos e curativos, individuais e coletivos, exigidos para cada caso em todos os níveis de complexidade do sistema; usar adequadamente novas tecnologias, tanto de informação e comunicação, quanto de ponta para o cuidar de enfermagem.

Embora não tenha definido um conteúdo curricular mínimo, definiu como necessários conteúdos de ciências da Enfermagem, Ciências Biológicas e da Saúde, Ciências Humanas e Sociais.

Dentro das Ciências da Enfermagem, incluem-se os seguintes tópicos: Fundamentos de Enfermagem (conteúdos técnicos, metodológicos e os meios e instrumentos inerentes ao trabalho do Enfermeiro e da Enfermagem em nível individual e coletivo); Assistência de Enfermagem (os conteúdos teóricos e práticos que compõem a assistência de Enfermagem em nível individual e coletivo prestada à criança, ao adolescente, ao adulto, à mulher $\mathrm{e}$ ao idoso, considerando os determinantes sócio-culturais, econômicos e ecológicos do processo saúde-doença, bem como os princípios éticos, legais e humanísticos inerentes ao cuidado de Enfermagem); Administração de Enfermagem (os conteúdos (teóricos e práticos da administração do processo de trabalho de enfermagem e da assistência de enfermagem); Ensino de Enfermagem (os conteúdos pertinentes à capacitação pedagógica do enfermeiro, independente da Licenciatura em Enfermagem).

Em suma,

Os conteúdos curriculares, as competências e as habilidades a serem assimilados e adquiridos no nível de graduação do enfermeiro devem conferir-lhe terminalidade e capacidade acadêmica e/ou profissional, considerando as demandas e necessidades prevalentes e prioritárias da população conforme o quadro epidemiológico do país/região. 
O parecer CNE/CES n ${ }^{\circ} 213 / 2008^{27}$, homologado pelo despacho do Ministro de Estado da Educação, endossou as diretrizes curriculares nacionais para a enfermagem (Resolução CNE/CES $n^{0} 3 / 2001^{28}$ ) que orienta a formação do enfermeiro generalista, em condições de atuar em todos os níveis de atenção à saúde, com capacidade de promover a saúde integral do ser humano, além da carga horária mínima de $4.000 \mathrm{~h}$ para o bacharelado de enfermagem.

Com a liberdade para definir parte dos currículos plenos, as instituições de ensino superior tornaram-se responsáveis pela formação de diferentes perfis profissionais a partir da vocação de cada curso/escola, mas considerando as necessidades do mercado de trabalho ${ }^{29}$.

Por outro lado, a graduação de enfermagem não pode ser direcionada somente pela lógica de mercado, regido pela ótica do lucro e do capital, que privilegia o saber imediato, o saber-fazer, a urgência, a eficiência em detrimento do cultivo do raciocínio, da reflexão, da criação ${ }^{30}$. Para que processo cognitivo se processe é preciso o conhecimento próprio das ciências da saúde, aliado ao de outras disciplinas, para que o aluno possa refletir e desenvolver o pensamento crítico na busca de soluções para as necessidades de cuidado do paciente e para a tomada de decisões.

Depreende-se de todo este processo evolutivo das legislações sobre ensino superior que a formação básica do enfermeiro deve preparar o aluno para atender a demanda de mercado, formar um enfermeiro generalista que possa atuar em qualquer cenário profissional, não o isentando de uma especialização na área escolhida e que o alinhamento da educação superior com os princípios do SUS, não prescinde de determinados conteúdos na sua formação.

O fato de a saúde coletiva ser o foco de atenção das políticas públicas em saúde, não significa que se devam ignorar as necessidades de atendimento secundário e terciário que tem um caráter mais individual que coletivo. A necessidade do conteúdo de $\mathrm{CC}$ extrapola a área de $\mathrm{CC}$, os avanços tecnológicos na área de diagnóstico por imagem com a realização de procedimentos minimamente invasivos para diagnóstico ou tratamento, bem como no preparo para determinadas cirurgias têm exigido que os enfermeiros que atuam nesse local tenham conhecimento de 
enfermagem perioperatória e reprocessamento de material. Além disso, expande-se a rede de clínicas que realizam procedimentos estéticos invasivos e de unidades de atenção primária a saúde que realizam procedimentos de pequeno porte.

\subsection{CONTEÚDO DE CENTRO CIRÚRGICO NO CURRÍCULO DA ESCOLA DE ENFERMAGEM DA UNIVERSIDADE DE SÃO PAULO}

O currículo na Escola de Enfermagem da Universidade de São Paulo (EEUSP), como ocorreu em outras escolas de enfermagem no Brasil, passou ao longo dos anos por mudanças de acordo com a época e situações econômicas e políticas do país, embora por muito tempo com uma carga horária total superior à estabelecida pelo currículo mínimo e talvez por isso, a Disciplina de Enfermagem em Centro Cirúrgico e de Enfermagem em Centro de Material tenham conseguido sobreviver, até o presente momento, com identidade própria. A EEUSP foi pioneira na histórica acadêmica a ministrar o conteúdo de Enfermagem em Centro Cirúrgico (ECC) na forma de uma disciplina independente.

$\mathrm{Na}$ análise da evolução da disciplina, pode-se verificar a trajetória do ensino da assistência perioperatória. Nesse sentido foram recuperadas informações nos arquivos da Secretaria de Graduação e nos relatos de alguns docentes de CC da EEUSP que acompanharam parte da história da disciplina ECC.

\section{Décadas de 40 a 60}

O currículo da primeira turma de graduandos em enfermagem da EEUSP era constituído de uma carga teórica muito menor que a carga prática, o que mostra que ainda mantinha a característica dos cursos de enfermagem oferecidos pelos hospitais. A primeira disciplina de abordagem cirúrgica - Clínica Cirúrgica - era composta de 40 horas teóricas e 340h práticas. Em 1947 foi introduzida no currículo a disciplina Sala de Operações com carga prática de 275h. Posteriormente, na turma de 1950, a disciplina, agora denominada Técnica de Sala de Operações, apresentava uma carga teórica de $35 \mathrm{~h}$ e $265 \mathrm{~h}$ de prática que a distinguia da disciplina Enfermagem em 
Clínica Cirúrgica. A disciplina assim denominada se alinhava com o determinado no decreto $27.246 / 49^{20}$.

A distribuição de horas, teóricas e práticas, variou bastante ao longo das modificações do currículo e, em 1963, a referida disciplina foi substituída pela disciplina propriamente dita de Enfermagem em Centro Cirúrgico com 53h teóricas e $115 \mathrm{~h}$ práticas.

\section{Década de 60}

A disciplina ECC era ministrada a todos os alunos de graduação em Enfermagem da EEUSP, no período de dois meses e os alunos dedicavam-se às atividades de circulante de sala de operações e era ministrada no segundo ano de graduação por dois docentes responsáveis, tendo como pré-requisito somente a disciplina Fundamentos de Enfermagem. O conteúdo programático desenvolvido abordava a atuação em centro de material e em centro cirúrgico.

Com a redução do número de semanas do semestre acadêmico, a disciplina que tinha oito semanas de práticas de campo, passou a ter somente quatro semanas e o programa teve de ser reformulado em termos de profundidade e flexibilidade ${ }^{31}$. Desta forma, a disciplina passou a ter $150 \mathrm{~h}$ e os seguintes objetivos: planejar e prestar assistência física e psicológica aos pacientes na SO antes, durante e após a cirurgia e fazer as anotações necessárias; planejar o trabalho, preparar a SO e circular em cirurgia gastrintestinal, das vias biliares, de cabeça e pescoço e ginecológica, observando os aspectos éticos envolvidos; citar as fontes de contaminação da ferida operatória e empregar os meios existentes para evitá-las; descrever os métodos de hemostasia e os princípios físicos empregados no funcionamento da unidade de eletrocirurgia e relacioná-los aos cuidados ao paciente durante a cirurgia; descrever e aplicar os princípios físico-químicos e microbiológicos nos processos de esterilização do material cirúrgico ${ }^{31}$. 
Ruth Natalia Teresa Turrini

\section{De 1970 a 1990}

Na década de 70, os docentes da disciplina defenderam a manutenção da disciplina ECC no currículo de graduação porque o Levantamento de Recursos e Necessidades de Enfermagem da Associação Brasileira de Enfermagem realizado em 1958 demonstrou que os enfermeiros estavam sendo requisitados para as chefias de centro cirúrgico; pelo reduzido número de enfermeiros existentes e pela urgência de sua contratação após a graduação sem tempo de adquirir a experiência necessária; porque o enfermeiro tem oportunidade de assistir física e psicologicamente o paciente desde sua entrada na sala de operações até sua volta à unidade de enfermagem; todas as técnicas de enfermagem desenvolvidas no CC têm como finalidade o paciente e a falta de observância de seus princípios pode acarretar complicações muitas vezes fatais ${ }^{31}$.

Em 1972, com a introdução dos cursos de habilitação, a disciplina ECC passou a ter $30 \mathrm{~h}$ teóricas e $90 \mathrm{~h}$ práticas. A exigência cada vez maior quanto ao preparo do enfermeiro para essa área de atuação, culminou com a contratação de mais docentes para a disciplina.

No curso de Habilitação em Enfermagem Médico-Cirúrgica, os alunos permaneciam um mês em estágio na coordenação do CC. A habilitação era um ano optativo após a graduação, mas procurado por muitos alunos.

Até o final da década de 70, a disciplina ECC abordava os conteúdos de central de material e de CC. Após diversos seminários, a partir de 1980 o conteúdo de central de material passou a compor a uma disciplina própria: Enfermagem em Central de Material (ECM) que precedia a disciplina ECC e para ambas era prérequisito ter cursado a disciplina Enfermagem Médico Cirúrgica. Estas disciplinas compunham a grade curricular do terceiro ano da graduação.

A disciplina ECM com carga horária de 60h desenvolvia temas de limpeza, esterilização e distribuição de materiais e tinha 10h de carga prática. Na disciplina de ECC, com $120 \mathrm{~h}$, dos quais $60 \mathrm{~h}$ de prática em dois campos distintos eram ministrados conteúdos cirúrgicos de cada área médica (cirurgias de abdome, ortopedia, pediátrica, vascular, gastrintestinal) com discussão de abordagem cirúrgica; anestesia; recuperação pós-anestésica; sistema de assistência perioperatória - com escolha de paciente no dia anterior para realizar o processo de enfermagem; 
Ruth Natalia Teresa Turrini

atividades de circulante de $\mathrm{SO}$, sem o acompanhamento do funcionário em sala, mas na retaguarda da atuação. Como nos seminários de avaliação constatou-se que a circulação de sala era fator de ansiedade para os alunos, modificou-se, então, a condução do estágio e o aluno passou a atuar em conjunto com o funcionário responsável pela circulação da sala e foi introduzida a instrumentação cirúrgica.

Ainda neste período iniciou-se um movimento para a realização de pesquisas de campo na área de centro cirúrgico. O quantitativo de docentes também foi aumentando, ficando um total de sete docentes paras duas disciplinas, e com duração de dois meses cada conjunto de disciplinas, sendo repetidas três vezes ao ano, e para três grupos em cada rodízio.

Grande mérito das docentes de CC desse período foi o desenvolvimento do processo de enfermagem para a unidade de CC que culminou com a proposta da Sistematização da Assistência de Enfermagem Perioperatória (SAEP) ${ }^{32}$ que apresentava todas as etapas do planejamento da assistência, implementação e avaliação do cuidado ao paciente no centro cirúrgico.

A assistência de enfermagem necessitava de um modelo para a condução tanto do modo de pensar como da forma de intervir do enfermeiro. Nesse sentido, a disciplina de ECC adotou o enfoque de fator de risco para subsidiar o planejamento da assistência perioperatória. Na opinião dos alunos, essa forma de observação do ambiente cirúrgico os ajudava a compreender a assistência de enfermagem perioperatória $^{33}$.

Um grupo de docentes em julho de 1988, após constatar que a unidade de CC era uma das áreas que mais se desenvolvia tecnologicamente e que a carga horária destinada ao ensino de graduação era insuficiente para o desenvolvimento exigido do enfermeiro em CC no mercado de trabalho, ofereceu o primeiro curso de especialização na área com 15 vagas. O Estado de São Paulo contribuiu com 82,4\% dos candidatos, mas também outros estados como Rio Grande do Sul, Rio de Janeiro, Minas Gerais e Santa Catarina marcaram a necessidade destes especialistas com no mínimo $2,9 \%$ de representantes no curso.

Novas mudanças curriculares em 1994 reduziram a carga horária das disciplinas que passaram a ter $30 \mathrm{~h}$ a de ECM e $90 \mathrm{~h}$ a de ECC. Nesse período, o curso 
Ruth Natalia Teresa Turrini

de habilitação já não era mais oferecido e se mantinha o curso de especialização que privilegiava entre seus critérios de seleção a experiência prévia em bloco cirúrgico.

\section{Década de 2000}

A estrutura curricular aprovada em 1994 perdurou por 16 anos e em 2010 no novo projeto pedagógico, a disciplina de ECM se manteve com 30h, no entanto, o conteúdo da disciplina de ECC foi incluído no Módulo Saúde do Adulto com uma carga horária pré-definida de 80h. Esse novo módulo foi implantado em 2012 para alunos do terceiro ano, ministrado em turmas de 40 alunos duas vezes ao ano. Este novo módulo incorpora conteúdos de CC, clínica médico-cirúrgica, cuidados intensivos e emergência.

Se por um lado houve o total envolvimento das docentes de CC em ressaltar a importância deste conteúdo no município de São Paulo, a cidade que mais realiza cirurgias de alta complexidade do país, por outro lado, a ECC não tem mais lugar de destaque na graduação, tentando-se reduzi-la a vivências de uma experiência cirúrgica para o paciente. Com a aposentadoria dos docentes de $\mathrm{CC}$ e com a nova estrutura curricular, o departamento tem oferecido resistência à continuidade de contratação docentes especialistas em CC para repor as vagas liberadas, o que progressivamente enfraquecerá as tentativas e os esforços para a manutenção deste conteúdo no currículo de graduação.

No ensino de pós-graduação, sensu strictu, não há programas de mestrado ou doutorado voltados especificamente para CC. As docentes oferecem disciplinas que abordam os temas de assistência perioperatória, controle de infecção e processamento de materiais, inseridas no Programa de Pós-graduação Enfermagem na Saúde do Adulto.

Fica patente a diversidade de apresentação de conteúdos relacionados a ECC tanto internacional como nacionalmente. Há necessidade de conhecer a situação na realidade brasileira, para traçar um panorama e possivelmente uma diretriz para o ensino de ECC no Brasil. 
Ruth Natalia Teresa Turrini

A presente investigação tem por finalidade conhecer como é oferecido o conteúdo de CC no país e verificar qual a opinião dos professores ou coordenadores dos cursos de enfermagem sobre sua importância na formação do enfermeiro no país.

\subsection{O CUIDADO PERIOPERATÓRIO}

Historicamente os alunos permaneciam de dois a três meses no CC instrumentando, reprocessando material e limpando o chão após a cirurgia ${ }^{4}$.

Estudo realizado em uma universidade estadual com 89 estudantes de enfermagem sobre a experiência em CC utilizando um instrumento com escala do tipo likert mostrou que os estudantes focam mais os procedimentos do que o papel do enfermeiro. Com base nisto, os docentes devem rever a experiência em CC, de modo a encorajá-los a enfocar o cuidado de enfermagem ${ }^{34}$.

O papel do enfermeiro mudou acompanhando a evolução técnica científica na cirurgia e passou a se envolver no planejamento, coordenação e gerenciamento do paciente cirúrgico; alem de propiciar um ambiente seguro para o paciente, fazer intervenções para o bem estar físico e psicológico do paciente. Assim como o papel do enfermeiro mudou, o cuidado aos pacientes cirúrgicos também ${ }^{35}$.

Um dos grandes avanços para o impulso da enfermagem como profíssão foi a introdução do processo de enfermagem (PE) na prática assistencial, que incluía uma metodologia para a prática do cuidar.

As preocupações sobre a observação do paciente e seu registro já se evidenciavam no início do século XX. Maria Adelaide Nutting ${ }^{36}$ na convenção do American Hospital Association em 1908 em Toronto, em sua fala expressava a necessidade do aluno de enfermagem desenvolver essas habilidades:

The Young student must be taught how to observe and record trifling change in the patient's condition, and what action such a change calls for. She must be taught every process needed, in its every detail, and theses processes are many. She must then practice each process assiduously, under criticism and supervision, until it can be performed with that ease which is the final perfection of skill; and then she must be taught further under what condition the process itself must be varied, adjusted, modified to suit the different temperaments and needs of the sick ${ }^{36}$. 32 . 
O PE teve sua origem no ensino para estudantes de enfermagem. Na década de 50, foi desenvolvido como uma ferramenta de ajuda para o aluno desenvolver habilidades para encontrar as necessidades de cuidado do indivíduo e em menos tempo. Esta estratégia de ensino foi vista inicialmente como uma maneira de o aluno escutar, estudar o que foi feito e de identificar como o que foi feito funcionou. $\mathrm{O}$ registro deste processo compreendia o relato escrito da conversação entre o enfermeiro e o paciente e também aquele da percepção do enfermeiro sobre o encontro. $\mathrm{O}$ instrutor e o aluno após estudarem o registro dessa interação individualmente discutiam o processo ${ }^{37}$.

No campo prático, o enfermeiro tinha de reconhecer quais atividades eram de sua competência, pois agora existia uma equipe de trabalho, e caminhar em direção às suas ações deliberativas. No final da década de 50 , em um esforço contínuo para estabelecer a profissão de enfermagem, iniciou-se o trabalho para definir as funções da enfermagem ${ }^{38}$.

Embora limitadas, há evidências da introdução do termo PE nos anos 50 e com reações de certos enfermeiros expressas em frases como "We have been doing it all the time" e "It is the same as the research process" 38 p.10. Embora consideradas manifestações reativas, os enfermeiros tinham uma parcela de razão, pois os enfermeiros utilizavam o processo, embora de modo intuitivo, ao identificar os problemas de saúde dos clientes, determinar seu papel no enfrentamento desses problemas, elaborar planos de ação e determinar quando e quanto a ação seria efetiva.

Apesar de o PE ter-se tornado parte integrante do currículo de enfermagem, muitos enfermeiros graduados não eram capazes de utilizar a teoria na prática hospitalar. Atribuía-se o fato à utilização de técnicas de produção em massa pelo enfermeiro, ao invés de conceitos básicos de enfermagem na dispensação de cuidados $^{39}$. Também se creditou parte do problema às enfermeiras com maior tempo de formadas, pois enquanto graduandas não tinham vivenciado a utilização do $\mathrm{PE}^{40} \mathrm{e}$ a instrução era feita por estudos de caso, seguindo o modelo médico. Desta forma, atuavam intuitivamente e suas ações eram uma resposta automática para a situação, ao invés de um julgamento clínico ${ }^{41}$. 
Na década de 60, Ida Orlando começou a utilizar o termo PE, distinguindo-o das atividades de enfermagem ${ }^{38}$ e nos hospitais ainda se discutia a dificuldade dos enfermeiros deixarem suas ações baseadas nas tarefas para intervirem com ações centradas no paciente ${ }^{42}$. As tentativas para compreender as dificuldades na implementação do PE nessa época se fizeram à luz da "Teoria do relacionamento dinâmico enfermeiro-paciente" da própria Ida Orlando.

Inicialmente, os enfermeiros do St Mary's Hospital em Tucson (EUA) atribuíram o problema à falta de compreensão do comportamento humano, mas depois se constatou que se tratava de uma falta de comunicação com o paciente e entre os próprios profissionais que não permitia ao enfermeiro identificar as necessidades de cuidado do paciente. Para modificar esta situação, alguns enfermeiros participaram de conferências sobre comunicação e decidiram utilizar o registro do processo para melhorar o cuidado e a interação com o paciente. Embora se tratasse de uma estratégia para o aprendizado dos alunos, os enfermeiros acreditavam que ao adotá-la poderiam guiar futuros contatos enfermeiro-paciente ${ }^{42}$.

Observa-se, assim, uma construção das funções do enfermeiro paralela ao desenvolvimento das teorias de enfermagem, tendo como pano de fundo a implementação do PE.

Apesar das iniciativas isoladas em adotar o registro do processo de enfermagem para desenvolver as habilidades de comunicação do enfermeiro, ainda na década de 70 este motivo era apontado como a razão pela qual os enfermeiros não eram entusiastas na sua implantação no centro cirúrgico, além de dizerem que não se aplicava para o centro cirúrgico ${ }^{43}$.

Em 1976, a Organização Mundial da Saúde incluiu o PE entre os termos da enfermagem para a Europa e identificou quatro fases: levantamento, planejamento, implementação e avaliação ${ }^{43}$. No CC, estas etapas são desenvolvidas como segue: (1) levantamento de problemas do paciente no pré-operatório, (2) planejamento do cuidado de enfermagem no pré-operatório, (3) implementação do plano de cuidados no intra-operatório e (4) avaliação dos cuidados de enfermagem realizados nas fases anteriores no pós-operatório.

$\mathrm{Na}$ década de 80, os enfermeiros assistenciais eram menos valorizados do que aqueles que exerciam atividades de gerência ou de educação, o que levou o Royal 
Ruth Natalia Teresa Turrini

College Nursing e o Departament of Health ans Social Security de Londres a elaborarem documentos voltados para o desenvolvimento dos enfermeiros assistenciais, mas os próprios enfermeiros deveriam assumir um papel pró-ativo para a valorização da prática clínica. Uma das maneiras dos enfermeiros alcançarem este propósito era por meio da implantação do processo de enfermagem nas SO. Surgia assim, a proposta de que o enfermeiro precisava se envolver no cuidado do paciente e para isso precisava sair do $\mathrm{CC}$ e aprender sobre o paciente no pré e no pós-operatório para uma assistência intra-operatória de qualidade ${ }^{43}$.

O PE e os padrões de enfermagem perioperatória são um enfoque sistemático e lógico para o cuidado de enfermagem. Estes elementos oferecem ao enfermeiro as ferramentas para identificar as necessidades do paciente acuradamente, com sensibilidade às mudanças em sua condição. Quando o Alleghany Regional Hospital, Clifton Forge (EUA), compôs um Comitê de Processo de Enfermagem com enfermeiros supervisores de CC para identificar informações para desenvolver o conhecimento baseado tanto no PE quanto nos padrões de cuidado relacionados ao perioperatório, já possuía o PE implantado em suas unidades de internação. Mesmo assim, como o CC é uma área especializada, foi preciso adaptar o PE ao processo de trabalho do enfermeiro de $\mathrm{CC}^{44}$.

A assistência de enfermagem perioperatória sistematizada propõe a aplicação do PE ao cuidado do paciente durante a fase transoperatória tanto no que se refere ao preparo físico do paciente para o ato anestésico-cirúrgico, como para prepará-lo para enfrentar a situação ${ }^{32}$.

Castellanos e Jouclas ${ }^{45}$ propuseram um modelo conceitual-filosófico de assistência perioperatória, a Sistematização da Assistência Perioperatória (SAEP), inicialmente utilizado no desenvolvimento do processo de ensino aprendizagem e posteriormente operacionalizado no centro cirúrgico do Hospital Universitário em cinco etapas: avaliação pré-operatória, identificação de problemas, planejamento de cuidados, implementação da assistência de enfermagem para o período transoperatório e avaliação pós-operatória.

Para uma boa coordenação e comunicação, a documentação do PE no CC deveria incluir: local da incisão e sítio cirúrgico, solução utilizada no preparo da pele, posição do paciente, contagem de materiais contáveis, local da placa de bisturi, 
Ruth Natalia Teresa Turrini

retirada de espécimes, implantes, cateteres, drenos e outros, outros dados importantes ${ }^{43}$.

Assim, o conteúdo de CC na graduação visa oferecer ao aluno oportunidades de desenvolver o PE no período perioperatório, mas mantendo o aprendizado técnico relacionado às intervenções cirúrgicas, uma vez que estas informações precisam estar incluídas no registro do PE.

Uma introdução compreensiva ao CC serve para: (1) prover melhor compreensão das necessidades do paciente no pré, intra e pós-operatório, (2) prover insights sobre as intervenções cirúrgicas que podem afetar diretamente a evolução (outcome) do paciente, (3) prover uma chance para os alunos refletirem se tem competência para esta área, (4) prover uma oportunidade para aprender o que as enfermeiras perioperatórias oferecem para a enfermagem em geral ${ }^{46}$.

Os resultados esperados da atividade de enfermagem no CC relacionam-se ao estabelecimento de prioridades para o gerenciamento da fase perioperatória do paciente, cuidado de enfermagem especializado, método de comunicação sistemática, garantia de continuidade do cuidado de enfermagem ao paciente, coordenação entre especialidades de enfermagem para o cuidado ao paciente, avaliação contínua e ativa do paciente, compromisso dos enfermeiros para com o cuidado do paciente.

No modelo focado no paciente, a enfermeira utiliza o PE para desenvolver o plano de cuidados e coordenar e oferecer cuidados ao paciente submetido a cirurgia ou outros procedimentos invasivos. A enfermeira deve ter habilidade e conhecimento para avaliar fazer diagnóstico, planejar, intervir e avaliar os resultados de suas intervenções. A enfermagem avalia as respostas fisiológicas, psicológicas, socioculturais e espirituais do paciente cirúrgico ${ }^{46}$.

Muitos procedimentos são realizados fora do $\mathrm{CC}$, como os endoscópicos e os procedimentos minimamente invasivos da radiologia intervencionista. Além disso, muitas internações são realizadas via hospital dia, o que reduziu a internação de pacientes no pré-operatório. Assim, habilidade de avaliação e técnica de entrevista passaram a ser essenciais para a implementação do processo de enfermagem no CC. 


\subsection{DEMANDA DE CIRURGIAS E RECURSOS DE ENFERMAGEM NO PAÍS}

Por meio de um levantamento no Sistema Nacional de Banco de Dados do Ministério da Saúde (www.datasus.gov.br) obtiveram-se dados sobre recursos humanos de enfermagem de nível superior, número de graduados em enfermagem, número de postos de trabalho de enfermeiros, número de leitos hospitalares por habitante, número de procedimentos cirúrgicos (alta e média complexidade) e nas unidades da federação do Brasil.

O Datasus é um banco de dados nacional que recebe informações do Instituto Brasileiro de Geografia e Estatística (IBGE), dos conselhos profissionais, Cadastro Nacional dos Estabelecimentos de Saúde do Brasil (CNES).

Este levantamento foi feito para que se pudesse ter uma ideia da situação cirúrgica no país e dos recursos humanos de enfermeiros. O Datasus apresenta diferentes formas de apresentação de seus dados. Alguns dados só estavam disponíveis para 2009 e, portanto, se igualou as informações esta data.

Observa-se pela Tabela 1, que a região $\mathrm{S}$ é a única região em que para todos os Estados o número de postos de trabalho para enfermeiro é menor do que o número de enfermeiros informados pelo Conselho profissional. $\mathrm{Na}$ região $\mathrm{CO}$, com exceção do DF, os estados também apresentam um número de enfermeiros superior ao de postos de trabalho.

A região que mais realiza procedimentos cirúrgicos no país é a SE $(40,1 \%)$, seguida pelo NE (28,1\%), S (17,0\%), N (7,8\%) e CO (7,0\%). A distribuição por complexidade desses procedimentos (Tabela 2) mostra um predomínio de intervenções de média complexidade para todos as unidades da federação. Os procedimentos de alta complexidade são proporcionalmente maiores na região $\mathrm{S}$ e SE.

Na Tabela 3 verifica-se que o percentual de enfermeiros com especialização em CC é baixíssimo, com uma proporção de $0,9 \%$ no país, e a maior proporção foi observada no Estado do AC (4,1\%). Quando se analisa a relação de enfermeiros especialistas em CC com os procedimentos cirúrgicos, os valores são menores ainda, 
0,2/100 procedimentos cirúrgicos no Brasil e o maior valor, 1,1/100 procedimentos cirúrgicos no Estado do AC.

Tabela 1 - Número de postos de trabalho de enfermeiros por 100 leitos e número de enfermeiros por 100 leitos segundo região e unidades da federação. Brasil, 2009.

\begin{tabular}{lcc}
\hline \hline Região & $\begin{array}{c}\text { No postos de } \\
\text { enferm*/100leitos }\end{array}$ & $\begin{array}{c}\text { No } \\
\text { enferm**/100leitos }\end{array}$ \\
\hline \hline AC & 28,2 & 25,3 \\
AM & 20,8 & 20,4 \\
AP & 21,4 & 17,7 \\
PA & 15,3 & 11,7 \\
RO & 18,1 & 11,1 \\
RR & 38,2 & 27,2 \\
TO & 22,2 & 21,3 \\
\hline N & 23,5 & 15,5 \\
\hline AL & 13,6 & 11,1 \\
BA & 20,8 & 16,8 \\
CE & 20,9 & 16,8 \\
MA & 16,0 & 12,1 \\
PB & 23,5 & 18,8 \\
PE & 21,8 & 14,9 \\
PI & 15,2 & 10,7 \\
RN & 19,4 & 15,2 \\
SE & 18,8 & 16,6 \\
\hline NE & 18,9 & 15,2 \\
\hline DF & 41,8 & 38,6 \\
GO & 9,9 & 10,8 \\
MS & 10,2 & 13,3 \\
MT & 13,5 & 16,3 \\
\hline CO & 18,9 & 16,8 \\
\hline ES & 17,6 & 15,3 \\
MG & 15,6 & 16,6 \\
RJ & 32,2 & 21,0 \\
SP & 27,9 & 25,6 \\
\hline SE & 23,3 & 22,1 \\
\hline PR & 13,4 & 15,4 \\
RS & 17,5 & 14,3 \\
SC & 13,4 & 16,3 \\
\hline S & 14,8 & \\
\hline \hline Brasil & 21,2 & \\
\hline \hline & & 18,5 \\
\hline
\end{tabular}

Fonte: www.datasus.gov.br

* IBGE- Pesquisa de Assistência Sanitária

** Conselho de Enfermagem 
Tabela 2 - Frequência de Procedimentos cirúrgicos segundo complexidade e unidade da federação e região. Brasil, 2009.

\begin{tabular}{|c|c|c|c|c|c|c|}
\hline Região & $\begin{array}{c}\text { Média } \\
\text { complexidade }\end{array}$ & $\%$ & $\begin{array}{r}\text { alt } \\
\text { comple }\end{array}$ & ade & $\begin{array}{c}\text { Proced. } \\
\text { Cirurgicos }\end{array}$ & $\%$ \\
\hline$A C$ & 1.254 & 97,3 & 35 & 2,7 & 1.289 & 100 \\
\hline AM & 3.542 & 94,1 & 224 & 5,9 & 3.766 & 100 \\
\hline$A P$ & 781 & 95,7 & 35 & 4,3 & 816 & 100 \\
\hline PA & 13.792 & 97,5 & 359 & 2,5 & 14.151 & 100 \\
\hline RO & 1.818 & 98,5 & 28 & 1,5 & 1.846 & 100 \\
\hline $\mathrm{RR}$ & 602 & 94,8 & 33 & 5,2 & 635 & 100 \\
\hline TO & 2.561 & 95,0 & 135 & 5,0 & 2.696 & 100 \\
\hline $\mathbf{N}$ & 24.350 & 96,6 & 849 & 3,4 & 25.199 & 100 \\
\hline$\overline{A L}$ & 5.540 & 95,6 & 253 & 4,4 & 5.793 & 100 \\
\hline BA & 22.550 & 93,9 & 1.453 & 6,1 & 24.003 & 100 \\
\hline $\mathrm{CE}$ & 13.454 & 92,2 & 1.132 & 7,8 & 14.586 & 100 \\
\hline MA & 8.088 & 94,9 & 432 & 5,1 & 8.520 & 100 \\
\hline PB & 5.754 & 93,5 & 400 & 6,5 & 6.154 & 100 \\
\hline $\mathrm{PE}$ & 14.917 & 92,1 & 1.272 & 7,9 & 16.189 & 100 \\
\hline $\mathrm{PI}$ & 5.711 & 91,9 & 503 & 8,1 & 6.214 & 100 \\
\hline RN & 5.526 & 90,0 & 614 & 10,0 & 6.140 & 100 \\
\hline SE & 2.793 & 93,9 & 181 & 6,1 & 2.974 & 100 \\
\hline $\mathrm{NE}$ & 84.333 & 93,1 & 6.240 & 6,9 & 90.573 & 100 \\
\hline $\mathrm{DF}$ & 4.096 & 91,9 & 363 & 8,1 & 4.459 & 100 \\
\hline GO & 8.332 & 89,8 & 942 & 10,2 & 9.274 & 100 \\
\hline MS & 4.239 & 92,7 & 332 & 7,3 & 4.571 & 100 \\
\hline MT & 4.087 & 95,2 & 204 & 4,8 & 4.291 & 100 \\
\hline $\mathrm{CO}$ & 20.754 & 91,9 & 1.841 & 8,1 & 22.595 & 100 \\
\hline ES & 5.492 & 89,3 & 658 & 10,7 & 6.150 & 100 \\
\hline MG & 30.068 & 90,2 & 3.261 & 9,8 & 33.329 & 100 \\
\hline RJ & 15.703 & 90,4 & 1.666 & 9,6 & 17.369 & 100 \\
\hline $\mathrm{SP}$ & 64.072 & 88,0 & 8.734 & 12,0 & 72.806 & 100 \\
\hline SE & 115.335 & 89,0 & 14.319 & 11,0 & 129.654 & 100 \\
\hline$P R$ & 18.664 & 84,5 & 3.412 & 15,5 & 22.076 & 100 \\
\hline RS & 18.209 & 84,6 & 3.316 & 15,4 & 21.525 & 100 \\
\hline SC & 9.788 & 88,2 & 1.314 & 11,8 & 11.102 & 100 \\
\hline $\mathrm{s}$ & 46.661 & 85,3 & 8.042 & 14,7 & 54.703 & 100 \\
\hline Brasil & 291.433 & 90,3 & 31.291 & 9,7 & 322.724 & 100 \\
\hline
\end{tabular}

Fonte: www.datasus.gov.br 
Tabela 3 - Frequência de enfermeiros e enfermeiros de centro cirúrgico, relação de enfermeiros de centro cirúrgico/ 100 procedimentos cirúrgicos por região e unidade da federação. Brasil, 2009.

\begin{tabular}{|c|c|c|c|c|}
\hline \multirow{2}{*}{$\begin{array}{l}\text { Região } \\
A C\end{array}$} & \multirow{2}{*}{$\frac{\text { No enferm }}{345}$} & \multicolumn{2}{|c|}{ N_enf CC (\%) } & \multirow{2}{*}{$\begin{array}{c}\begin{array}{c}\text { Relação de } \\
\text { enf/100proc cirúrg }\end{array} \\
1,1\end{array}$} \\
\hline & & 14 & $(4,1)$ & \\
\hline AM & 1.071 & 7 & $(0,7)$ & 0,2 \\
\hline $\mathrm{AP}$ & 193 & 2 & $(1,0)$ & 0,2 \\
\hline PA & 1.609 & 21 & $(1,3)$ & 0,1 \\
\hline RO & 374 & 1 & $(0,3)$ & 0,1 \\
\hline RR & 197 & - & $(-)$ & 0,0 \\
\hline TO & 574 & - & $(-)$ & 0,0 \\
\hline $\mathbf{N}$ & 4.363 & 45 & $(1,0)$ & 0,2 \\
\hline $\mathrm{AL}$ & 659 & 5 & $(0,8)$ & 0,1 \\
\hline BA & 4.883 & 48 & $(1,0)$ & 0,2 \\
\hline $\mathrm{CE}$ & 2.646 & 18 & $(0,7)$ & 0,1 \\
\hline MA & 1.459 & 21 & $(1,4)$ & 0,2 \\
\hline PB & 1.531 & 11 & $(0,7)$ & 0,2 \\
\hline PE & 2.853 & 13 & $(0,5)$ & 0,1 \\
\hline $\mathrm{PI}$ & 829 & 7 & $(0,8)$ & 0,1 \\
\hline $\mathrm{RN}$ & 1.042 & 12 & $(1,2)$ & 0,2 \\
\hline SE & 551 & 1 & $(0,2)$ & 0,0 \\
\hline NE & 16.453 & 136 & $(0,8)$ & 0,2 \\
\hline $\mathrm{DF}$ & 2.045 & 31 & $(1,5)$ & 0,7 \\
\hline GO & 1.648 & 8 & $(0,5)$ & 0,1 \\
\hline MS & 759 & 1 & $(0,1)$ & 0,0 \\
\hline MT & 980 & 2 & $(0,2)$ & 0,0 \\
\hline $\mathrm{CO}$ & 5.432 & 42 & $(0,8)$ & 0,2 \\
\hline ES & 1.172 & 14 & $(1,2)$ & 0,2 \\
\hline MG & 7.307 & 43 & $(0,6)$ & 0,1 \\
\hline RJ & 8.932 & 106 & $(1,2)$ & 0,6 \\
\hline $\mathrm{SP}$ & 24.517 & 245 & $(1,0)$ & 0,3 \\
\hline SE & 41.928 & 408 & $(1,0)$ & 0,3 \\
\hline PR & 4.113 & 34 & $(0,8)$ & 0,2 \\
\hline RS & 5.551 & 58 & $(1,0)$ & 0,3 \\
\hline SC & 2.226 & 5 & $(0,2)$ & 0,0 \\
\hline $\mathrm{s}$ & 11.890 & 97 & $(0,8)$ & 0,2 \\
\hline Brasil & 80.066 & 728 & $(0,9)$ & 0,2 \\
\hline
\end{tabular}

Fonte: www. datasus.gov.br - dados de recursos humanos do conselho profissional 
Pelas informações apresentadas, pode-se inferir que o número de enfermeiros que atuam em centro cirúrgico sem o título de especialista nos hospitais do país é elevado.

\subsection{PANORAMA NACIONAL DAS INSTITUIÇÕES DE ENSINO SUPERIOR: CURSO DE BACHARELADO EM ENFERMAGEM}

Em levantamento realizado no site do Ministério da Educação (http://emec.mec.gov.br/) em abril de 2011 e atualizado em setembro de 2011, obteve-se uma lista de 841 cursos presenciais de bacharelado em Enfermagem no Brasil. Dos cursos, 702 (83,5\%) tinham uma administração privada (Figura 1).

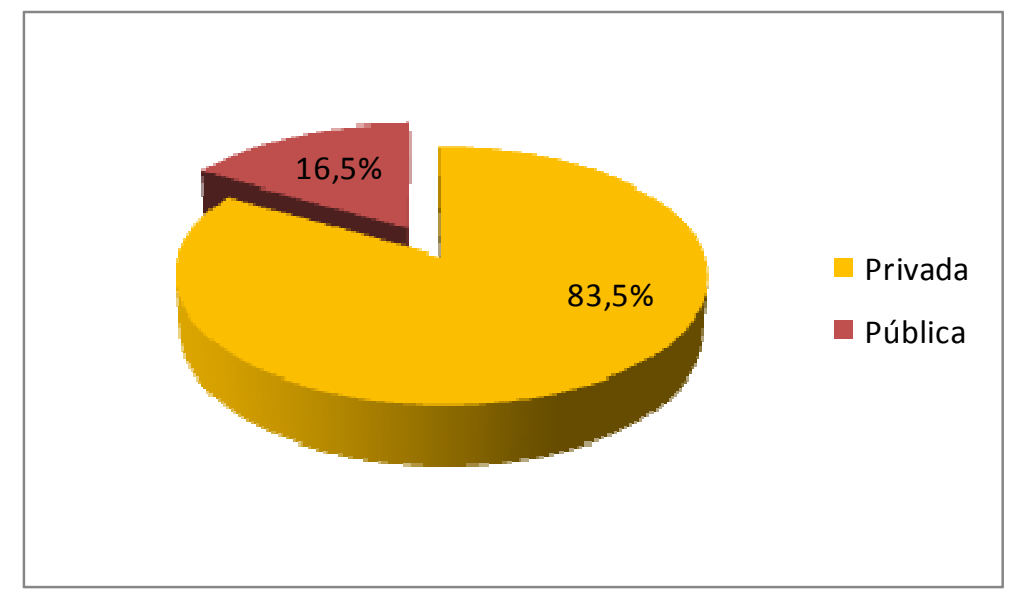

Figura 1 - Distribuição de cursos de Enfermagem segundo tipo instituição quanto à sua administração. Brasil, 2011.

De acordo com o tipo de Instituição de Ensino Superior, a maioria dos cursos de Enfermagem $(n=434 ; 51,6 \%)$ é oferecido em faculdades, 301 (36,1\%) em universidades, $103(12,2 \%)$ em centros universitários e um $(0,1 \%)$ é instituto (Figura 2). 


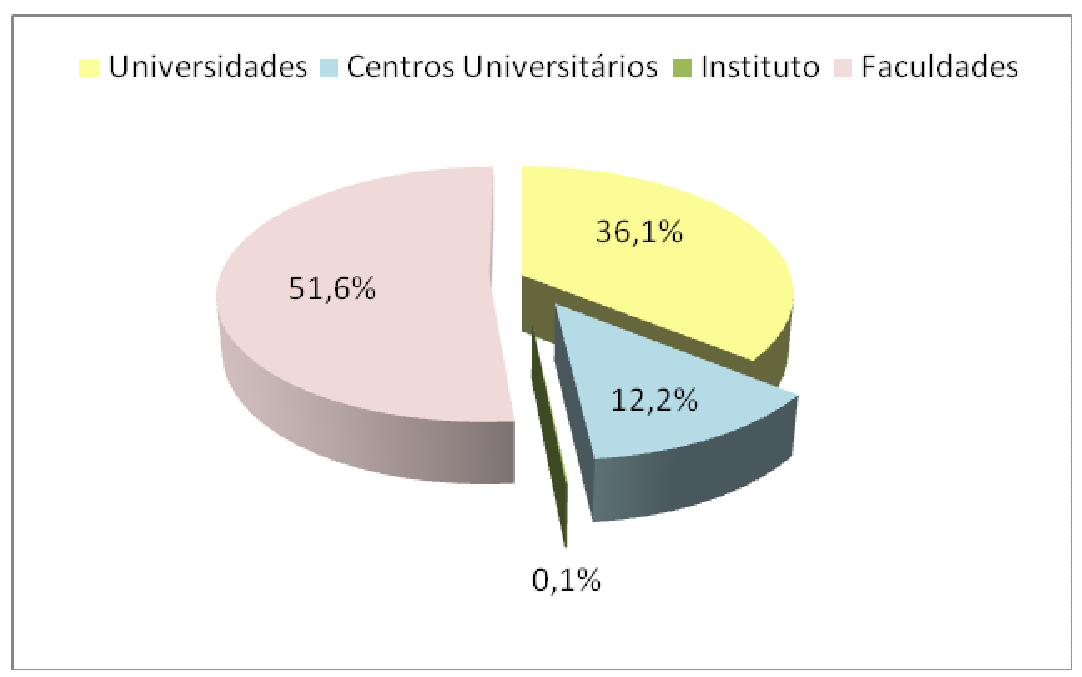

Figura 2 - Distribuição de cursos de Enfermagem segundo classificação do estabelecimento de ensino. Brasil, 2011.

A região SE é aquela que concentra o maior número de cursos de Enfermagem do país $(n=377 ; 44,9 \%)$, seguido pela região $\mathrm{NE}(\mathrm{n}=191 ; 22,7 \%)$ (Tabela 4).

Tabela 4 - Distribuição de cursos de Enfermagem segundo região do país. Brasil, 2011.

\begin{tabular}{lrrr}
\hline & \multicolumn{3}{c}{ Frequência } \\
\cline { 2 - 4 } Região & $\mathrm{N}$ & $\%$ & $\%$ cumulada \\
\hline Sudeste & 377 & 44,9 & 44,9 \\
Nordeste & 191 & 22,7 & 67,6 \\
Sul & 129 & 15,3 & 82,9 \\
Centro-Oeste & 87 & 10,3 & 93,2 \\
Norte & 57 & 6,8 & 100,0 \\
\hline Total & 841 & 100,0 & \\
\hline
\end{tabular}

A figura 3 apresenta a distribuição dos cursos segundo estados do Brasil. Observa-se que por estado, aqueles da região $\mathrm{N}$ apresentam o menor número de cursos oscilando entre três $(0,4 \%)$ e $16(1,9 \%)$. Os estados que concentram o maior quantitativo de cursos em ordem decrescente são: São Paulo ( $n=181 ; 21,5 \%)$, Minas Gerais $(n=124 ; 14,7 \%)$, Paraná $(n=58 ; 6,9 \%)$, Rio de Janeiro $(n=55 ; 6,5 \%)$ e Bahia $(\mathrm{n}=54 ; 6,4 \%)$. 


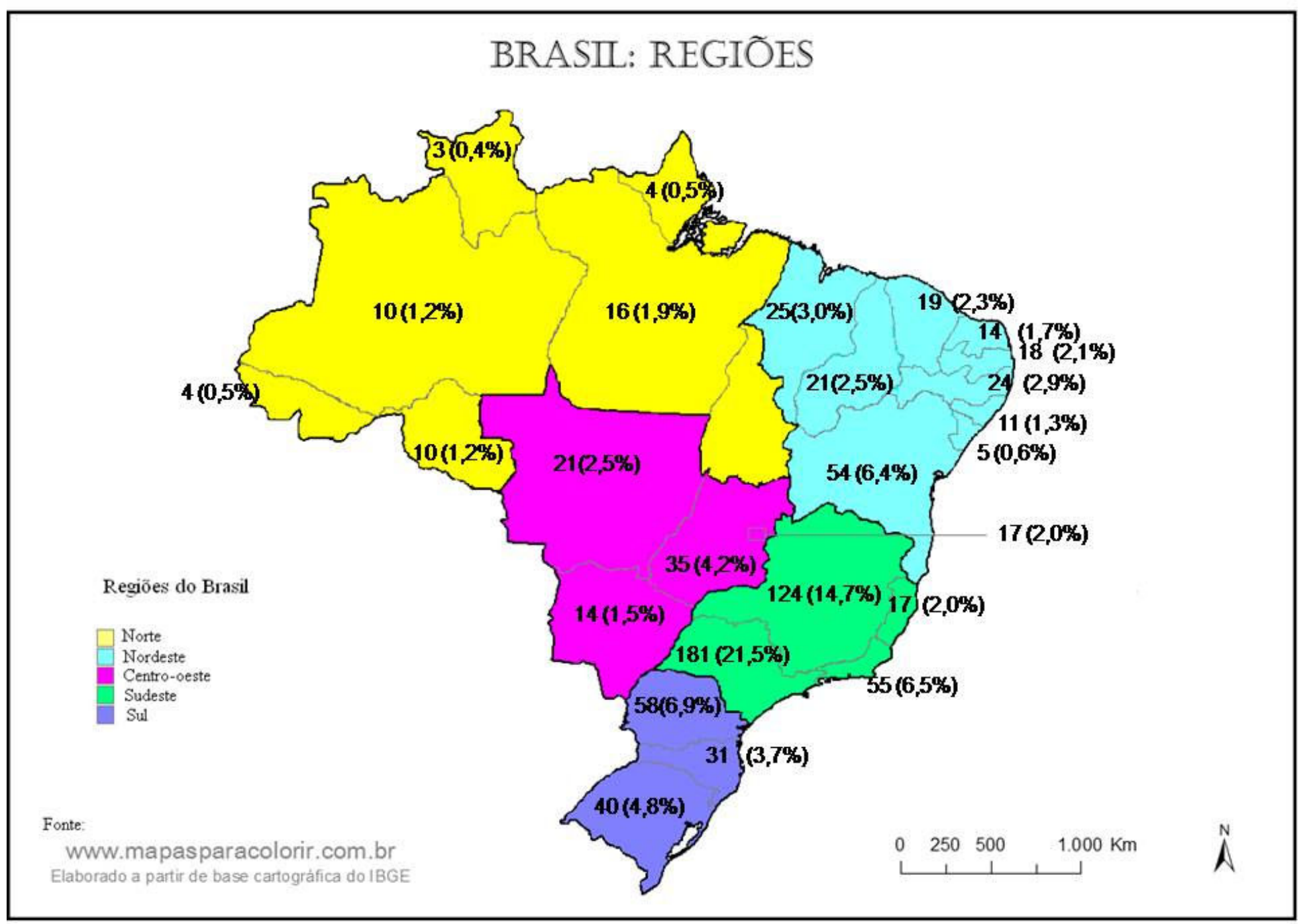

Figura 3 - Frequência absoluta e relativa dos cursos de Enfermagem segundo estado e região do país. Brasil, 2011. 
Considerando-se o total dos cursos, $83,5 \%$ são gerenciados por uma instituição privada (Tabela 5), e a principal presença da gestão pública foi observada nas universidades, embora com apenas 39,9\% (121) dos cursos ministrados nesta categoria.

Tabela 5 - Distribuição de cursos de Enfermagem segundo o tipo de instituição e o tipo de administração da entidade mantenedora. Brasil, 2011.

\begin{tabular}{l|cc|cc|c|c}
\hline \multirow{2}{*}{ Tipo de instituição } & \multicolumn{3}{|c|}{ Tipo de administração } & \multicolumn{2}{|c}{} \\
\cline { 2 - 7 } & \multicolumn{2}{|c|}{ Pública } & \multicolumn{2}{c|}{ Privada } & \multicolumn{2}{c}{ Total } \\
\cline { 2 - 7 } & $\mathrm{N}$ & $\%$ & $\mathrm{~N}$ & $\%$ & $\mathrm{~N}$ & $\%$ \\
\hline Universidade & 121 & 39,9 & 182 & 60,1 & 303 & 100,0 \\
Faculdade & 16 & 3,7 & 418 & 96,3 & 434 & 100,0 \\
Centro Universitário & 1 & 1,0 & 102 & 99,0 & 103 & 100,0 \\
Instituto & 1 & 100,0 & - & - & 1 & 100,0 \\
\hline \multicolumn{1}{c|}{ Total } & 139 & 16,5 & 702 & 83,5 & 841 & 100,0 \\
\hline
\end{tabular}

Os cursos ministrados em instituições de gestão pública concentram-se principalmente nas regiões NE $(n=46 ; 33,1 \%)$ e SE $(n=33 ; 23,7 \%)$ (Tabela 6).

Tabela 6 - Distribuição de Cursos de Bacharelado em Enfermagem segundo o tipo de administração e a região do país. Brasil, 2011.

\begin{tabular}{|c|c|c|c|c|c|c|}
\hline \multirow{3}{*}{ Regiões do Brasil } & \multicolumn{4}{|c|}{ Tipo de administração } & \multirow{2}{*}{\multicolumn{2}{|c|}{ Total }} \\
\hline & \multicolumn{2}{|c|}{ Pública } & \multicolumn{2}{|c|}{ Privada } & & \\
\hline & $\mathrm{N}$ & $\begin{array}{c}\% \\
(\%)^{*}\end{array}$ & $\mathrm{~N}$ & $\begin{array}{c}\% \\
(\%)^{*}\end{array}$ & $\mathrm{~N}$ & $\begin{array}{c}\% \\
(\%) *\end{array}$ \\
\hline Nordeste & 46 & $\begin{array}{c}24,1 \\
(33,2)\end{array}$ & 145 & $\begin{array}{c}75,9 \\
(20,7)\end{array}$ & 191 & $\begin{array}{l}100,0 \\
(22,7)\end{array}$ \\
\hline Sudeste & 33 & $\begin{array}{c}8,8 \\
(23,7)\end{array}$ & 344 & $\begin{array}{c}91,2 \\
(49,0)\end{array}$ & 377 & $\begin{array}{l}100,0 \\
(44,8)\end{array}$ \\
\hline Sul & 22 & $\begin{array}{c}17,1 \\
(15,8)\end{array}$ & 107 & $\begin{array}{c}82,9 \\
(15,2)\end{array}$ & 129 & $\begin{array}{l}100,0 \\
(15,3)\end{array}$ \\
\hline Centro Oeste & 20 & $\begin{array}{c}23,0 \\
(14,4)\end{array}$ & 67 & $\begin{array}{l}77,0 \\
(9,5)\end{array}$ & 103 & $\begin{array}{l}100,0 \\
(10,3)\end{array}$ \\
\hline Norte & 18 & $\begin{array}{c}31,6 \\
(12,9)\end{array}$ & 39 & $\begin{array}{l}68,4 \\
(5,6)\end{array}$ & 57 & $\begin{array}{c}100,0 \\
(6,8)\end{array}$ \\
\hline Total & 139 & $\begin{array}{c}16,5 \\
(100,0)\end{array}$ & 702 & $\begin{array}{c}83,5 \\
(100,0)\end{array}$ & 841 & $\begin{array}{c}100,0 \\
(100,0)\end{array}$ \\
\hline
\end{tabular}

* $(\%)$ em coluna 
Por outro lado considerando-se cada região, a SE $(33,2 \%)$ e a $N(31,6 \%)$ apresentam a maior proporção interna de cursos de gestão pública.

De acordo com o tipo de instituição, a região sudeste concentra o maior número de todas as modalidades, exceto o instituto (Tabela 7), seguida pela região sul, no entanto, a região nordeste supera a região sul no quantitativo de faculdades.

Tabela 7 - Distribuição de Cursos de Bacharelado em Enfermagem segundo o tipo de instituição e a região do país. Brasil, 2011.

\begin{tabular}{|c|c|c|c|c|c|c|c|c|c|c|c|c|}
\hline \multirow{3}{*}{ Tipo de instituição } & \multicolumn{12}{|c|}{ Região } \\
\hline & \multicolumn{2}{|c|}{$\mathrm{N}$} & \multicolumn{2}{|c|}{$\mathrm{NE}$} & \multicolumn{2}{|c|}{$\mathrm{CO}$} & \multicolumn{2}{|c|}{ SE } & \multicolumn{2}{|c|}{$\mathrm{S}$} & \multicolumn{2}{|c|}{ Total } \\
\hline & $\mathrm{N}$ & $\%$ & $\mathrm{~N}$ & $\%$ & $\mathrm{~N}$ & $\%$ & $\mathrm{~N}$ & $\%$ & $\mathrm{~N}$ & $\%$ & $\mathrm{~N}$ & $\%$ \\
\hline Universidade & 17 & 5,6 & 60 & 19,8 & 28 & 9,2 & 130 & 42,9 & 68 & 22,4 & 303 & 100,0 \\
\hline Centro Universit & 7 & 6,8 & 6 & 5,8 & 12 & 11,7 & 67 & 65,0 & 11 & 10,7 & 103 & 100,0 \\
\hline Faculdade & 33 & 7,6 & 125 & 28,8 & 47 & 10,8 & 180 & 41,5 & 49 & 11,3 & 434 & 100,0 \\
\hline Instituto & - & - & - & - & - & - & - & - & 1 & 100 & - & 100,0 \\
\hline Total & 57 & 6,8 & 191 & 22,7 & 87 & 10,3 & 377 & 44,8 & 129 & 15,3 & 841 & 100,0 \\
\hline
\end{tabular}

Excluindo-se a região SE (52,7\%), a proporção interna de universidades em cada região pouco oscila: S $(34,5 \%), \mathrm{CO}(32,2 \%)$, NE $(31,4 \%)$ e $\mathrm{N}(29,8 \%)$. Por outro lado, a situação nas faculdades se inverte: NE (65,4\%), N (57,9\%), CO $(54,0 \%)$, SE $(47,7 \%)$ e S $(38,0 \%)$. As regiões $\mathrm{S}$ e $\mathrm{NE}$ são as que possuem o menor quantitativo proporcional de centros universitários, $8,5 \%$ e 3,1\%, respectivamente.

Para duas faculdades não se conseguiu obter a carga horária do curso (um curso de escola pública no Estado de Tocantins e um de escola privada no Estado de São Paulo). A carga horária média dos cursos de Enfermagem é de 4.077,4h (DP \pm 356h), variação de 3.150 a 5.850h (Tabela 8), uma mediana de $4.018 \mathrm{~h}$. 
Tabela 8 - Distribuição de Curso de Enfermagem segundo carga horária do curso. Brasil, 2011.

\begin{tabular}{lrrr}
\hline & \multicolumn{3}{c}{ Frequência } \\
\cline { 2 - 4 } Carga horária $(\mathrm{h})$ & $\mathrm{N}$ & $\%$ & \% cumulada \\
\hline $3.150 \mid-3.500$ & 34 & 4,0 & 4,0 \\
$3.500 \mid-4.000$ & 166 & 19,8 & 23,8 \\
$4.000 \mid-4.500$ & 554 & 66,0 & 89,8 \\
$4.500 \mid-5.000$ & 73 & 8,7 & 98,5 \\
$5.000 \mid-5.500$ & 8 & 1,0 & 99,5 \\
$5.500 \mid-5.851$ & 4 & 0,5 & 100,0 \\
\hline Total & 839 & 100,0 \\
\hline
\end{tabular}

Quando se observa, os cursos que apresentam mais de 5.000h, verifica-se que cerca de 75,0\% desses cursos são mantidos por entidades públicas (Tabela 9).

Tabela 9 - Distribuição de Cursos de Enfermagem segundo carga horária e entidade mantenedora. Brasil, 2011.

\begin{tabular}{l|cc|cc|c|c}
\hline \multirow{2}{*}{ Carga horária } & \multicolumn{4}{|c|}{ Tipo de administração } & \multicolumn{2}{c}{} \\
\cline { 2 - 6 } & \multicolumn{2}{|c|}{ Pública } & \multicolumn{2}{c|}{ Privada } & \multicolumn{2}{c}{ Total } \\
\cline { 2 - 7 } & $\mathrm{N}$ & $\%$ & $\mathrm{~N}$ & $\%$ & $\mathrm{~N}$ & $\%$ \\
\hline $3.150 \mid-3.500$ & 5 & 14,7 & 29 & 85,3 & 34 & 100,0 \\
$3.500 \mid-4.000$ & 25 & 15,1 & 141 & 84,9 & 166 & 100,0 \\
$4.000 \mid-4.500$ & 77 & 13,9 & 477 & 86,1 & 554 & 100,0 \\
$4.500 \mid-5.000$ & 22 & 30,1 & 51 & 69,9 & 73 & 100,0 \\
$5.000 \mid-5.500$ & 6 & 75,0 & 2 & 25,0 & 8 & 100,0 \\
$5.500 \mid-5.851$ & 3 & 75,0 & 1 & 25,0 & 4 & 100,0 \\
\hline Total & 138 & 16,4 & 701 & 83,6 & 839 & 100,0 \\
\hline
\end{tabular}

Nota-se que 23,8\% (200) dos cursos precisam se adaptar à nova legislação ${ }^{28}$ da carga horária mínima para os cursos de graduação em Enfermagem. Considerando-se a entidade mantenedora, cerca de $85,0 \%$ dos cursos que precisam se adequar tem gestão privada.

Os cursos que precisam adequar suas cargas horárias mínimas localizam-se principalmente nas regiões SE e NE (Tabela 10). 
Tabela 10 - Distribuição de Cursos de Enfermagem segundo carga horária e região. Brasil, 2011.

\begin{tabular}{|c|c|c|c|c|c|c|c|c|c|c|c|c|}
\hline \multirow{3}{*}{ Carga horária } & \multicolumn{12}{|c|}{ Região } \\
\hline & \multicolumn{2}{|c|}{$\mathrm{N}$} & \multicolumn{2}{|c|}{$\mathrm{NE}$} & \multicolumn{2}{|c|}{$\mathrm{CO}$} & \multicolumn{2}{|c|}{ SE } & \multicolumn{2}{|c|}{$\mathrm{S}$} & \multicolumn{2}{|c|}{ Total } \\
\hline & $\mathrm{N}$ & $\%$ & $\mathrm{~N}$ & $\%$ & $\mathrm{~N}$ & $\%$ & $\mathrm{~N}$ & $\%$ & $\mathrm{~N}$ & $\%$ & $\mathrm{~N}$ & $\%$ \\
\hline $3.150 \mid-3.500$ & 1 & 2,9 & 12 & 35,3 & 4 & 11,8 & 16 & 47,1 & 1 & 2,9 & 34 & 100,0 \\
\hline $3.500 \mid-4.000$ & 14 & 8,4 & 37 & 22,3 & 10 & 6,0 & 73 & 44,0 & 32 & 19,3 & 166 & 100,0 \\
\hline $4.000 \mid-4.500$ & 34 & 6,1 & 120 & 21,7 & 65 & 11,7 & 253 & 45,7 & 82 & 14,8 & 554 & 100,0 \\
\hline $4.500 \mid-5.000$ & 6 & 8,2 & 19 & 26,0 & 8 & 11,0 & 28 & 38,4 & 12 & 16,4 & 73 & 100,0 \\
\hline $5.000 \mid-5.500$ & 1 & 12,5 & 2 & 25,0 & - & - & 4 & 50,0 & 1 & 12,5 & 8 & 100,0 \\
\hline $5.500 \mid-5.851$ & - & - & 1 & 25,0 & - & - & 2 & 50,0 & 1 & 25,0 & 4 & 100,0 \\
\hline Total & 56 & 6,7 & 191 & 22,7 & 87 & 10,4 & 376 & 44,8 & 129 & 15,4 & 839 & 100,0 \\
\hline
\end{tabular}

Considerando-se as regiões isoladamente, a região CO tem 14 (16,1\%) cursos com menos de 4.000 h, a região $\mathrm{N} 15$ (26,8\%), a região $\mathrm{NE} 49$ (25,7\%), a região $\mathrm{SE}$ $89(23,7 \%)$ e a região S $33(25,6 \%)$.

Os 841 cursos de bacharelado cadastrados no MEC oferecem em conjunto 1236 turmas. Observou-se que alguns estabelecimentos de ensino oferecem turmas em todos os períodos dentro de um mesmo curso de bacharelado cadastrado e outros apresentam um cadastro de curso de bacharelado separado para cada período. Os períodos em que são distribuídas as turmas de alunos são diferentes dependendo da região. Há maior número de turmas no período noturno (41,7\%) (Tabela 11).

Tabela 11 - Distribuição das turmas dos Cursos de Enfermagem segundo período e região. Brasil, 2011.

\begin{tabular}{|c|c|c|c|c|c|c|c|c|c|c|c|c|}
\hline \multirow{3}{*}{ Período } & \multicolumn{10}{|c|}{ Região } & & \\
\hline & \multicolumn{2}{|c|}{$\mathrm{N}$} & \multicolumn{2}{|c|}{$\mathrm{NE}$} & \multicolumn{2}{|c|}{$\mathrm{CO}$} & \multicolumn{2}{|c|}{ SE } & \multicolumn{2}{|c|}{$\mathrm{S}$} & \multicolumn{2}{|c|}{ Total } \\
\hline & $\mathrm{N}$ & $\%$ & $\mathrm{~N}$ & $\%$ & $\mathrm{~N}$ & $\%$ & $\mathrm{~N}$ & $\%$ & $\mathrm{~N}$ & $\%$ & $\mathrm{~N}$ & $\%$ \\
\hline Manhã & 24 & 27,9 & 117 & 41,6 & 43 & 33,8 & 218 & 37,3 & 43 & 27,6 & 445 & 36,0 \\
\hline Tarde & 14 & 16,3 & 47 & 16,7 & 8 & 6,3 & 33 & 5,6 & 10 & 6,4 & 112 & 9,0 \\
\hline Noite & 28 & 32,6 & 77 & 27,5 & 51 & 40,2 & 293 & 50,3 & 66 & 42,3 & 515 & 41,7 \\
\hline Integral & 20 & 23,3 & 40 & 14,2 & 25 & 19,7 & 42 & 6,8 & 37 & 23,7 & 164 & 13,3 \\
\hline Total & 86 & 100 & 281 & 100 & 127 & 100 & 586 & 100 & 156 & 100 & 1236 & 100,0 \\
\hline
\end{tabular}

A região NE concentra turmas no período da manhã $(41,6 \%)$, enquanto as demais regiões oferecem maior número de turmas a noite. No período da tarde é 
oferecido o menor número de turmas em todas as regiões, exceto no NE. As turmas de período integral constituem apenas 13,3\% (164) das turmas, com maiores proporções nas regiões N $(23,3 \%)$ e S $(23,7 \%)$.

Os estabelecimentos de gestão pública abrangem 12,1\% (149) de todas as turmas e oferecem preferencialmente cursos de período integral, representando $61,0 \%$ de todas as turmas de período integral (Figura 4).

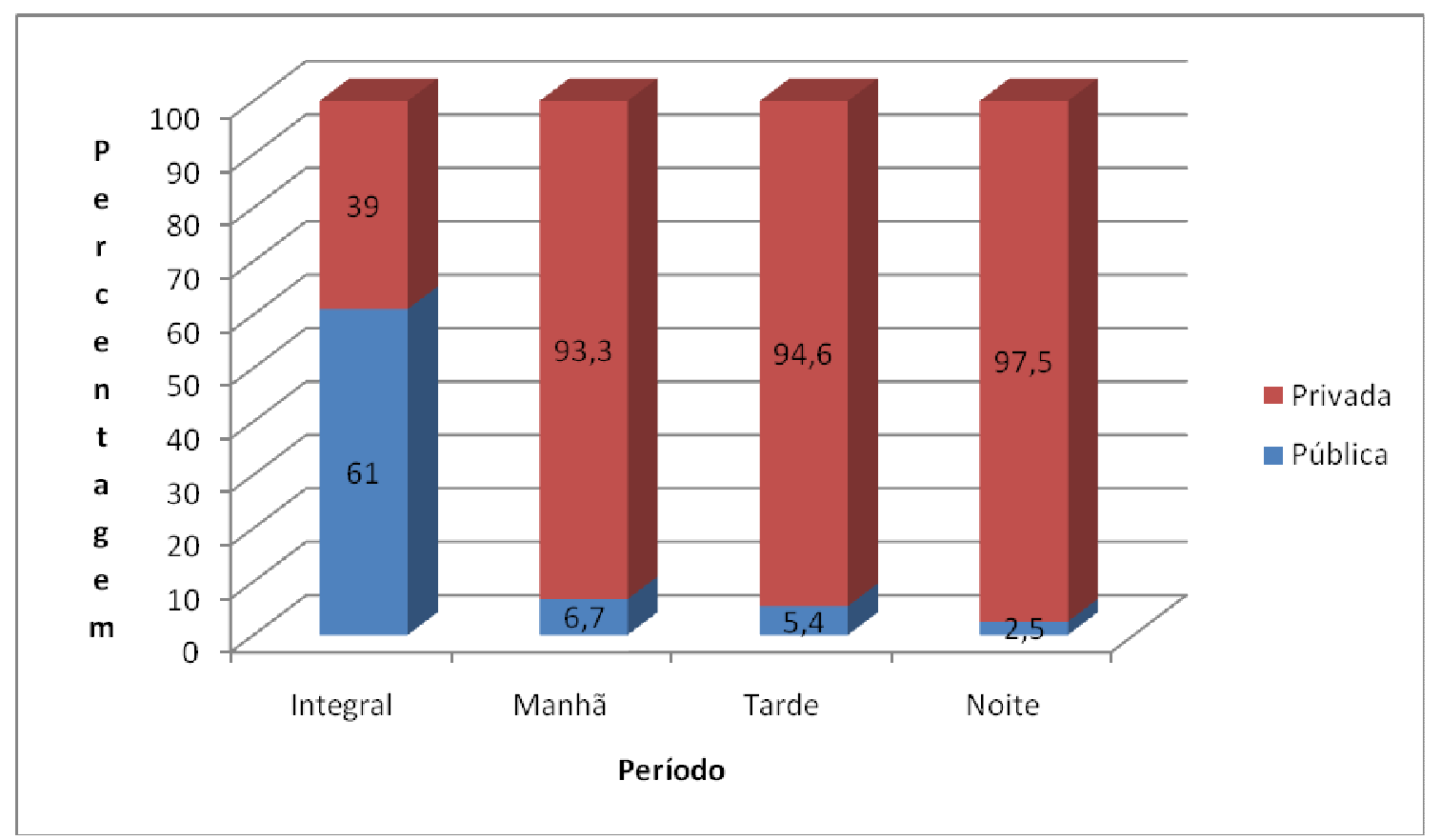

Figura 4 - Distribuição de turmas segundo o período e tipo de administração. Brasil, 2011.

De todos os cursos, apenas cinco $(0,6 \%)$ não apresentavam informações sobre o número de vagas oferecidas, portanto, a análise foi feita para 836 cursos de bacharelado. O número de vagas oferecidas no país é de 125.716 (variação de 25 a 1.200), com uma média de 149,5 (DP $\pm 135,7$ ) vagas por curso de enfermagem e uma mediana de 100 vagas.

$\mathrm{Na}$ figura 5 observa-se a maior proporção de vagas noturnas oferecidas na região $\mathrm{SE}(52,1 \%)$ e a menor na região $\mathrm{N}(34,3 \%)$. A região $\mathrm{NE}$ é a que concentra mais vagas no período da manhã $(43,5 \%)$; a região $\mathrm{N}(14,1 \%)$ e NE $(14,7 \%)$ a tarde 
e para os cursos integrais, o maior percentual de vagas está no $\mathrm{N}(19,3 \%)$ e no $\mathrm{S}$ $(20,2 \%)$.

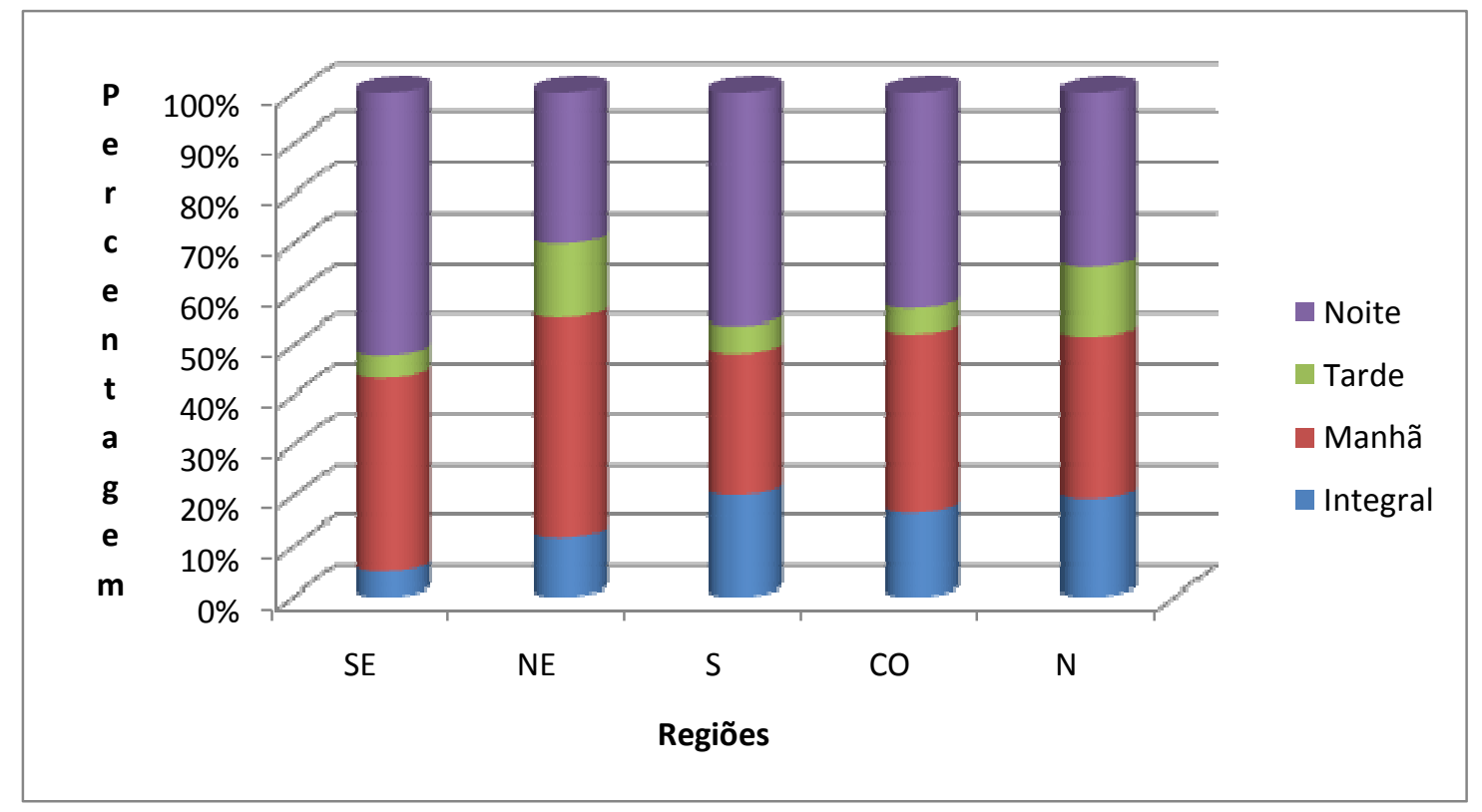

Figura 5 - Distribuição de vagas (\%) por região por período. Brasil, 2011.

Os cursos de período integral limitam a entrada de estudantes com baixo poder aquisitivo, embora alguns alunos tentem conciliar trabalho noturno com o estudo. O perfil dos estudantes de enfermagem tende a ser de trabalhadores, muitos já atuam como profissional de enfermagem, daí a oferta e a procura por cursos noturnos ou de meio período.

As figuras de 6 a 32 apresentam os mapas das unidades da federação com a localização dos municípios que possuem cursos de bacharelado em enfermagem. Cada figura também está acompanhada de um quadro com dados demográficos, geográficos e número de vagas oferecidas.

Em termos de percentual de municípios com cursos de enfermagem em cada unidade da federação, o DF é o que apresenta mais cursos justamente por ser uma área única. Nos Estados, o número de vagas variou de 2,2\% na PB a 12,8\% no ES. Estes valores não representam necessariamente maior número de cursos, mas é o Estado que possui poucos municípios. Municípios com poucos cursos podem tê-los bem distribuídos espacialmente como é o caso de TO, AL e PB. O PA tem 4,2\% de municípios com cursos, mas todos localizados na região centro-norte do Estado. 
Observou-se uma tendência de oferta de cursos ao redor da capital e próximo a cidades do litoral. Em alguns Estados observa-se a localização de cursos em cidades próximas às fronteiras estaduais.

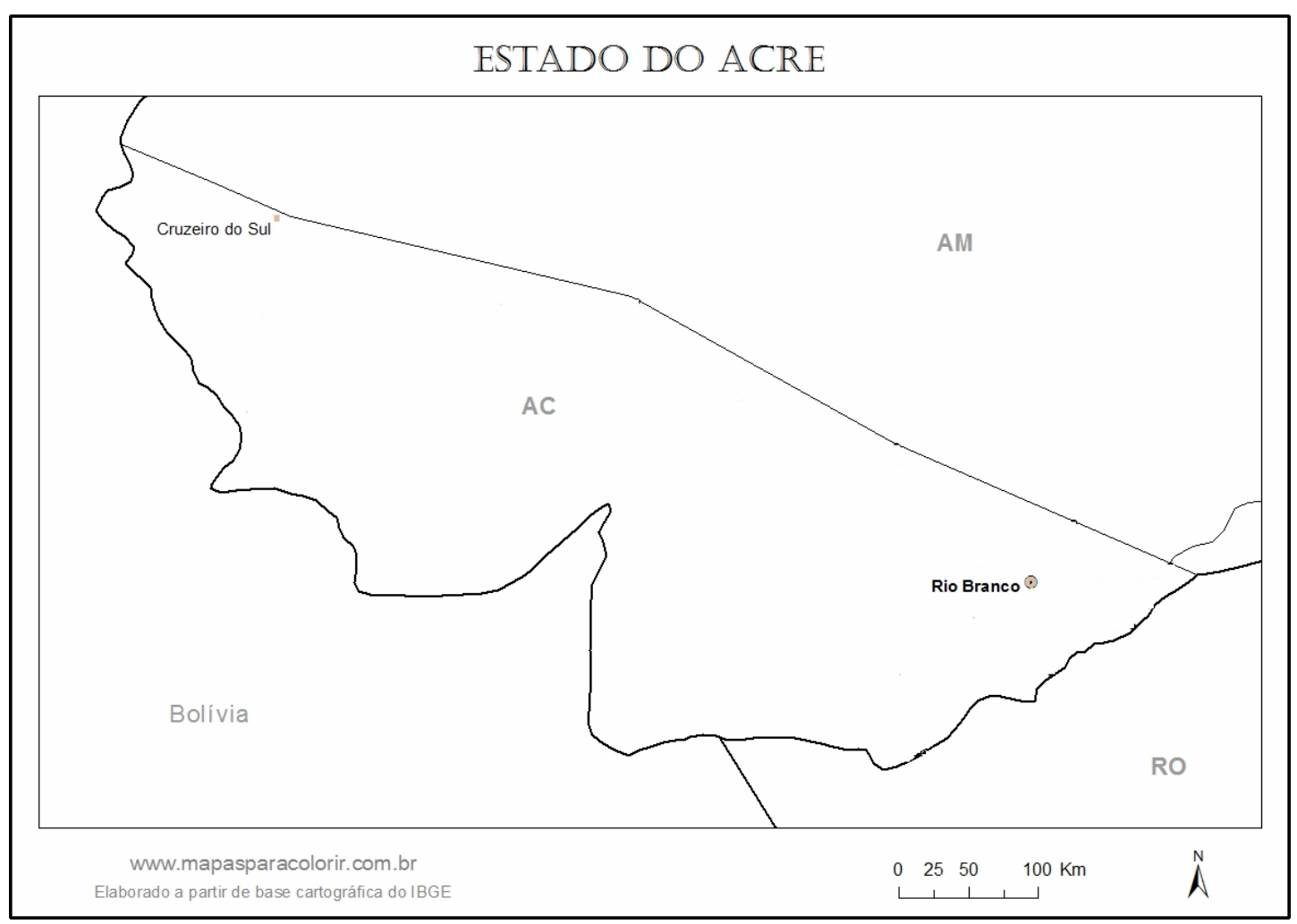

Fonte: www.mapasparacolorir.com.br

Figura 6 - Mapa do Estado do Acre e cidades com curso de bacharelado presencial em Enfermagem. Brasil, 2011.

\section{Capital: Rio Branco}

$\mathrm{N}^{\mathrm{o}}$ municípios: 22

$\mathrm{N}^{\mathrm{o}}$ municípios com curso de Enfermagem: 2 (4,5\%) 
Quadro 1 - Dados sobre população, extensão territorial densidade demográfica, número de cursos de bacharelado, vagas oferecidas e número de vagas/10.000 hab. Acre, 2010.

\begin{tabular}{lcrcccc}
\hline \hline LOCALIDADE & População* & Extensão* & hab/km & $\begin{array}{c}\text { № } \\
\text { cursos** }\end{array}$ & $\begin{array}{c}\text { Total } \\
\text { vagas** }\end{array}$ & $\begin{array}{c}\text { № vagas } \\
\text { \%oo hab }\end{array}$ \\
\hline \hline ACRE & 733.559 & $164.122,28$ & 4,5 & 4 & 310 & 4,2 \\
Rio Branco & 336.038 & $8.835,68$ & 38,0 & 3 & 180 & 5,4 \\
Cruzeiro do Sul & 78.507 & $8.779,19$ & 8,9 & 1 & 30 & 3,8 \\
\hline \hline
\end{tabular}

Fonte:

*http://www.ibge.gov.br/home/estatistica/populacao/censo2010/resultados_preliminares/default_resul tados_preliminares.shtm

**http://emec.mec.gov.br/

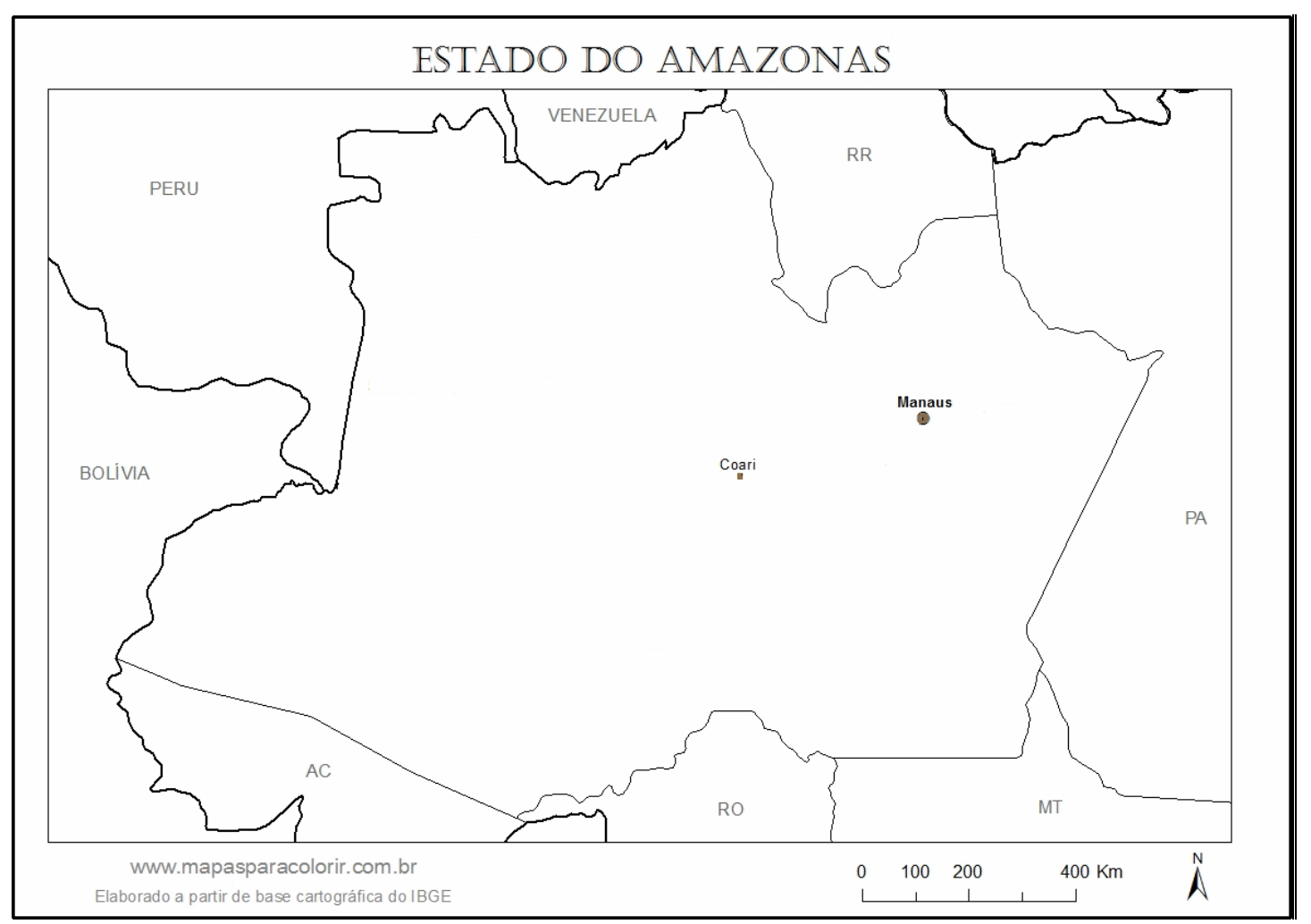

Fonte: www.mapasparacolorir.com.br

Figura 7 - Mapa do Estado do Amazonas e cidades com curso de bacharelado presencial em Enfermagem. Brasil, 2011.

Capital: Manaus

$\mathrm{N}^{\mathrm{o}}$ municípios: 62

$\mathrm{N}^{\mathrm{o}}$ municípios com curso de Enfermagem: 2 (3,2\%) 
Quadro 2 - Dados sobre população, extensão territorial densidade demográfica, número de cursos de bacharelado, vagas oferecidas e número de vagas/10.000 hab. Amazonas, 2010.

\begin{tabular}{|c|c|c|c|c|c|c|}
\hline LOCALIDADE & População* & Extensão* & $\mathrm{hab} / \mathrm{km}^{2}$ & $\begin{array}{c}\text { № } \\
\text { cursos** } \\
\end{array}$ & $\begin{array}{c}\text { Total } \\
\text { vagas** }\end{array}$ & $\begin{array}{l}\text { № vagas } \\
\% \text { habab }\end{array}$ \\
\hline AMAZONAS & 3.483 .985 & $\begin{array}{r}1.559 .161,6 \\
8\end{array}$ & 2,2 & 10 & 1874 & 5,4 \\
\hline Manaus & 1.802 .014 & $11.401,08$ & 158,1 & 9 & 1834 & 10,2 \\
\hline Coari & 75.965 & $57.921,91$ & 1,3 & 1 & 40 & 5,3 \\
\hline
\end{tabular}

Fonte:

*http://www.ibge.gov.br/home/estatistica/populacao/censo2010/resultados_preliminares/default_resul tados_preliminares.shtm

**http://emec.mec.gov.br/

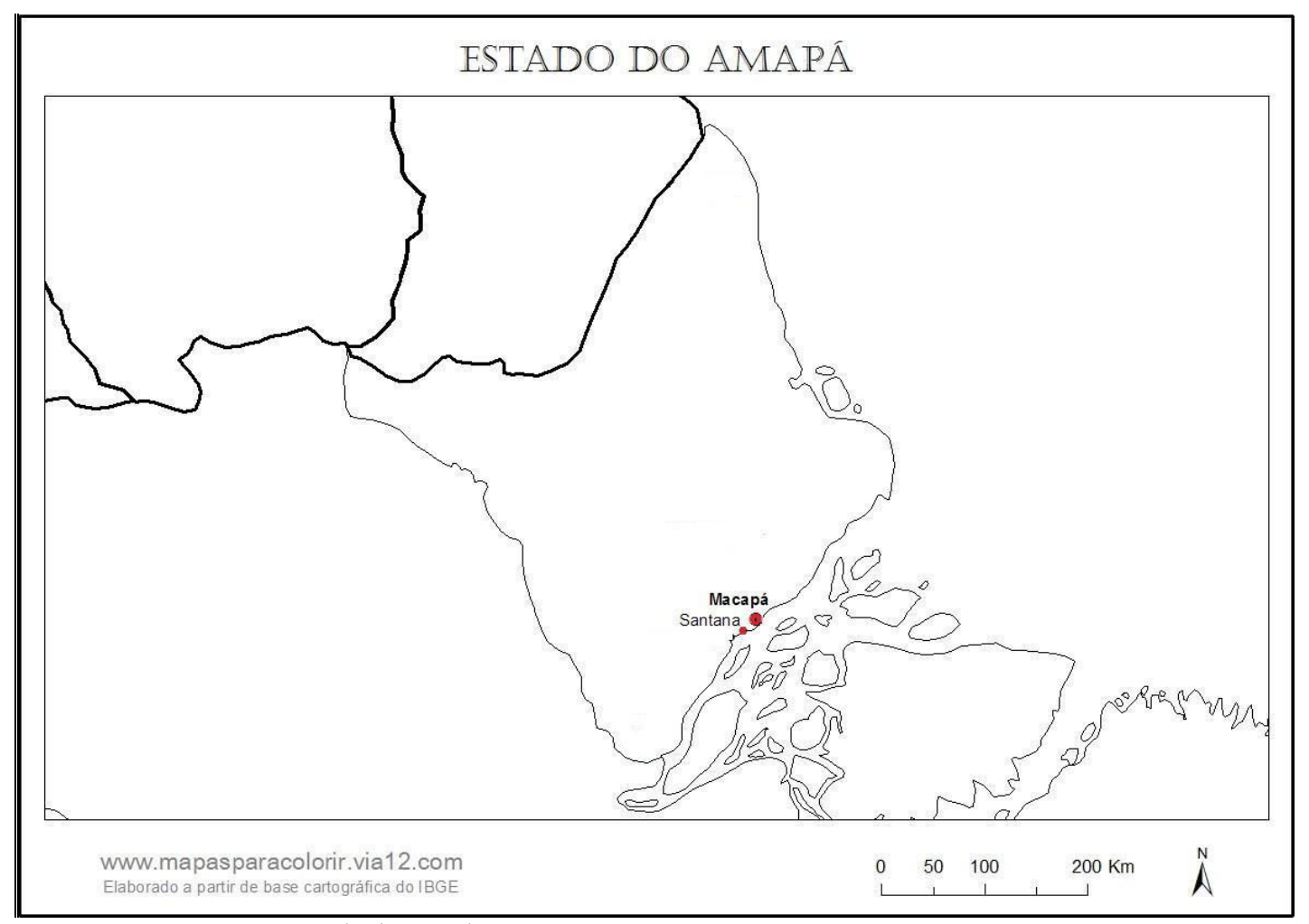

Fonte: www.mapasparacolorir.com.br

Figura 8 - Mapa do Estado do Amapá e cidades com curso de bacharelado presencial em Enfermagem. Brasil, 2011.

Capital: Macapá

$\mathrm{N}^{\mathrm{o}}$ municípios: 16

$\mathrm{N}^{\mathrm{o}}$ municípios com curso de Enfermagem: 2 (12,5\%) 
Quadro 3 - Dados sobre população, extensão territorial densidade demográfica, número de cursos de bacharelado, vagas oferecidas e número de vagas/10.000 hab. Amapá, 2010.

\begin{tabular}{lrrrrrr}
\hline \hline LOCALIDADE & População* & Extensão* & hab/km ${ }^{2}$ & $\begin{array}{c}\text { № } \\
\text { cursos** }\end{array}$ & $\begin{array}{c}\text { Total } \\
\text { vagas** }\end{array}$ & $\begin{array}{c}\text { № vagas } \\
\% \\
\text { \%oohab }\end{array}$ \\
\hline \hline AMAPÁ & 669.526 & $142.827,90$ & 4,6 & 4 & 350 & 5,2 \\
Macapá & 398.204 & $6.408,52$ & 62,1 & 3 & 250 & 6,3 \\
Santana & 101.262 & $1.579,60$ & 64,1 & 1 & 100 & 9,9 \\
\hline \hline
\end{tabular}

Fonte:

*http://www.ibge.gov.br/home/estatistica/populacao/censo2010/resultados_preliminares/default_resul tados_preliminares.shtm

**http://emec.mec.gov.br/

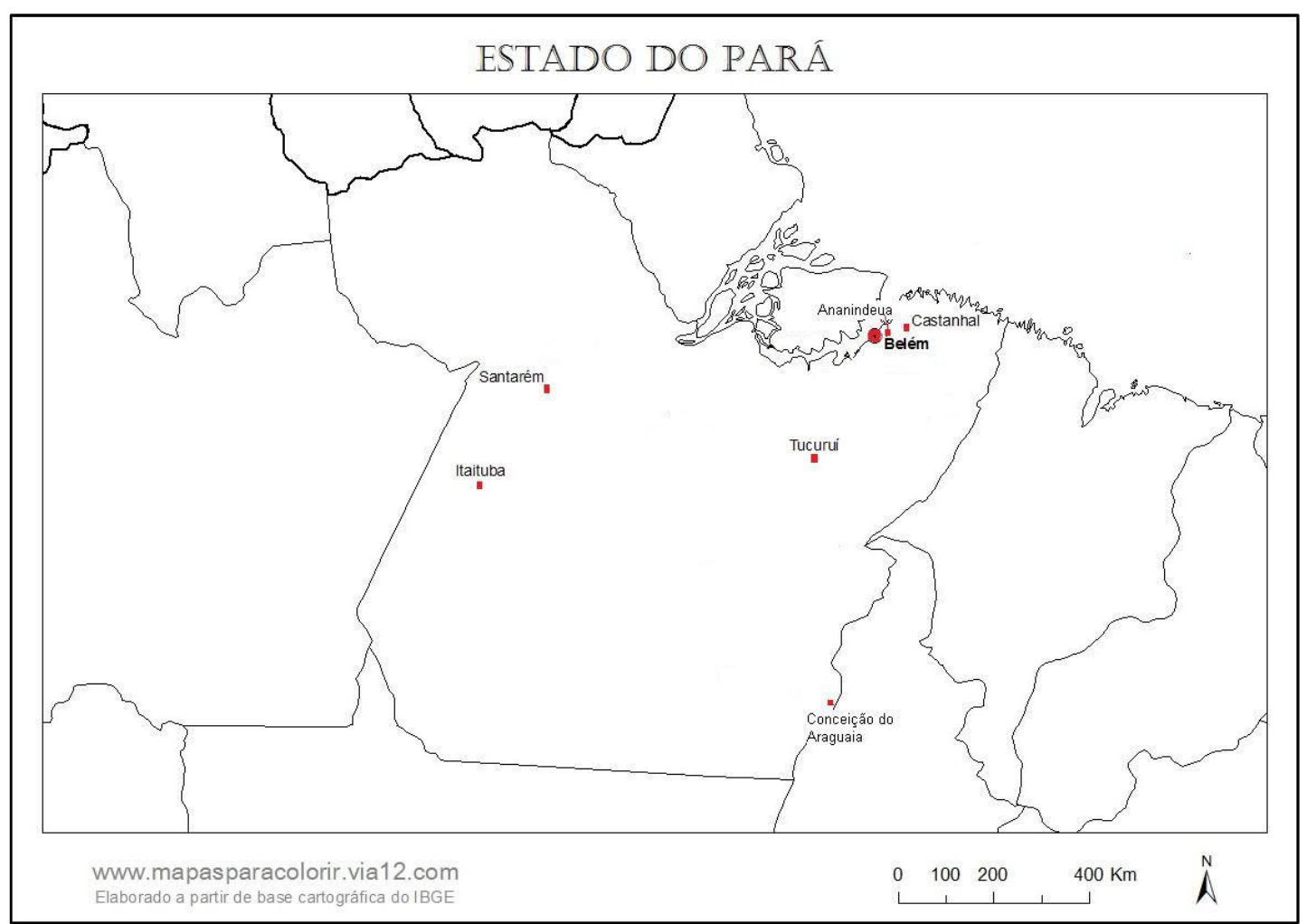

Fonte: www.mapasparacolorir.com.br

Figura 9 - Mapa do Estado do Pará e cidades com curso de bacharelado presencial em Enfermagem. Brasil, 2011.

Capital: Belém

$\mathrm{N}^{\mathrm{o}}$ municípios: 143

$\mathrm{N}^{\mathrm{o}}$ municípios com curso de Enfermagem: 6 (4,2\%) 
Quadro 4 - Dados sobre população, extensão territorial densidade demográfica, número de cursos de bacharelado, vagas oferecidas e número de vagas/10.000 hab. Pará, 2010.

\begin{tabular}{lrrrrrr}
\hline \hline LOCALIDADE & População* & Extensão* & hab/km & $\begin{array}{c}\text { № } \\
\text { cursos** }\end{array}$ & $\begin{array}{c}\text { Total } \\
\text { vagas** }\end{array}$ & $\begin{array}{c}\text { № vagas } \\
\text { \%ooohab }\end{array}$ \\
\hline \hline PARÁ & 7.581 .051 & $1.247 .950,00$ & 6,1 & 16 & 1926 & 2,5 \\
Belém & 1.393 .399 & $1.059,40$ & $1.315,3$ & 8 & 1080 & 7,8 \\
Ananindeua & 471.980 & 190,50 & $2.477,6$ & 1 & 100 & 2,1 \\
Castanhal & 173.149 & $1.028,89$ & 168,3 & 1 & 200 & 11,6 \\
C. do Araguaia & 45.557 & $5.829,47$ & 7,8 & 1 & 26 & 5,7 \\
Itaituba & 97.493 & $62.040,11$ & 1,5 & 1 & 200 & 20,5 \\
Santarém & 294.580 & $22.886,76$ & 12,9 & 3 & 290 & 9,8 \\
Tucuruí & 97.128 & $2.086,20$ & 46,6 & 1 & 30 & 3,1 \\
\hline \hline
\end{tabular}

Fonte: * http://www.ibge.gov.br/home/estatistica/populacao/censo2010/resultados_preliminares /default_resultados_preliminares.shtm

**http://emec.mec.gov.br/ 


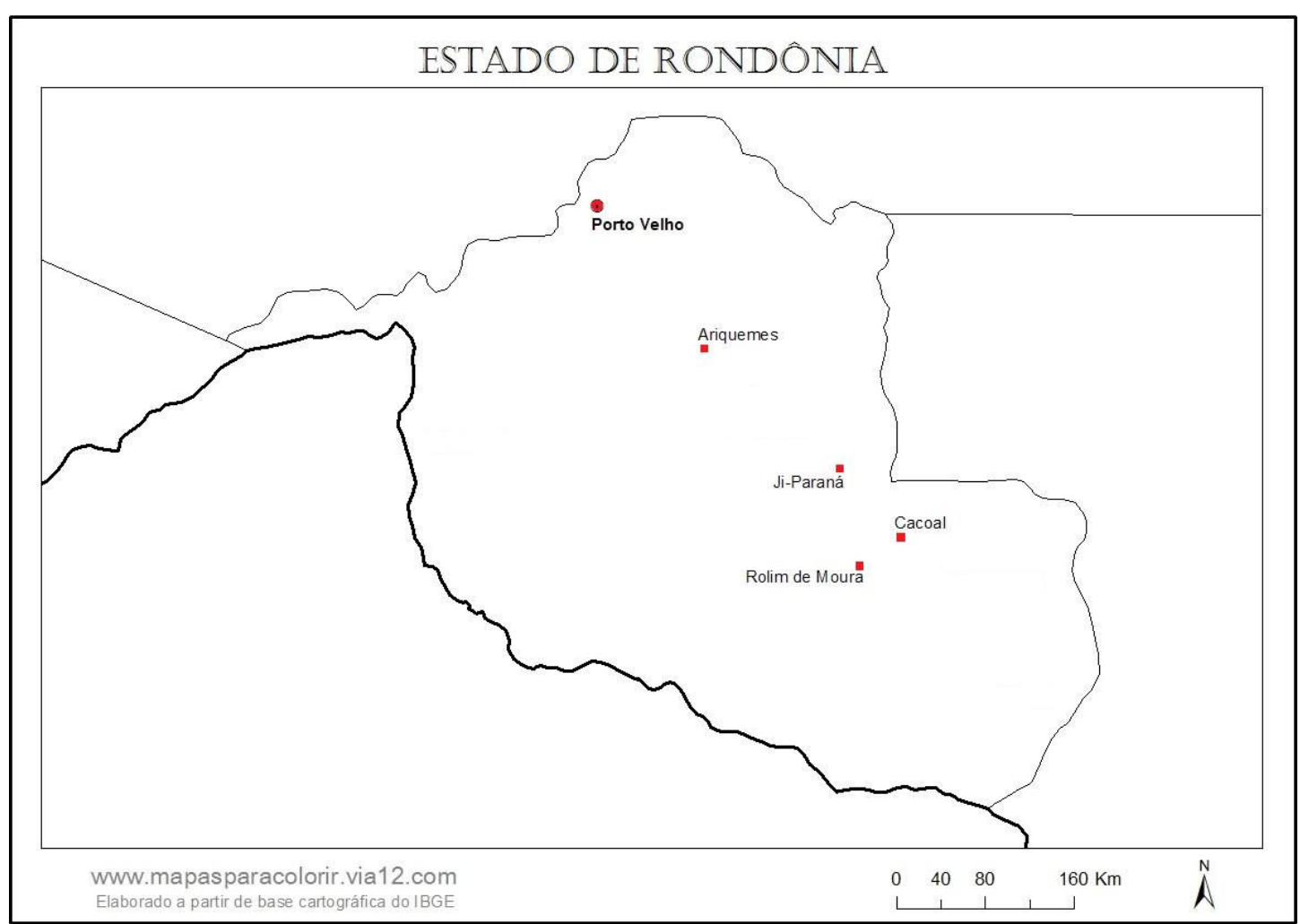

Fonte: www.mapasparacolorir.com.br

Figura 10 - Mapa do Estado de Rondônia e cidades com curso de bacharelado presencial em Enfermagem. Brasil, 2011.

\section{Capital: Porto Velho}

$\mathrm{N}^{\mathrm{o}}$ municípios: 52

$\mathrm{N}^{\mathrm{o}}$ municípios com curso de Enfermagem: $5(9,6 \%)$

Quadro 5 - Dados sobre população, extensão territorial densidade demográfica, número de cursos de bacharelado, vagas oferecidas e número de vagas/10.000 hab. Rondônia 2010.

\begin{tabular}{lrrrrrr}
\hline \hline LOCALIDADE & População* & Extensão* & hab/km & $\begin{array}{c}\text { № } \\
\text { cursos** }\end{array}$ & $\begin{array}{r}\text { Total } \\
\text { vagas** }\end{array}$ & $\begin{array}{r}\text { № vagas } \\
\text { \%oohab }\end{array}$ \\
\hline \hline RONDÔNIA & 1.562 .409 & $237.590,86$ & 6,6 & 10 & 1040 & 6,7 \\
Porto Velho & 428.527 & $34.096,43$ & 12,6 & 5 & 590 & 13,8 \\
Ariquemes & 90.353 & $4.426,58$ & 20,4 & 2 & 150 & 16,6 \\
Cacoal & 78.574 & $3.792,81$ & 20,7 & 1 & 100 & 12,7 \\
Ji-Paraná & 116.610 & $6.896,74$ & 16,9 & 1 & 100 & 8,6 \\
Rolim de Moura & 50.648 & $1.457,89$ & 34,7 & 1 & 100 & 19,7 \\
\hline \hline
\end{tabular}

Fonte: *http://www.ibge.gov.br/home/estatistica/populacao/censo2010/resultados_preliminares/ default_resultados_preliminares.shtm

**http://emec.mec.gov.br/ 


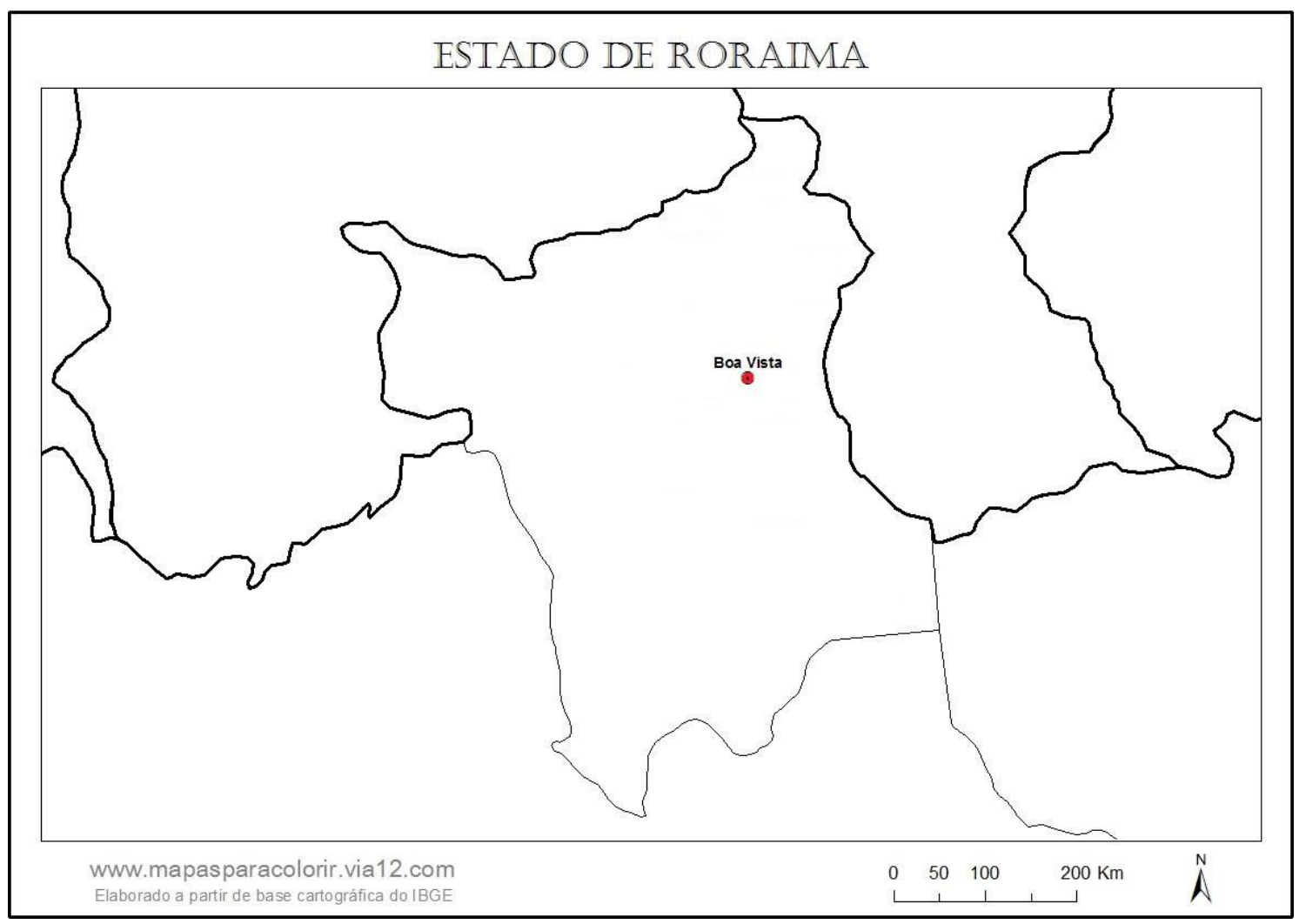

Fonte: www.mapasparacolorir.com.br

Figura 11 - Mapa do Estado de Roraima e cidades com curso de bacharelado presencial em Enfermagem. Brasil, 2011.

Capital: Boa Vista

$\mathrm{N}^{\mathrm{o}}$ municípios: 15

$\mathrm{N}^{\mathrm{o}}$ municípios com curso de Enfermagem: $1(6,7 \%)$

Quadro 6 - Dados sobre população, extensão territorial densidade demográfica, número de cursos de bacharelado, vagas oferecidas e número de vagas/10.000 hab. Roraima, 2010.

\begin{tabular}{lrrrrrr}
\hline \hline LOCALIDADE & População* & Extensão* & hab/km ${ }^{2}$ & $\begin{array}{c}\text { № } \\
\text { cursos** }\end{array}$ & $\begin{array}{r}\text { Total } \\
\text { vagas** }\end{array}$ & $\begin{array}{r}\text { № vagas } \\
\text { \%ooohab }\end{array}$ \\
\hline \hline RORAIMA & 450.479 & $224.301,04$ & 2,1 & 3 & 372 & 8,3 \\
Boa Vista & 284.313 & $5.687,02$ & 50,0 & 3 & 372 & 13,1 \\
\hline
\end{tabular}

\section{Fonte:}

*http://www.ibge.gov.br/home/estatistica/populacao/censo2010/resultados_preliminares/default_resul tados_preliminares.shtm

**http://emec.mec.gov.br/ 


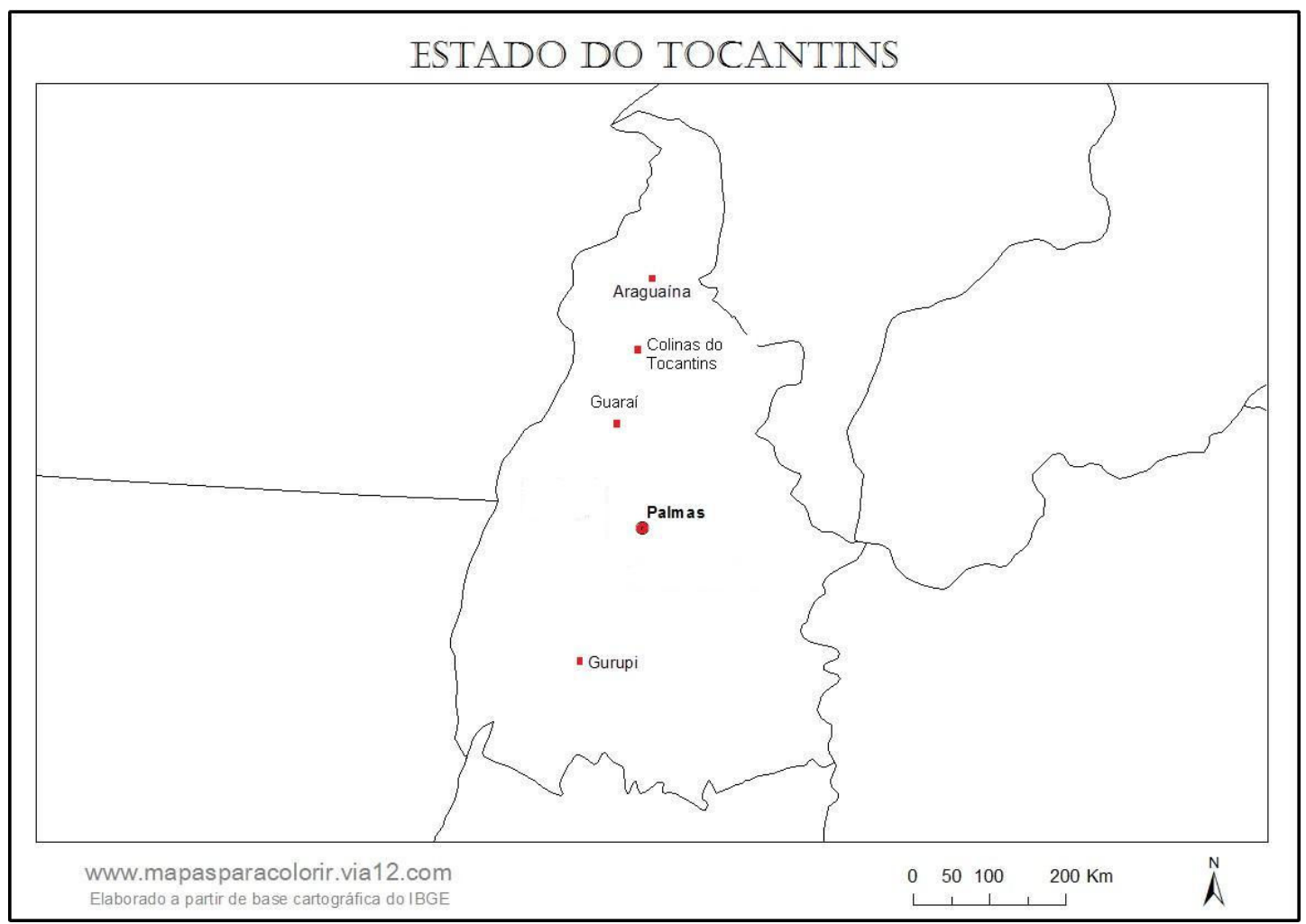

Fonte: www.mapasparacolorir.com.br

Figura 12 - Mapa do Estado de Tocantins e cidades com curso de bacharelado presencial em Enfermagem. Brasil, 2011.

\section{Capital: Palmas}

$\mathrm{N}^{\mathrm{o}}$ municípios: 139

$\mathrm{N}^{\mathrm{o}}$ municípios com curso de Enfermagem: 5 (3,6\%)

Quadro 7 - Dados sobre população, extensão territorial densidade demográfica, número de cursos de bacharelado, vagas oferecidas e número de vagas/10.000 hab. Tocantins, 2010.

\begin{tabular}{lrrrrrr}
\hline \hline LOCALIDADE & População* & Extensão* & hab/km ${ }^{2}$ & $\begin{array}{c}\text { No } \\
\text { cursos** }\end{array}$ & $\begin{array}{c}\text { Total } \\
\text { vagas** }\end{array}$ & $\begin{array}{r}\text { № vagas } \\
\text { \%ooohab }\end{array}$ \\
\hline \hline TOCANTINS & 1.383 .445 & $277.621,86$ & 5,0 & 10 & 980 & 7,1 \\
Palmas & 228.332 & $2.218,94$ & 102,9 & 4 & 400 & 17,5 \\
Araguaína & 150.484 & $4.000,40$ & 37,6 & 3 & 280 & 18,6 \\
Colinas de TO & 30.838 & 843,84 & 36,5 & 1 & 100 & 32,4 \\
Guaraí & 23.200 & $2.268,16$ & 10,2 & 1 & 80 & 34,5 \\
Gurupi & 76.755 & $1.836,09$ & 41,8 & 1 & 120 & 15,6 \\
\hline \hline
\end{tabular}

Fonte: *http://www.ibge.gov.br/home/estatistica/populacao/censo2010/resultados_preliminares/ default_resultados_preliminares.shtm

**http://emec.mec.gov.br/ 


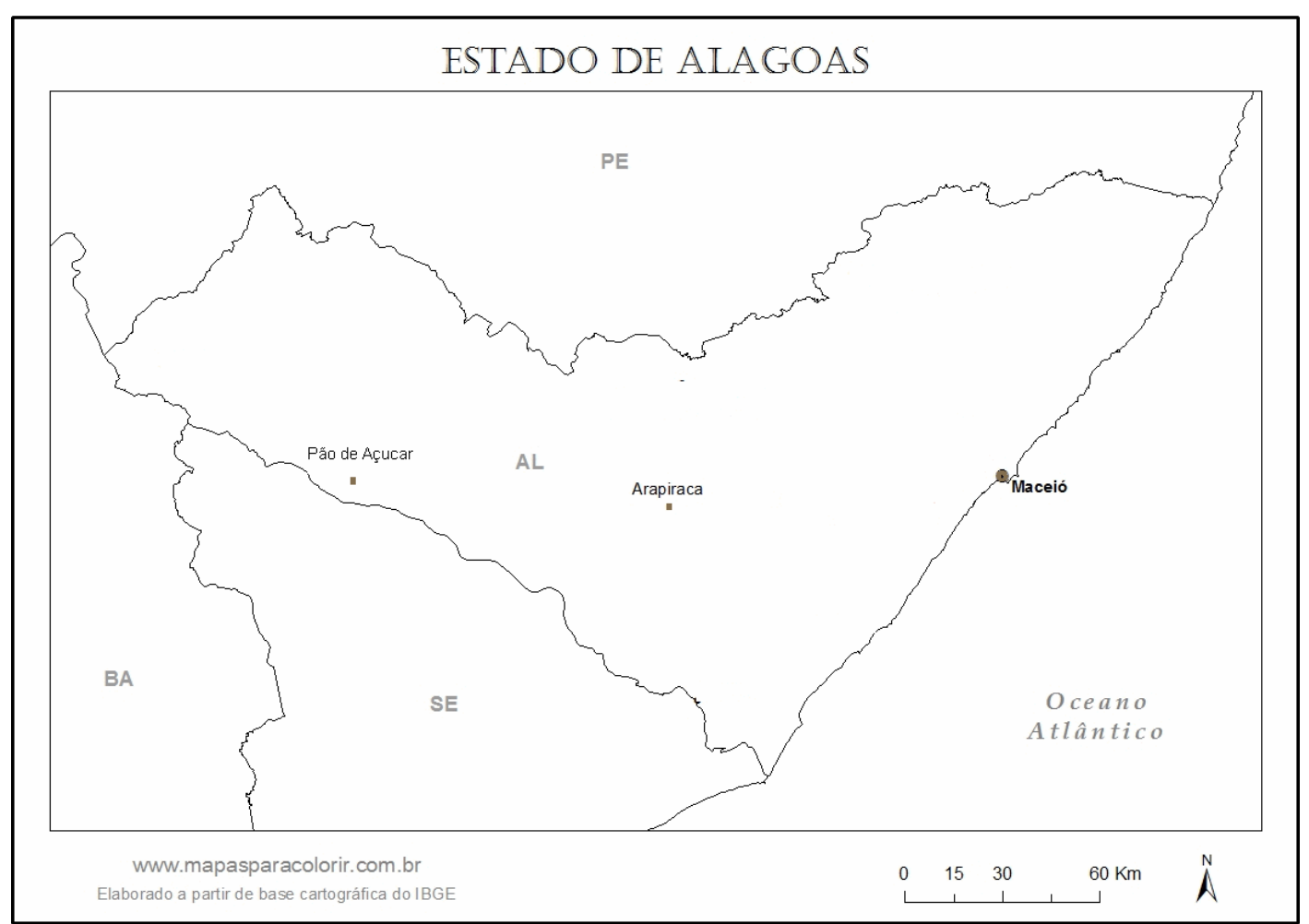

Fonte: www.mapasparacolorir.com.br

Figura 13 - Mapa do Estado de Alagoas e cidades com curso de bacharelado presencial em Enfermagem. Brasil, 2011.

\author{
Capital: Maceió \\ $\mathrm{N}^{\mathrm{o}}$ municípios: 102 \\ $\mathrm{N}^{\mathrm{o}}$ municípios com curso de Enfermagem: 3 (2,9\%)
}

Quadro 8 - Dados sobre população, extensão territorial densidade demográfica, número de cursos de bacharelado, vagas oferecidas e número de vagas/10.000 hab. Alagoas, 2010.

\begin{tabular}{lrrrrrr}
\hline \hline LOCALIDADE & População* & $\begin{array}{c}\text { Extensão } \\
*\end{array}$ & hab/km & $\begin{array}{c}\text { № } \\
\text { cursos** }\end{array}$ & $\begin{array}{c}\text { Total } \\
\text { vagas** }\end{array}$ & $\begin{array}{c}\text { № vagas } \\
\text { \%ooohab }\end{array}$ \\
\hline ALAGOAS & 3.120 .494 & $27.779,34$ & 112,3 & 11 & 1470 & 4,7 \\
Maceió & 932.748 & 503,07 & $1.854,1$ & 9 & 1270 & 13,6 \\
Arapicara & 214.006 & 356,18 & 600,8 & 1 & 40 & 1,9 \\
Pão de Açúcar & 23.811 & 682,99 & 34,9 & 1 & 160 & 67,2 \\
\hline Fonte: & \\
*http://www.ibge.gov.br/home/estatistica/populacao/censo2010/resultados_preliminares/default_resul \\
tados_preliminares.shtm \\
**http://emec.mec.gov.br/
\end{tabular}




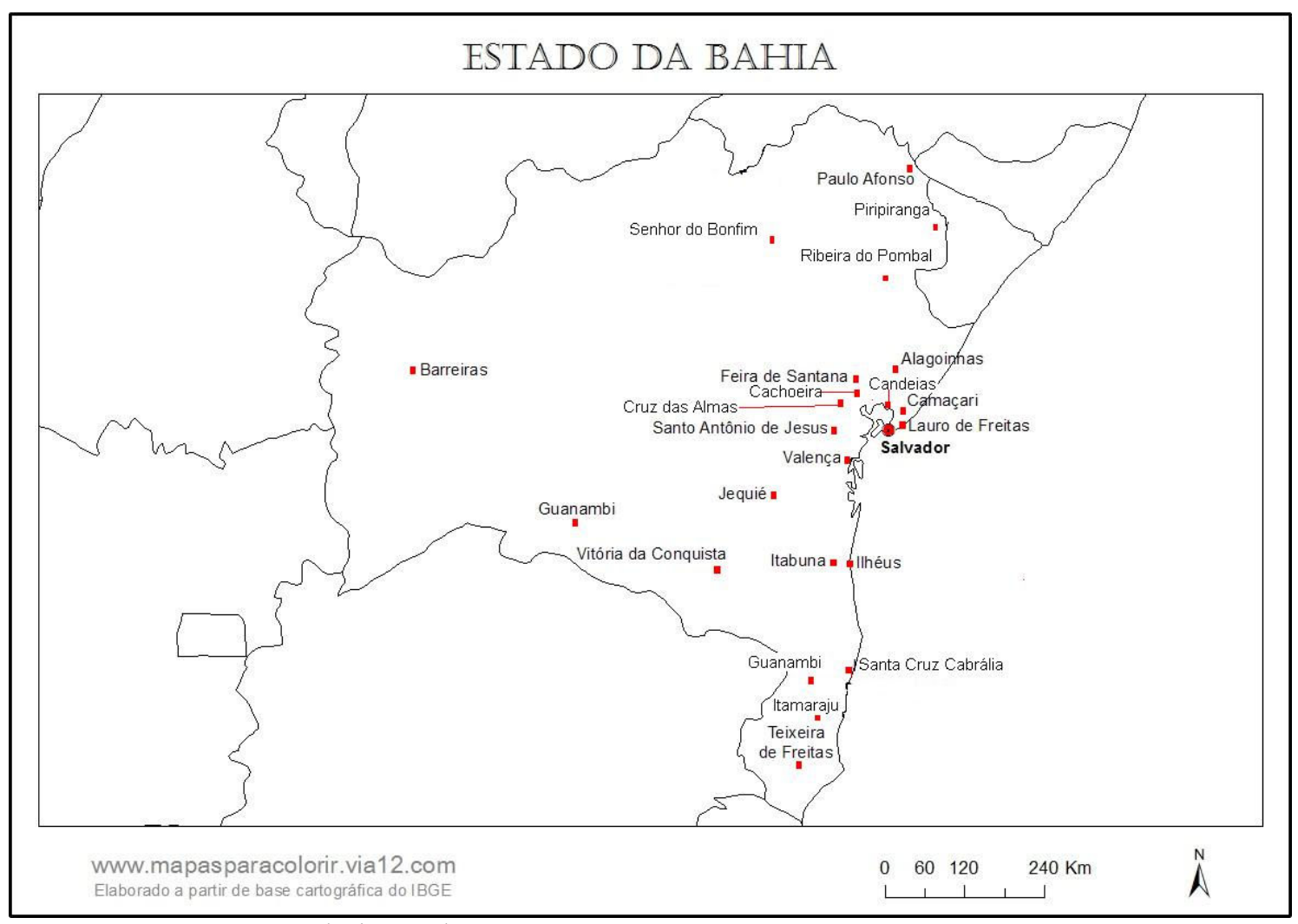

Fonte: www.mapasparacolorir.com.br

Figura 14 - Mapa do Estado da Bahia e cidades com curso de bacharelado presencial em Enfermagem. Brasil, 2011.

Capital: Salvador

$\mathrm{N}^{\mathrm{o}}$ municípios: 417

$\mathrm{N}^{\mathrm{o}}$ municípios com curso de Enfermagem: 24 (5,8\%) 
Ruth Natalia Teresa Turrini

Quadro 9 - Dados sobre população, extensão territorial densidade demográfica, número de cursos de bacharelado, vagas oferecidas e número de vagas/10.000 hab. Bahia, 2010.

\begin{tabular}{|c|c|c|c|c|c|c|}
\hline LOCALIDADE & População* & Extensão* & $\mathrm{hab} / \mathrm{km}^{2}$ & $\begin{array}{c}\text { № } \\
\text { cursos** } \\
\end{array}$ & $\begin{array}{c}\text { Total } \\
\text { vagas** }\end{array}$ & $\begin{array}{l}\text { № vagas } \\
\% \text { oodhab }\end{array}$ \\
\hline BAHIA & 14.016 .906 & $564.830,86$ & 24,82 & 54 & 8470 & 6,0 \\
\hline Salvador & 2.675 .656 & 693,29 & $3.859,35$ & 17 & 3800 & 14,2 \\
\hline Alagoinhas & 141.949 & 752,39 & 188,66 & 2 & 360 & 25,4 \\
\hline Barreiras & 137.427 & $7.859,13$ & 17,49 & 1 & 80 & 5,8 \\
\hline Cachoeira & 32.026 & 395,21 & 81,04 & 1 & 100 & 31,2 \\
\hline Camaçari & 242.970 & 784,66 & 309,65 & 1 & 100 & 4,1 \\
\hline Candeias & 83.158 & 258,36 & 321,87 & 1 & 150 & 18,0 \\
\hline Cruz das Almas & 58.606 & 145,75 & 402,11 & 1 & 100 & 17,1 \\
\hline Eunápolis & 100.196 & $1.179,12$ & 84,98 & 1 & 100 & 10,0 \\
\hline Feira de Santana & 556.642 & $1.337,99$ & 416,03 & 5 & 640 & 11,5 \\
\hline Guanambi & 78.833 & $1.296,66$ & 60,8 & 2 & 250 & 31,7 \\
\hline Ilhéus & 184.236 & $1.760,00$ & 104,68 & 3 & 360 & 19,5 \\
\hline Itabuna & 204.667 & $4.32,24$ & 473,5 & 2 & 250 & 12,2 \\
\hline Itamaraju & 63.069 & $2.274,27$ & 27,73 & 1 & 100 & 15,9 \\
\hline Jequié & 151.895 & $3.227,34$ & 47,07 & 2 & 200 & 13,2 \\
\hline Lauro de Freitas & 163.449 & $57.686,00$ & $2.833,40$ & 1 & 200 & 12,2 \\
\hline Paripiranga & 27.778 & 435,70 & 63,75 & 1 & 300 & 108,0 \\
\hline Paulo Afonso & 108.396 & $1.579,72$ & 68,62 & 1 & 100 & 9,2 \\
\hline Ribeira do Pombal & 47.518 & 788,63 & 60,25 & 1 & 200 & 42,1 \\
\hline Santa Cruz Cabrália & 26.264 & $1.562,70$ & 16,81 & 1 & 120 & 45,7 \\
\hline S. Antônio de Jesus & 90.985 & 261,35 & 348,14 & 1 & 30 & 3,3 \\
\hline Senhor do Bonfim & 74.419 & 827,48 & 89,93 & 1 & 50 & 6,7 \\
\hline Teixeira de Freitas & 138.341 & $1.163,87$ & 118,86 & 2 & 320 & 23,1 \\
\hline Valença & 88.673 & $1.192,61$ & 74,35 & 1 & 200 & 22,6 \\
\hline Vitoria da Conquista & 306.866 & $3.405,58$ & 90,11 & 4 & 360 & 11,7 \\
\hline
\end{tabular}

Fonte:

*http://www.ibge.gov.br/home/estatistica/populacao/censo2010/resultados_preliminares/default_resul tados preliminares.shtm

**http://emec.mec.gov.br/ 


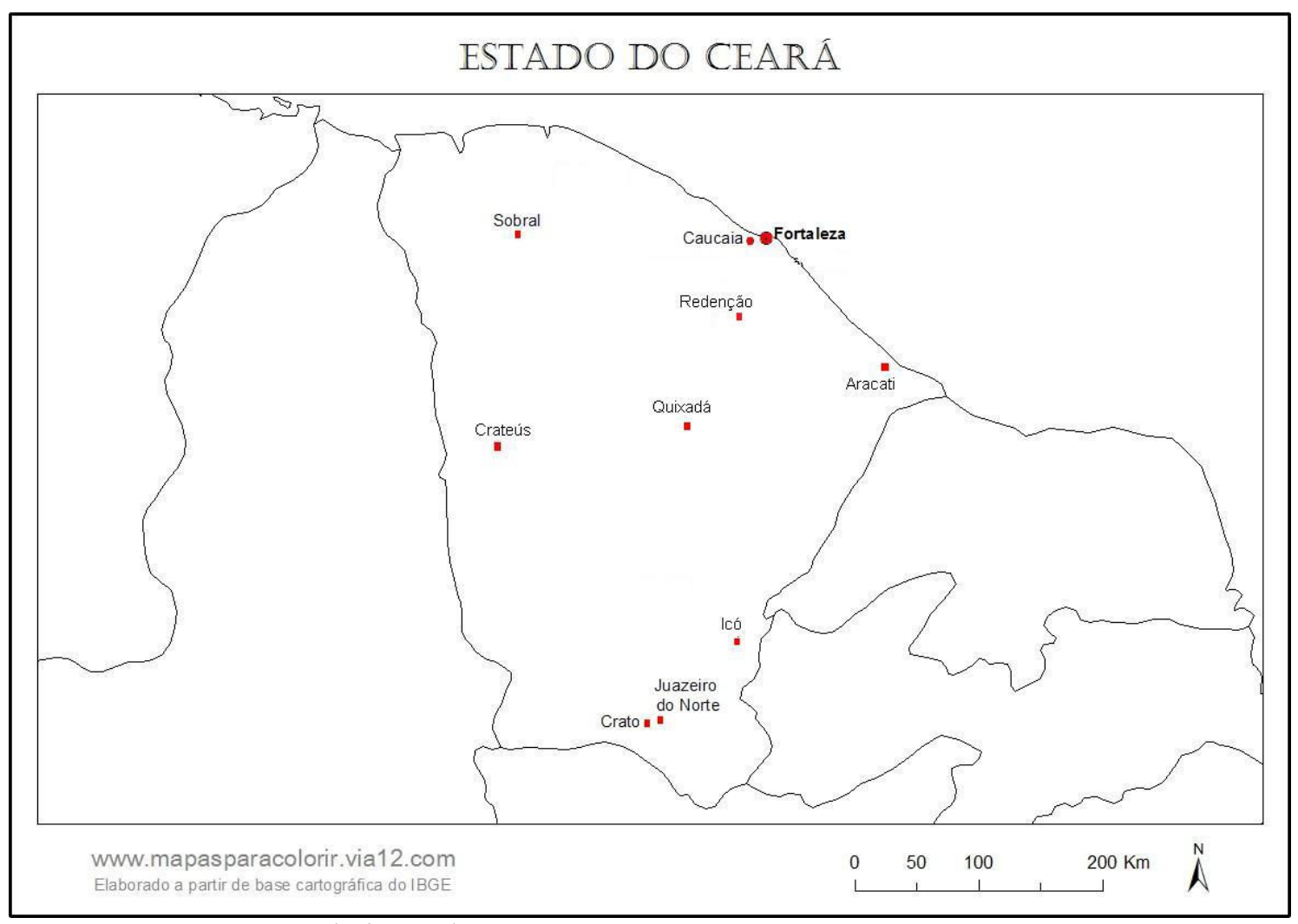

Fonte: www.mapasparacolorir.com.br

Figura 15 - Mapa do Estado do Ceará e cidades com curso de bacharelado presencial em Enfermagem. Brasil, 2011.

Capital: Fortaleza

$\mathrm{N}^{\mathrm{o}}$ municípios: 184

$\mathrm{N}^{\mathrm{o}}$ municípios com curso de Enfermagem: 10 (5,3\%) 
Quadro 10 - Dados sobre população, extensão territorial densidade demográfica, número de cursos de bacharelado, vagas oferecidas e número de vagas/10.000 hab. Ceará, 2010.

\begin{tabular}{|c|c|c|c|c|c|c|}
\hline LOCALIDADE & População* & Extensão* & $\mathrm{hab} / \mathrm{km}^{2}$ & $\begin{array}{r}\text { № } \\
\text { cursos** } \\
\end{array}$ & $\begin{array}{c}\text { Total } \\
\text { vagas** }\end{array}$ & $\begin{array}{l}\text { № vagas } \\
\% \text { ooohab }\end{array}$ \\
\hline CEARÁ & 8.452 .381 & $148.920,54$ & 56,76 & 19 & 2292 & 2,7 \\
\hline Fortaleza & 2.452 .185 & 314,93 & $7.786,52$ & 8 & 1180 & 4,8 \\
\hline Aracati & 69.159 & $1.247,30$ & 55,45 & 1 & 100 & 14,5 \\
\hline Caucaia & 325.441 & $1.223,80$ & 265,93 & 1 & 200 & 6,1 \\
\hline Crateús & 72.812 & $2.988,29$ & 24,37 & 1 & 50 & 6,9 \\
\hline Crato & 121.428 & $1.157,91$ & 104,87 & 1 & 30 & 2,5 \\
\hline Icó & 65.456 & $1.872,00$ & 34,97 & 1 & 100 & 15,3 \\
\hline Juazeiro do Norte & 249.939 & 248,22 & $1.006,91$ & 2 & 320 & 12,8 \\
\hline Quixadá & 80.604 & $2.019,82$ & 39,91 & 1 & 80 & 9,9 \\
\hline Redenção & 26.415 & 225,59 & 117,09 & 1 & 72 & 27,3 \\
\hline Sobral & 188.233 & $2.122,89$ & 88,67 & 2 & 160 & 8,5 \\
\hline
\end{tabular}




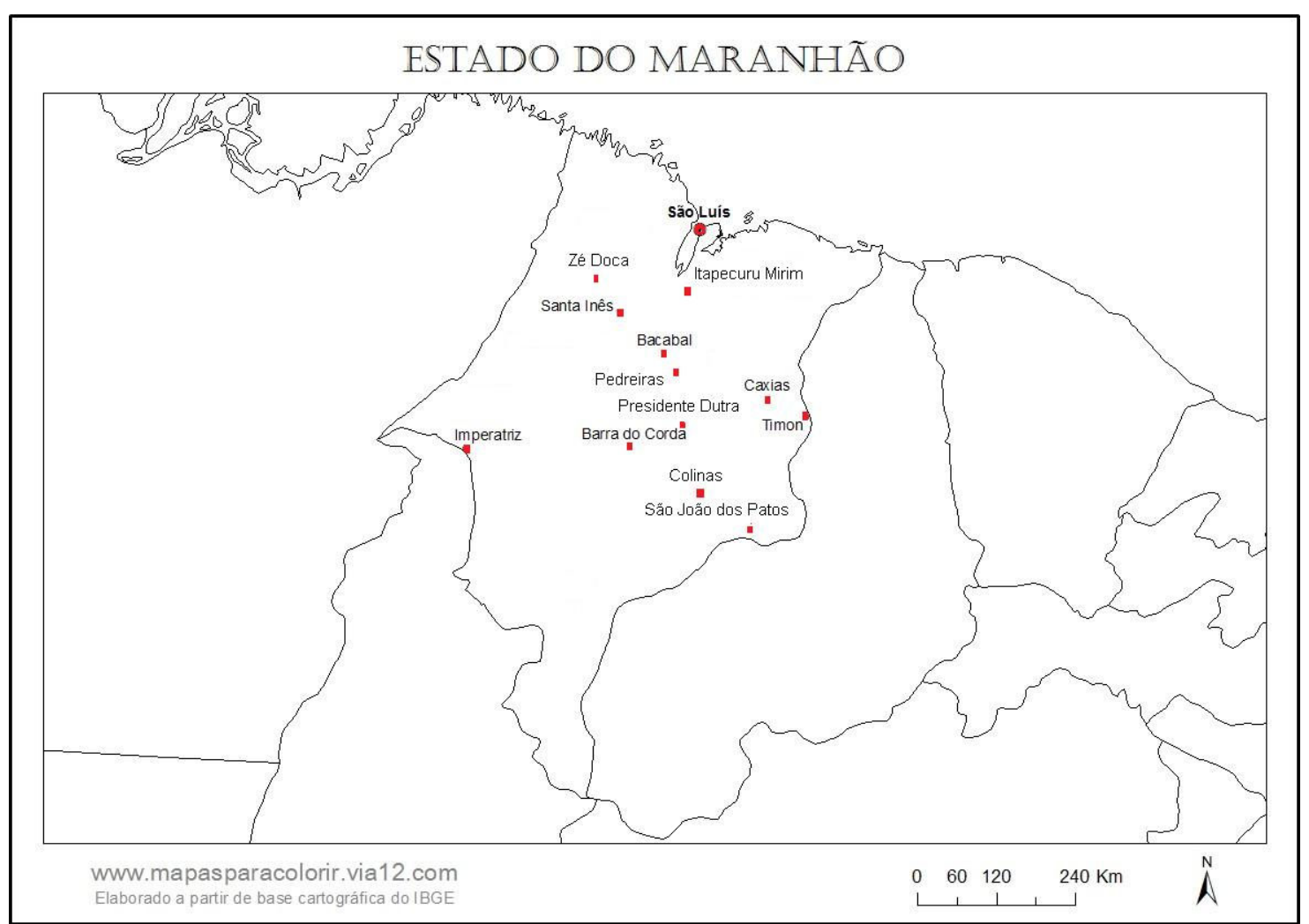

Fonte: www.mapasparacolorir.com.br

Figura 16 - Mapa do Estado de Maranhão e cidades com curso de bacharelado presencial em Enfermagem. Brasil, 2011.

Capital: São Luís

$\mathrm{N}^{\mathrm{o}}$ municípios: 217

$\mathrm{N}^{\mathrm{o}}$ municípios com curso de Enfermagem: 13 (6,0\%) 
Quadro 11 - Dados sobre população, extensão territorial densidade demográfica, número de cursos de bacharelado, vagas oferecidas e número de vagas/10.000 hab. Maranhão, 2010.

\begin{tabular}{|c|c|c|c|c|c|c|}
\hline LOCALIDADE & População* & Extensão* & $\mathrm{hab} / \mathrm{km}^{2}$ & $\begin{array}{c}\text { № } \\
\text { cursos** }\end{array}$ & $\begin{array}{l}\text { Total } \\
\text { vagas** }\end{array}$ & $\begin{array}{l}\text { № vagas } \\
\% \text { ooohab }\end{array}$ \\
\hline MARANHÃO & 6.574 .789 & $331.935,51$ & 19,81 & 24 & 2720 & 4,1 \\
\hline São Luís & 1.014 .837 & 834,78 & $1.215,69$ & 10 & 1680 & 16,6 \\
\hline Bacabal & 100.014 & $1.683,06$ & 59,42 & 1 & 100 & 10,0 \\
\hline Barra do Corda & 82.830 & $5.202,68$ & 15,92 & 1 & 30 & 3,6 \\
\hline Caxias & 155.129 & $5.150,65$ & 30,12 & 1 & 230 & 14,8 \\
\hline Colinas & 39.132 & $1.980,55$ & 19,76 & 1 & 30 & 7,7 \\
\hline Imperatriz & 247.505 & $1.368,98$ & 180,79 & 3 & 300 & 12,1 \\
\hline Itapecuru Mirim & 62.110 & $1.471,43$ & 42,21 & 1 & 45 & 7,2 \\
\hline Pedreiras & 39.448 & 288,43 & 136,77 & 1 & 100 & 25,3 \\
\hline Presidente Dutra & 44.731 & 771,57 & 57,97 & 1 & 30 & 6,7 \\
\hline Santa Inês & 77.282 & 410,00 & 188,49 & 1 & $\ldots$ & .. \\
\hline São João dos Patos & 24.928 & $1.500,62$ & 16,61 & 1 & 30 & 12,0 \\
\hline Timon & 155.460 & $1.743,23$ & 89,18 & 1 & 100 & 6,4 \\
\hline Zé Doca & 50.173 & $2.416,05$ & 20,77 & 1 & 45 & 9,0 \\
\hline
\end{tabular}

Fonte:

*http://www.ibge.gov.br/home/estatistica/populacao/censo2010/resultados_preliminares/default_resul tados_preliminares.shtm

**http://emec.mec.gov.br/ 


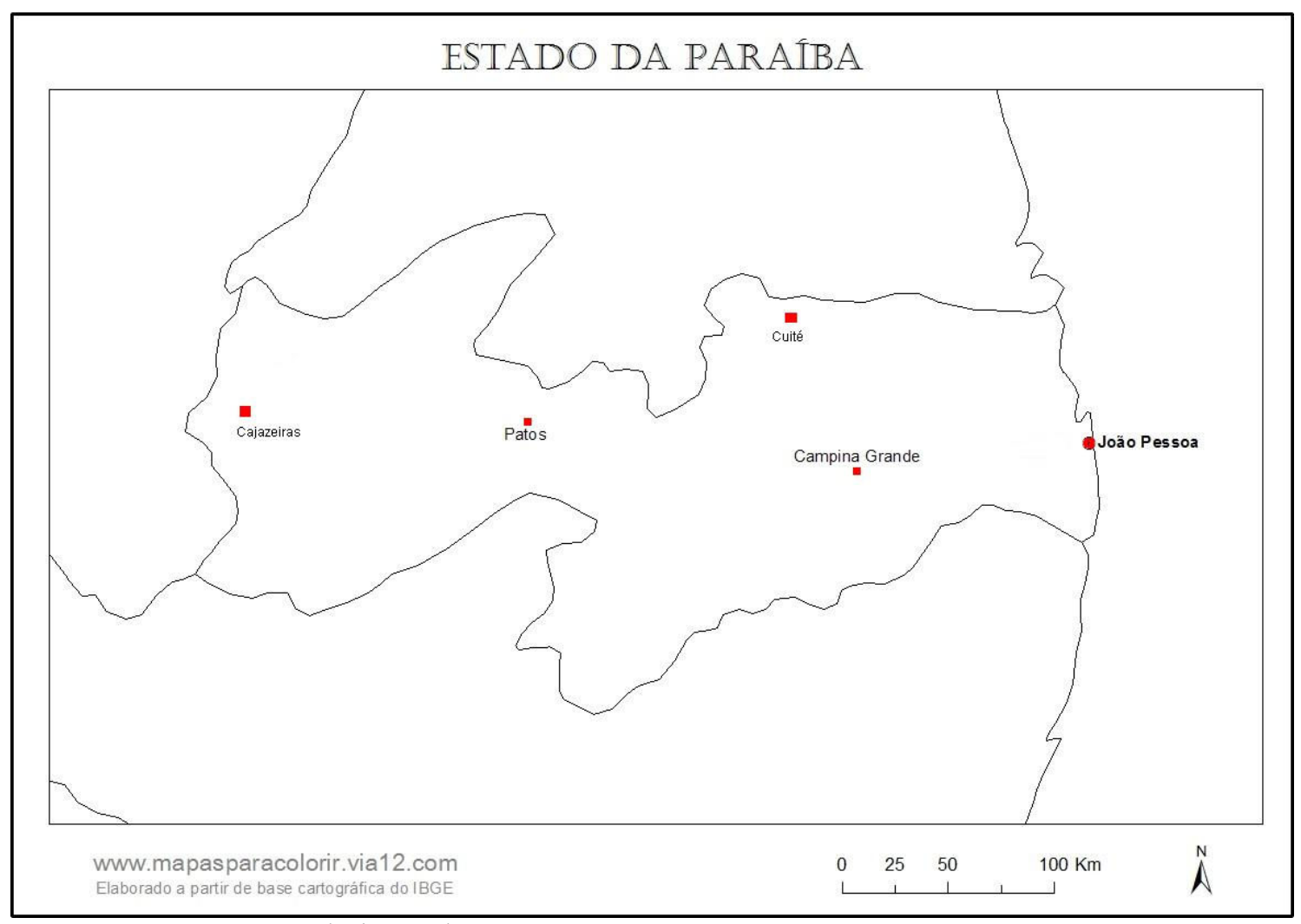

Fonte: www.mapasparacolorir.com.br

Figura 17 - Mapa do Estado da Paraíba e cidades com curso de bacharelado presencial em Enfermagem. Brasil, 2011.

Capital: João Pessoa

$\mathrm{N}^{\mathrm{o}}$ municípios: 223

$\mathrm{N}^{\mathrm{o}}$ municípios com curso de Enfermagem: 5 (2,2\%)

Quadro 12 - Dados sobre população, extensão territorial densidade demográfica, número de cursos de bacharelado, vagas oferecidas e número de vagas/10.000 hab. Paraíba, 2010.

\begin{tabular}{|c|c|c|c|c|c|c|}
\hline LOCALIDADE & População* & Extensão* & $\mathrm{hab} / \mathrm{km}^{2}$ & $\begin{array}{c}\text { № } \\
\text { cursos** }\end{array}$ & $\begin{array}{c}\text { Total } \\
\text { vagas** }\end{array}$ & $\begin{array}{l}\text { № vagas } \\
\% \text { ooohab }\end{array}$ \\
\hline PARAIIBA & 3.766 .528 & $56.469,47$ & 66,7 & 18 & 2780 & 7,4 \\
\hline João Pessoa & 723.515 & 211,47 & $3.421,30$ & 10 & 1620 & 22,4 \\
\hline Cajazeiras & 58.446 & 565,90 & 103,28 & 2 & 230 & 39,4 \\
\hline Campina Grande & 385.213 & 594,18 & 648,31 & 4 & 690 & 17,9 \\
\hline Cuité & 19.978 & 741,84 & 26,93 & 1 & 90 & 45,0 \\
\hline Patos & 100.674 & 473,05 & 212,82 & 1 & 150 & 14,9 \\
\hline
\end{tabular}

Fonte:

*http://www.ibge.gov.br/home/estatistica/populacao/censo2010/resultados_preliminares/default_resul tados_preliminares.shtm

**http://emec.mec.gov.br/ 


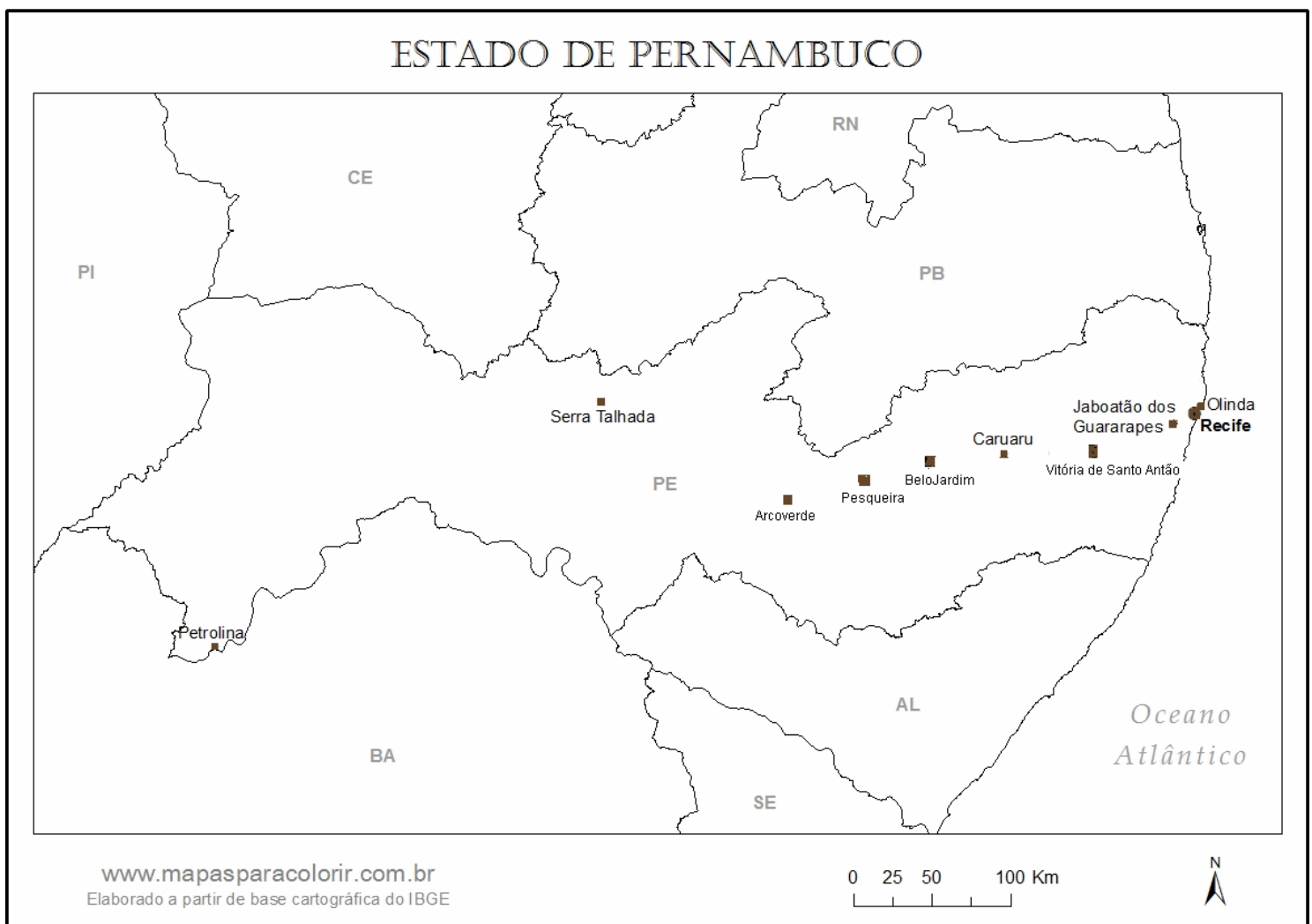

Fonte: www.mapasparacolorir.com.br

Figura 18 - Mapa do Estado de Pernambuco e cidades com curso de bacharelado presencial em Enfermagem. Brasil, 2011.

Capital: João Pessoa

$\mathrm{N}^{\mathrm{o}}$ municípios: 185

$\mathrm{N}^{\mathrm{o}}$ municípios com curso de Enfermagem: 10(5,4\%) 
Quadro 13 - Dados sobre população, extensão territorial densidade demográfica, número de cursos de bacharelado, vagas oferecidas e número de vagas/10.000 hab. Pernambuco, 2010.

\begin{tabular}{|c|c|c|c|c|c|c|}
\hline LOCALIDADE & População* & Extensão* & $\mathrm{hab} / \mathrm{km}^{2}$ & $\begin{array}{c}\text { № } \\
\text { cursos** } \\
\end{array}$ & $\begin{array}{c}\text { Total } \\
\text { vagas** }\end{array}$ & $\begin{array}{l}\text { № vagas } \\
\% \text { ood hab }\end{array}$ \\
\hline PERNAMBUCO & 8.796 .448 & $98.146,32$ & 89,63 & 24 & 3245 & 3,7 \\
\hline Recife & 1.537 .704 & 218,50 & $7.037,61$ & 10 & 1810 & 11,8 \\
\hline Arcoverde & 68.793 & 350,90 & 196,05 & 1 & 50 & 7,3 \\
\hline Belo Jardim & 72.432 & 647,69 & 111,83 & 1 & 100 & 13,8 \\
\hline $\begin{array}{l}\text { Caruaru } \\
\text { Jaboatão dos }\end{array}$ & 314.912 & 920,61 & 342,07 & 3 & 280 & 8,9 \\
\hline Guararapes & 644.620 & 258,57 & $2.493,06$ & 1 & 240 & 3,7 \\
\hline Olinda & 377.779 & 41,66 & $9.068,36$ & 2 & 280 & 7,4 \\
\hline Pesqueira & 62.931 & 995,53 & 63,21 & 1 & 40 & 6,4 \\
\hline Petrolina & 293.962 & $4.558,40$ & 64,49 & 2 & 80 & 2,7 \\
\hline Serra Talhada & 79.232 & $2.979,99$ & 26,59 & 1 & 100 & 12,6 \\
\hline Vitória de Santo Antão & 129.974 & 371,80 & 349,58 & 2 & 265 & 20,4 \\
\hline
\end{tabular}

Fonte:

*http://www.ibge.gov.br/home/estatistica/populacao/censo2010/resultados_preliminares/default_resul tados_preliminares.shtm

**http://emec.mec.gov.br/ 


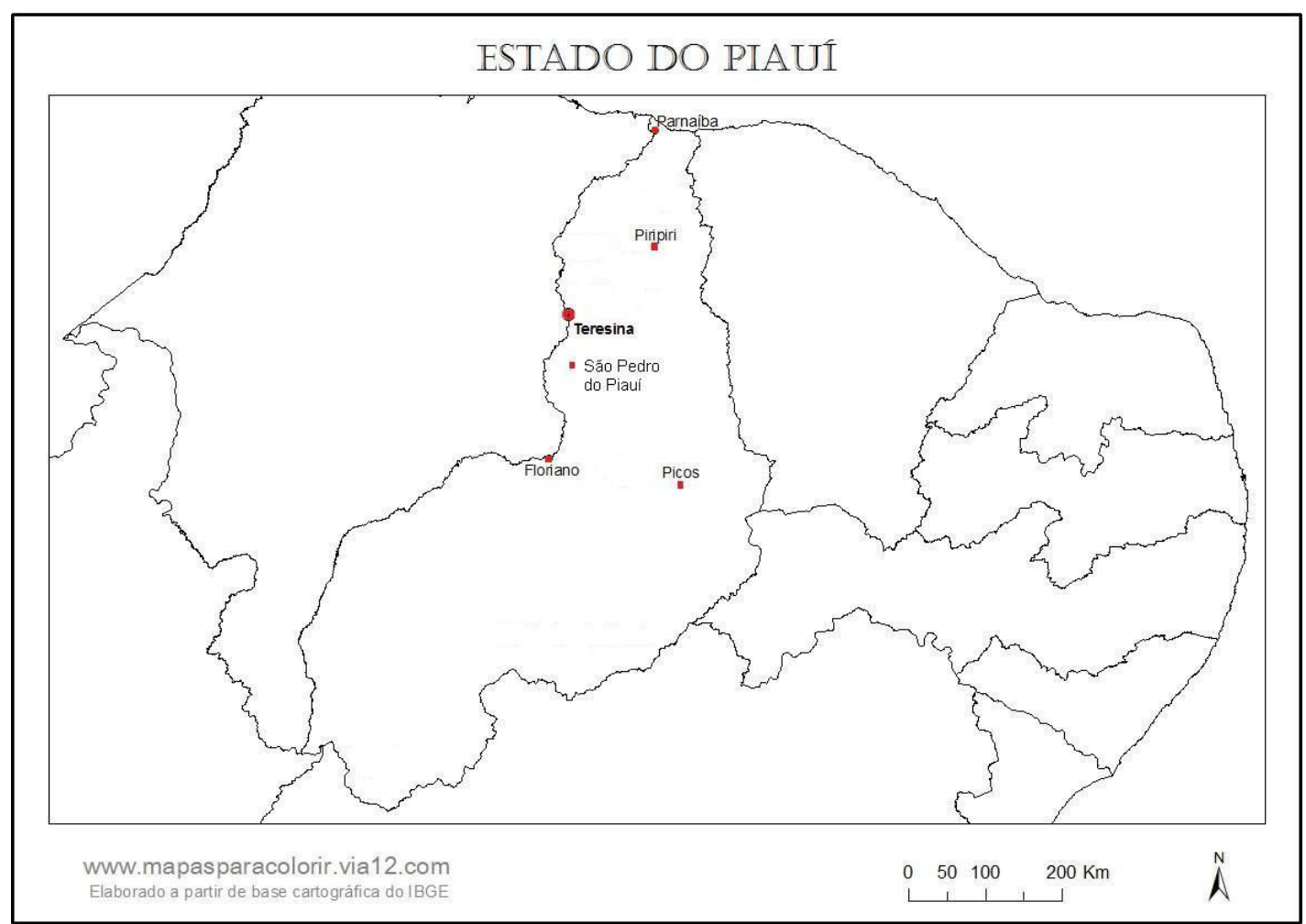

Fonte: www.mapasparacolorir.com.br

Figura 19 - Mapa do Estado do Piauí e cidades com curso de bacharelado presencial em Enfermagem. Brasil, 2011.

Capital: Teresina

$\mathrm{N}^{\mathrm{o}}$ municípios: 224

$\mathrm{N}^{\mathrm{o}}$ municípios com curso de Enfermagem: $6(2,7 \%)$

Quadro 14 - Dados sobre população, extensão territorial densidade demográfica, número de cursos de bacharelado, vagas oferecidas e número de vagas/10.000 hab. Piauí, 2010.

\begin{tabular}{lrrrrrr}
\hline \hline LOCALIDADE & População* & Extensão* & hab/km² & $\begin{array}{c}\text { № } \\
\text { cursos** }\end{array}$ & $\begin{array}{c}\text { Total } \\
\text { vagas** }\end{array}$ & $\begin{array}{r}\text { № vagas } \\
\text { \%ooohab }\end{array}$ \\
\hline \hline PIAUÍ & 3.118 .360 & $251.576,64$ & 12,4 & 21 & 2130 & 6,8 \\
Teresina & 814.230 & $1.391,97$ & 584,95 & 12 a & 1325 & 16,3 \\
Floriano & 57.690 & $3.409,63$ & 16,92 & $3 a$ & 180 & 31,2 \\
Parnaíba & 145.705 & 435,57 & 334,52 & 2 & 225 & 15,4 \\
Picos & 73.414 & 534,71 & 137,3 & 2 a & 100 & 13,6 \\
Piripiri & 61.834 & $1.408,93$ & 43,89 & 1 & 100 & 16,2 \\
São Pedro do Piauí & 13.639 & 518,29 & 26,32 & 1 & 200 & 146,6 \\
\hline \hline
\end{tabular}

Fonte: *http://www.ibge.gov.br/home/estatistica/populacao/censo2010/resultados_preliminares/ default_resultados_preliminares.shtm

**http://emec.mec.gov.br/

a em cada uma dessas cidades não houve informação de vagas para um dos cursos 


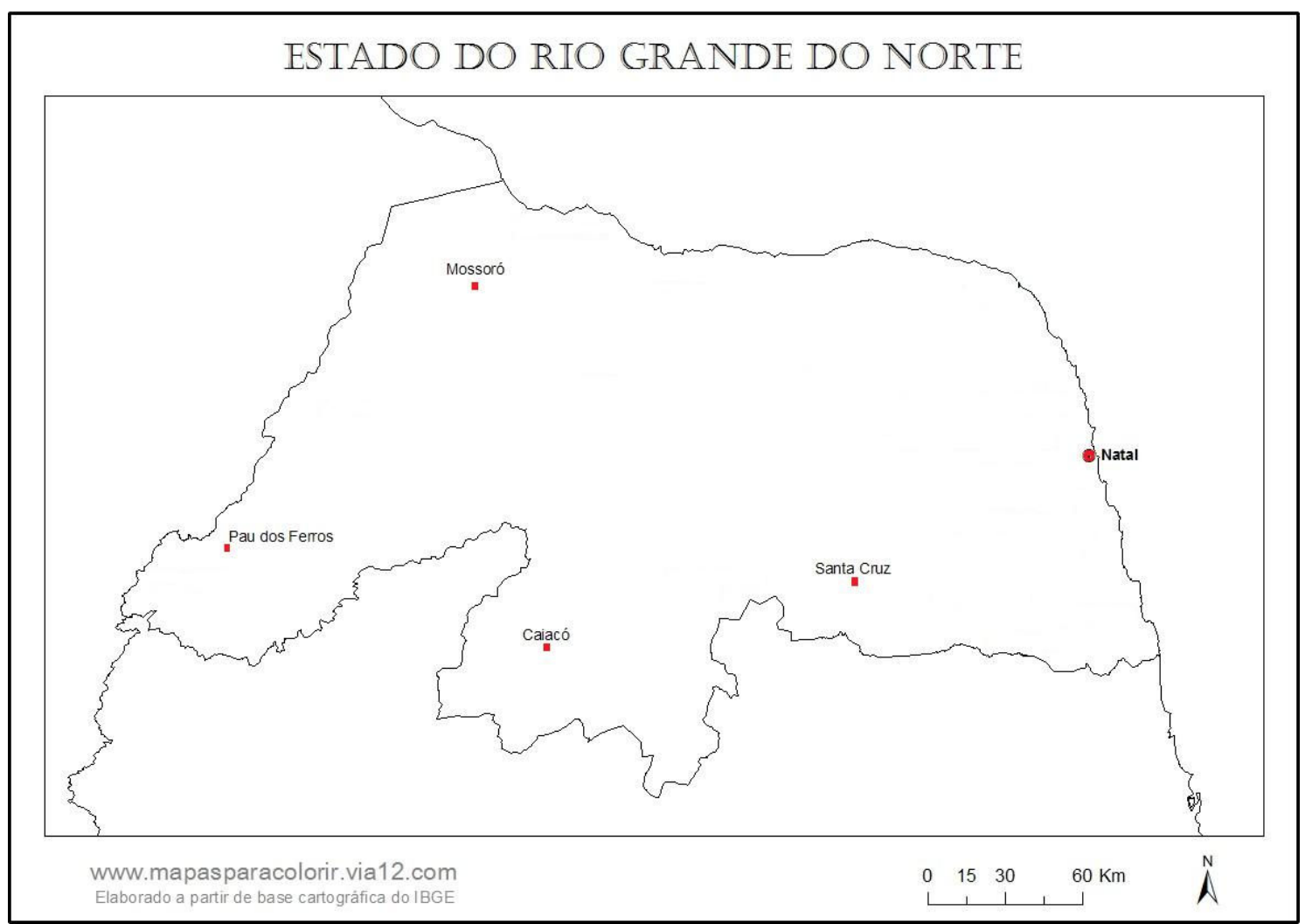

Fonte: www.mapasparacolorir.com.br

Figura 20 - Mapa do Estado do Rio Grande do Norte e cidades com curso de bacharelado presencial em Enfermagem. Brasil, 2011.

\section{Capital: Natal \\ $\mathrm{N}^{\mathrm{o}}$ municípios: 167}

$\mathrm{N}^{\mathrm{o}}$ municípios com curso de Enfermagem: $5(3,0 \%)$

Quadro 15 - Dados sobre população, extensão territorial densidade demográfica, número de cursos de bacharelado, vagas oferecidas e número de vagas/10.000 hab. Rio Grande do Norte, 2010.

\begin{tabular}{lrrrrrr}
\hline \hline LOCALIDADE & & & & $\begin{array}{c}\text { No } \\
\text { cursos** }\end{array}$ & $\begin{array}{r}\text { Total } \\
\text { vagas** }\end{array}$ & $\begin{array}{r}\text { No vagas } \\
\text { \%ooohab }\end{array}$ \\
\hline \hline RIO GRANDE DO NORTE & 3.168 .027 & $52.810,70$ & 59,99 & 14 & 2464 & 7,8 \\
Natal & 803.739 & 167,16 & $4.808,20$ & 7 & 1660 & 20,7 \\
Mossón & 259.815 & $2.099,33$ & 123,76 & 3 & 686 & 26,4 \\
Caicó & 62.709 & $1.228,58$ & 51,04 & 1 & 26 & 4,1 \\
Pau dos Ferros & 27.745 & 259,96 & 106,73 & 1 & 26 & 9,4 \\
Santa Cruz & 35.797 & 624,35 & 57,33 & 2 & 66 & 18,4 \\
\hline
\end{tabular}

Fonte: *http://www.ibge.gov.br/home/estatistica/populacao/censo2010/resultados_preliminares/ default_resultados_preliminares.shtm

**http://emec.mec.gov.br/ 


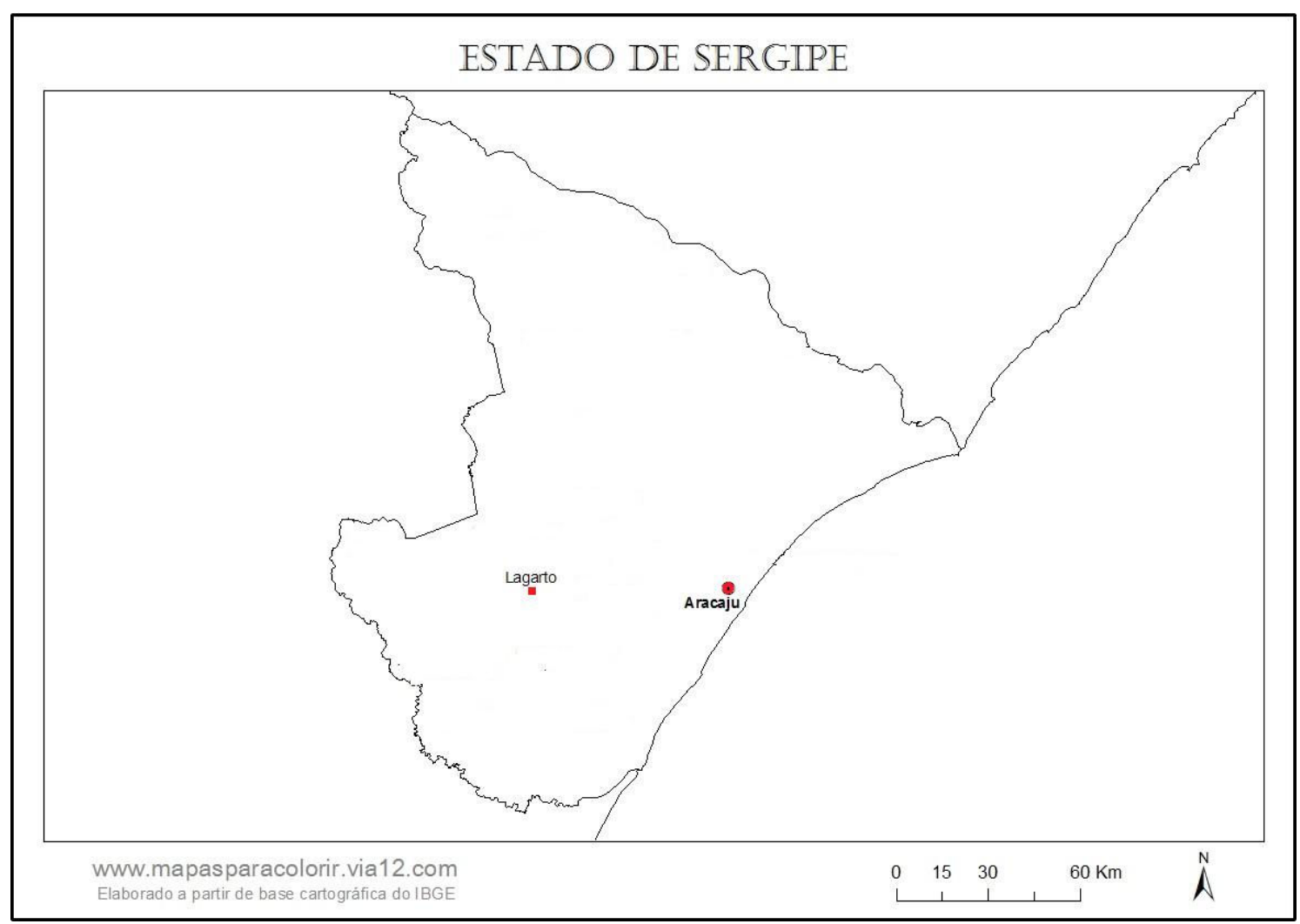

Fonte: www.mapasparacolorir.com.br

Figura 21 - Mapa do Estado do Sergipe e cidades com curso de bacharelado presencial em Enfermagem. Brasil, 2011.

\section{Capital: Aracajú}

$\mathrm{N}^{\mathrm{o}}$ municípios: 75

$\mathrm{N}^{\mathrm{o}}$ municípios com curso de Enfermagem: 2 (2,7\%)

Quadro 16 - Dados sobre população, extensão territorial densidade demográfica, número de cursos de bacharelado, vagas oferecidas e número de vagas/10.000 hab. Sergipe, 2010.

\begin{tabular}{lrrrrrr}
\hline \hline LOCALIDADE & População* & Extensão* & hab/km² & $\begin{array}{c}\text { № } \\
\text { cursos** }\end{array}$ & $\begin{array}{c}\text { Total } \\
\text { vagas** }\end{array}$ & $\begin{array}{c}\text { № vagas } \\
\text { \%oohhab }\end{array}$ \\
\hline SERGIPE & 2.068 .017 & $21.918,35$ & 94,35 & 5 & 1030 & 5,0 \\
Aracaju & 571.149 & 181,86 & $3.140,67$ & 4 & 980 & 17,2 \\
Lagarto & 94.861 & 969,57 & 97,84 & 1 & 50 & 5,3 \\
\hline \hline
\end{tabular}

Fonte:

*http://www.ibge.gov.br/home/estatistica/populacao/censo2010/resultados_preliminares/default_resul tados_preliminares.shtm

**http://emec.mec.gov.br/ 


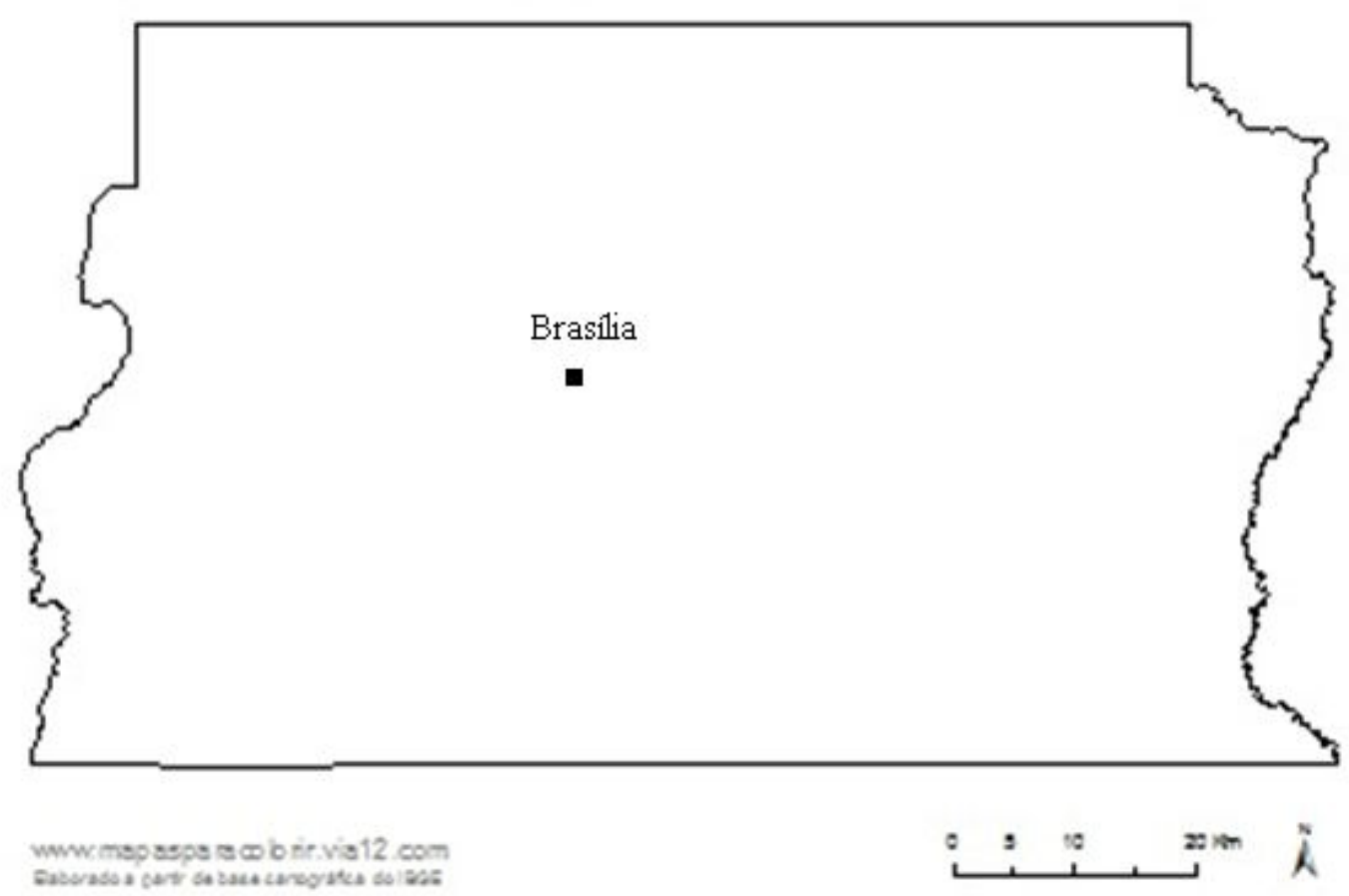

Fonte: www.mapasparacolorir.com.br

Figura 22 - Mapa do Distrito Federal. Brasil, 2011.

Capital: Brasília

Quadro 17 - Dados sobre população, extensão territorial densidade demográfica, número de cursos de bacharelado, vagas oferecidas e número de vagas/10.000 hab. Brasília, 2010.

\begin{tabular}{|c|c|c|c|c|c|c|}
\hline LOCALIDADE & População* & Extensão* & $\mathrm{hab} / \mathrm{km}^{2}$ & $\begin{array}{c}\text { № } \\
\text { cursos** }\end{array}$ & $\begin{array}{c}\text { Total } \\
\text { vagas** }\end{array}$ & $\begin{array}{l}\text { № vagas } \\
\% \text { ooohab }\end{array}$ \\
\hline Brasília & 2.570 .160 & $5.787,78$ & 444,1 & 17 & 3465 & 13,5 \\
\hline
\end{tabular}




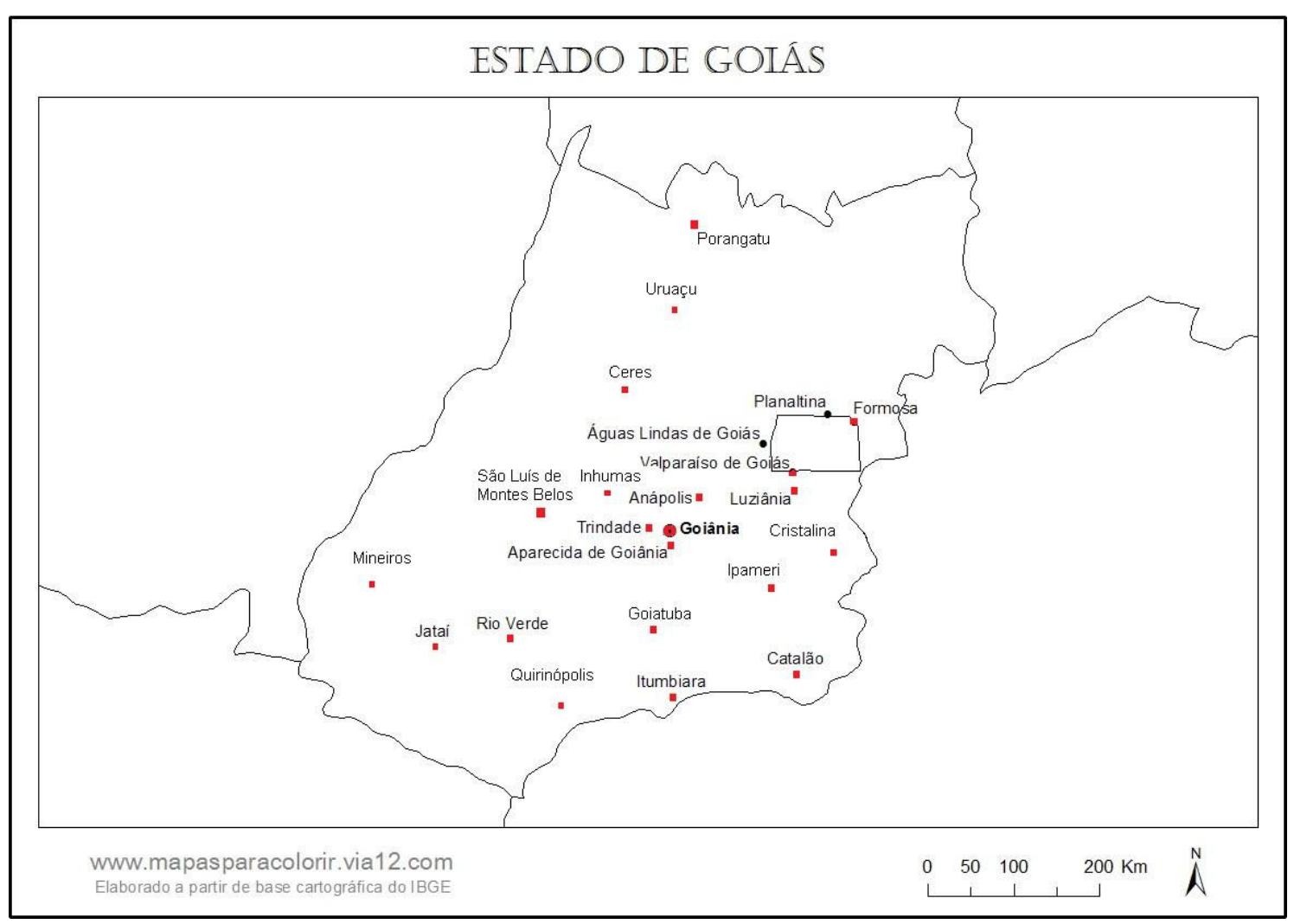

Fonte: www.mapasparacolorir.com.br

Figura 23 - Mapa do Estado de Goiás e cidades com curso de bacharelado presencial em Enfermagem. Brasil, 2011.

Capital: Goiânia

$\mathrm{N}^{\mathrm{o}}$ municípios: 246

$\mathrm{N}^{\mathrm{o}}$ municípios com curso de Enfermagem: $21(8,5 \%)$ 
Quadro 18 - Dados sobre população, extensão territorial densidade demográfica, número de cursos de bacharelado, vagas oferecidas e número de vagas/10.000 hab. Goiás, 2010.

\begin{tabular}{|c|c|c|c|c|c|c|}
\hline LOCALIDADE & População* & Extensão* & $\mathrm{hab} / \mathrm{km}^{2}$ & $\begin{array}{c}\text { № } \\
\text { cursos** } \\
\end{array}$ & $\begin{array}{l}\text { Total } \\
\text { vagas** }\end{array}$ & $\begin{array}{l}\text { № vagas } \\
\% \text { ooohab }\end{array}$ \\
\hline GOIÁS & 6.003 .788 & $340.103,47$ & 17,65 & 35 & 4322 & 7,2 \\
\hline Goiânia & 1.302 .001 & 732,80 & $1.776,75$ & 8 & 1780 & 13,7 \\
\hline Anápolis & 334.613 & 933,16 & 358,58 & 5 & 490 & 14,6 \\
\hline Aparecida de Goiânia & 455.657 & 288,34 & $1.580,27$ & 2 & 300 & 6,6 \\
\hline Catalão & 86.647 & $3.821,46$ & 22,67 & 1 & 40 & 4,6 \\
\hline Ceres & 20.722 & 214,32 & 96,69 & 1 & 100 & 48,3 \\
\hline Cristalina & 46.580 & $6.162,06$ & 7,56 & 1 & 40 & 8,6 \\
\hline Formosa & 100.085 & $5.811,78$ & 17,22 & 1 & 100 & 10,0 \\
\hline Goiatuba & 32.492 & $2.475,11$ & 13,13 & 1 & 50 & 15,4 \\
\hline Inhumas & 48.246 & 613,23 & 78,68 & 1 & 40 & 8,3 \\
\hline Ipameri & 24.735 & $4.368,99$ & 5,66 & 1 & 100 & 40,4 \\
\hline Itumbiara & 92.883 & $2.462,93$ & 37,71 & 2 & 130 & 14,0 \\
\hline Jataí & 88.006 & $7.174,23$ & 12,27 & 1 & 30 & 3,4 \\
\hline Luziânia & 174.531 & $3.961,12$ & 44,06 & 1 & 62 & 3,6 \\
\hline Mineiros & 52.935 & $9.060,10$ & 5,84 & 1 & 100 & 18,9 \\
\hline Porangatu & 42.355 & $4.820,51$ & 8,79 & 1 & 80 & 18,9 \\
\hline Quirinópolis & 43.220 & $3.786,70$ & 11,41 & 1 & 200 & 46,3 \\
\hline Rio Verde & 176.424 & $8.379,66$ & 21,05 & 2 & 140 & 7,9 \\
\hline São Luís de Montes Belos & 30.034 & 826,00 & 36,36 & 1 & 160 & 53,3 \\
\hline Trindade & 104.488 & 710,71 & 147,02 & 1 & 100 & 9,6 \\
\hline Uruaçu & 36.929 & $2.141,82$ & 17,24 & 1 & 40 & 10,8 \\
\hline Valparaíso de Goiás & 132.982 & 60,53 & $2.197,14$ & 1 & 240 & 18,0 \\
\hline
\end{tabular}




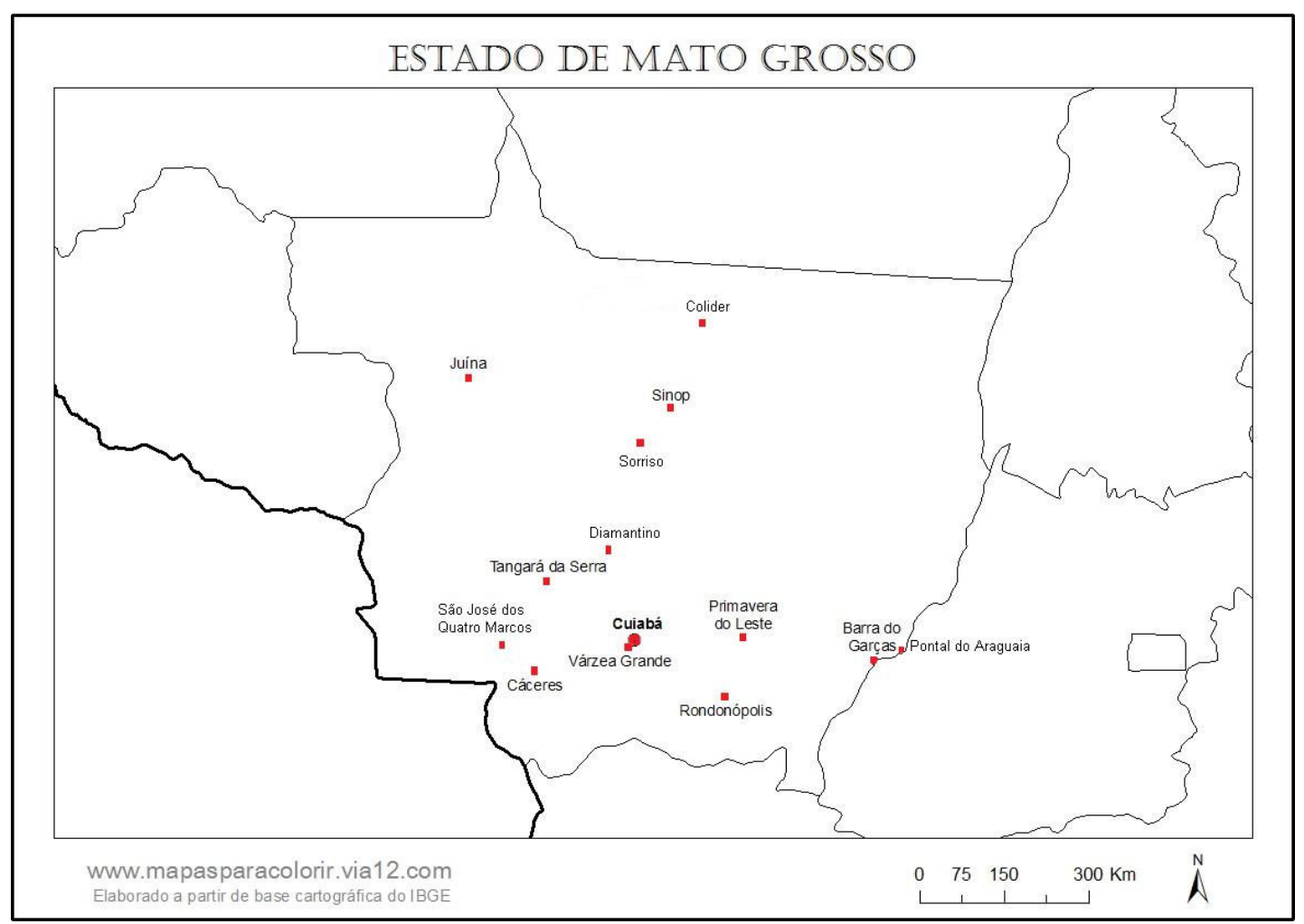

Fonte: www.mapasparacolorir.com.br

Figura 24 - Mapa do Estado de Mato Grosso e cidades com curso de bacharelado presencial em Enfermagem. Brasil, 2011.

\section{Capital: Cuiabá}

$\mathrm{N}^{\mathrm{o}}$ de municípios: 141

$\mathrm{N}^{\mathrm{o}}$ de municípios com cursos de Enfermagem: 14 (9,9\%) 
Quadro 19 - Dados sobre população, extensão territorial densidade demográfica, número de cursos de bacharelado, vagas oferecidas e número de vagas/10.000 hab. Mato Grosso, 2010.

\begin{tabular}{|c|c|c|c|c|c|c|}
\hline LOCALIDADE & População* & Extensão* & $\mathrm{hab} / \mathrm{km}^{2}$ & $\begin{array}{l}\text { № } \\
\text { cursos** }\end{array}$ & $\begin{array}{l}\text { Total } \\
\text { vagas** }\end{array}$ & $\begin{array}{l}\text { № vagas } \\
\% \text { ooohab }\end{array}$ \\
\hline MATO GROSSO & 3.035 .122 & $903.329,70$ & 3,36 & 21 & 2210 & 7,3 \\
\hline Cuiabá & 551.098 & $3.362,76$ & 163,88 & 5 & 570 & 10,3 \\
\hline Barra do Garças & 56.560 & $9.078,98$ & 6,23 & 1 & 120 & 21,2 \\
\hline Cáceres & 87.942 & $24.351,45$ & 3,61 & 1 & 80 & 9,1 \\
\hline Colíder & 30.766 & $3.093,64$ & 9,94 & 1 & 60 & 19,5 \\
\hline Diamantino & 20.341 & $8.230,05$ & 2,47 & 1 & 90 & 44,2 \\
\hline Juína & 39.255 & $26.395,85$ & 1,49 & 1 & 100 & 25,5 \\
\hline Pontal do Araguaia & 5.395 & $2.738,63$ & 1,97 & 1 & 30 & 55,6 \\
\hline Primavera do Leste & 52.066 & $5.471,65$ & 9,52 & 1 & 100 & 19,2 \\
\hline Rondonópolis & 195.476 & $4.159,12$ & 47 & 2 & 230 & 11,8 \\
\hline S. José dos Quatro Marcos & 18.998 & $1.289,09$ & 14,74 & 1 & 90 & 47,4 \\
\hline Sinop & 113.099 & $3.942,22$ & 28,69 & 3 & 360 & 31,8 \\
\hline Sorriso & 66.521 & $9.329,55$ & 7,13 & 1 & 200 & 30,1 \\
\hline Tangará da Serra & 83.431 & $11.391,31$ & 7,32 & 1 & 80 & 9,6 \\
\hline Várzea Grande & 252.596 & 888,00 & 284,45 & 1 & 100 & 4,0 \\
\hline
\end{tabular}

Fonte:

*http://www.ibge.gov.br/home/estatistica/populacao/censo2010/resultados_preliminares/default_resul tados_preliminares.shtm

**http://emec.mec.gov.br/ 


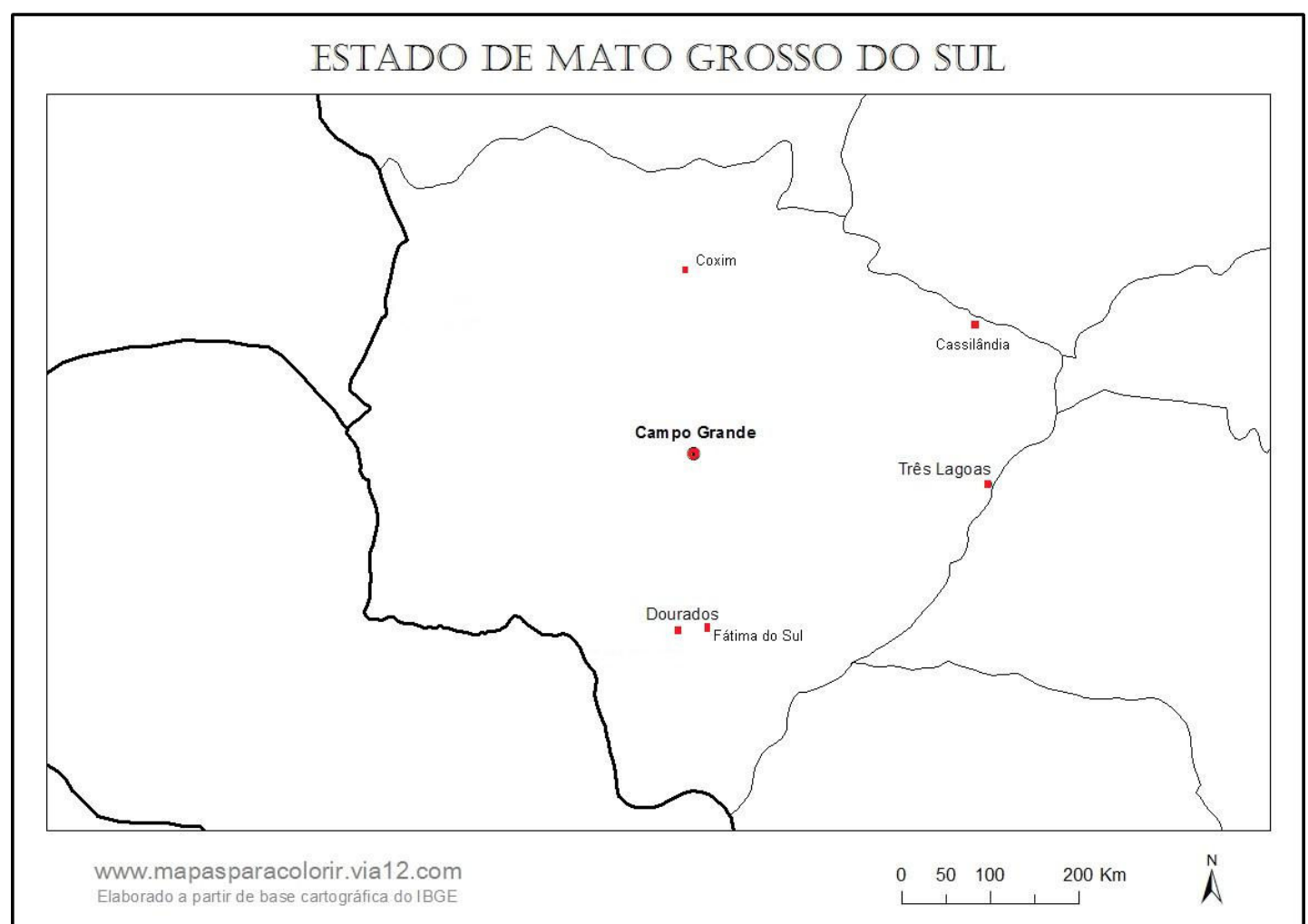

Fonte: www.mapasparacolorir.com.br

Figura 25 - Mapa do Estado de Mato Grosso do Sul e cidades com curso de bacharelado presencial em Enfermagem. Brasil, 2011.

\section{Capital: Campo Grande \\ $\mathrm{N}^{\mathrm{o}}$ de municípios: 78}

$\mathrm{N}^{\mathrm{o}}$ de municípios com cursos de Enfermagem: $6(7,7 \%)$

Quadro 20 - Dados sobre população, extensão territorial densidade demográfica, número de cursos de bacharelado, vagas oferecidas e número de vagas/10.000 hab. Mato Grosso do Sul, 2010.

\begin{tabular}{lrrrrrr}
\hline \hline LOCALIDADE & \multicolumn{1}{c}{ População* } & Extensão* & hab/km² & $\begin{array}{c}\text { № } \\
\text { cursos** }\end{array}$ & $\begin{array}{c}\text { Total } \\
\text { vagas** }\end{array}$ & $\begin{array}{r}\text { № vagas } \\
\text { \%ooohab }\end{array}$ \\
\hline \hline MATO GROSSO SUL & 2.449 .024 & $357.145,84$ & 6,86 & 14 & 1730 & 7,1 \\
Campo Grande & 786.797 & $8.092,97$ & 97,22 & 7 & 1040 & 13,2 \\
Cassilândia & 20.966 & $3.649,57$ & 5,74 & 1 & 80 & 38,2 \\
Coxim & 32.159 & $6.409,23$ & 5,02 & 1 & 50 & 15,5 \\
Dourados & 196.035 & $4.086,24$ & 47,97 & 2 & 280 & 14,3 \\
Fátima do Sul & 19.035 & 315,16 & 60,4 & 1 & 80 & 42,0 \\
Três Lagoas & 101.791 & $10.207,05$ & 9,97 & 2 & 200 & 19,6 \\
\hline \hline
\end{tabular}

Fonte: *http://www.ibge.gov.br/home/estatistica/populacao/censo2010/resultados_preliminares/ default_resultados_preliminares.shtm

**http://emec.mec.gov.br/ 


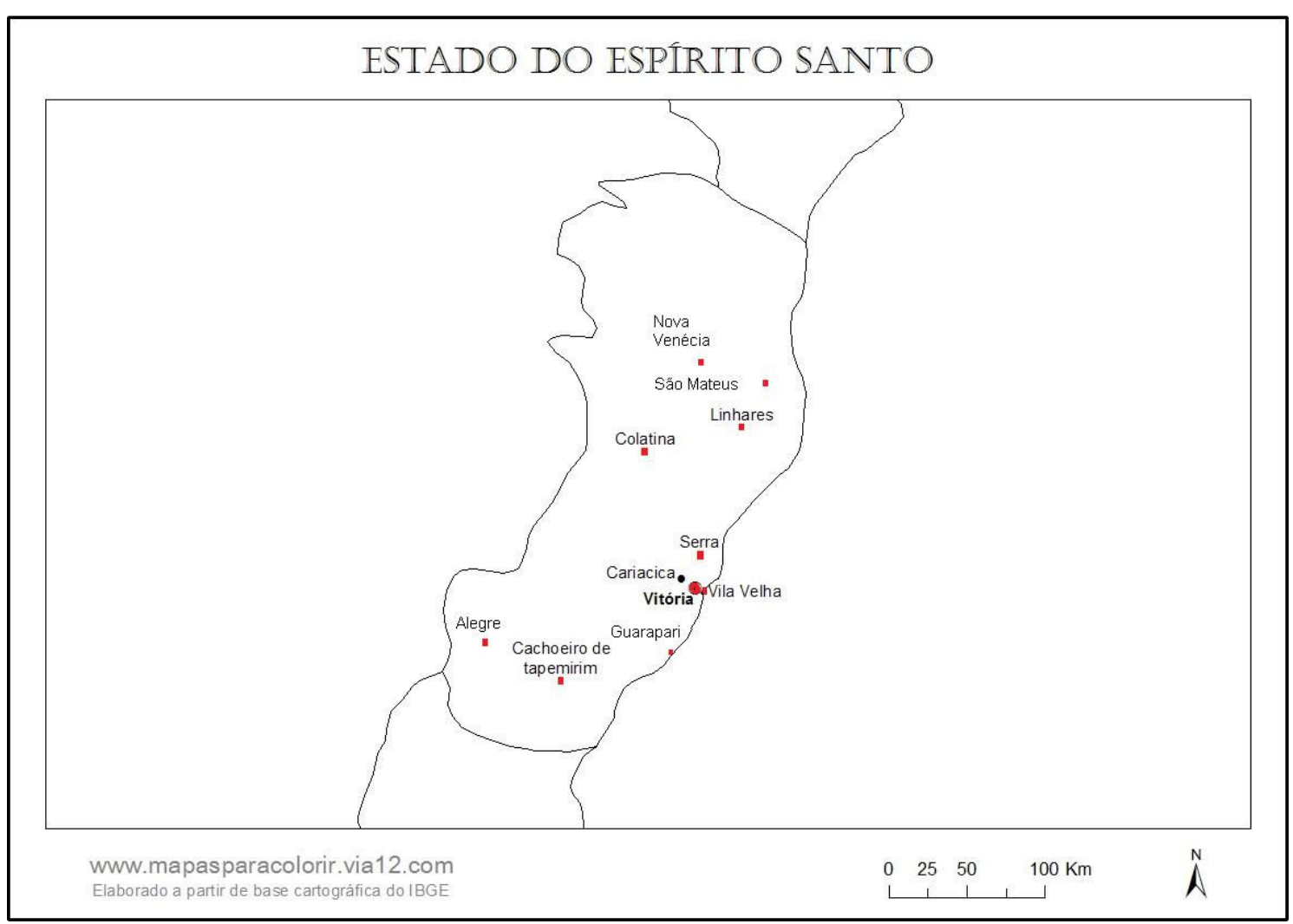

Fonte: www.mapasparacolorir.com.br

Figura 26 - Mapa do Estado de Espírito Santo e cidades com curso de bacharelado presencial em Enfermagem. Brasil, 2011.

Capital: Vitória

$\mathrm{N}^{\mathrm{o}}$ de municípios: 78

$\mathrm{N}^{\mathrm{o}}$ de municípios com cursos de Enfermagem: 10 (12,8\%) 
Quadro 21 - Dados sobre população, extensão territorial densidade demográfica, número de cursos de bacharelado, vagas oferecidas e número de vagas/10.000 hab. Espírito Santo, 2010.

\begin{tabular}{lrrrrrr}
\hline \hline LOCALIDADE & População* & Extensão* & hab/km & $\begin{array}{l}\text { No } \\
\text { cursos** }\end{array}$ & $\begin{array}{l}\text { Total } \\
\text { vagas** }\end{array}$ & $\begin{array}{r}\text { No vagas } \\
\text { \% ooohab }\end{array}$ \\
\hline \hline ESPíRITO SANTO & 3.514 .952 & $46.098,57$ & 76,25 & 17 & 1680 & 4,8 \\
Vitória & 327.801 & 98,51 & $3.327,73$ & 5 & 680 & 20,7 \\
Alegre & 30.768 & 772,72 & 39,82 & 1 & 80 & 26,0 \\
Cachoeiro de & & & & & & \\
Itapemirim & 189.889 & 876,80 & 216,57 & 1 & 50 & 2,6 \\
Colatina & 111.788 & $1.423,28$ & 78,54 & 2 & 150 & 13,4 \\
Guarapari & 105.286 & 595,48 & 176,81 & 2 & 180 & 17,1 \\
Linhares & 141.306 & $3.501,63$ & 40,35 & 1 & 100 & 7,1 \\
Nova Venécia & 46.031 & $1.448,36$ & 31,78 & 1 & 80 & 17,4 \\
São Mateus & 109.028 & $2.343,15$ & 46,53 & 1 & 50 & 4,6 \\
Serra & 409.267 & 553,53 & 739,38 & 1 & 80 & 2,0 \\
Vila Velha & 414.586 & 212,40 & $1.951,99$ & 2 & 230 & 5,5 \\
\hline \hline
\end{tabular}

Fonte:

*http://www.ibge.gov.br/home/estatistica/populacao/censo2010/resultados_preliminares/default_resul tados_preliminares.shtm

**http://emec.mec.gov.br/ 


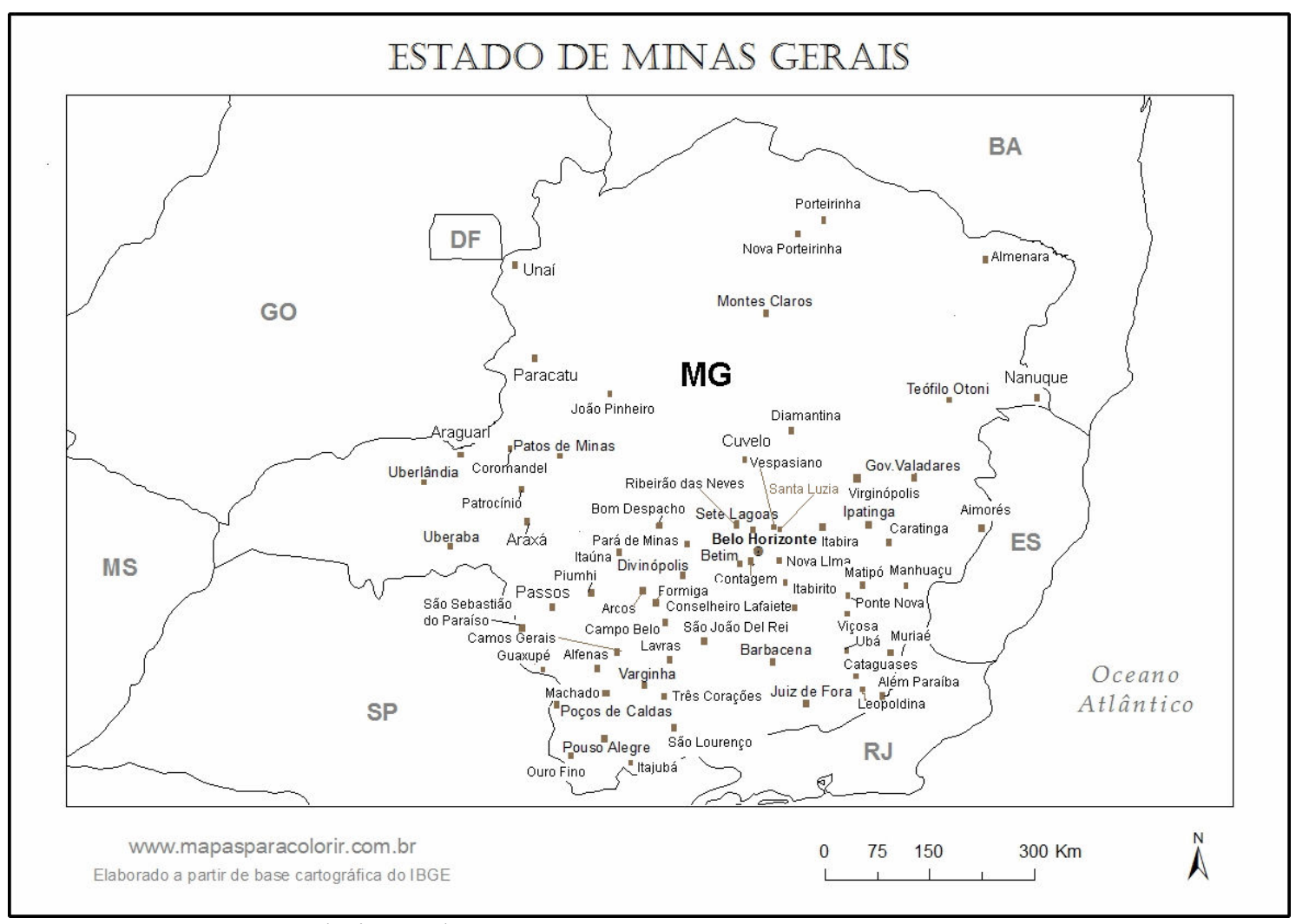

Fonte: www.mapasparacolorir.com.br

Figura 27 - Mapa do Estado de Minas Gerais e cidades com curso de bacharelado presencial em Enfermagem. Brasil, 2011.

\section{Capital: Belo Horizonte}

$\mathrm{N}^{\mathrm{o}}$ de municípios: 853

$\mathrm{N}^{\mathrm{o}}$ de municípios com cursos de Enfermagem: $69(8,1 \%)$ 
Ruth Natalia Teresa Turrini

Quadro 22 - Dados sobre população, extensão territorial densidade demográfica, número de cursos de bacharelado, vagas oferecidas e número de vagas/10.000 hab. Minas Gerais, 2010.

\begin{tabular}{|c|c|c|c|c|c|c|}
\hline LOCALIDADE & População* & Extensão* & $\mathrm{hab} / \mathrm{km}^{2}$ & $\begin{array}{c}\text { № } \\
\text { cursos** } \\
\end{array}$ & $\begin{array}{c}\text { Total } \\
\text { vagas** }\end{array}$ & $\begin{array}{l}\text { № vagas } \\
\% \text { ooohab }\end{array}$ \\
\hline MINAS GERAIS & 19.597 .330 & $586.520,37$ & 33,41 & 124 & 15811 & 8,1 \\
\hline Belo Horizonte & 2.375 .151 & 331,4 & $7.167,02$ & 17 & 2826 & 11,9 \\
\hline Aimorés & 24.959 & $1.348,77$ & 18,5 & 1 & 100 & 40,1 \\
\hline Além Paraíba & 34.349 & 510,35 & 67,3 & 1 & 60 & 17,5 \\
\hline Alfenas & 73.774 & 850,45 & 86,75 & 2 & 280 & 38,0 \\
\hline Almenara & 38.775 & $2.294,42$ & 16,9 & 1 & 50 & 12,9 \\
\hline Araguari & 109.801 & $2.729,51$ & 40,23 & 1 & 120 & 10,9 \\
\hline Araxá & 93.672 & $1.164,36$ & 80,45 & 1 & 60 & 6,4 \\
\hline Arcos & 36.597 & 509,87 & 71,78 & 1 & 120 & 32,8 \\
\hline Barbacena & 126.284 & 759,19 & 166,34 & 1 & 100 & 7,9 \\
\hline Betim & 378.089 & 342,85 & $1.102,80$ & 3 & 340 & 9,0 \\
\hline Bom Despacho & 45.624 & $1.223,86$ & 37,28 & 1 & 120 & 26,3 \\
\hline Campo Belo & 51.544 & 528,23 & 97,58 & 1 & 160 & 31,0 \\
\hline Campos Gerais & 27.600 & 769,50 & 35,87 & 1 & 100 & 36,2 \\
\hline Caratinga & 85.239 & $1.258,78$ & 67,72 & 2 & 300 & 35,2 \\
\hline Cataguases & 69.757 & 491,77 & 141,85 & 1 & 100 & 14,3 \\
\hline Conselheiro Lafaiete & 116.512 & 370,25 & 314,69 & 2 & 340 & 29,2 \\
\hline Contagem & 603.442 & 195,27 & $3.090,33$ & 2 & 320 & 5,3 \\
\hline Coromandel & 27.547 & $3.313,12$ & 8,31 & 1 & 100 & 36,3 \\
\hline Curvelo & 74.219 & $3.298,79$ & 22,5 & 1 & 200 & 26,9 \\
\hline Diamantina & 45.880 & $3.891,65$ & 11,79 & 1 & 30 & 6,5 \\
\hline Divinópolis & 213.016 & 708,12 & 300,82 & 3 & 280 & 13,1 \\
\hline Formiga & 65.128 & $1.501,92$ & 43,36 & 1 & 60 & 9,2 \\
\hline \multicolumn{7}{|l|}{ Governador } \\
\hline Valadares & 263.689 & $2.342,32$ & 112,58 & 2 & 245 & 9,3 \\
\hline Guaxupé & 49.430 & 286,40 & 172,59 & 1 & 80 & 16,2 \\
\hline Ipatinga & 239.468 & 164,88 & $1.452,34$ & 3 & 370 & 15,5 \\
\hline Itabira & 109.783 & $1.253,70$ & 87,57 & 2 & 220 & 20,0 \\
\hline Itabirito & 45.449 & 542,61 & 83,76 & 1 & 60 & 13,2 \\
\hline Itajubá & 90.658 & 294,84 & 307,49 & 2 & 175 & 19,3 \\
\hline Itaúna & 85.463 & 495,77 & 172,39 & 1 & 120 & 14,0 \\
\hline João Pinheiro & 45.260 & $10.727,46$ & 4,22 & 1 & 120 & 26,5 \\
\hline Juiz de Fora & 516.247 & $1.435,66$ & 359,59 & 5 & 1110 & 21,5 \\
\hline Lavras & 92.200 & 564,74 & 163,26 & 1 & 60 & 6,5 \\
\hline Leopoldina & 51.130 & 943,08 & 54,22 & 1 & 120 & 23,5 \\
\hline Machado & 38.688 & 585,96 & 66,03 & 1 & 100 & 25,8 \\
\hline Manhuaçu & 79.574 & 628,32 & 126,65 & 1 & 120 & 15,1 \\
\hline Matipó & 17.639 & 266,99 & 66,07 & 1 & 240 & 136,1 \\
\hline
\end{tabular}


Ruth Natalia Teresa Turrini

\begin{tabular}{|c|c|c|c|c|c|c|}
\hline $\begin{array}{l}\text { Cont. } \\
\text { LOCALIDADE }\end{array}$ & População* & Extensão* & $\mathrm{hab} / \mathrm{km}^{2}$ & $\begin{array}{c}\text { № } \\
\text { Cursos** }\end{array}$ & $\begin{array}{l}\text { Total } \\
\text { vagas** }\end{array}$ & $\begin{array}{l}\text { № vagas } \\
\% \text { ooohab }\end{array}$ \\
\hline Montes Claros & 361.915 & $3.568,94$ & 101,41 & 6 & 690 & 19,1 \\
\hline Muriaé & 100.765 & 841,692 & 119,72 & 1 & 180 & 17,9 \\
\hline Nanuque & 40.834 & $1.517,97$ & 26,9 & 2 & 120 & 29,4 \\
\hline Nova Lima & 80.998 & 429,06 & 188,78 & 1 & 200 & 24,7 \\
\hline Nova Porteirinha & 7.398 & 120,94 & 61,17 & 1 & 100 & 135,2 \\
\hline Ouro Fino & 31.568 & 533,66 & 59,15 & 1 & 100 & 31,7 \\
\hline Pará de Minas & 84.215 & 551,25 & 152,77 & 2 & 200 & 23,7 \\
\hline Paracatu & 84.718 & $8.229,59$ & 10,29 & 1 & 100 & 11,8 \\
\hline Passos & 106.290 & $1.338,07$ & 79,44 & 1 & 100 & 9,4 \\
\hline Patos de Minas & 138.710 & $3.189,77$ & 43,49 & 2 & 210 & 15,1 \\
\hline Patrocínio & 82.471 & $2.874,34$ & 28,69 & 1 & 100 & 12,1 \\
\hline Piumhi & 31.883 & 902,47 & 35,33 & 1 & 100 & 31,4 \\
\hline Poços de Caldas & 152.435 & 547,26 & 278,54 & 2 & 320 & 21,0 \\
\hline Ponte Nova & 57.390 & 470,64 & 121,94 & 1 & 120 & 20,9 \\
\hline Porteirinha & 37.627 & $1.749,68$ & 21,51 & 1 & 100 & 26,6 \\
\hline Pouso Alegre & 130.615 & 543,07 & 240,51 & 1 & 120 & 9,2 \\
\hline Ribeirão das Neves & 296.317 & 154,50 & $1.917,90$ & 1 & 120 & 4,0 \\
\hline Sabinópolis & 15.704 & 919,81 & 17,07 & 1 & 100 & 63,7 \\
\hline Santa Luzia & 202.942 & 235,33 & 862,38 & 1 & 200 & 9,9 \\
\hline São João del Rei & 84.469 & $1.464,33$ & 57,68 & 2 & 220 & 26,0 \\
\hline São Lourenço & 41.657 & 58,02 & 717,99 & 1 & 50 & 12,0 \\
\hline \multicolumn{7}{|l|}{ São Sebastião do } \\
\hline Paraíso & 64.980 & 814,93 & 79,74 & 1 & 50 & 7,7 \\
\hline Sete Lagoas & 214.152 & 537,64 & 398,32 & 3 & 340 & 15,9 \\
\hline Teófilo Otoni & 134.745 & $3.242,26$ & 41,56 & 2 & 200 & 14,8 \\
\hline Três Corações & 72.765 & 828,04 & 87,88 & 1 & 100 & 13,7 \\
\hline Ubá & 101.519 & 407,45 & 249,16 & 1 & 120 & 11,8 \\
\hline Uberaba & 295.988 & $4.523,96$ & 65,43 & 3 & 285 & 9,6 \\
\hline Uberlândia & 604.013 & $4.115,21$ & 146,78 & 5 & 1120 & 18,5 \\
\hline Unaí & 77.565 & $8.447,10$ & 9,18 & 2 & 300 & 38,7 \\
\hline Varginha & 123.081 & 395,40 & 311,29 & 2 & 170 & 13,8 \\
\hline Vespasiano & 104.527 & 71,18 & $1.468,49$ & 1 & 60 & 5,7 \\
\hline Viçosa & 72.220 & 299,42 & 241,2 & 2 & 160 & 22,2 \\
\hline Virginópolis & 10.572 & 439,88 & 24,03 & 1 & 50 & 47,3 \\
\hline
\end{tabular}




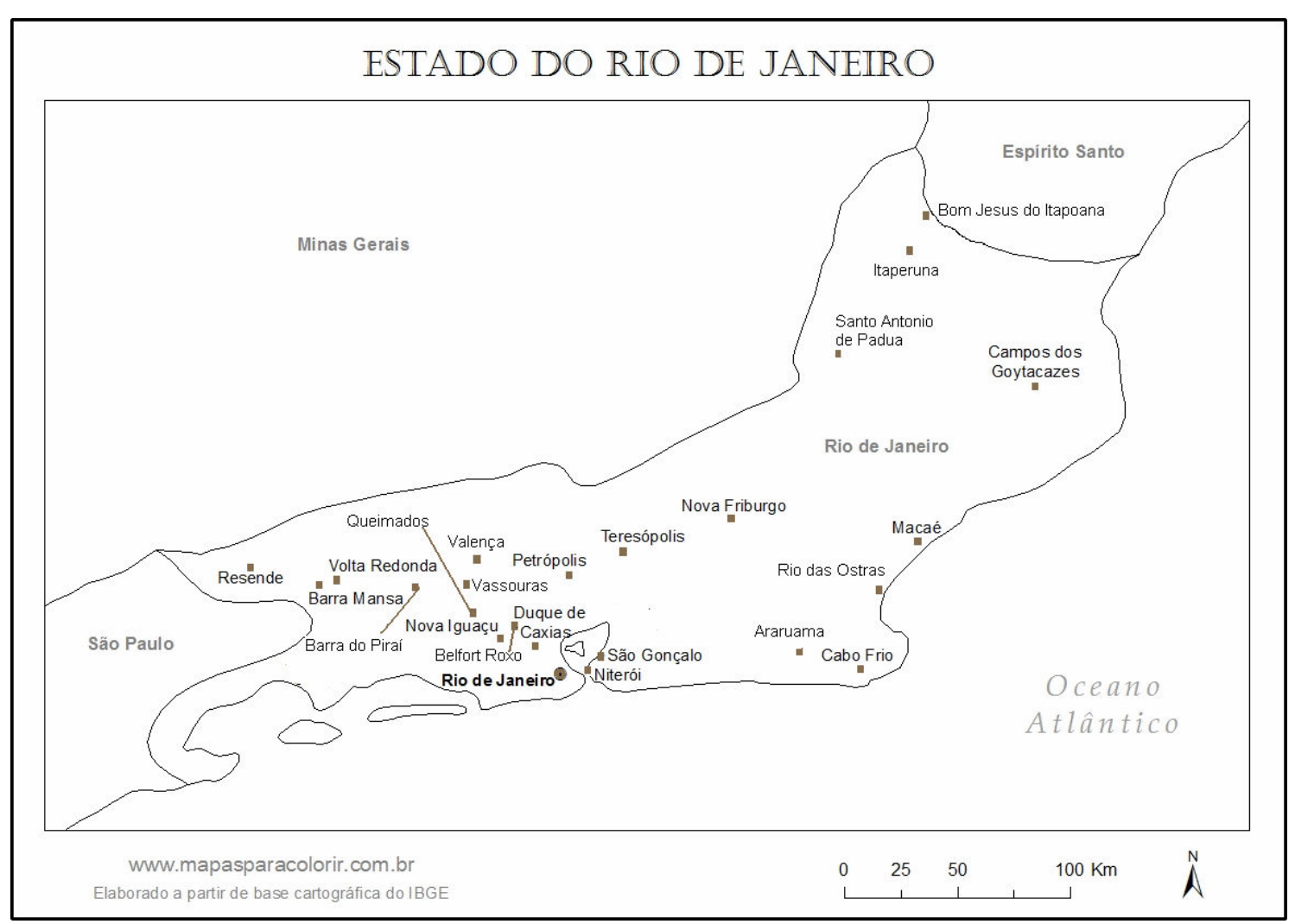

Fonte: www.mapasparacolorir.com.br

Figura 28 - Mapa do Estado do Rio de Janeiro e cidades com curso de bacharelado presencial em Enfermagem. Brasil, 2011.

Capital: Rio de Janeiro

$\mathrm{N}^{\mathrm{o}}$ de municípios: 92

$\mathrm{N}^{\mathrm{o}}$ de municípios com cursos de Enfermagem: 24 (26,1\%) 
Quadro 23 - Dados sobre população, extensão territorial densidade demográfica, número de cursos de bacharelado, vagas oferecidas e número de vagas/10.000 hab. Rio de Janeiro, 2010.

\begin{tabular}{|c|c|c|c|c|c|c|}
\hline LOCALIDADE & População* & Extensão* & $\mathrm{hab} / \mathrm{km}^{2}$ & $\begin{array}{c}\text { № } \\
\text { cursos** } \\
\end{array}$ & $\begin{array}{l}\text { Total } \\
\text { vagas** }\end{array}$ & $\begin{array}{r}\text { № vagas } \\
\% \text { ooohab }\end{array}$ \\
\hline RIO DE JANEIRO & 15.989 .929 & $43.780,16$ & 365,23 & 55 & 11536 & 7,2 \\
\hline Rio de Janeiro & 6.320 .446 & $1.200,28$ & $5.265,81$ & 22 & 5064 & 8,0 \\
\hline Araruama & 112.008 & 638,02 & 175,55 & 1 & 200 & 17,9 \\
\hline Barra do Piraí & 94.778 & 578,97 & 163,7 & 1 & 100 & 10,6 \\
\hline Barra Mansa & 177.813 & 547,23 & 324,94 & 1 & 50 & 2,8 \\
\hline Belfort Roxo & 469.332 & 77,82 & $6.031,38$ & 1 & 420 & 8,9 \\
\hline Bom Jesus do Itabapoana & 35.411 & 598,82 & 59,13 & 1 & 60 & 16,9 \\
\hline Cabo Frio & 186.227 & 410,42 & 453,75 & 1 & 240 & 12,9 \\
\hline Campos dos Goytacazes & 463.731 & $4.026,71$ & 115,16 & 3 & 920 & 19,8 \\
\hline Duque de Caxias & 855.048 & 467,62 & $1.828,51$ & 2 & 580 & 6,8 \\
\hline Itaperuna & 95.841 & $1.105,34$ & 86,71 & 3 & 280 & 29,2 \\
\hline Macaé & 206.728 & $1.216,85$ & 169,89 & 2 & 170 & 8,2 \\
\hline Niterói & 487.562 & 133,92 & $3.640,80$ & 4 & 1240 & 25,4 \\
\hline Nova Friburgo & 182.082 & 933,41 & 195,07 & 1 & 160 & 8,8 \\
\hline Nova Iguaçu & 796.257 & 521,25 & $1.527,60$ & 2 & 460 & 5,8 \\
\hline Petrópolis & 295.917 & 795,80 & 371,85 & 1 & 160 & 5,4 \\
\hline Queimados & 137.962 & 75,70 & $1.822,60$ & 1 & 120 & 8,7 \\
\hline Resende & 119.769 & $1.095,25$ & 109,35 & 1 & 120 & 10,0 \\
\hline Rio das Ostras & 105.676 & 229,04 & 461,38 & 1 & 60 & 5,7 \\
\hline Santo Antônio de Pádua & 40.589 & 603,36 & 67,27 & 1 & 240 & 59,1 \\
\hline São Gonçalo & 999.728 & 247,71 & $4.035,90$ & 1 & 600 & 6,0 \\
\hline Teresópolis & 163.746 & 770,60 & 212,49 & 1 & 80 & 4,9 \\
\hline Valença & 71.843 & $1.304,81$ & 55,06 & 1 & 64 & 8,9 \\
\hline Vassouras & 34.410 & 538,13 & 63,94 & 1 & 40 & 11,6 \\
\hline Volta Redonda & 257.803 & 182,48 & $1.412,75$ & 1 & 108 & 4,2 \\
\hline
\end{tabular}




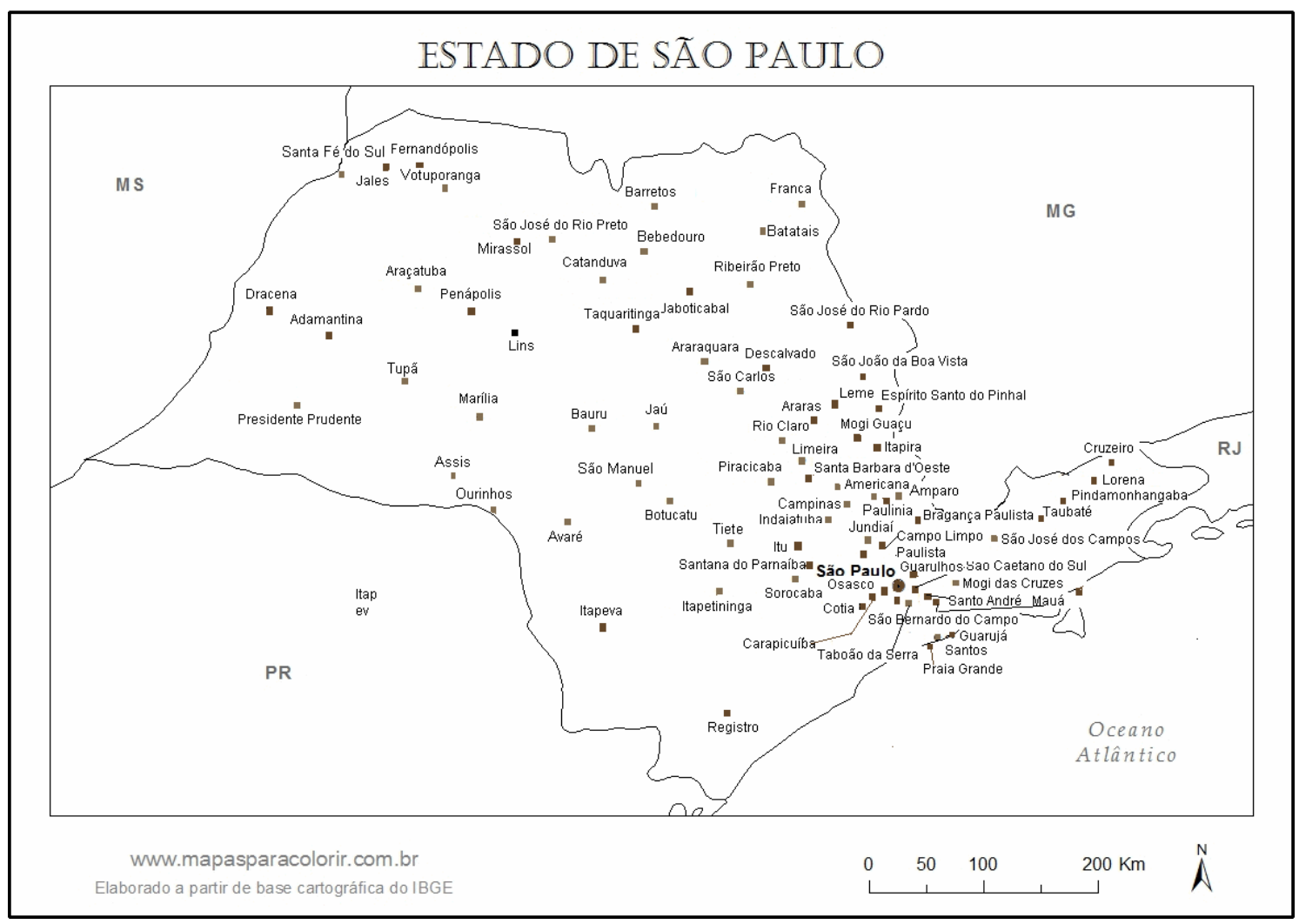

Fonte: www.mapasparacolorir.com.br

Figura 29 - Mapa do Estado de São Paulo e cidades com curso de bacharelado presencial em Enfermagem. Brasil, 2011.

Capital: São Paulo

$\mathrm{N}^{\mathrm{o}}$ de municípios: 645

$\mathrm{N}^{\mathrm{o}}$ de municípios com cursos de Enfermagem: 78 (12,1\%)

Quadro 24 - Dados sobre população, extensão territorial densidade demográfica, número de cursos de bacharelado, vagas oferecidas e número de vagas/10.000 hab. São Paulo, 2010.

\begin{tabular}{|c|c|c|c|c|c|c|}
\hline LOCALIDADE & População* & Extensão* & hab/km ${ }^{2}$ & $\begin{array}{c}\text { № } \\
\text { cursos** } \\
\end{array}$ & $\begin{array}{l}\text { Total } \\
\text { vagas** }\end{array}$ & $\begin{array}{l}\text { № vagas } \\
\% \text { ooohab }\end{array}$ \\
\hline SÃO PAULO & 41.262.199 & $248.196,96$ & 166,25 & 181 & 38778 & 9,4 \\
\hline São Paulo & 11.253 .503 & $1.523,28$ & $7.387,69$ & 49 & 14983 & 13,3 \\
\hline Adamantina & 33.797 & 411,36 & 82,16 & 1 & 200 & 59,2 \\
\hline Americana & 210.638 & 133,35 & $1.579,59$ & 1 & 150 & 7,1 \\
\hline Amparo & 65.829 & 445,55 & 147,75 & 1 & 100 & 15,2 \\
\hline Araçatuba & 181.579 & $1.167,44$ & 155,54 & 2 & 660 & 36,3 \\
\hline Araraquara & 208.662 & $1.004,14$ & 207,8 & 2 & 560 & 26,8 \\
\hline
\end{tabular}




\begin{tabular}{|c|c|c|c|c|c|c|}
\hline Cont.LOCALIDADE & População* & Extensão* & $\mathrm{hab} / \mathrm{km}^{2}$ & $\begin{array}{l}\text { № } \\
\text { cursos** }\end{array}$ & $\begin{array}{l}\text { Total } \\
\text { vagas** }\end{array}$ & $\begin{array}{c}\text { № vagas } \\
\% \text { o0o hab }\end{array}$ \\
\hline Assis & 95.144 & 460,31 & 206,7 & 2 & 330 & 34,7 \\
\hline Avaré & 82.934 & $1.213,06$ & 68,37 & 2 & 180 & 21,7 \\
\hline Barretos & 112.101 & $1.565,64$ & 71,6 & 1 & 100 & 8,9 \\
\hline Batatais & 56.476 & 849,53 & 66,48 & 1 & 120 & 21,2 \\
\hline Bauru & 343.937 & 667,68 & 515,12 & 4 & 585 & 17,0 \\
\hline Bebedouro & 75.035 & 683,30 & 109,81 & 1 & 150 & 20,0 \\
\hline Botucatu & 127.328 & $1.482,64$ & 85,88 & 1 & 30 & 2,4 \\
\hline Bragança Paulista & 146.744 & 512,62 & 286,26 & 1 & 140 & 9,5 \\
\hline Campinas & 1.080 .113 & 795,00 & $1.358,63$ & 4 & 880 & 8,1 \\
\hline Campo Limpo Paulista & 74.074 & 79,58 & 930,79 & 1 & 50 & 6,8 \\
\hline Caraguatatuba & 100.840 & 485,38 & 207,76 & 1 & 160 & 15,9 \\
\hline Carapicuíba & 369.584 & 34,61 & $10.680,08$ & 2 & 420 & 11,4 \\
\hline Catanduva & 112.820 & 290,60 & 388,24 & 1 & 90 & 8,0 \\
\hline Cotia & 201.150 & 323,10 & 622,55 & 3 & 480 & 23,9 \\
\hline Cruzeiro & 77.039 & 305,70 & 252,01 & 1 & 120 & 15,6 \\
\hline Descalvado & 31.056 & 753,71 & 41,2 & 1 & 100 & 32,2 \\
\hline Dracena & 43.258 & 488,04 & 88,64 & 1 & 100 & 23,1 \\
\hline Espírito Santo do Pinhal & 41.907 & 389,42 & 107,61 & 1 & 40 & 9,5 \\
\hline Fernandópolis & 64.696 & 550,03 & 117,62 & 1 & 160 & 24,7 \\
\hline Franca & 318.640 & 605,68 & 526,09 & 1 & 300 & 9,4 \\
\hline Guarujá & 290.752 & 142,88 & $2.034,91$ & 1 & 300 & 10,3 \\
\hline Guarulhos & 1.221 .979 & 319,19 & $3.828,36$ & 4 & 650 & 5,3 \\
\hline Indaiatuba & 201.619 & 311,36 & 647,54 & 2 & 320 & 15,9 \\
\hline Itapeva & 87.753 & $1.826,26$ & 48,05 & 1 & 100 & 11,4 \\
\hline Itapira & 68.537 & 518,39 & 132,21 & 1 & 100 & 14,6 \\
\hline Itú & 154.147 & 640,76 & 240,57 & 1 & 360 & 23,4 \\
\hline Jaboticabal & 71.662 & 706,60 & 101,42 & 1 & 120 & 16,7 \\
\hline Jaguariúna & 44.311 & 141,77 & 312,56 & 1 & 120 & 27,1 \\
\hline Jales & 47.012 & 368,52 & 127,57 & 1 & 100 & 21,3 \\
\hline Jaú & 131.040 & 685,77 & 191,09 & 1 & 120 & 9,2 \\
\hline Jundiaí & 370.126 & 431,50 & 857,77 & 4 & 680 & 18,4 \\
\hline Leme & 91.756 & 402,87 & 227,75 & 1 & 160 & 17,4 \\
\hline Limeira & 276.022 & 581,00 & 475,08 & 3 & 510 & 18,5 \\
\hline Lins & 71.432 & 570,24 & 125,27 & 2 & 180 & 25,2 \\
\hline Lorena & 82.537 & 414,36 & 199,19 & 1 & 80 & 9,7 \\
\hline Marília & 216.745 & $1.170,25$ & 185,21 & 2 & 120 & 5,5 \\
\hline Mauá & 417.064 & 61,30 & $6.803,54$ & 1 & 100 & $\begin{array}{r}2,4 \\
\text { Cont }\end{array}$ \\
\hline
\end{tabular}


Ruth Natalia Teresa Turrini

\begin{tabular}{|c|c|c|c|c|c|c|}
\hline Cont .LOCALIDADE & População* & Extensão* & $\mathrm{hab} / \mathrm{km}^{2}$ & $\begin{array}{l}\text { № } \\
\text { cursos** }\end{array}$ & $\begin{array}{l}\text { Total } \\
\text { vagas** }\end{array}$ & $\begin{array}{c}\text { № vagas } \\
\% \text { hab } \\
\end{array}$ \\
\hline Mirassol & 53.792 & 243,16 & 221,22 & 1 & 100 & 18,6 \\
\hline Mogi das Cruzes & 387.779 & 713,29 & 543,65 & 2 & 950 & 24,5 \\
\hline Mogi Guaçu & 137.245 & 812,19 & 168,98 & 1 & 100 & 7,3 \\
\hline Osasco & 666.740 & 64,04 & $10.411,79$ & 2 & $270^{a}$ & 4,0 \\
\hline Ourinhos & 103.035 & 296,27 & 347,78 & 2 & 200 & 19,4 \\
\hline Paulínia & 82.146 & 138,83 & 591,72 & 1 & 160 & 19,5 \\
\hline Penápolis & 58.510 & 710,83 & 82,31 & 1 & 80 & 13,7 \\
\hline Pindamonhangaba & 146.995 & 729,89 & 201,39 & 1 & 100 & 6,8 \\
\hline Piracicaba & 364.571 & $1.376,91$ & 264,77 & 2 & 380 & 10,4 \\
\hline Praia Grande & 262.051 & 147,54 & $1.776,09$ & 1 & 150 & 5,7 \\
\hline Presidente Prudente & 207.610 & 562,80 & 368,89 & 2 & 220 & 10,6 \\
\hline Registro & 54.261 & 722,41 & 75,11 & 1 & 100 & 18,4 \\
\hline Ribeirão Preto & 604.682 & 651,28 & 928,46 & 6 & 1030 & 17,0 \\
\hline Rio Claro & 186.253 & 498,71 & 373,47 & 1 & 150 & 8,1 \\
\hline Santa Bárbara d'Oeste & 180.009 & 271,48 & 663,08 & 2 & 180 & 10,0 \\
\hline Santa Fé do Sul & 29.239 & 208,22 & 140,43 & 1 & 100 & 34,2 \\
\hline Santana de Parnaiba & 108.813 & 179,81 & 605,17 & 1 & 460 & 42,3 \\
\hline Santo André & 676.407 & 174,95 & $3.866,35$ & 3 & 1530 & 22,6 \\
\hline Santos & 419.400 & 281,06 & $1.492,23$ & 4 & 900 & 21,5 \\
\hline \multicolumn{7}{|l|}{ São Bernardo do } \\
\hline Campo & 765.463 & 408,77 & $1.872,59$ & 2 & 380 & 5,0 \\
\hline São Caetano do Sul & 149.263 & 15,37 & $9.708,79$ & 1 & 240 & 16,1 \\
\hline São Carlos & 221.950 & $1.137,30$ & 195,15 & 2 & 150 & 6,8 \\
\hline São João da Boa Vista & 83.639 & 516,42 & 161,96 & 1 & 60 & 7,2 \\
\hline São José do Rio Pardo & 51.900 & 419,19 & 123,81 & 1 & 230 & 44,3 \\
\hline São José do Rio Preto & 408.258 & 431,32 & 946,53 & 6 & 1940 & 47,5 \\
\hline São José dos Campos & 629.921 & $1.099,78$ & 572,77 & 3 & 800 & 12,7 \\
\hline São Manuel & 38.342 & 650,77 & 58,92 & 1 & 150 & 39,1 \\
\hline Sorocaba & 586.625 & 448,99 & $1.306,55$ & 3 & 760 & 13,0 \\
\hline Taboão da Serra & 244.528 & 20,29 & $12.049,87$ & 1 & 200 & 8,2 \\
\hline Taquaritinga & 53.988 & 593,58 & 90,95 & 1 & 120 & 22,2 \\
\hline Taubaté & 278.686 & 624,89 & 445,98 & 4 & 470 & 16,9 \\
\hline Tietê & 36.835 & 404,79 & 91 & 1 & 200 & 54,3 \\
\hline Tupã & 63.476 & 100,99 & 100,99 & 2 & 350 & 55,1 \\
\hline Votuporanga & 84.692 & 424,12 & 199,69 & 1 & 100 & 11,8 \\
\hline
\end{tabular}

Fonte:

*http://www.ibge.gov.br/home/estatistica/populacao/censo2010/resultados_preliminares/default_resul tados_preliminares.shtm

**http://emec.mec.gov.br/ 
$\mathrm{a}$ - informação de apenas um curso

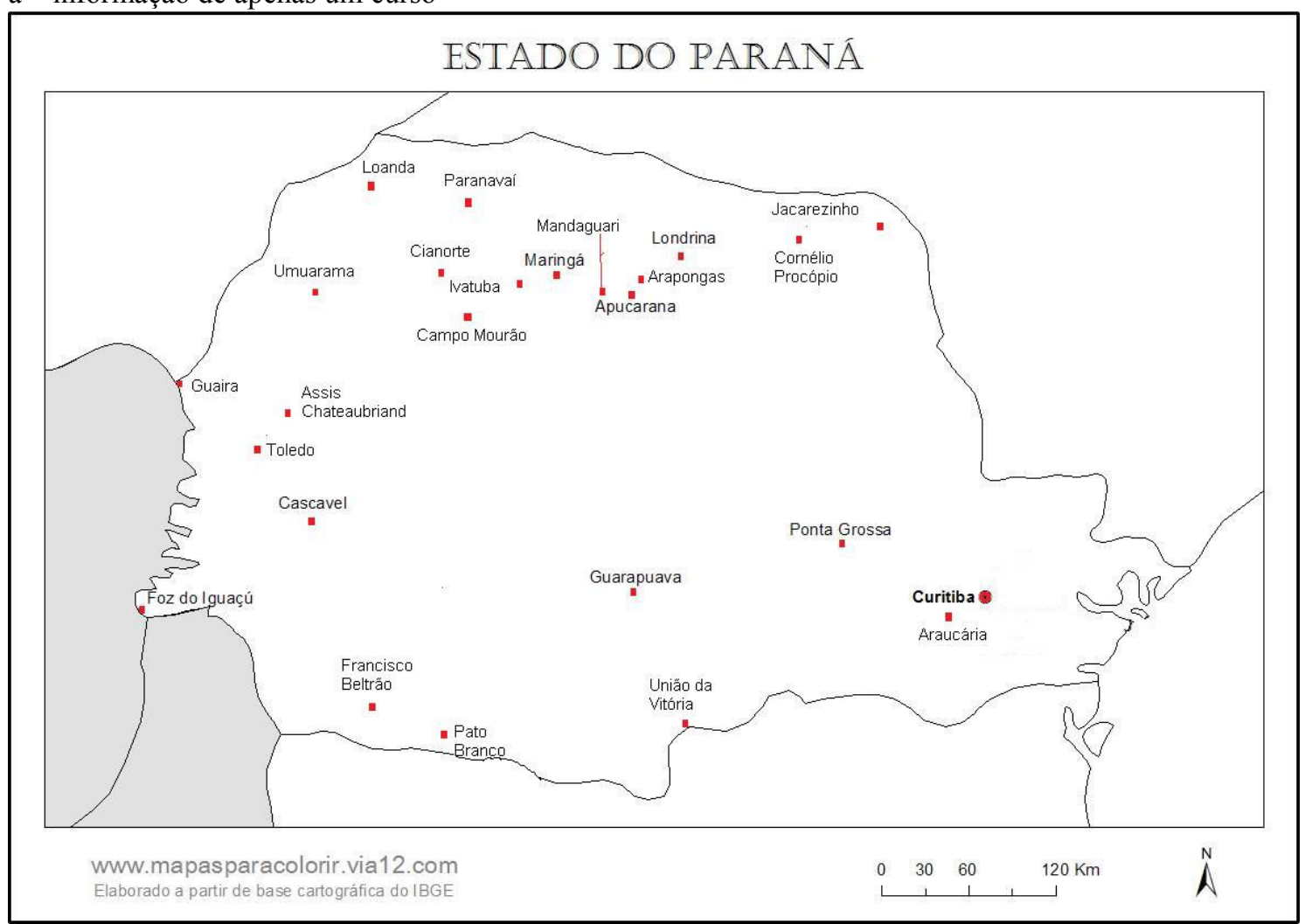

Fonte: www.mapasparacolorir.com.br

Figura 30 - Mapa do Estado do Paraná e cidades com curso de bacharelado presencial em Enfermagem. Brasil, 2011.

\section{Capital: Curitiba}

$\mathrm{N}^{\mathrm{o}}$ de municípios: 399

$\mathrm{N}^{\mathrm{o}}$ de municípios com cursos de Enfermagem: 25(6,3\%) 
Ruth Natalia Teresa Turrini

Quadro 25 - Dados sobre população, extensão territorial densidade demográfica, número de cursos de bacharelado, vagas oferecidas e número de vagas/10.000 hab. Paraná, 2010.

\begin{tabular}{|c|c|c|c|c|c|c|}
\hline LOCALIDADE & População* & Extensão* & $\mathrm{hab} / \mathrm{km}^{2}$ & $\begin{array}{l}\text { № } \\
\text { cursos** } \\
\end{array}$ & $\begin{array}{l}\text { Total } \\
\text { vagas** }\end{array}$ & $\begin{array}{l}\text { № vagas } \\
\% \text { ooohab }\end{array}$ \\
\hline PARANÁ & 10.444 .526 & $199.316,69$ & 52,4 & 58 & 6216 & 6,0 \\
\hline Curitiba & 1.751 .907 & 435,27 & $4.024,84$ & 14 & 2218 & 12,7 \\
\hline Apucarana & 120.919 & 558,39 & 216,55 & 1 & 100 & 8,3 \\
\hline Arapongas & 104.150 & 381,08 & 273,3 & 1 & 120 & 11,5 \\
\hline Araucária & 119.123 & 469,17 & 253,9 & 1 & 100 & 8,4 \\
\hline Assis Chateaubriand & 33.025 & 969,59 & 34,06 & 1 & 100 & 30,3 \\
\hline Campo Mourão & 87.194 & 757,88 & 115,05 & 2 & 160 & 18,3 \\
\hline Cascavel & 286.205 & $2.100,84$ & 136,23 & 3 & 207 & 7,2 \\
\hline Cianorte & 69.958 & 811,67 & 86,19 & 1 & 62 & 8,9 \\
\hline Cornélio Procópio & 46.928 & 635,10 & 73,89 & 1 & 100 & 21,3 \\
\hline Foz do Iguaçu & 256.088 & 617,70 & 414,58 & 5 & 510 & 19,9 \\
\hline Francisco Beltrão & 78.943 & 735,11 & 107,39 & 1 & 60 & 7,6 \\
\hline Guaíra & 30.704 & 560,49 & 54,78 & 1 & 65 & 21,2 \\
\hline Guarapuava & 167.328 & $3.116,31$ & 53,69 & 3 & 290 & 17,3 \\
\hline Ivatuba & 3.010 & 96,66 & 31,14 & 1 & 50 & 166,1 \\
\hline Jacarezinho & 39.121 & 602,53 & 64,93 & 1 & 80 & 20,4 \\
\hline Loanda & 21.201 & 722,50 & 29,34 & 1 & 40 & 18,9 \\
\hline Londrina & 506.701 & $1.653,26$ & 306,49 & 6 & 632 & 12,5 \\
\hline Mandaguari & 32.658 & 335,82 & 97,25 & 1 & 100 & 30,6 \\
\hline Maringá & 357.077 & 487,73 & 732,12 & 4 & 489 & 13,7 \\
\hline Paranavaí & 81.590 & $1.202,27$ & 67,86 & 2 & 106 & 13,0 \\
\hline Pato Branco & 72.370 & 539,09 & 134,24 & 1 & 100 & 13,8 \\
\hline Ponta Grossa & 311.611 & $2.067,55$ & 150,72 & 2 & 240 & 7,7 \\
\hline Toledo & 119.313 & $1.197,00$ & 99,68 & 2 & 120 & 10,1 \\
\hline Umuarama & 100.676 & $1.232,77$ & 81,67 & 1 & 67 & 6,7 \\
\hline União da Vitória & 52.735 & 720,21 & 73,22 & 1 & 100 & 19,0 \\
\hline
\end{tabular}




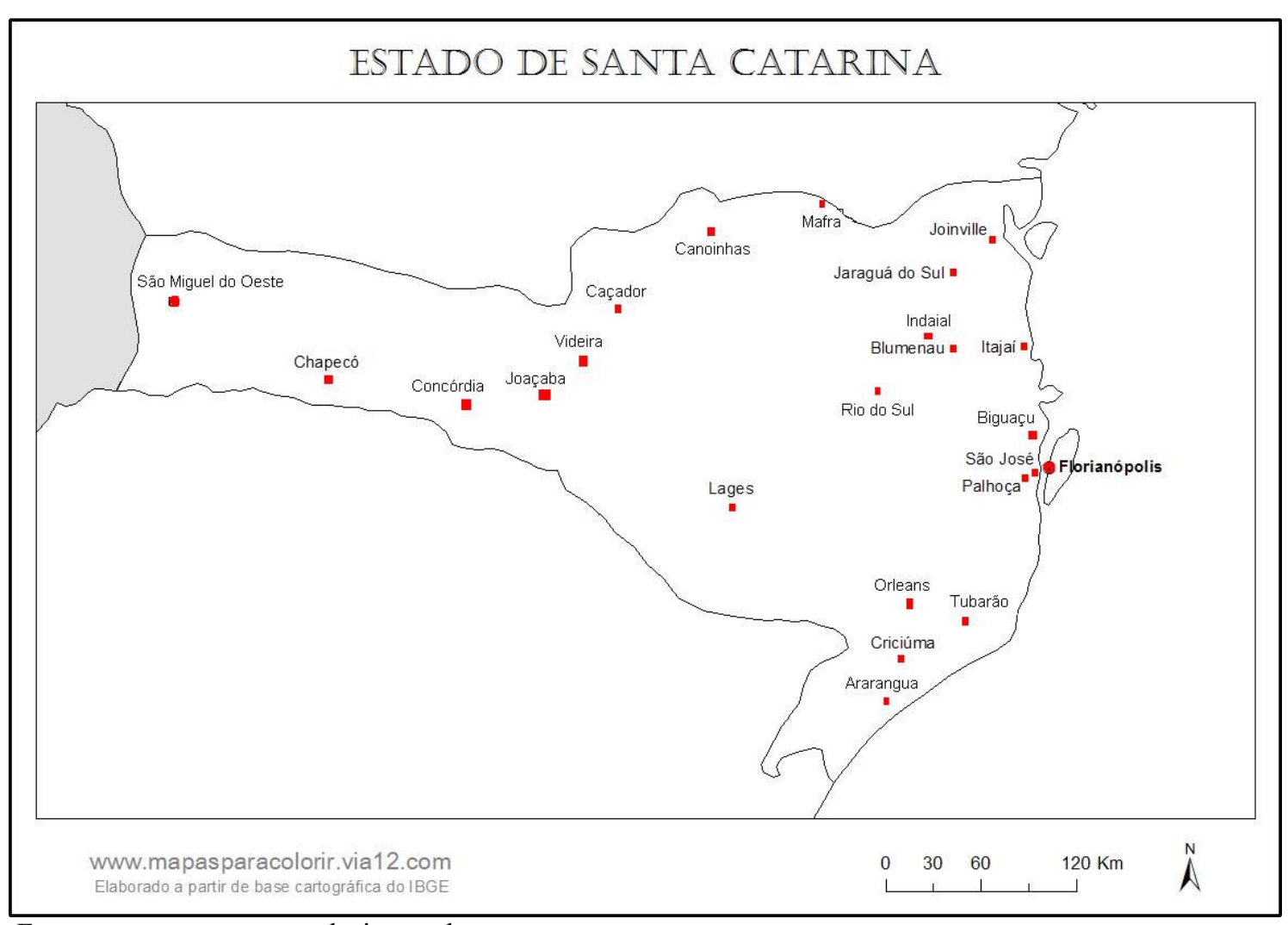

Fonte: www.mapasparacolorir.com.br

Figura 31 - Mapa do Estado de Santa Catarina e cidades com curso de bacharelado presencial em Enfermagem. Brasil, 2011.

Capital: Florianópolis

$\mathrm{N}^{\mathrm{o}}$ de municípios: 293

$\mathrm{N}^{\mathrm{o}}$ de municípios com cursos de Enfermagem: 23 (7,8\%) 
Quadro 26 - Dados sobre população, extensão territorial densidade demográfica, número de cursos de bacharelado, vagas oferecidas e número de vagas/10.000 hab. Santa Catarina, 2010.

\begin{tabular}{|c|c|c|c|c|c|c|}
\hline LOCALIDADE & População* & Extensão* & $\mathrm{hab} / \mathrm{km}^{2}$ & $\begin{array}{c}\text { № } \\
\text { cursos** } \\
\end{array}$ & $\begin{array}{l}\text { Total } \\
\text { vagas** }\end{array}$ & $\begin{array}{l}\text { № vagas } \\
\% \text { ooo hab }\end{array}$ \\
\hline SANTA CATARINA & 6.248 .436 & $95.703,49$ & 65,29 & 31 & 2250 & 3,6 \\
\hline Florianópolis & 421.240 & 671,58 & 627,24 & 2 & 135 & 3,2 \\
\hline Araranguá & 61.310 & 303,91 & 201,74 & 1 & 80 & 13,0 \\
\hline Biguaçu & 58.206 & 374,45 & 155,44 & 1 & 40 & 6,9 \\
\hline Blumenau & 309.011 & 519,84 & 594,44 & 2 & 180 & 5,8 \\
\hline Caçador & 70.762 & 981,90 & 72,07 & 1 & 50 & 7,1 \\
\hline Canoinhas & 52.765 & $1.144,84$ & 46,09 & 1 & 50 & 9,5 \\
\hline Chapecó & 183.530 & 624,30 & 293,98 & 2 & 85 & 4,6 \\
\hline Concordia & 68.621 & 797,26 & 86,07 & 1 & 40 & 5,8 \\
\hline Criciúma & 192.308 & 235,63 & 816,15 & 2 & 170 & 8,8 \\
\hline Indaial & 54.854 & 430,54 & 127,41 & 1 & 200 & 36,5 \\
\hline Itajaí & 183.373 & 289,35 & 633,75 & 1 & 110 & 6,0 \\
\hline Jaraguá do Sul & 143.123 & 532,59 & 268,73 & 1 & 80 & 5,6 \\
\hline Joaçaba & 27.020 & 232,35 & 116,29 & 1 & 40 & 14,8 \\
\hline Joinville & 515.288 & $1.146,87$ & 449,3 & 1 & 40 & 0,8 \\
\hline Lages & 156.727 & $2.629,79$ & 59,6 & 3 & 190 & 12,1 \\
\hline Mafra & 52.912 & $1.404,21$ & 37,68 & 1 & 50 & 9,4 \\
\hline Orleans & 21.393 & 549,83 & 38,91 & 1 & 50 & 23,4 \\
\hline Palhoça & 137.334 & 395 & 347,68 & 1 & 40 & 2,9 \\
\hline Rio do Sul & 61.198 & 258,40 & 236,83 & 1 & 50 & 8,2 \\
\hline São José & 209.804 & 151,14 & $1.388,17$ & 3 & 440 & 21,0 \\
\hline São Miguel do Oeste & 36.306 & 234,40 & 154,89 & 1 & 40 & 11,0 \\
\hline Tubarão & 97.235 & 300,34 & 323,76 & 1 & 50 & 5,1 \\
\hline Videira & 47.188 & 377,86 & 124,88 & 1 & 40 & 8,5 \\
\hline
\end{tabular}




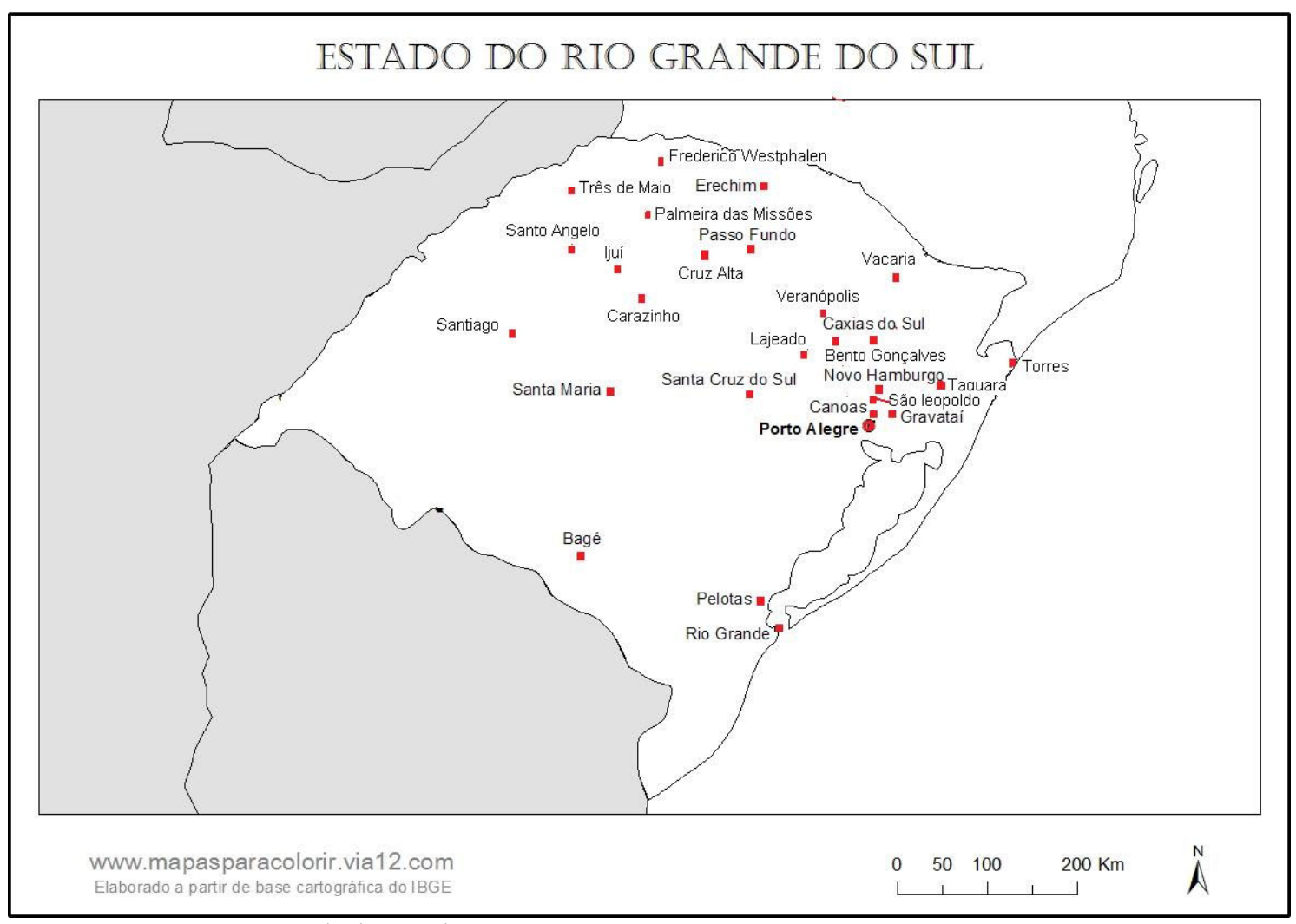

Fonte: www.mapasparacolorir.com.br

Figura 32 - Mapa do Estado do Rio Grande do Sul e cidades com curso de bacharelado presencial em Enfermagem. Brasil, 2011.

Capital: Porto Alegre

$\mathrm{N}^{\mathrm{o}}$ de municípios: 496

$\mathrm{N}^{\mathrm{o}}$ de municípios com cursos de Enfermagem: 27 (5,4\%) 
Quadro 27 - Dados sobre população, extensão territorial densidade demográfica, número de cursos de bacharelado, vagas oferecidas e número de vagas/10.000 hab. Rio Grande do Sul, 2010.

\begin{tabular}{|c|c|c|c|c|c|c|}
\hline LOCALIDADE & População* & Extensão* & $\mathrm{hab} / \mathrm{km}^{2}$ & $\begin{array}{c}\text { № } \\
\text { Cursos** } \\
\end{array}$ & $\begin{array}{c}\text { Total } \\
\text { vagas** }\end{array}$ & $\begin{array}{l}\text { № vagas } \\
\% \text { oodhab }\end{array}$ \\
\hline RIO GANDE DO SUL & 10.693 .929 & $268.781,90$ & 39,79 & 40 & 3625 & 3,4 \\
\hline Porto Alegre & 1.409 .351 & 496,68 & $2.837,52$ & 6 & 632 & 4,5 \\
\hline Bagé & 116.794 & $4.095,55$ & 28,52 & 2 & 105 & 9,0 \\
\hline Bento Gonçalves & 107.278 & 381,96 & 280,86 & 1 & 100 & 9,3 \\
\hline Canoas & 323.827 & 131,10 & $2.470,13$ & 2 & 240 & 7,4 \\
\hline Carazinho & 59.317 & 665,09 & 89,19 & 1 & 60 & 10,1 \\
\hline Caxias do Sul & 435.564 & $1.644,30$ & 264,89 & 3 & 390 & 9,0 \\
\hline Cruz Alta & 62.821 & $1.360,38$ & 46,18 & 1 & 80 & 12,7 \\
\hline Erechim & 96.087 & 430,67 & 223,11 & 1 & 50 & 5,2 \\
\hline Frederico Westphalen & 28.843 & 264,98 & 108,85 & 1 & 50 & 17,3 \\
\hline Gravataí & 255.660 & 463,50 & 551,58 & 1 & 80 & 3,1 \\
\hline ljuí & 78.915 & 689,14 & 114,51 & 1 & 40 & 5,1 \\
\hline Lajeado & 71.445 & 90,09 & 793,06 & 1 & 110 & 15,4 \\
\hline Novo Hamburgo & 238.940 & 223,82 & $1.067,54$ & 1 & 140 & 5,9 \\
\hline Palmeira das Missões & 34.328 & $1.419,44$ & 24,18 & 1 & 40 & 11,7 \\
\hline Passo Fundo & 184.826 & 783,42 & 235,92 & 1 & 80 & 4,3 \\
\hline Pelotas & 328.275 & $1.610,09$ & 203,89 & 2 & 280 & 8,5 \\
\hline Rio Grande & 197.228 & $2.709,53$ & 72,79 & 2 & 180 & 9,1 \\
\hline Santa Cruz do Sul & 118.374 & 733,412 & 161,4 & 1 & 110 & 9,3 \\
\hline Santa Maria & 261.031 & $1.788,13$ & 145,98 & 3 & 270 & 10,3 \\
\hline Santiago & 49.071 & $2.413,14$ & 20,33 & 1 & 50 & 10,2 \\
\hline Santo Ângelo & 76.275 & 680,5 & 112,09 & 1 & 50 & 6,6 \\
\hline São Leopoldo & 214.087 & 102,739 & $2.083,79$ & 1 & 148 & 6,9 \\
\hline Taquara & 54.643 & 457,86 & 119,35 & 1 & 120 & 22,0 \\
\hline Torres & 34.656 & 160,19 & 216,34 & 1 & 50 & 14,4 \\
\hline Três de Maio & 23.726 & 422,2 & 56,2 & 1 & 50 & 21,1 \\
\hline Vacaria & 61.342 & $2.123,68$ & 28,88 & 1 & 40 & 6,5 \\
\hline Veranópolis & 22.810 & 289,34 & 78,83 & 1 & 80 & 35,1 \\
\hline
\end{tabular}

Fonte:

*http://www.ibge.gov.br/home/estatistica/populacao/censo2010/resultados_preliminares/default_resul tados preliminares.shtm

**http://emec.mec.gov.br/ 


\section{Objetivo}




\section{OBJETIVO GERAL}

Analisar o ensino de enfermagem em centro cirúrgico em cursos de bacharelado de enfermagem no Brasil.

\subsection{OBJETIVOS ESPECÍFICOS}

- identificar o perfil de escolas no país que ministram o conteúdo de centro cirúrgico

- analisar o conteúdo ministrado em enfermagem em centro cirúrgico na graduação

- analisar a opinião dos docentes sobre o ensino de enfermagem em centro cirúrgico na graduação

- descrever a oferta de cursos de especialização em centro cirúrgico 
Material Método 


\section{MATERIAL E MÉTODO}

Trata-se de um estudo descritivo e exploratório de abordagem quantiqualitativa, realizado no período de agosto a dezembro de 2011.

\subsection{POPULAÇÃO DE ESTUDO}

A população de estudo constitui-se de enfermeiros coordenadores de cursos ou docentes que ministram conteúdo de enfermagem perioperatória em cursos de bacharelado em enfermagem de instituições de ensino superior brasileiras.

\subsection{INSTRUMENTO DE COLETA}

Para a coleta de dados foi elaborado um instrumento semi-estruturado com perguntas relacionadas ao ensino de enfermagem perioperatória (existência de disciplina específica ou inserção do conteúdo em outra disciplina, conteúdo ministrado, carga horária, corpo docente, importância da disciplina, oferta de cursos de especialização) (APÊNDICE 1).

Também foram coletados dados secundários obtidos do site do MEC sobre nome da IES, localização, e-mail de contato, site da escola, tipo de gestão, tipo de estabelecimento, vagas oferecidas, duração do curso, carga horária do curso e turmas oferecidas e inseridos numa planilha do excel. Nesta planilha também eram inseridas informações sobre data do envio de e-mail, data da resposta e outros contatos fornecidos da IES sobre o coordenador do curso, como nome e e-mail de contato. 


\subsection{PROCEDIMENTO DE COLETA}

No site do MEC (http://emec.mec.gov.br/) foi obtida a relação das 653 escolas cadastradas com cursos de graduação em enfermagem. De posse da lista das escolas, foi feita uma nova busca na Internet para localizar os e-mails eletrônicos das escolas e para coletar as informações para caracterizar os cursos.

Foi enviada uma carta convite (APÊNDICE II) à escola solicitando contato do Coordenador do Curso de Enfermagem por e-mail com apresentação do projeto, constando informações sobre a garantia de anonimato e que, caso respondesse ao questionário, seria entendido como aceite para a realização da pesquisa. O questionário enviado também continha as informações éticas do estudo. Foi solicitado ao coordenador do curso que remetesse o questionário ao docente responsável pelo conteúdo de enfermagem perioperatória, quando o mesmo fizesse parte do currículo de graduação.

Quando o retorno informava o nome do coordenador ou do professor responsável pelo conteúdo, se encaminhava a mesma carta convite, porém direcionando ao respectivo contato.

Após 40 dias na falta de resposta, foi tentado novamente o contato e após mais 40 dias a ausência de resposta foi entendida como não interesse em participar da pesquisa.

Para o segundo contato elaborou-se também um questionário eletrônico utilizando-se a ferramenta do Google, na tentativa de obter maior retorno de questionários. Por e-mail era enviada a carta convite e as instruções oferecendo a opção do questionário em arquivo ou eletrônico. No entanto, o retorno dos questionários eletrônicos foi pouco.

\subsection{VARIÁVEIS DE ESTUDO}

As variáveis utilizadas para caracterizar as IES foram:

- Tipo de gestão da escola: pública ou privada 
- Tipo de estabelecimento: universidade, faculdade, centro universitário instituto

- Localização do curso: município, Estado

- Região da escola: norte, sul, nordeste, sudeste ou centro oeste

- Carga horária do curso em horas

As variáveis para caracterizar o ensino de centro cirúrgico foram:

- Disciplina específica: sim ou não

- Carga horária total de CC em horas

- Carga horária teórica em horas

- Carga horária prática em horas

- Conteúdos ministrados: planejamento físico e recursos humanos em centro cirúrgico, modelo do SAEP, assistência de enfermagem nos períodos pré, trans e pós-operatório, riscos físicos, biológicos e psicológicos da equipe cirúrgica, antissepsia e degermação, posição cirúrgica, instrumentação cirúrgica, hemostasia (sutura e bisturi elétrico), anestesia, monitorização do paciente cirúrgico, recuperação anestésica, riscos e controle de infecção em centro cirúrgico, assistência ao paciente em cirurgia ambulatorial, avanços tecnológicos no centro cirúrgico: videocirurgias, robótica, laser e, outros.

- Semestre de oferecimento do conteúdo

- Ensino de campo: pergunta aberta

- Número de docentes que participam do desenvolvimento do conteúdo

- Formação dos docentes: especialista, mestre ou doutor

- Oferecimento de cursos de especialização

- Número de cursos oferecidos

- Opinião sobre o conteúdo na formação do aluno de graduação: pergunta aberta

- Opinião sobre o conteúdo para a atuação do enfermeiro no contexto hospitalar: pergunta aberta

- Comentário sobre o conteúdo dessa disciplina: pergunta aberta 


\subsection{ANÁLISE DE DADOS}

Os dados foram apresentados em gráficos, freqüências absolutas e relativas, quando possível foram feitas análises de tendência central e de variabilidade. Utilizou-se o teste de proporções para comparar características dos cursos que participaram do estudo com os existentes no país e o teste não paramétrico de Kruskall Wallis ou Mann Whitney para os testes de diferença de médias para algumas variáveis quantitativas.

Para as perguntas abertas foi feito uma análise de conteúdo utilizando o referencial de Bardin ${ }^{\mathrm{a}}$ e quando possível foi feita categorização dos temas abordados. As falas dos respondentes foram identificadas por " $R$ ", seguido da unidade da federação e o número da IES na unidade da federação.

Para análise dos dados quantitativos foram utilizados dois softwares Epinfo 3.5.1 e Statistical Package for the Social Sciences (SPSS 15.0).

\subsection{ASPECTOS ÉTICOS DA PESQUISA}

O projeto foi submetido ao Comitê de Ética em Pesquisa da Escola de Enfermagem da USP (processo $n^{\circ} 1018 / 2011$ ). Por se tratar de um levantamento de dados via internet, o projeto dispensou o Termo de Consentimento Livre e Esclarecido, pois o envio do questionário preenchido implicaria em aceite na participação desta pesquisa. Mesmo assim garantiu-se o anonimato dos informantes e das escolas participantes, bem como a liberdade de retirar sua participação a qualquer instante.

\footnotetext{
${ }^{a}$ Bardin L. Análise de conteúdo. Lisboa: Edições 70; 2007
} 
Resultados 


\section{RESULTADOS}

Foi enviado e-mail de contato contendo questionário em anexo a $825(98,1 \%)$ cursos de bacharelado em Enfermagem cadastrados no MEC, pois a resposta de 16 (1,9\%) professores foi obtida durante o Fórum sobre Ensino de Enfermagem em CC por ocasião do $10^{\circ}$ Congresso Brasileiro da Sociedade Brasileira de Enfermeiros de CC e Recuperação Anestésica, realizado em São Paulo (SP) em julho de 2011.

Somados os retornos de respostas pós envio de e-mails às diretorias das escolas e os questionários preenchidos diretamente pelo professor no dia do evento, houve uma taxa de resposta de 29,8\% (251) (Tabela 12). O teor dos e-mails relacionou-se ao fornecimento do nome do coordenador do curso de enfermagem ou informação de que o e-mail havia sido redirecionado pela própria escola ao coordenador. Alguns e-mails foram enviados pelos próprios coordenadores informando o nome do docente responsável pelo conteúdo de CC.

Obtiveram-se 166 (19,7\%) respostas sobre a inserção do conteúdo de CC na matriz curricular, com $159(18,9 \% \%)$ questionários preenchidos. Daqueles que não preencheram o questionário, seis informaram que o curso estava no início e ainda não ministraram a disciplina que contemplará o conteúdo de CC. No entanto, um deles informou que a disciplina de Enfermagem em Centro Cirúrgico e Central de Material está na matriz curricular localizada no sétimo semestre e terá duração de 80 horas. Um coordenador de curso oferecido no estado de Minas Gerais comunicou que o curso foi encerrado e, dos respondentes, apenas um coordenador de curso $(0,6 \%)$ no estado de Espírito Santo respondeu que o conteúdo de CC não é ministrado não é ministrado na graduação.

Um dos questionários foi respondido pelo coordenador geral de 23 cursos de bacharelado em enfermagem no país pertencentes à mesma instituição de ensino superior e informou que as respostas eram válidas para todos os cursos. Sendo assim cada um desses 23 cursos foi incluído na análise quantitativa dos dados, mas para a análise das respostas qualitativas, considerou-se apenas um respondente. 
Tabela 12 - Distribuição das respostas aos e-mails enviados, segundo retorno de resposta e retorno de questionário por unidade a federação. Brasil, 2011.

\begin{tabular}{|c|c|c|c|c|c|c|c|}
\hline \multirow[b]{2}{*}{ Região } & \multirow[b]{2}{*}{ Estado } & \multicolumn{2}{|c|}{ e-mails respondidos } & \multicolumn{2}{|c|}{ Quest. recebidos } & \multicolumn{2}{|c|}{ Total de cursos } \\
\hline & & $\mathrm{N}$ & \%* & $\mathrm{N}$ & \%* & $\mathrm{N}$ & $\%$ \\
\hline \multirow[t]{8}{*}{ Norte } & AC & $\overline{11}$ & 25,0 & 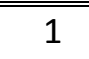 & 25,0 & 4 & 100 \\
\hline & AM & 8 & 80,0 & 3 & 30,0 & 10 & 100 \\
\hline & AP & 1 & 25,0 & 1 & 25,0 & 4 & 100 \\
\hline & PA & 8 & 50,0 & 4 & 25,0 & 16 & 100 \\
\hline & RO & 4 & 40,0 & 2 & 20,0 & 10 & 100 \\
\hline & $\mathrm{RR}$ & - & - & - & - & 3 & 100 \\
\hline & TO & 3 & 30,0 & 1 & 10,0 & 10 & 100 \\
\hline & Sub-total & 25 & 43,9 & 12 & 21,1 & 57 & 100 \\
\hline \multirow{10}{*}{ Nordeste } & $\mathrm{AL}$ & 2 & 18,2 & 1 & 9,1 & 11 & 100 \\
\hline & BA & 18 & 33,3 & 6 & 11,1 & 54 & 100 \\
\hline & $\mathrm{CE}$ & 6 & 31,6 & 2 & 10,5 & 19 & 100 \\
\hline & MA & 2 & 8,0 & 1 & 4,0 & 25 & 100 \\
\hline & PB & 7 & 38,9 & 5 & 27,8 & 18 & 100 \\
\hline & $\mathrm{PE}$ & 3 & 12,5 & 1 & 4,2 & 24 & 100 \\
\hline & $\mathrm{PI}$ & 4 & 19,1 & 4 & 19,1 & 21 & 100 \\
\hline & RN & 2 & 14,3 & - & - & 14 & 100 \\
\hline & SE & 2 & 40,0 & - & - & 5 & 100 \\
\hline & Sub-total & 46 & 24,1 & 20 & 10,5 & 191 & 100 \\
\hline \multirow[t]{5}{*}{ Centro-oeste } & DF & 8 & 47,1 & 7 & 41,2 & 17 & 100 \\
\hline & GO & 13 & 37,1 & 8 & 22,9 & 35 & 100 \\
\hline & MS & 3 & 21,4 & 2 & 14,3 & 14 & 100 \\
\hline & MT & 6 & 28,6 & 2 & 9,5 & 21 & 100 \\
\hline & Sub-total & 29 & 33,3 & 19 & 21,8 & 87 & 100 \\
\hline \multirow[t]{5}{*}{ Sudeste } & ES & 6 & 35,3 & 2 & 11,8 & 17 & 100 \\
\hline & MG & 29 & 23,4 & 17 & 13,7 & 124 & 100 \\
\hline & RJ & 20 & 36,4 & 11 & 20,0 & 55 & 100 \\
\hline & SP & 59 & 32,6 & 52 & 28,7 & 181 & 100 \\
\hline & Sub-total & 114 & 30,2 & 82 & 21,8 & 377 & $\begin{array}{l}100 \\
\text { cont }\end{array}$ \\
\hline
\end{tabular}




\begin{tabular}{|c|c|c|c|c|c|c|c|}
\hline \multirow{2}{*}{$\begin{array}{l}\text { Cont. } \\
\text { Região }\end{array}$} & \multirow[b]{2}{*}{ Estado } & \multicolumn{2}{|c|}{ e-mails respondidos } & \multicolumn{2}{|c|}{ Quest. recebidos } & \multicolumn{2}{|c|}{ Total de cursos } \\
\hline & & $\mathrm{N}$ & \%* & $\mathrm{N}$ & $\% *$ & $\mathrm{~N}$ & $\%$ \\
\hline \multirow[t]{4}{*}{ Sul } & PR & 17 & 29,3 & 12 & 20,7 & 58 & 100 \\
\hline & RS & 12 & 30,0 & 11 & 27,5 & 40 & 100 \\
\hline & SC & 8 & 25,8 & 4 & 12,9 & 31 & 100 \\
\hline & Sub-total & 36 & 27,9 & 26 & 20,2 & 129 & 100 \\
\hline Total & & 251 & 29,8 & 159 & 18,9 & 841 & 100 \\
\hline
\end{tabular}

Comparando-se as regiões, a $\mathrm{N}$ foi aquela com a maior percentagem de resposta $(43,9 \% ; n=25)$ e a NE a menor $(24,1 \% ; n=46)$. Para todas as regiões as taxas de preenchimento do questionário oscilaram em torno de $20 \%$, com exceção na região NE em que a taxa foi de 10,5\% (20). As unidades da federação com maior taxa de preenchimento de questionários foram Distrito Federal $(\mathrm{n}=7 ; 41,2 \%)$, Amazonas ( $n=3 ; 30,0 \%)$, São Paulo $(n=52 ; 28,7 \%)$, Paraíba $(n=5 ; 27,8 \%)$ e Rio Grande do Sul (n=11;27,5\%).

A tabela 13 apresenta um comparativo das vagas oferecidas por todos os cursos de bacharelado em enfermagem do país por unidade da federação e daquelas relativas aos cursos que possuem o conteúdo de $\mathrm{CC}$ na matriz curricular. Segundo as vagas oferecidas por período, observou-se uma proporcionalidade semelhante entre os cursos que participaram do estudo e a totalidade dos cursos. $\mathrm{Na}$ análise por região do país, verificou-se que o fato se repete salvo algumas exceções, como na região NE e $\mathrm{S}$ em que as diferenças ocorreram no período integral e noturno. 
Tabela 13 - Distribuição de vagas por período dos cursos de enfermagem e dos que ministram o conteúdo de CC por unidade da federação. Brasil, 2011.

\begin{tabular}{|c|c|c|c|c|c|c|c|c|c|c|c|c|c|}
\hline \multirow[b]{3}{*}{ Região } & \multirow[b]{3}{*}{ Estado } & & & \multicolumn{10}{|c|}{ Vagas $\left(^{*}\right)$} \\
\hline & & \multicolumn{2}{|c|}{ Cursos $\left({ }^{*}\right)$} & \multicolumn{2}{|c|}{ Integral } & \multicolumn{2}{|c|}{ Manhã } & \multicolumn{2}{|c|}{ Tarde } & \multicolumn{2}{|c|}{ Noite } & \multicolumn{2}{|c|}{ Total } \\
\hline & & $\mathrm{N}$ & $\%$ & $\mathrm{~N}$ & $\%$ & $\mathrm{~N}$ & $\%$ & $\mathrm{~N}$ & $\%$ & $\mathrm{~N}$ & $\%$ & $\mathrm{~N}$ & $\%$ \\
\hline \multirow[t]{14}{*}{ Norte } & \multirow[t]{2}{*}{ AC } & 4 & 100 & 60 & $\begin{array}{l}19,3 \\
\end{array}$ & 100 & 32,3 & - & - & 150 & 48,4 & 310 & 100 \\
\hline & & $(1)$ & $(25,0)$ & $(-)$ & $(-)$ & $(100)$ & $(50,0)$ & $(-)$ & $(-)$ & $(100)$ & $(50,0)$ & $(200)$ & (100) \\
\hline & \multirow[t]{2}{*}{ AM } & 10 & 100 & 204 & 10,9 & 580 & 30,9 & 330 & 17,6 & 760 & 40,6 & 1874 & 100 \\
\hline & & $(4)$ & $(40,0)$ & $(-)$ & $(-)$ & $(380)$ & $(40,0)$ & (150) & $(15,8)$ & $(420)$ & $(44,2)$ & $(950)$ & (100) \\
\hline & \multirow[t]{2}{*}{$\mathrm{AP}$} & 4 & 100 & 50 & 11,1 & 250 & 55,6 & - & - & 150 & 33,3 & 450 & 100 \\
\hline & & $(1)$ & $(25,0)$ & $(-)$ & $(-)$ & $(100)$ & $(-)$ & $(-)$ & $(-)$ & $(-)$ & $(100)$ & $(200)$ & (100) \\
\hline & \multirow[t]{2}{*}{ PA } & 16 & 100 & 206 & 10,7 & 480 & 24,9 & 420 & 21,8 & 820 & 42,6 & 1926 & 100 \\
\hline & & $(5)$ & $(31,3)$ & (180) & $(37,5)$ & $(150)$ & $(31,3)$ & $(100)$ & $(20,8)$ & (50) & $(10,4)$ & $(480)$ & $(100)$ \\
\hline & \multirow[t]{2}{*}{ Ro } & 10 & 100 & 130 & 12,5 & 475 & 45,7 & 130 & 12,5 & 305 & 29,3 & 1040 & 100 \\
\hline & & $(2)$ & $(20,0)$ & $(-)$ & $(-)$ & $(250)$ & $(100)$ & $(-)$ & $(-)$ & $(-)$ & $(-)$ & $(250)$ & (100) \\
\hline & \multirow[t]{2}{*}{$\mathrm{RR}$} & 3 & 100 & 32 & 8,6 & 140 & 37,6 & 100 & 26,9 & 100 & 26,9 & 372 & 100 \\
\hline & & $(-)$ & $(-)$ & $(-)$ & $(-)$ & $(-)$ & $(-)$ & $(-)$ & $(-)$ & $(-)$ & $(-)$ & $(-)$ & $(-)$ \\
\hline & \multirow[t]{2}{*}{ TO } & 10 & 100 & 660 & 67,4 & 220 & 22,4 & - & - & 100 & 10,2 & 980 & 100 \\
\hline & & $(2)$ & $(20,0)$ & (80) & $(44,4)$ & $(100)$ & $(55,6)$ & $(-)$ & $(-)$ & $(-)$ & $(-)$ & (180) & $(100)$ \\
\hline \multirow{2}{*}{\multicolumn{2}{|c|}{ Sub-total }} & 57 & 100 & 1342 & 19,3 & 2245 & 32,3 & 980 & 14,1 & 2385 & 34,3 & 6952 & 100 \\
\hline & & (15) & $(26,3)$ & $(260)$ & $(11,5)$ & (1080) & $(47,8)$ & $(250)$ & $(11,1)$ & $(670)$ & $(29,6)$ & (2260) & (100) \\
\hline \multirow[t]{6}{*}{ Nordeste } & \multirow[t]{2}{*}{$\mathrm{AL}$} & 11 & 100 & 100 & 6,8 & 770 & 52,4 & 230 & 15,6 & 370 & 25,2 & 1470 & 100 \\
\hline & & $(1)$ & $(9,1)$ & (60) & (100) & $(-)$ & $(-)$ & $(-)$ & $(-)$ & $(-)$ & $(-)$ & (60) & (100) \\
\hline & \multirow[t]{2}{*}{$\mathrm{BA}$} & 54 & 100 & 910 & 10,7 & 3985 & 47,1 & 985 & 11,6 & 2590 & 30,6 & 8470 & 100 \\
\hline & & $(6)$ & $(11,1)$ & $(200)$ & $(35,1)$ & $(210)$ & $(36,8)$ & $(-)$ & $(-)$ & $(160)$ & $(28,1)$ & $(570)$ & (100) \\
\hline & \multirow[t]{2}{*}{ CE } & 19 & 100 & 320 & 14,0 & 890 & 38,8 & 560 & 24,4 & 522 & 22,8 & 2292 & 100 \\
\hline & & $(4)$ & $(21,1)$ & $(-)$ & $(-)$ & $(250)$ & $(43,7)$ & $(250)$ & $(43,7)$ & (72) & $(12,6)$ & $(572)$ & (100) cont. \\
\hline
\end{tabular}




\begin{tabular}{|c|c|c|c|c|c|c|c|c|c|c|c|c|c|}
\hline \multirow[b]{3}{*}{ Região } & \multirow[b]{3}{*}{ Estado } & & & \multicolumn{10}{|c|}{ Vagas $\left({ }^{*}\right)$} \\
\hline & & \multicolumn{2}{|c|}{ Cursos $\left({ }^{*}\right)$} & \multicolumn{2}{|c|}{ Integral } & \multicolumn{2}{|c|}{ "Manhã } & \multicolumn{2}{|c|}{ Tarde } & \multicolumn{2}{|c|}{ Noite } & \multicolumn{2}{|c|}{ Total } \\
\hline & & $\mathrm{N}$ & $\%$ & $\mathrm{~N}$ & $\%$ & $\mathrm{~N}$ & $\%$ & $\mathrm{~N}$ & $\%$ & $\mathrm{~N}$ & $\%$ & $\mathrm{~N}$ & $\%$ \\
\hline & \multirow[t]{2}{*}{$\overline{\mathrm{MA}}$} & 25 & 100 & 300 & $\begin{array}{l}11,0 \\
\end{array}$ & 11190 & $\overline{443,8}$ & 560 & 20,6 & 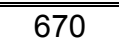 & 24,6 & 2720 & 100 \\
\hline & & $(1)$ & $(4,0)$ & $(100)$ & $(100)$ & $(-)$ & $(-)$ & $(-)$ & $(-)$ & $(-)$ & $(-)$ & $(100)$ & (100) \\
\hline & \multirow[t]{2}{*}{ PB } & 18 & 100 & 360 & 12,9 & 1550 & 55,8 & 270 & 9,7 & 600 & 21,6 & 2780 & 100 \\
\hline & & $(5)$ & $(27,8)$ & (270) & $(31,0)$ & $(500)$ & $(57,5)$ & $(-)$ & $(-)$ & (100) & $(11,5)$ & $(870)$ & (100) \\
\hline & \multirow[t]{2}{*}{ PE } & 24 & 100 & 535 & 16,5 & 1005 & 31,0 & 450 & 13,9 & 1255 & 38,6 & 3245 & 100 \\
\hline & & $(1)$ & $(4,2)$ & $(-)$ & $(-)$ & $(-)$ & $(-)$ & $(100)$ & $(100)$ & $(-)$ & $(-)$ & $(100)$ & $(100)$ \\
\hline & \multirow[t]{2}{*}{$\mathrm{PI}$} & 21 & 100 & 460 & 21,6 & 758 & 35,6 & 462 & 21,7 & 450 & 21,1 & 2130 & 100 \\
\hline & & $(4)$ & $(19,1)$ & $(360)$ & $(100)$ & $(-)$ & $(-)$ & $(-)$ & $(-)$ & $(-)$ & $(-)$ & $(360)$ & (100) \\
\hline & \multirow[t]{2}{*}{ RN } & 14 & 100 & 140 & 5,7 & 984 & 39,9 & 310 & 12,6 & 1030 & 41,8 & 2464 & 100 \\
\hline & & $(-)$ & $(-)$ & $(-)$ & $(-)$ & $(-)$ & $(-)$ & $(-)$ & $(-)$ & $(-)$ & $(-)$ & $(-)$ & $(-)$ \\
\hline & \multirow[t]{2}{*}{ SE } & 5 & 100 & - & - & 450 & 43,7 & 80 & 7,8 & 500 & 48,5 & 1030 & 100 \\
\hline & & $(-)$ & $(-)$ & $(-)$ & $(-)$ & $(-)$ & $(-)$ & $(-)$ & $(-)$ & $(-)$ & $(-)$ & $(-)$ & $(-)$ \\
\hline \multirow{2}{*}{\multicolumn{2}{|c|}{ Sub-total }} & 191 & 100 & 3125 & 11,7 & 11582 & 43,5 & 3907 & 14,7 & 7987 & 30,1 & 26601 & 100 \\
\hline & & (22) & $(11,5)$ & (990) & $(37,6)$ & (960) & $(36,5)$ & $(350)$ & $(13,3)$ & (332) & $(12,6)$ & (2632) & (100) \\
\hline \multirow{8}{*}{$\begin{array}{l}\text { Centro- } \\
\text { Oeste }\end{array}$} & \multirow[t]{2}{*}{ DF } & 17 & 100 & 170 & 4,9 & 1550 & 44,7 & 255 & 7,4 & 1490 & 43,0 & 3465 & 100 \\
\hline & & $(7)$ & $(41,2)$ & (90) & $(6,4)$ & $(550)$ & $(39,3)$ & $(230)$ & $(16,4)$ & (530) & $(37,9)$ & (1400) & (100) \\
\hline & \multirow[t]{2}{*}{ GO } & 35 & 100 & 840 & 19,4 & 1645 & 38,1 & - & - & 1837 & 42,5 & 4322 & 100 \\
\hline & & $(8)$ & $(22,9)$ & $(210)$ & $(10,8)$ & (860) & $(44,6)$ & $(-)$ & $(-)$ & (860) & $(44,6)$ & (1930) & (100) \\
\hline & \multirow[t]{2}{*}{ MS } & 14 & 100 & 500 & 28,9 & 255 & 14,7 & 80 & 4,6 & 895 & 51,8 & 1730 & 100 \\
\hline & & $(2)$ & $(14,3)$ & $(40)$ & $(33,3)$ & $(-)$ & $(-)$ & $(-)$ & $(-)$ & (80) & $(66,7)$ & $(120)$ & (100) \\
\hline & \multirow[t]{2}{*}{ MT } & 21 & 100 & 430 & 19,5 & 735 & 33,3 & 250 & 11,2 & 795 & 36,0 & 2210 & 100 \\
\hline & & $(2)$ & $(9,5)$ & (80) & $(44,4)$ & $(-)$ & $(-)$ & $(-)$ & $(-)$ & (100) & $(55,6)$ & $(180)$ & (100) \\
\hline \multirow{2}{*}{\multicolumn{2}{|c|}{ Sub-total }} & 87 & 100 & 1940 & 16,5 & 4185 & 35,7 & 585 & 5,0 & 5017 & 42,8 & 11727 & 100 \\
\hline & & (19) & $(21,8)$ & $(420)$ & $(11,6)$ & (1410) & $(38,8)$ & $(230)$ & $(6,3)$ & $(1570)$ & $(43,3)$ & $(3630)$ & (100) cont. \\
\hline
\end{tabular}




\begin{tabular}{|c|c|c|c|c|c|c|c|c|c|c|c|c|c|}
\hline \multirow[b]{3}{*}{ Região } & \multirow[b]{3}{*}{ Estado } & & & \multicolumn{10}{|c|}{ Vagas $\left({ }^{*}\right)$} \\
\hline & & \multicolumn{2}{|c|}{ Cursos $\left({ }^{*}\right)$} & \multicolumn{2}{|c|}{ Integral } & \multicolumn{2}{|c|}{ Manhã } & \multicolumn{2}{|c|}{ Tarde } & \multicolumn{2}{|c|}{ Noite } & \multicolumn{2}{|c|}{ Total } \\
\hline & & $\mathrm{N}$ & $\%$ & $\mathrm{~N}$ & $\%$ & $\mathrm{~N}$ & $\%$ & $\mathrm{~N}$ & $\%$ & $\mathrm{~N}$ & $\%$ & $\mathrm{~N}$ & $\%$ \\
\hline \multirow[t]{8}{*}{ Sudeste } & \multirow[t]{2}{*}{ ES } & 17 & 100 & 230 & $\bar{~} 13,7$ & 950 & $\bar{~} 56,5$ & - & - & 500 & 29,8 & 1680 & 100 \\
\hline & & (2) & $(11,8)$ & - & - & (80) & $(61,5)$ & - & - & (50) & $(38,5)$ & (130) & (100) \\
\hline & \multirow[t]{2}{*}{ MG } & 124 & 100 & 1614 & 10,2 & 5121 & 32,4 & 785 & 5,0 & 8291 & 52,4 & 15811 & 100 \\
\hline & & (18) & $(14,5)$ & (220) & $(12,0)$ & (796) & $(43,5)$ & $(100)$ & $(5,3)$ & (720) & $(39,2)$ & (1836) & (100) \\
\hline & \multirow[t]{2}{*}{ RJ } & 55 & 100 & 714 & 6,2 & 4590 & 39,8 & 910 & 7,9 & 5322 & 46,1 & 11536 & 100 \\
\hline & & (12) & $(21,8)$ & (384) & $(15,8)$ & (880) & $(36,3)$ & (80) & $(3,3)$ & (1080) & $(44,6)$ & (2424) & (100) \\
\hline & \multirow[t]{2}{*}{ SP } & $181^{* *}$ & 100 & 768 & 2,0 & 15415 & 39,8 & 1400 & 3,5 & 21195 & 54,7 & 38778 & 100 \\
\hline & & (52) & $(28,7)$ & $(240)$ & $(1,8)$ & (5523) & $(40,6)$ & $(360)$ & $(2,6)$ & (7473) & $(55,0)$ & (13596) & (100) \\
\hline \multirow{2}{*}{\multicolumn{2}{|c|}{ Subtotal }} & 377 & 100 & 3326 & 4,9 & 26076 & 38,5 & 3095 & 4,6 & 35308 & 52,0 & 67805 & 100 \\
\hline & & (84) & $(22,3)$ & (844) & $(4,7)$ & (7279) & $(40,5)$ & $(540)$ & $(3,0)$ & (9323) & $(51,8)$ & (17986) & (100) \\
\hline \multirow[t]{6}{*}{ Sul } & \multirow[t]{2}{*}{ PR } & 58 & 100 & 579 & 9,3 & 2305 & 37,1 & 50 & 0,8 & 3282 & 52,8 & 6216 & 100 \\
\hline & & (11) & $(19,0)$ & (244) & $(20,9)$ & (370) & $(31,8)$ & - & - & (551) & $(47,3)$ & (1165) & (100) \\
\hline & \multirow[t]{2}{*}{ RS } & 40 & 100 & 1135 & 31,3 & 705 & 19,4 & 495 & 13,7 & 1290 & 35,6 & 3625 & 100 \\
\hline & & (11) & $(27,5)$ & $(540)$ & $(54,6)$ & (200) & $(20,2)$ & $(140)$ & $(14,1)$ & (110) & $(11,1)$ & (990) & (100) \\
\hline & \multirow[t]{2}{*}{ SC } & 31 & 100 & 445 & 19,8 & 475 & 21,1 & 150 & 6,7 & 1180 & 52,4 & 2250 & 100 \\
\hline & & (4) & $(12,9)$ & $(225)$ & $(81,8)$ & - & - & - & - & (50) & $(18,2)$ & 275 & (100) \\
\hline \multirow{2}{*}{\multicolumn{2}{|c|}{ Sub-total }} & 129 & 100 & 2159 & 17,9 & 3485 & 28,8 & 695 & 5,7 & 5752 & 47,6 & 12091 & 100 \\
\hline & & $(26)$ & $(20,2)$ & (1009) & $(41,5)$ & $(570)$ & $(23,4)$ & $(140)$ & $(5,8)$ & (711) & $(29,3)$ & (2430) & (100) \\
\hline \multirow{2}{*}{\multicolumn{2}{|c|}{ Total }} & 841 & 100 & 11892 & 9,5 & 47573 & 38,0 & 9262 & 7,4 & 56449 & 45,1 & 125176 & 100 \\
\hline & & (165) & $(19,6)$ & (3523) & $(12,2)$ & (11299) & $(39,0)$ & (1510) & $(5,2)$ & (12606) & $(43,6)$ & (28938) & (100) \\
\hline
\end{tabular}

$\left(^{*}\right)$ dados relativos aos cursos com questionários preenchidos $\quad * *$ sem informação no MEC sobre as vagas, contabilizado como zero 


\subsection{CARACTERÍSTICAS DOS CURSOS QUE PREENCHERAM O QUESTIONÁRIO}

Em relação ao total de cursos de cada região, a participação de cursos que preencheram o questionário foi semelhante entre as regiões, em torno de $20,0 \%$ dos cursos, com exceção da região NE onde a participação foi menor (10,5\%) (Figura33).

$\square$ Preencheram o questionário $\quad \square$ Não preencheram o questionário

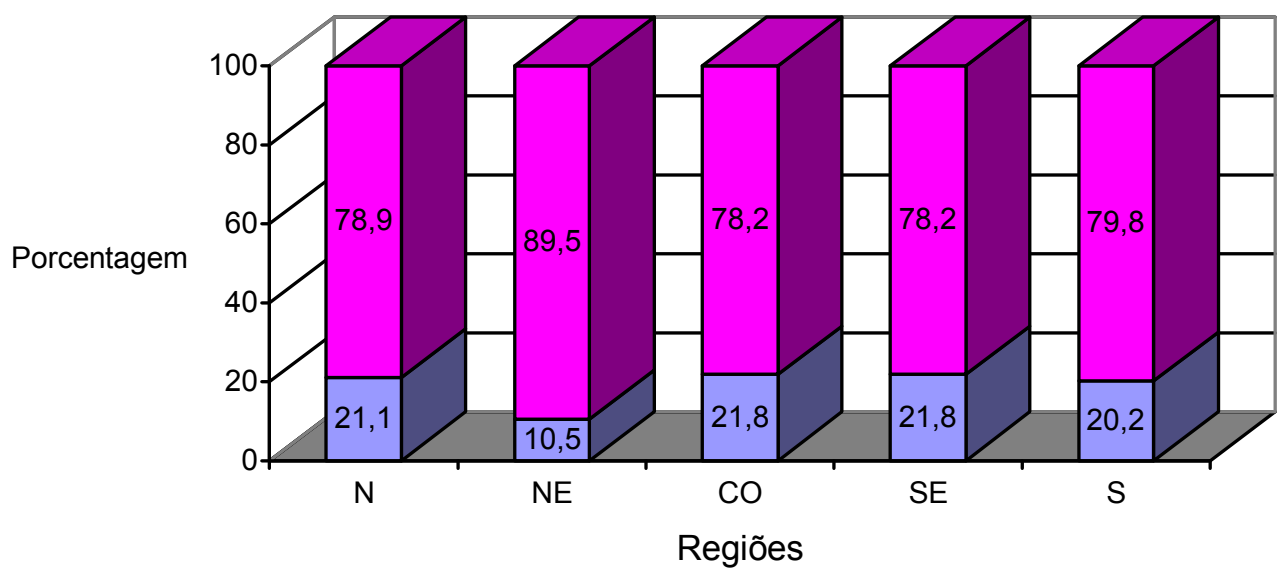

Figura 33 - Proporção de cursos com participação no estudo segundo região do país. Brasil, 2011

Com relação à localização das escolas observou-se que 108 (67,9\%) delas se localizam no interior do estado e $51(32,1 \%)$ nas capitais (Figura 34). Na análise por região, a situação se inverte no $\mathrm{N}$, enquanto que no $\mathrm{CO}$ e $\mathrm{NE}$ a proporção de escolas no interior e na capital são quase semelhantes. A análise comparativa das proporções na amostra e na população não apresentou diferença estatística significativa $(p>0,05)$. 
Ruth Natalia Teresa Turrini

$\square$ Capitais $\quad$ Interior

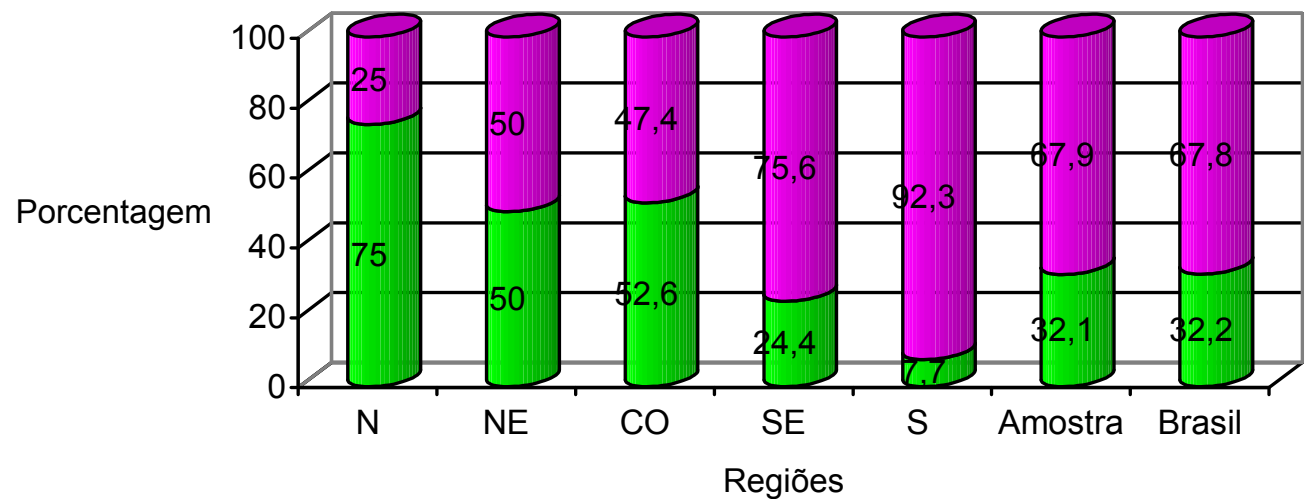

Figura 34 - Proporção de cursos segundo a localização da escola por regiões, na amostra e no país. Brasil, 2011.

Das 159 escolas que preencheram o questionário, 37 (23,3\%) eram de gestão pública e $122(76,7 \%)$ de administração privada. Ao se compararem as regiões, no N e NE houve proporcionalmente maior participação de escolas de gestão pública (Figura 35). Análise comparativa da amostra com a população brasileira mostrou que as proporções entre cursos públicos e privados foi estatisticamente diferente $(\mathrm{P}<0,05)$, pela maior participação de escolas públicas no $\mathrm{N}$ e NE.

$\square$ Público 口Privado

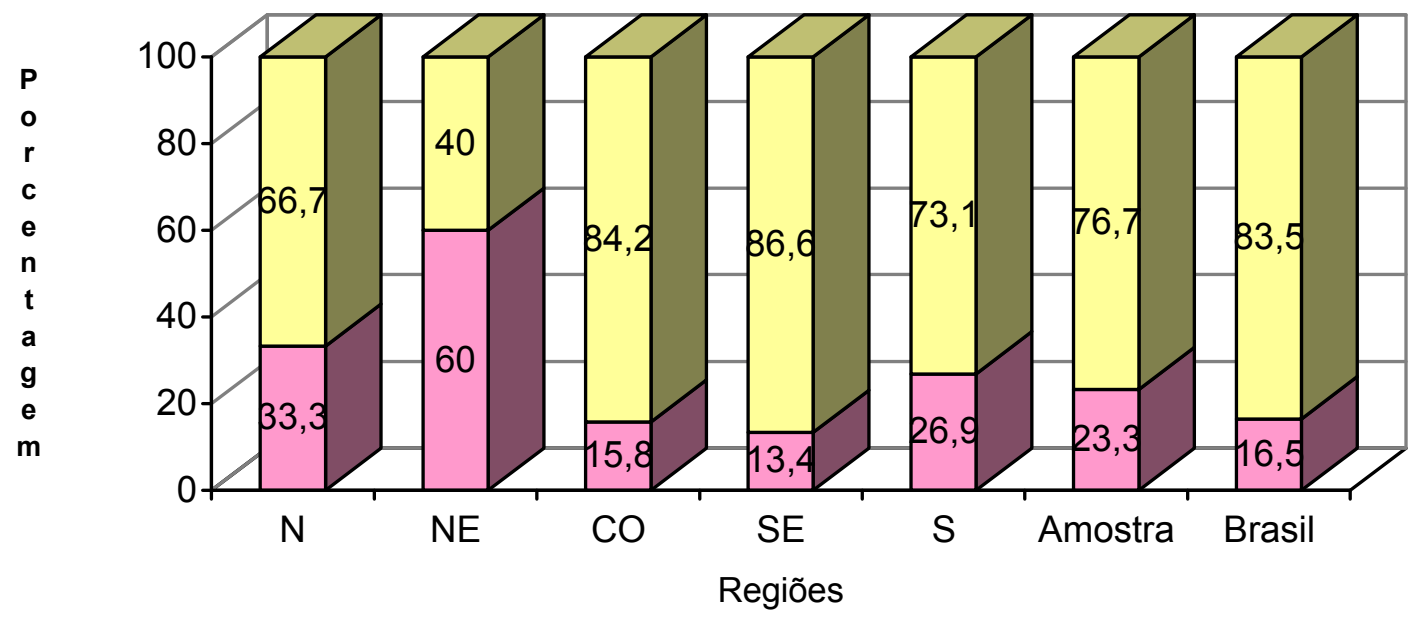

Figura 35 - Proporção de cursos que preencheram o questionário segundo a região e a entidade mantenedora. Brasil, 2011. 
Ruth Natalia Teresa Turrini

Quanto ao quantitativo de vagas, a amostra por região do país apresentou cursos que ofereciam vagas nos diferentes períodos (Figura 36), embora com uma distribuição diferente entre as regiões. A principal diferença foi observada na região $\mathrm{NE}, \mathrm{CO}$ e $\mathrm{S}$ que apresentaram maior proporção de vagas de período integral. A região SE apresenta maior número de vagas no período noturno e a $\mathrm{CO}$ no período da tarde. Quando se compara a distribuição de vagas por período na amostra e no Brasil, observa-se uma distribuição semelhante de vagas nos diferentes períodos $(\mathrm{p}>0,05)$.

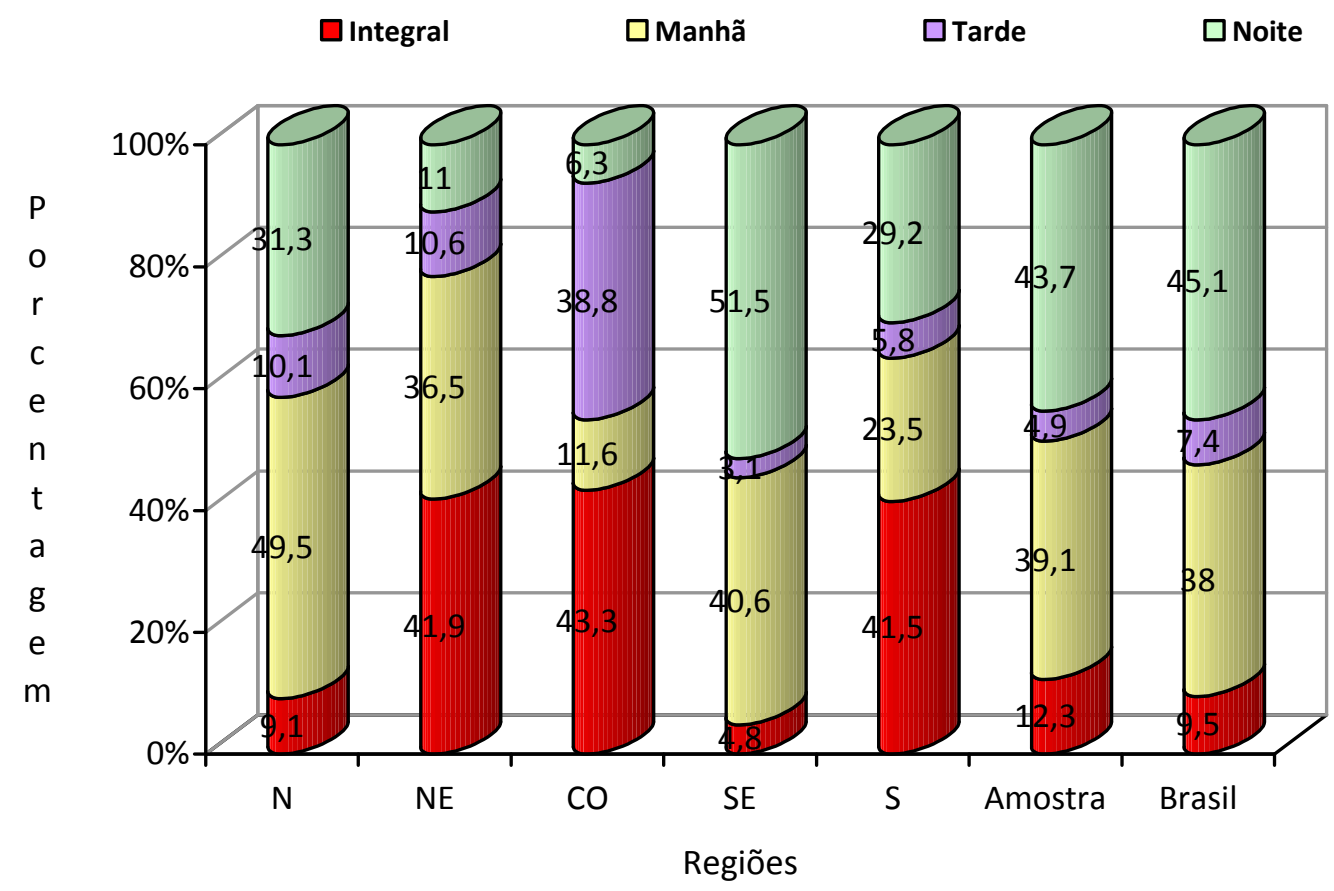

Figura 36 - Proporção de vagas dos cursos que preencheram o questionário por região por período e no país. Brasil, 2011.

A carga horária dos cursos de bacharelado no país varia de 3500 a 5850 horas. De modo geral, houve participação no estudo de pelo menos um curso em cada faixa de carga horária (variação de 1 a 62) (Figura 37). Com exceção da região $\mathrm{N}$ e $\mathrm{CO}$, houve representação na amostra de cursos com mais de 5500 horas. Cabe ressaltar, que na região $\mathrm{CO}$ não há cursos de enfermagem $\geq 5000 \mathrm{hs}$ e na região $\mathrm{N}$ acima de 5300hs. 
Entre os cursos incluídos no estudo, 23 (14,5\%) ainda tem uma carga horária inferior a 4000h, segundo dados obtidos do site do MEC, sendo 12 na região SE, cinco na região $\mathrm{S}, 4$ no $\mathrm{NE}$ e 2 no $\mathrm{N}$.

Ao se comparar as proporções para cada faixa de carga horária dos cursos entre a amostra e todos os cursos do país, observou-se uma diferença estatística $(\mathrm{p}<0,05)$ para todas as faixas, com exceção das faixas de 3501 a 4000 horas e de 4001 a 4500 horas $(\mathrm{P}>0,05)$
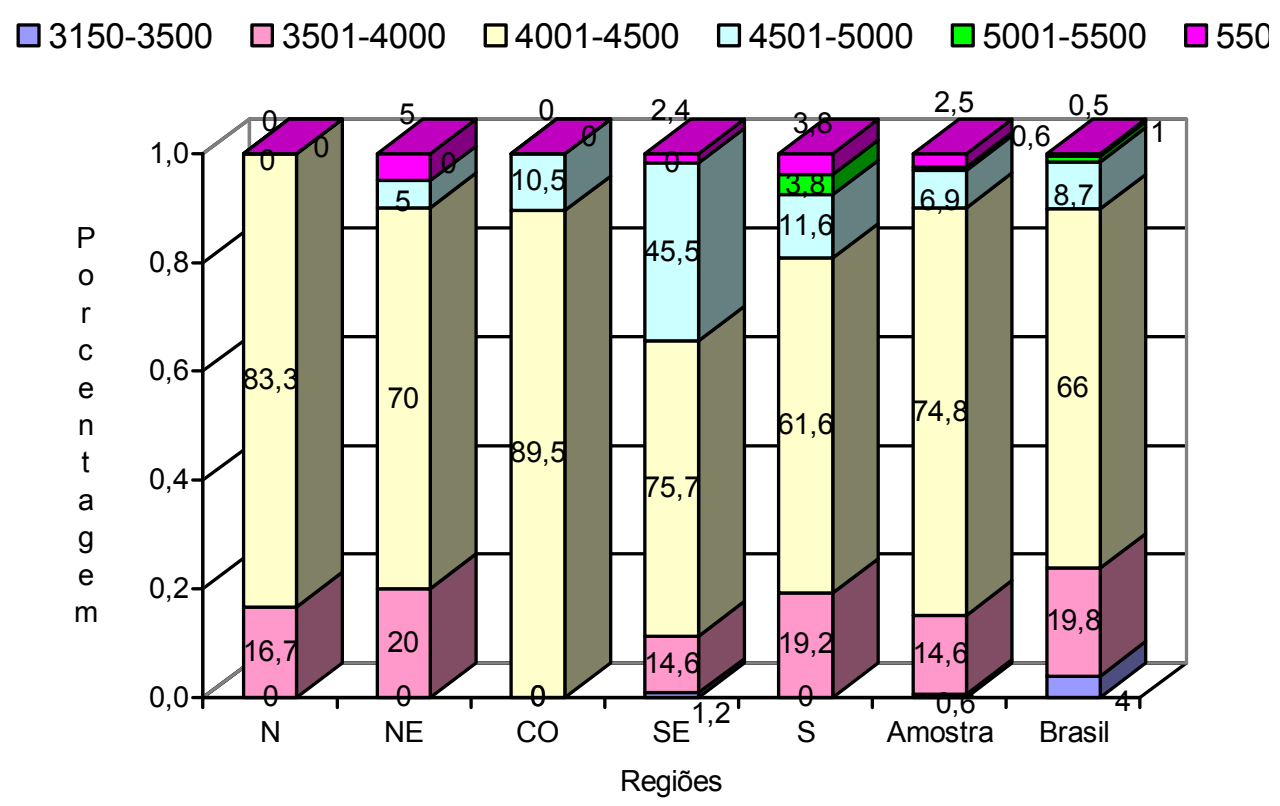

Figura 37 - Distribuição de cursos por regiões e carga horária no país. Brasil, 2011.

Os poucos cursos com carga horária acima de 5000 horas $(2,2 \%)$ são oferecidos em período integral ou matinal (1,3\%) (Figura 38), da mesma maneira aqueles com carga horária inferior a $3500 \mathrm{hs}(2,2 \%)$. 


\section{$\square 3150-3500 \square 3501-4000 \quad \square 4001-4500 \quad \square 4501-5000 \quad \square 5001-5500 \quad \square 5501-5 \varepsilon$}

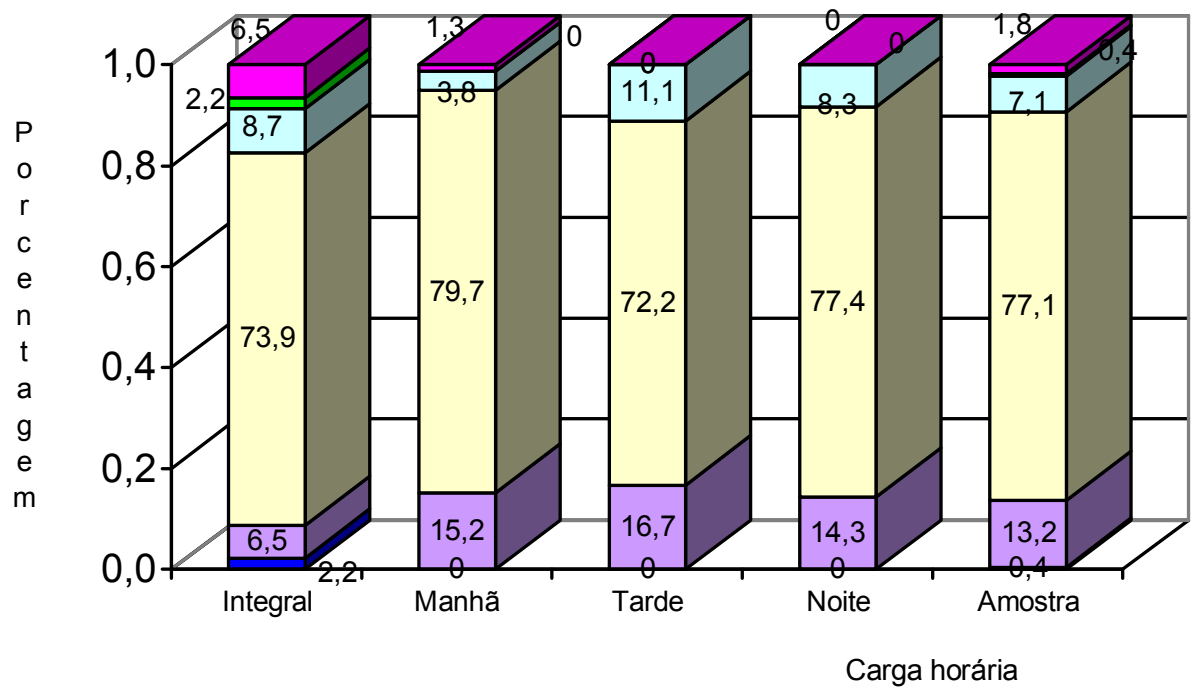

Figura 38 - Proporção de cursos segundo o período e carga horária. Brasil, 2011.

A figura 39 apresenta a distribuição dos cursos segundo sua duração. Verificou-se que a maioria dos cursos é ministrada em oito ou dez semestres em proporções semelhantes.

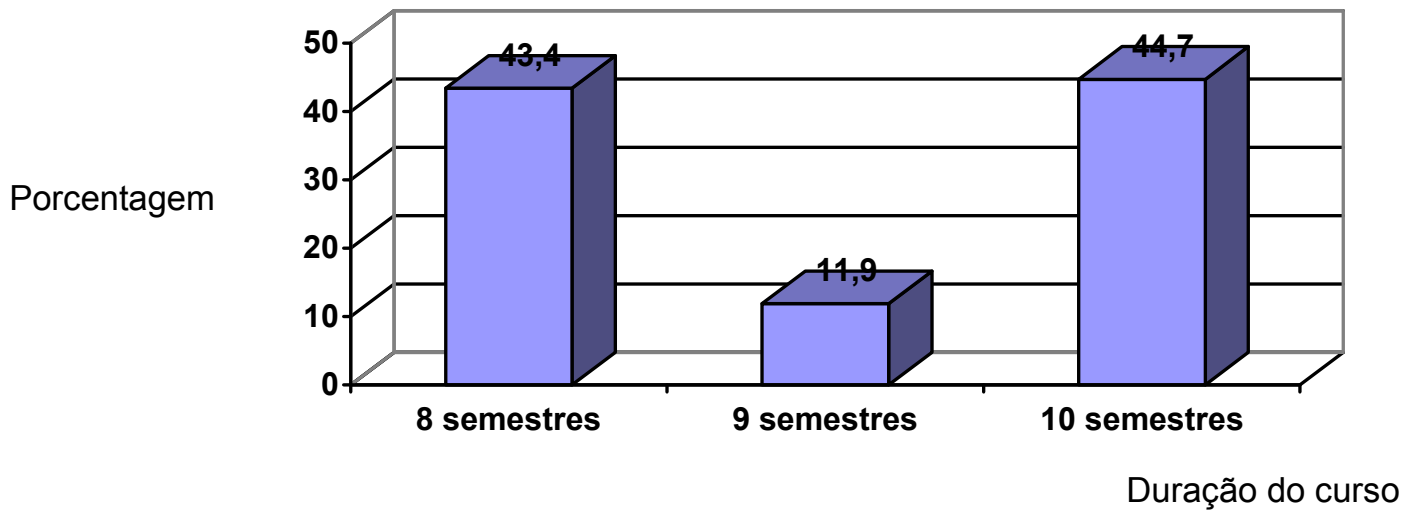

Figura 39 - Proporção de cursos segundo a duração em semestres. Brasil, 2011. 


\subsection{CARACTERÍSTICAS DO CONTEÚDO DE CC}

Dos 159 cursos que preencheram os questionários, 147 (92,6\%) informaram a carga horária total de $\mathrm{CC}$, com uma média de $94,7 \mathrm{~h}(\mathrm{DP} \pm 80 \mathrm{~h})$, mediana de $80 \mathrm{~h}$ (5 330) e uma variação interquartil de 60h (Figura 40).

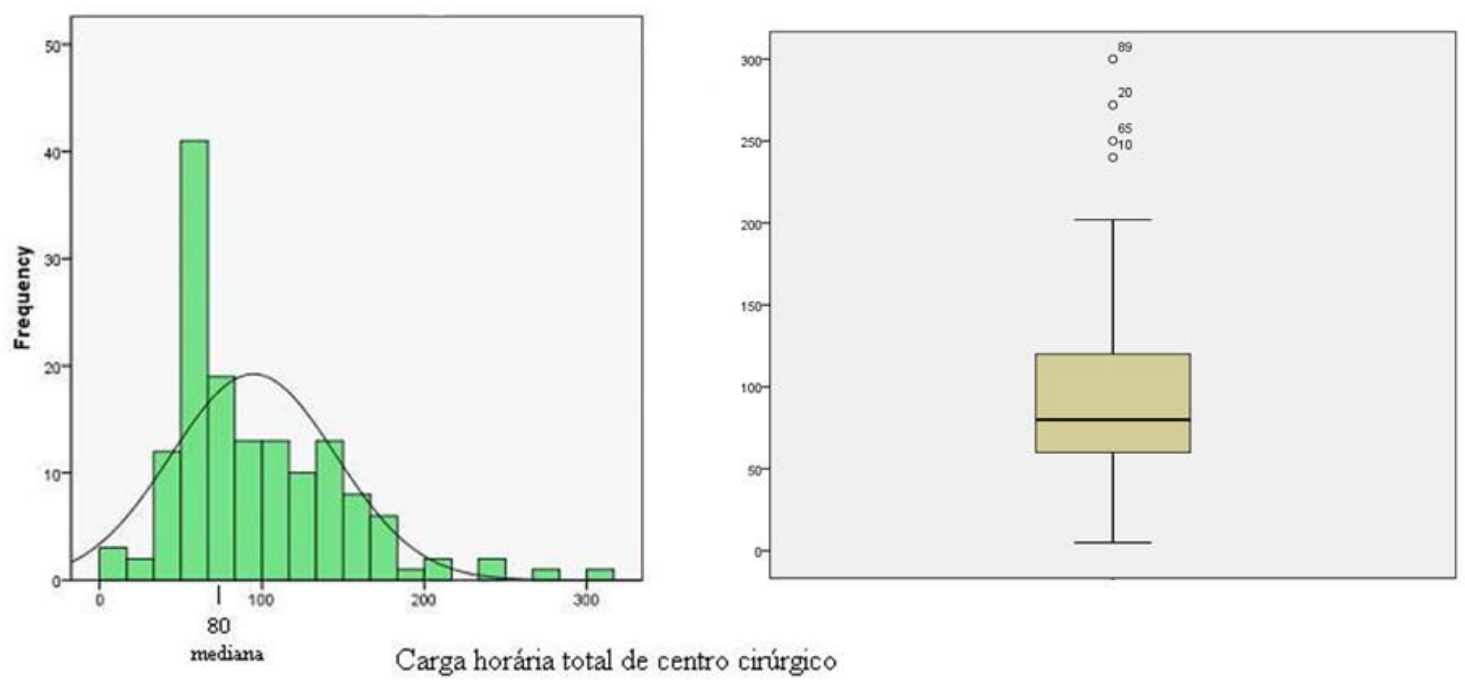

Figura 40 - Distribuição da carga horária total de CC e box plot. Brasil, 2011

Quando se analisam as cargas horárias teórica e prática separadamente, a distribuição apresenta uma configuração um pouco diferente.

A informação sobre a carga horária teórica foi obtida para $133(83,6 \%)$ cursos, com uma média de 56,1h (DP $\pm 29,9)$, mediana de $45 \mathrm{~h}(0-200)$ e intervalo interquartil de 60h (Figura 41). 


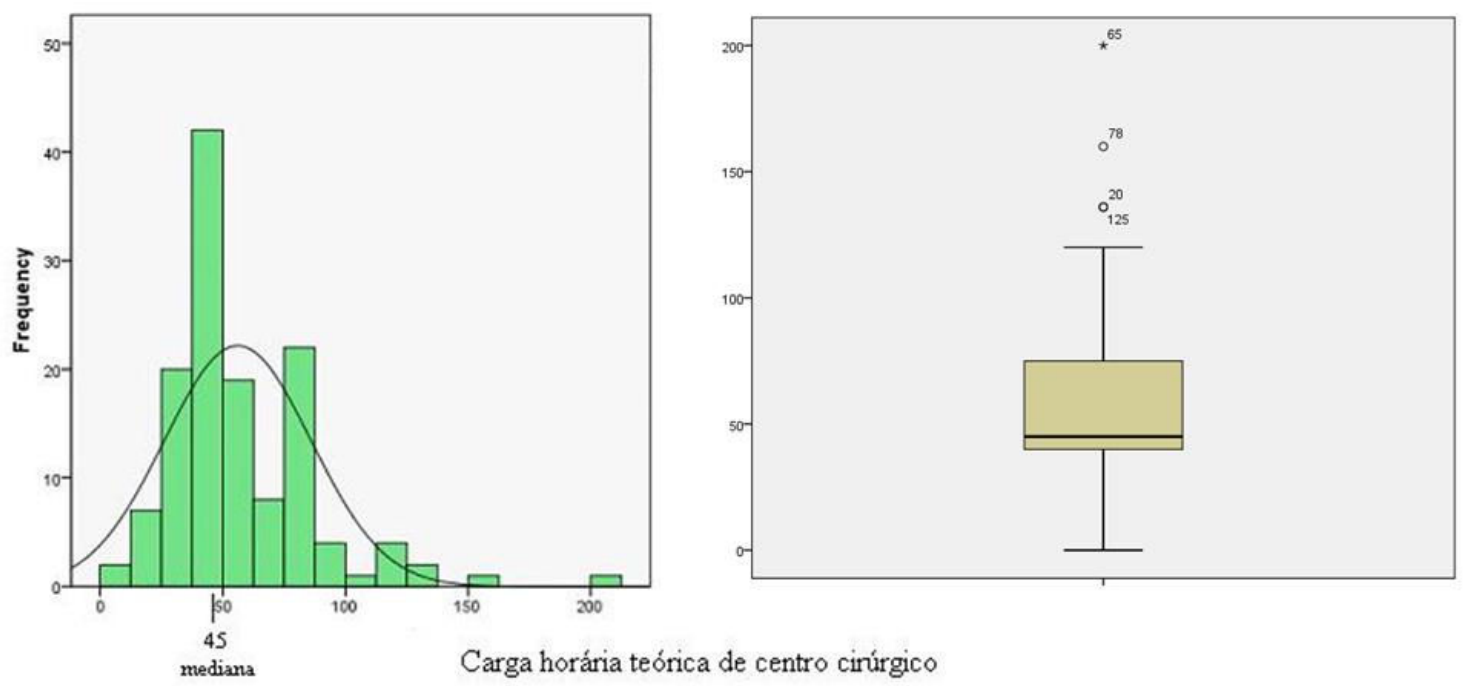

Figura 41 - Distribuição da carga horária teórica de CC e box plot. Brasil, 2011

Dos cursos, $134(84,3 \%)$ forneceram informações sobre a carga horária prática, com uma média de 42,3h (DP $\pm 33,2)$, mediana de 34,5h $(0$ - 198) e intervalo interquartil de 40h (Figura 42). Embora a amplitude das cargas horárias, teórica e prática, tenham sido semelhantes, para a carga horária prática obteve-se uma mediana menor, ou seja, metade dos cursos tinham até $34,5 \mathrm{~h}$ de carga horária prática.

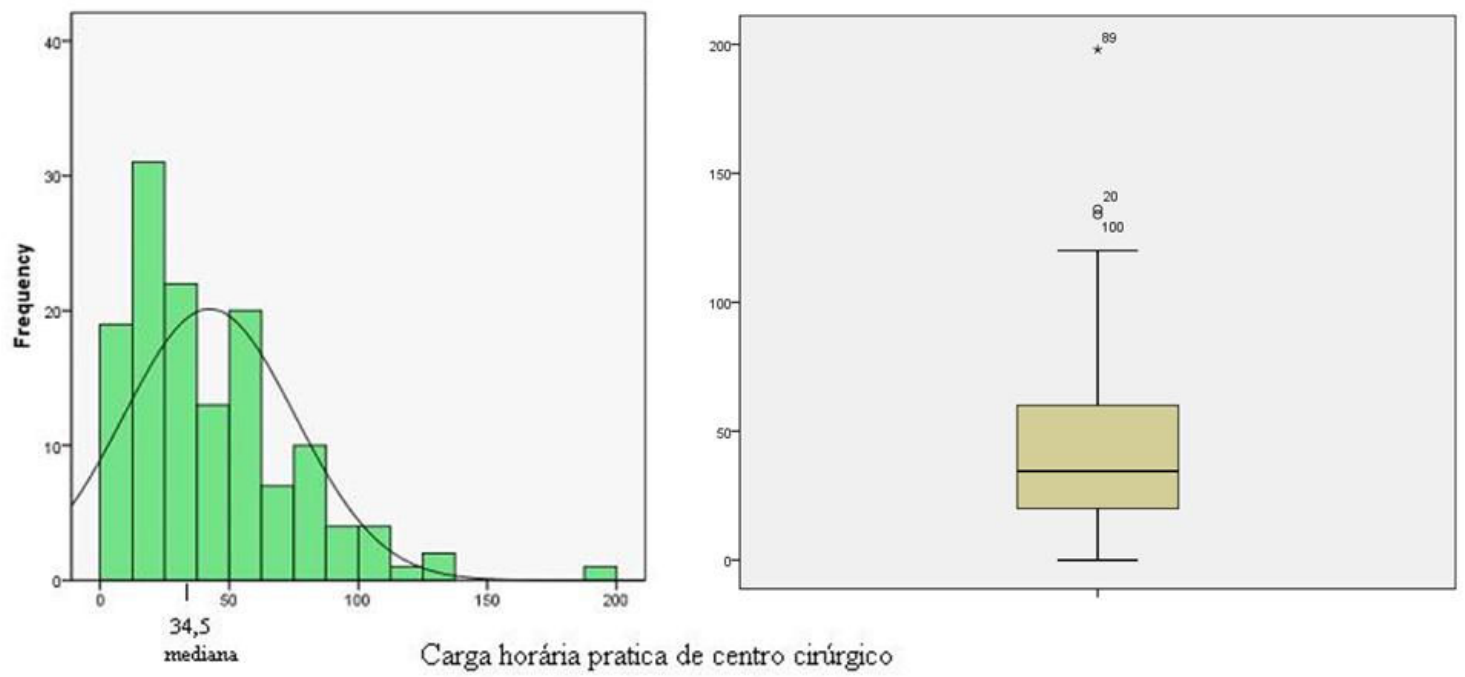

Figura 42 - Distribuição da carga horária prática de CC e Box plot. Brasil, 2011 
Dos respondentes, 107 (67,3\%) informaram que há uma disciplina específica para ministrar o conteúdo de CC e em 52 (32,7\%) está inserido em outras disciplinas.

Para os cursos com disciplinas específicas, observa-se que a carga horária prática tende a ser menor que a teórica (Tabela 14). A média para a carga horária teórica foi de 59,0h $(\mathrm{DP} \pm 28,8 \mathrm{~h})$ e para a carga horária prática de 42,5 h $(\mathrm{DP} \pm 35,1)$.

Em dois cursos, os sujeitos informaram que na carga prática foram incluídas as atividades em laboratório de procedimentos de enfermagem.

Observou-se também que $16(15,0 \%)$ dos cursos ministram apenas um conteúdo teórico aos alunos.

Tabela 14 - Distribuição de carga horária teórica e prática, para os cursos que oferecem uma disciplina específica de CC. Brasil, 2011.

\begin{tabular}{|c|c|c|c|c|c|c|}
\hline \multirow[b]{2}{*}{ Carga horária } & \multicolumn{3}{|c|}{ Teórica } & \multicolumn{3}{|c|}{ Prática } \\
\hline & $\mathrm{N}$ & $\%$ & $\%$ acum. & $\mathrm{N}$ & $\%$ & $\%$ acum. \\
\hline zero & - & - & - & 16 & 15,0 & 15,0 \\
\hline $10-20$ & 1 & 0,9 & 0,9 & 27 & 25,2 & 40,2 \\
\hline $20-130$ & 9 & 8,4 & 9,3 & 9 & 8,4 & 49,3 \\
\hline $30-40$ & 38 & 35,5 & 44,8 & 8 & 7,5 & 56,8 \\
\hline $40-150$ & 5 & 4,7 & 49,5 & 3 & 2,8 & 59,6 \\
\hline $50-60$ & 13 & 12,1 & 61,6 & $15^{*}$ & 14,0 & 73,0 \\
\hline $60-170$ & 3 & 2,8 & 64,4 & 4 & 3,8 & 76,8 \\
\hline $70-180$ & 23 & 21,5 & 85,9 & 11 & 10,2 & 87,0 \\
\hline $80-190$ & 3 & 2,8 & 88,7 & $3 *$ & 2,8 & 89,8 \\
\hline $90-100$ & - & - & 88,7 & 1 & 0,9 & 90,7 \\
\hline $100-\mid 110$ & 1 & 0,9 & 89,6 & 3 & 2,8 & 93,5 \\
\hline $110-\mid 120$ & 4 & 3,8 & 93,3 & 1 & 0,9 & 94,4 \\
\hline $120-130$ & - & - & 93,4 & - & - & 94,4 \\
\hline $130-\mid 140$ & 2 & 1,9 & 95,3 & 1 & 0,9 & 95,3 \\
\hline$:$ & $:$ & $:$ & $:$ & $:$ & $:$ & $:$ \\
\hline $190-200$ & 1 & 0,9 & 96,2 & 1 & 0,9 & 96,2 \\
\hline Sem informação & 4 & 3,8 & 100 & 4 & 3,8 & 100 \\
\hline Total & 107 & 100 & & 107 & 100 & \\
\hline
\end{tabular}


Os quatro cursos sem informação referem-se àqueles que não informaram a carga teórica e prática, embora três deles tenham informado a carga total do conteúdo.

A carga horária teórica variou de 20 a 200 horas (Figura 43), com mediana de $45 \mathrm{~h}$ e intervalo interquartil de $40 \mathrm{~h}$. Para as aulas teóricas a moda foi 40 . Identificouse um curso com o valor extremo de $200 \mathrm{~h}$.

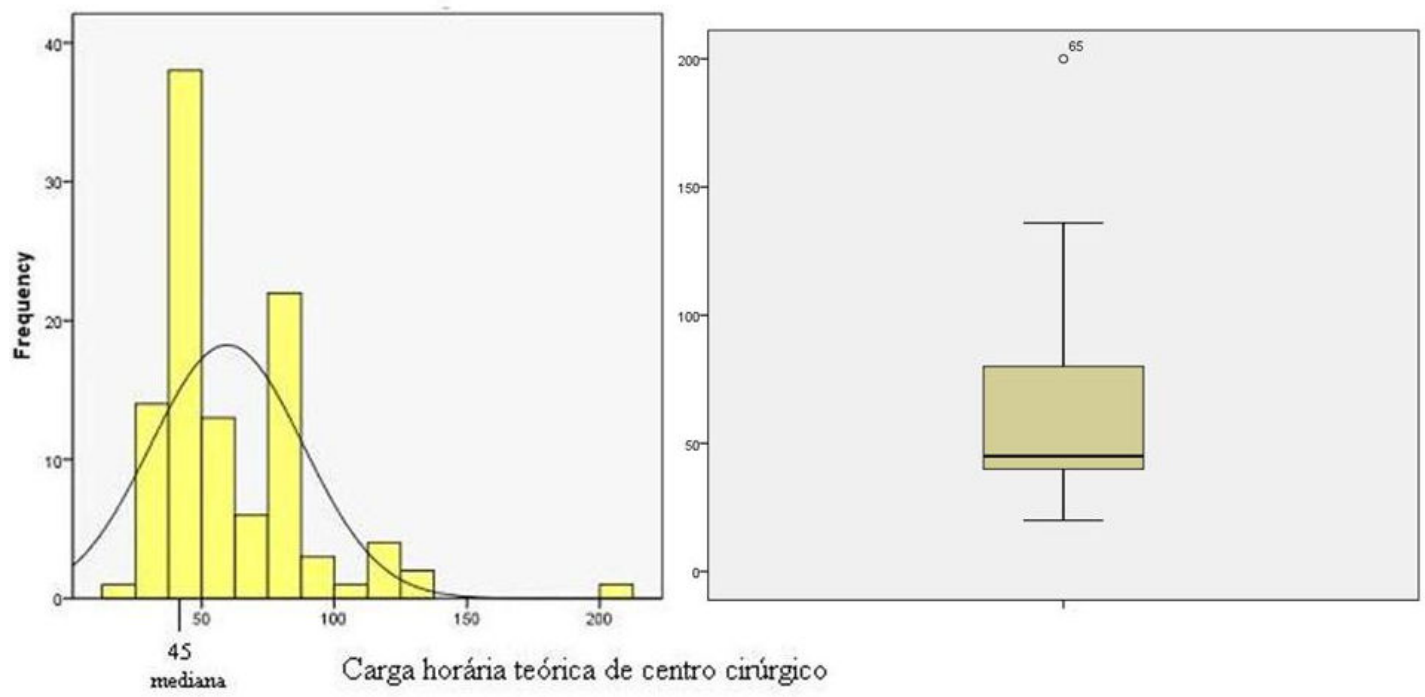

Figura 43 - Distribuição da carga horária teórica de CC nos cursos com disciplina específica e box plot. Brasil, 2011

A carga horária prática apresentou um curso com um valor extremo de $198 \mathrm{~h}$ e cursos dispersos acima da mediana de $30 \mathrm{~h}$, com intervalo interquartil de $40 \mathrm{~h}$. Para as aulas práticas a moda foi de 20h (Figura 44). 


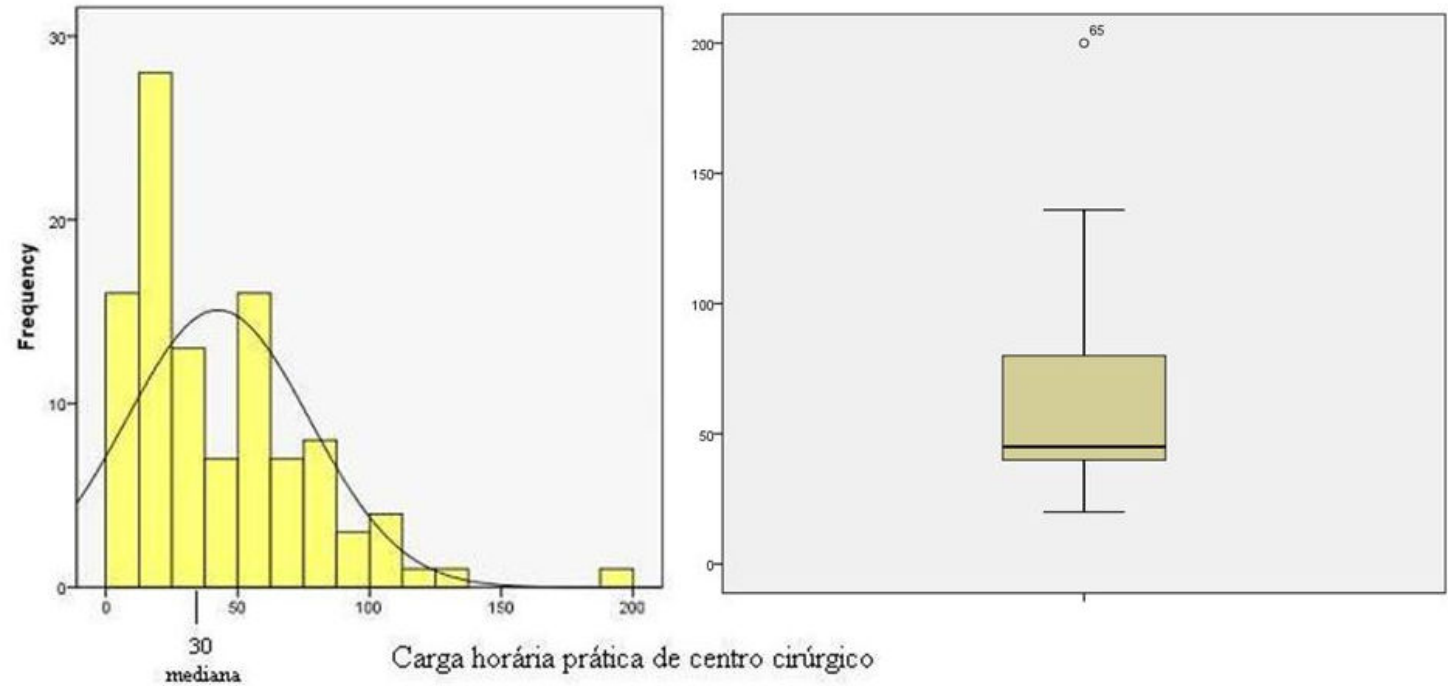

Figura 44 - Distribuição da carga horária prática de CC nos cursos com disciplina específica e box plot. Brasil, 2011

A Tabela 15 apresenta a relação das disciplinas que contém o conteúdo de CC mencionado pelos $47(90,4 \%)$ cursos. Dois respondentes não mencionaram o nome da disciplina e outros dois disseram que a grade curricular não apresenta disciplinas e não souberam informar qual a carga teórica desse conteúdo. 
Tabela 15 - Distribuição de disciplinas que integram CC, segundo carga horária da disciplina e a relativa ao conteúdo de CC. Brasil, 2011.

\begin{tabular}{|c|c|c|c|c|c|c|c|}
\hline \multirow[b]{2}{*}{ Disciplina } & \multicolumn{3}{|c|}{ Carga horária disciplina } & \multicolumn{4}{|c|}{ Carga horária CC } \\
\hline & Teórica & Prática & Total & Teórica & Prática & Total & $\%$ total \\
\hline Adultos em situações críticas de vida & 45 & 245 & 390 & 30 & 54 & 84 & 21,5 \\
\hline Alta complexidade & $\ldots$ & $\ldots$ & $\ldots$ & $\ldots$ & $\ldots$ & $\ldots$ & ... \\
\hline $\begin{array}{l}\text { Assistência de enfermagem ao adulto em situações clínicas e cirúrgicas } \\
\text { Assistência de enfermagem a criança e ao adolescente em situações clínicas e } \\
\text { cirúrgicas }\end{array}$ & $\cdots$ & $\cdots$ & $\cdots$ & 30 & 40 & 70 & $\cdots$ \\
\hline Assistência Integral a Saúde do Adulto e Idoso & $\cdots$ & $\cdots$ & $\ldots$ & 60 & 40 & 100 & $\ldots$ \\
\hline $\begin{array}{l}\text { Assistência médico-cirúrgica I } \\
\text { Assistência médico-cirúrgica II } \\
\text { Cuidados integrais na assistência de enfermagem I }\end{array}$ & $\cdots$ & $\cdots$ & $\cdots$ & $\begin{array}{l}80 \\
80\end{array}$ & - & 200 & $\cdots$ \\
\hline Atenção à saúde do adulto & $\cdots$ & $\cdots$ & 270 & $\ldots$ & $\ldots$ & $94 ?$ & $34,8 ?$ \\
\hline Cuidado integral ao adulto e idoso no perioperatório & 30 & 120 & $\ldots$ & $\ldots$ & $\ldots$ & 40 & $\ldots$ \\
\hline Cuidados de enfermagem a clientes hospitalizados III & 45 & 60 & 105 & 20 & 30 & 50 & 47,6 \\
\hline Cuidados de enfermagem a pessoa no contexto hospitalar & 136 & 170 & 306 & 51 & 54 & 105 & 34,3 \\
\hline Enfermagem Cirúrgica & 45 & 75 & 120 & 16 & 38 & 52 & 43,3 \\
\hline $\begin{array}{l}\text { Enfermagem cirúrgica I } \\
\text { Enfermagem cirúrgica II }\end{array}$ & $\begin{array}{l}60 \\
60\end{array}$ & $\begin{array}{l}60 \\
60\end{array}$ & $\begin{array}{l}120 \\
120\end{array}$ & $\cdots$ & $\cdots$ & $\cdots$ & $\cdots$ \\
\hline Enfermagem cirúrgica, CC, SRPA e CME & 75 & 60 & 135 & - & 12 & 12 & 8,8 \\
\hline Enfermagem clínica e cirúrgica & $\cdots$ & $\cdots$ & $\ldots$ & - & 35 & 35 & $\ldots$ \\
\hline Enfermagem e saúde do adulto II & $\ldots$ & $\ldots$ & $\ldots$ & 60 & 20 & 80 & $\ldots$ \\
\hline $\begin{array}{l}\text { Enfermagem e Saúde do Adulto } \\
\text { Enfermagem em Situação de Risco } \\
\text { Administração } \\
\text { Biossegurança } \\
\text { Internato }\end{array}$ & $\cdots$ & $\cdots$ & $\begin{array}{c}120 \\
120 \\
60 \\
30\end{array}$ & $\begin{array}{l}20 \\
20 \\
\cdots \\
\cdots\end{array}$ & $\begin{array}{l}- \\
- \\
- \\
\ldots \\
\ldots \\
\end{array}$ & 120 & $\begin{array}{l}36,4 \\
\text { (cont) }\end{array}$ \\
\hline
\end{tabular}




\begin{tabular}{|c|c|c|c|c|c|c|c|}
\hline Enfermagem em bloco cirúrgico/CME - incluindo $\mathrm{CCIH}$ & 30 & 30 & 60 & $\cdots$ & $\cdots$ & $18 ?$ & $30,0 ?$ \\
\hline $\begin{array}{l}\text { Enfermagem em Saúde do Adulto } 2 \\
\text { Estágio Supervisionado II }\end{array}$ & $\begin{array}{c}140 \\
-\end{array}$ & - & 620 & $\begin{array}{c}60 \\
-\end{array}$ & 80 & 140 & 22,3 \\
\hline Enfermagem em Saúde do adulto II & 50 & 50 & 100 & $\ldots$ & $\ldots$ & $\ldots$ & $\ldots$ \\
\hline $\begin{array}{l}\text { Enfermagem Médico-Cirúrgica } 2 \\
\text { Estágio Supervisionado }\end{array}$ & $\cdots$ & $\cdots$ & $\cdots$ & 90 & 90 & 180 & $\ldots$ \\
\hline Enfermagem na Clínica Cirúrgica & 120 & 40 & 160 & $\cdots$ & $\cdots$ & $5 ?$ & $3,1 ?$ \\
\hline Enfermagem na saúde do adulto & $\cdots$ & $\cdots$ & $\cdots$ & 40 & 40 & 80 & \\
\hline $\begin{array}{l}\text { Enfermagem na Saúde do Adulto } 2 \\
\text { Laboratório de Enfermagem na Saúde do Adulto } 2\end{array}$ & 60 & $\begin{array}{l}60 \\
30\end{array}$ & $\begin{array}{c}120 \\
30\end{array}$ & $\cdots$ & $\cdots$ & $32 ?$ & $21,3 ?$ \\
\hline Enfermagem na Saúde do Adulto e Idoso. & $\cdots$ & $\cdots$ & $\cdots$ & 30 & 18 & 48 & $\cdots$ \\
\hline Enfermagem na Saúde do Adulto II & 30 & 90 & 120 & 20 & 30 & 50 & 41,7 \\
\hline Enfermagem na saúde do adulto II & 240 & 60 & 300 & $\ldots$ & $\ldots$ & $\cdots$ & $\cdots$ \\
\hline Enfermagem no cuidado a saúde do adulto em situações cirúrgicas & 90 & 45 & 135 & $\cdots$ & $\cdots$ & $68 ?$ & $50,4 ?$ \\
\hline Enfermagem no cuidado ao adulto I & $\cdots$ & $\cdots$ & 540 & $\ldots$ & $\ldots$ & $\cdots$ & $\ldots$ \\
\hline $\begin{array}{l}\text { Enfermagem no cuidado integral à saúde do adulto e do idoso } \\
\text { Enfermagem no cuidado integral à saúde da Mulher } \\
\text { Enfermagem no cuidado integral à saúde do RN, Criança e adolescente }\end{array}$ & $\begin{array}{c}80 \\
100 \\
80\end{array}$ & $\begin{array}{l}120 \\
100 \\
200\end{array}$ & $\begin{array}{l}200 \\
200 \\
280\end{array}$ & $\begin{array}{l}\cdots \\
\cdots \\
\cdots\end{array}$ & $\begin{array}{l}\cdots \\
\cdots \\
\cdots\end{array}$ & $\ldots$ & $\ldots$ \\
\hline $\begin{array}{l}\text { Ensino clínico na saúde do adulto, idoso e cirúrgico } \\
\text { Estágio Supervisionado }\end{array}$ & 132 & 88 & $\begin{array}{l}220 \\
154\end{array}$ & $\cdots$ & $\cdots$ & $\cdots$ & $\cdots$ \\
\hline $\begin{array}{l}\text { Fundamentos de enfermagem II } \\
\text { Saúde do Adulto }\end{array}$ & $\cdots$ & $\cdots$ & $\begin{array}{l}180 \\
200\end{array}$ & $\cdots$ & $\cdots$ & $\cdots$ & $\cdots$ \\
\hline Médico Cirúrgico 2 & $\cdots$ & $\cdots$ & $\cdots$ & 30 & 20 & 50 & $\ldots$ \\
\hline O cuidado no processo de viver I & 122 & 310 & 432 & $\cdots$ & $\ldots$ & 60 & $\ldots$ \\
\hline Prática do cuidado em enfermagem hospitalar & 260 & 360 & 620 & 30 & 60 & 90 & 13,8 \\
\hline
\end{tabular}




\begin{tabular}{|c|c|c|c|c|c|c|c|}
\hline $\begin{array}{l}\text { Saúde da mulher, criança e do adolescente } \\
\text { Saúde do adulto e idoso }\end{array}$ & $\begin{array}{l}150 \\
150\end{array}$ & $\begin{array}{l}180 \\
180\end{array}$ & $\begin{array}{l}330 \\
330\end{array}$ & 60 & 60 & 120 & 18,2 \\
\hline Saúde do Adulto & $\cdots$ & $\ldots$ & 320 & 15 & $\ldots$ & 15 & $\ldots$ \\
\hline Saúde do Adulto 1 e 2 & $\cdots$ & $\cdots$ & $\ldots$ & 18 & 20 & 38 & $\ldots$ \\
\hline Saúde do adulto e do idoso II & 120 & 80 & 200 & $\ldots$ & $\ldots$ & $80 ?$ & 40,0 \\
\hline Saúde do Adulto e Idoso I & 170 & 136 & 306 & 60 & 45 & 105 & 34,3 \\
\hline $\begin{array}{l}\text { Saúde do Adulto I } \\
\text { Saúde do Adulto II }\end{array}$ & $\begin{array}{l}\cdots \\
\cdots\end{array}$ & $\cdots$ & $\begin{array}{l}240 \\
240\end{array}$ & $\cdots$ & $\cdots$ & $\cdots$ & $\begin{array}{l}\cdots \\
\cdots\end{array}$ \\
\hline Saúde do Adulto II & $\ldots$ & $\ldots$ & $\ldots$ & 72 & 36 & 108 & $\ldots$ \\
\hline Saúde do Adulto II & 165 & 322 & 487 & 68 & 134 & 202 & 41,5 \\
\hline Saúde do Adulto II & $\ldots$ & $\cdots$ & $\cdots$ & 30 & 30 & 60 & $\ldots$ \\
\hline Saúde do adulto e do idoso & 221 & 184 & 405 & 45 & 35 & 80 & 19,8 \\
\hline Saúde do adulto & $\ldots$ & $\ldots$ & $\ldots$ & 20 & 25 & 45 & $\ldots$ \\
\hline $\begin{array}{l}\text { Semiologia } \\
\text { Processo de Cuidar da Saúde do Adulto }\end{array}$ & $\cdots$ & $\cdots$ & $\cdots$ & $\cdots$ & $\cdots$ & 40 & $\cdots$ \\
\hline Semiotécnica & $\ldots$ & $\ldots$ & 149 & 12 & 4 & 16 & 10,7 \\
\hline Sistematização da assistência de Enfermagem Cirúrgica & 30 & 30 & 60 & 15 & 30 & 45 & 75,0 \\
\hline
\end{tabular}

... sem informação ? informação imprecisa (utilizou-se percentual informado no questionário) 
Ao se analisar a inserção do conteúdo em outras disciplinas observou-se uma variedade de denominações e cargas horárias. Em 13 (25,0\%) cursos o conteúdo de CC está distribuído em mais de uma disciplina, embora nem todos tenham detalhado a carga horária em cada uma delas. A maioria dos cursos tem o conteúdo inserido em disciplinas de saúde do adulto ou de enfermagem cirúrgica.

Alguns respondentes mencionaram a carga horária total da disciplina e outros a carga do conteúdo de CC. Nos casos em que foi citada a porcentagem do conteúdo de $\mathrm{CC}$ em relação ao total da disciplina utilizou-se esta informação para compor a tabela (valores com “?”). Também se recorreu a uma busca das ementas e matrizes curriculares das disciplinas mencionadas pelos respondentes nos sites das escolas para tentar completar as informações ou esclarecer dúvidas. No entanto, são poucos os cursos que dispõem essas informações na internet. Além disso, apenas duas ementas das relacionadas apresentavam no seu teor referência aos cuidados pré, trans e pósoperatórios ou cuidados em CC.

Para os cursos $(n=38 ; 73,1 \%)$ em que se obteve a carga horária total de $\mathrm{CC}$ ministrada dentro de outras disciplinas, obteve-se uma média de 74,1h (DP $\pm 48,7 \mathrm{~h})$ e mediana de 64h (variação de 5 a 202 horas).

Não necessariamente, disciplinas com maiores cargas horárias destinaram uma carga horária elevada ao conteúdo de CC.

As informações sobre carga teórica e prática, em separado, quando o conteúdo de CC é ministrado dentro de outras disciplinas foram obtidas para $29(76,3 \%)$ cursos. Observou-se na carga horária teórica uma média de 42,1h ( $\mathrm{DP} \pm 31,3 \mathrm{~h})$, uma mediana de 30h (Figura 45), amplitude variou de 0 a 160h e variação interquartil de 40h; moda de 30. 


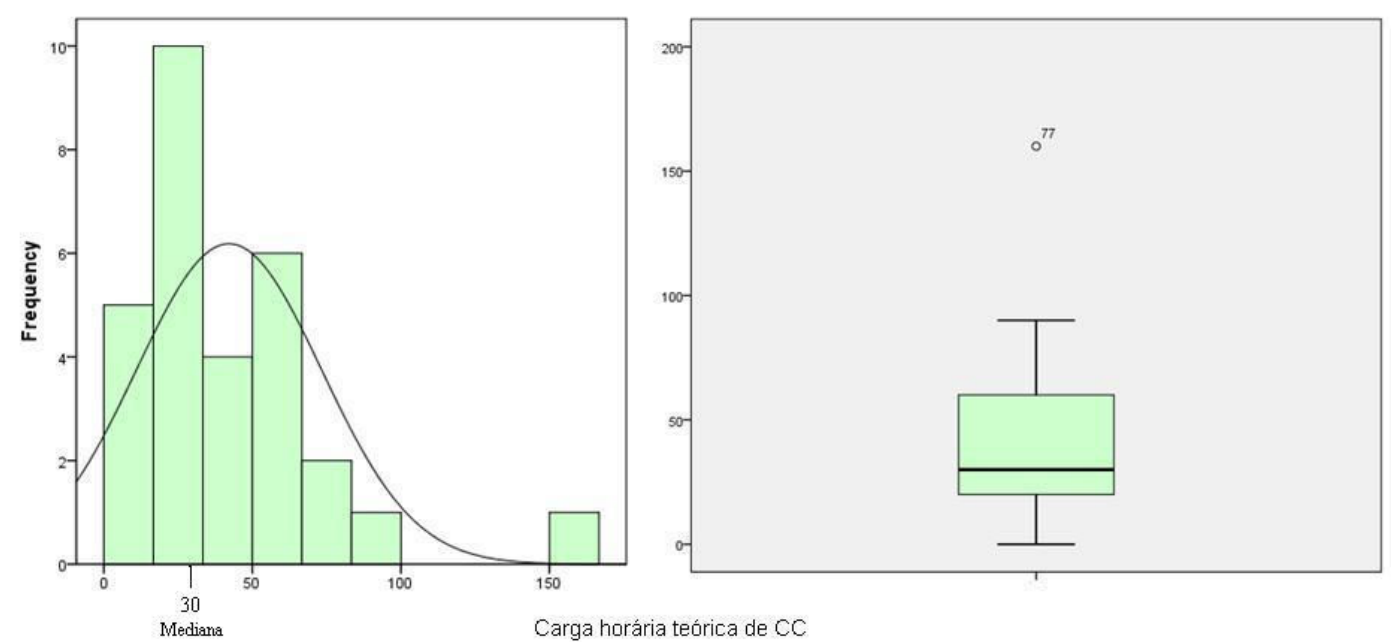

Figura 45 - Distribuição da carga horária teórica de CC e box plot nos cursos com conteúdo de CC em outras disciplinas. Brasil, 2011

Considerando-se apenas a carga horária prática, obteve-se uma média de 41,7h ( $\mathrm{DP} \pm 27,7 \mathrm{~h}$ ), uma mediana de 36h (Figura 46), amplitude variou de 0 a $134 \mathrm{~h}$ e variação interquartil de $26 \mathrm{~h}$. A moda foi de $30 \mathrm{~h}$.

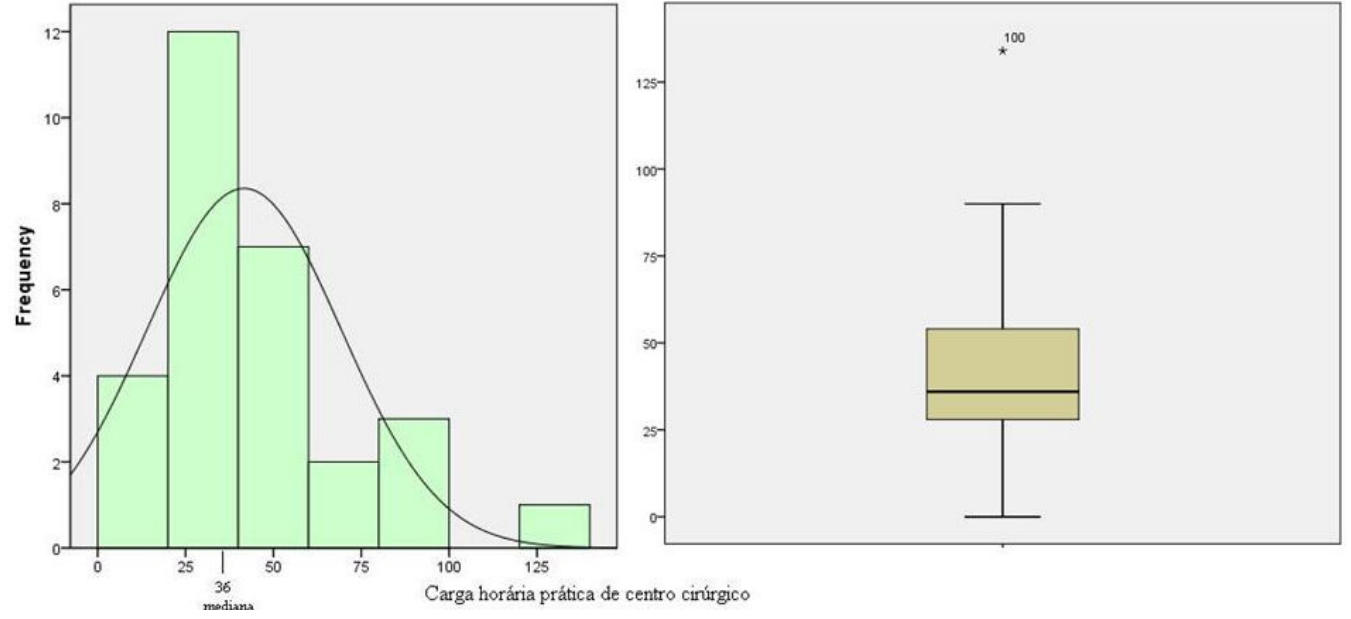

Figura 46 - Distribuição da carga horária prática de $\mathrm{CC}$ e box plot nos cursos com conteúdo de $\mathrm{CC}$ em outras disciplinas. Brasil, 2011 
A seguir apresenta-se um comparativo entre as cargas horárias das disciplinas específicas e inespecíficas.

Ao se considerar a carga total do conteúdo de CC nas disciplinas específicas, observou-se uma média de 101,6h ( $\mathrm{DP} \pm 50,4 \mathrm{~h})$, mediana de 87,5h (variação de 40 a $300 \mathrm{~h}$ ), um intervalo interquartil de $75 \mathrm{~h}$ e uma moda de 60 . Poucos foram os cursos com uma carga horária de CC acima de 180h (Tabela 16 e Figura 47).

$\mathrm{Na}$ carga total do conteúdo de $\mathrm{CC}$ ministrado em outras disciplinas, observouse uma média de 75,4h ( $\mathrm{DP} \pm 47,3 \mathrm{~h}$ ), mediana de $68 \mathrm{~h}$ (variação de 5 a 202h), um intervalo interquartil de $60 \mathrm{~h}$ e uma moda de 80 (Tabela 16 e Figura 48).

Tabela 16 - Distribuição de carga horária total para os cursos que oferecem uma disciplina específica de CC e dentro de outra disciplina. Brasil, 2011.

\begin{tabular}{|c|c|c|c|c|c|c|}
\hline \multirow[b]{2}{*}{ Carga horária } & \multicolumn{3}{|c|}{ Total (disciplina específica) } & \multicolumn{3}{|c|}{$\begin{array}{c}\text { Total (dentro de outra } \\
\text { disciplina) }\end{array}$} \\
\hline & $\mathrm{N}$ & $\%$ & $\%$ acum. & $\mathrm{N}$ & $\%$ & $\%$ acum. \\
\hline zero & 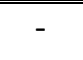 & 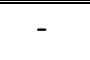 & - & 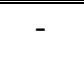 & 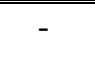 & 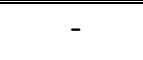 \\
\hline $5 \mid-20$ & - & - & - & 5 & 13,2 & 13,2 \\
\hline $20 \mid-40$ & - & - & - & 3 & 7,9 & 21,1 \\
\hline $40 \mid-60$ & 5 & 4,7 & 4,7 & 9 & 23,7 & 44,8 \\
\hline $60 \mid-80$ & 39 & 36,5 & 41,2 & 4 & 10,5 & 55,3 \\
\hline $80 \mid-100$ & 19 & 17,8 & 59,0 & 7 & 18,4 & 73,7 \\
\hline $100 \mid-120$ & 7 & 6,5 & 65,5 & 4 & 10,5 & 84,2 \\
\hline $120 \mid-140$ & 13 & 12,1 & 77,6 & 2 & 5,3 & 89,5 \\
\hline $140 \mid-160$ & 10 & 9,3 & 86,9 & 1 & 2,6 & 92,1 \\
\hline $160 \mid-180$ & 8 & 7,5 & 94,4 & - & - & 92,1 \\
\hline $180 \mid-200$ & 2 & 1,9 & 96,3 & 1 & 2,6 & 94,7 \\
\hline $200 \mid-220$ & - & - & 96,3 & 2 & 5,3 & 100 \\
\hline $220 \mid-240$ & - & - & 96,3 & - & - & 100 \\
\hline $240 \mid-260$ & 2 & 1,9 & 98,2 & - & - & 100 \\
\hline $260 \mid-280$ & 1 & 0,9 & 99,1 & - & - & 100 \\
\hline $280 \mid-300$ & 1 & 0,9 & 100 & - & - & 100 \\
\hline Total & 107 & 100 & & $38^{*}$ & 100 & \\
\hline
\end{tabular}


Os valores das cargas horárias de CC obtidos para as disciplinas não específicas foram menores do que aqueles encontrados nas disciplinas específicas de $\mathrm{CC}$, e a média foi estatisticamente diferente nos dois grupos $(\mathrm{p}=0,0011)$.

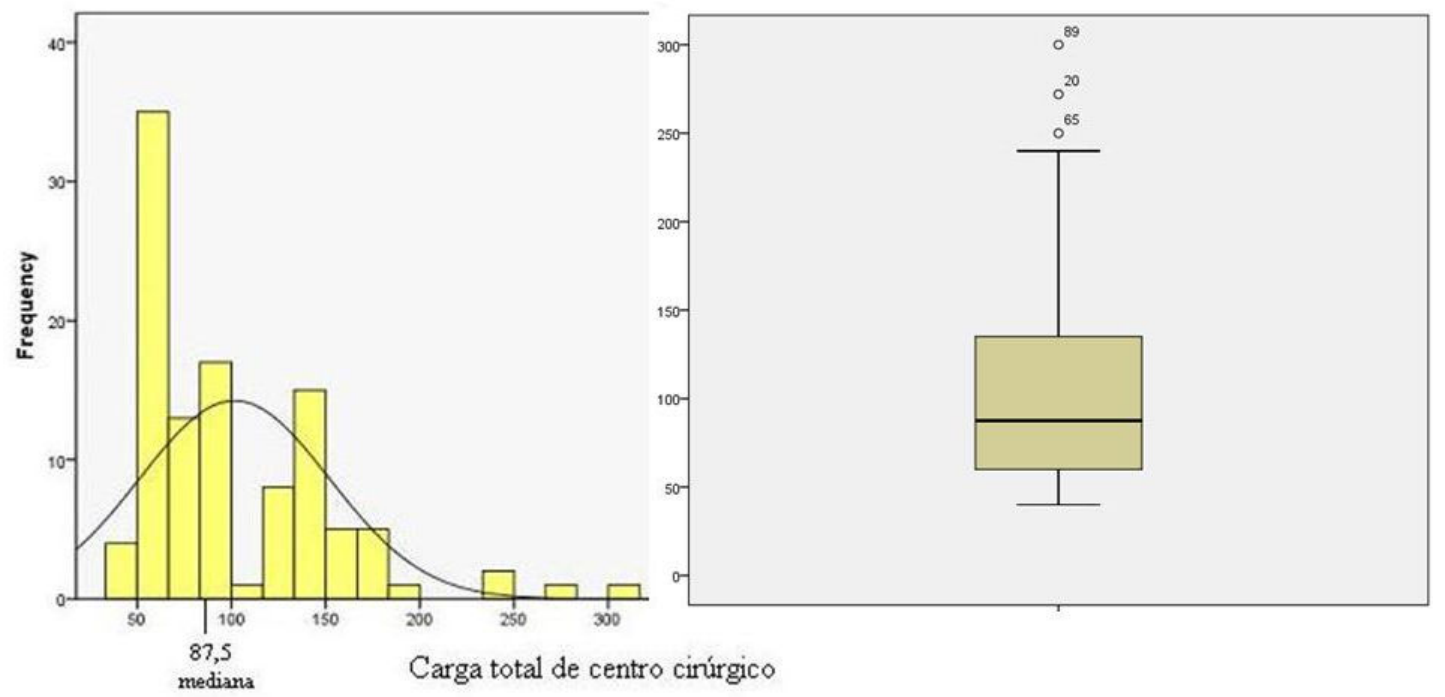

Figura 47 - Distribuição da carga horária total de CC e box plot nos cursos com disciplina específica. Brasil, 2011

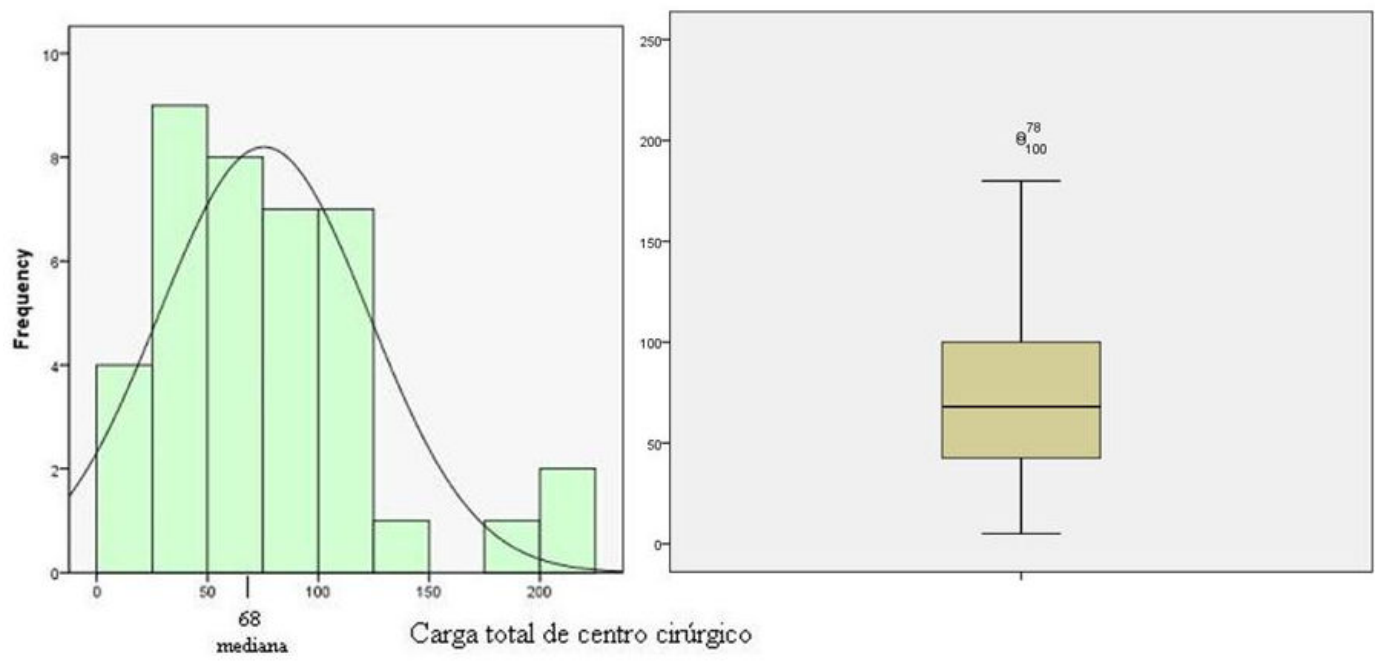

Figura 48 - Distribuição da carga horária total de CC e box plot nos cursos com conteúdo de CC inserido em outras disciplinas. Brasil, 2011 
Analisou-se a distribuição dos cursos com disciplina específicas e inespecíficas de acordo com a relação entre carga horária teórica e prática (Tabela 17). As disciplinas específicas tendem a apresentar uma carga horária teórica superior à prática em contraoposição às disciplinas não específicas. Considerando-se o conjunto de cursos de bacharelado, $68(51,1 \%)$ apresentam uma carga horária teórica superior a prática.

Tabela 17 - Distribuição das cargas horárias segundo a relação entre teoria e prática. Brasil, 2011.

\begin{tabular}{lcccccc}
\hline Carga horária & \multicolumn{2}{c}{ disciplina específica } & \multicolumn{2}{c}{ disciplina não específica } & \multicolumn{2}{c}{ total } \\
\cline { 2 - 7 } & $\mathrm{N}$ & $\%$ & $\mathrm{~N}$ & $\%$ & $\mathrm{~N}$ & $\%$ \\
\hline \hline Teórica > prática & 58 & 55,8 & 10 & 34,5 & 68 & 51,1 \\
Teórica= prática & 23 & 22,1 & 4 & 13,8 & 27 & 20,3 \\
Teórica < prática & 23 & 22,1 & 15 & 51,7 & 38 & 28,6 \\
\hline \hline Total & $104 *$ & 100 & 29 & $100 *$ & 133 & 100 \\
\hline \hline
\end{tabular}

Ao se considerar as diferenças entre a carga horária teórica e prática nas disciplinas específicas de $\mathrm{CC}$ em que a teoria foi superior observou-se uma média de 42,3 h $(\mathrm{DP} \pm 29,9 \mathrm{~h})$; variação de 6 a $150 \mathrm{~h}$, mediana de $30 \mathrm{~h}$ e o intervalo interquartil dessa variação de 43h (Figura 49). 


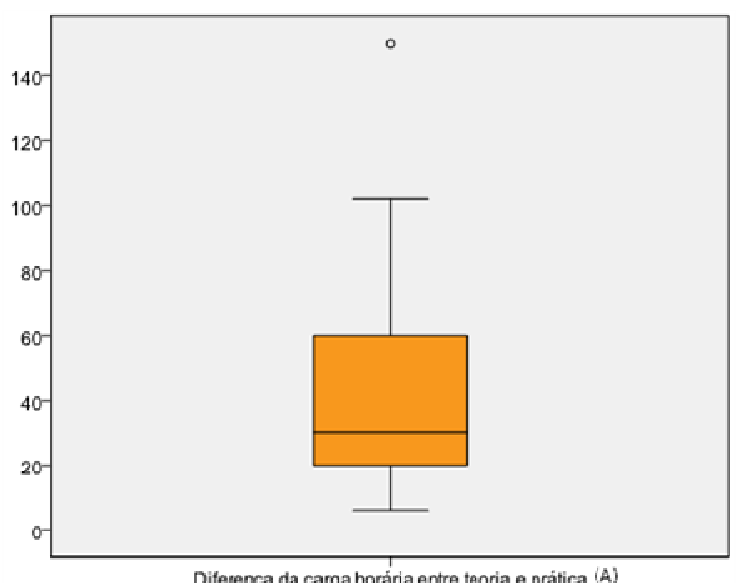

Figura 49 - Representação do intervalo interquartil quando a carga horária teórica foi superior que a prática nas disciplinas específicas (A) e nas disciplinas inespecíficas (B) de CC. Brasil, 2011.

Ao se considerar as diferenças entre a carga horária teórica e prática do conteúdo de CC ministrado em outras disciplinas em que a teoria foi superior observou-se uma média de 28,6 h $(\mathrm{DP} \pm 33,9)$ e variação de 8 a 120h, mediana de $15 \mathrm{~h}$ e intervalo interquartil dessa variação de $27 \mathrm{~h}$ (Figura 49).

Comparando-se as imagens A e B da figura 49 observou-se uma amplitude de variação próxima entre os dois grupos, apesar da mediana e do intervalo interquartil terem sido menores no grupo de cursos que oferecem o conteúdo de $\mathrm{CC}$ em disciplinas não específicas para o tema.

Com relação à diferença de carga horária quando a prática foi superior à teórica nas disciplinas específicas obteve-se uma média de $30,8 \mathrm{~h}(\mathrm{DP} \pm 21,9 \mathrm{~h})$ e variação de 2 a 96h, mediana de $22 \mathrm{~h}$ e intervalo interquartil de $20 \mathrm{~h}$ (Figura 50). 

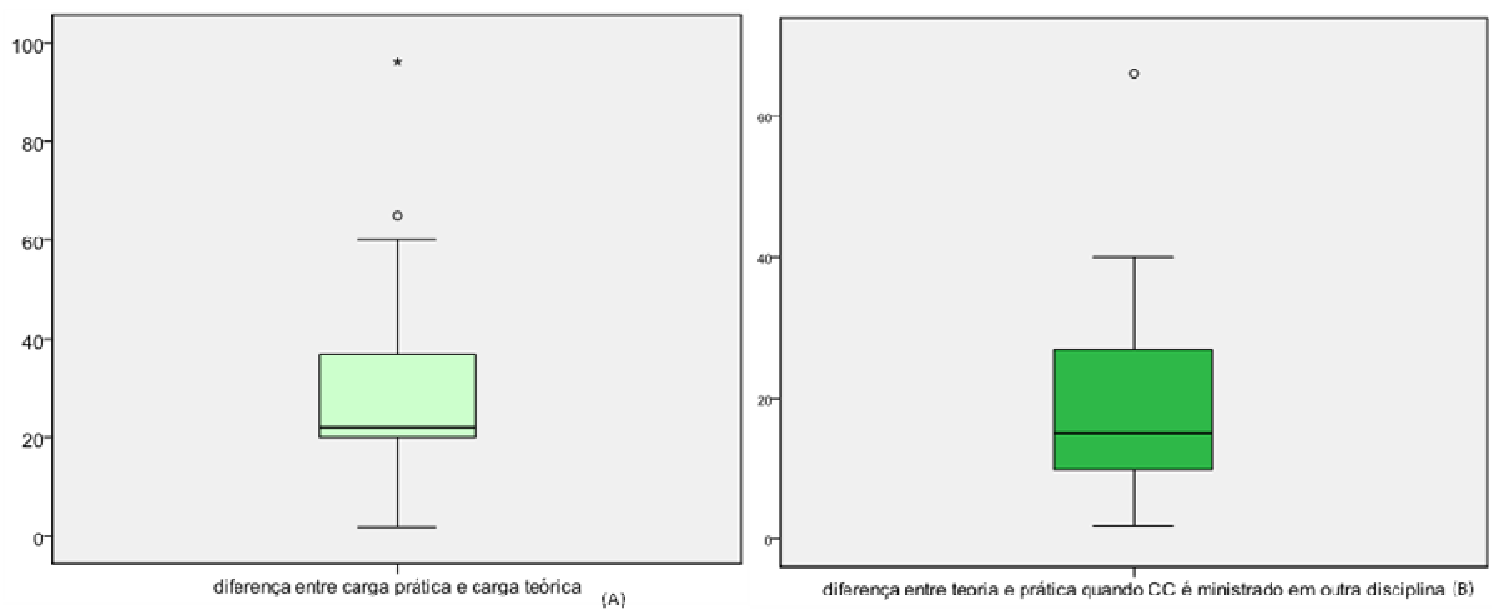

Figura 50 - Representação do intervalo interquartil quando a carga horária prática foi superior a teórica nas disciplinas específicas (A) e inespecíficas (B) de CC. Brasil, 2011.

Com relação à diferença de carga horária quando a prática foi superior à teórica nas disciplinas não específicas obteve-se uma média de 20,3h ( $\mathrm{DP} \pm 17,1 \mathrm{~h})$ e variação de 2 a $66 \mathrm{~h}$, mediana de $15 \mathrm{~h}$ e intervalo interquartil de $20 \mathrm{~h}$ (Figura50 ).

$\mathrm{O}$ intervalo interquartil da carga teórica superior à prática foi quase o dobro do interquartil da carga prática superior à teórica nas disciplinas específicas, indicando maior variabilidade na diferença da carga teórica.

Embora o mesmo fato tenha sido observado nas disciplinas não específicas de $\mathrm{CC}$, os valores dos intervalos interquartis não foram tão diferentes como no grupo de disciplinas específicas.

Com relação ao período em que o conteúdo é ministrado, as citações foram diversificadas (Tabela 18 ). Nas disciplinas específicas o conteúdo de CC é ministrado preferencialmente no quinto semestre, enquanto nas disciplinas não específicas ocorre no sexto semestre. Há um conjunto de cursos em ambas as situações, em que o conteúdo é ministrado em mais de um semestre, 15,0 \% (16) nas disciplinas específicas e 35,2\% (18) nas disciplinas não específicas. Um dos cursos, que não soube informar a carga horária, informou que o conteúdo de CC é ministrado ao longo do curso. 
Tabela 18 - Distribuição de cursos de enfermagem segundo o fato da disciplina ser específica ou não e o semestre em que o conteúdo é ministrado. Brasil, 2011.

\begin{tabular}{|c|c|c|c|c|}
\hline \multirow[b]{2}{*}{ Semestre } & \multicolumn{2}{|c|}{ disciplina específica } & \multicolumn{2}{|c|}{ disciplina não específica } \\
\hline & $\mathrm{N}$ & $\%$ & $\mathrm{~N}$ & $\%$ \\
\hline 3 & 1 & 0,9 & - & - \\
\hline 4 & 8 & 7,6 & 5 & 9,6 \\
\hline 5 & 51 & 47,7 & 9 & 17,3 \\
\hline 6 & 18 & 16,8 & 14 & 26,9 \\
\hline 7 & 7 & 6,5 & 6 & 11,5 \\
\hline 8 & 4 & 3,8 & - & - \\
\hline 9 & 2 & 1,9 & - & - \\
\hline 3 e 4 & 2 & 1,9 & - & - \\
\hline 3 e 5 & - & - & 1 & 1,9 \\
\hline $3,4,5$ e 6 & 1 & 0,9 & - & - \\
\hline 4 e 5 & $1^{*}$ & 0,9 & 2 & 3,8 \\
\hline 4 e 8 & $1^{*}$ & 0,9 & - & - \\
\hline 5 e 6 & 3 & 2,8 & 5 & 9,6 \\
\hline 5 ou 6 & - & - & 1 & 1,9 \\
\hline 5 e 7 & $2^{*}$ & 1,9 & - & - \\
\hline 5 e 8 & $1^{*}$ & 0,9 & $1 ; 1^{*}$ & 3,8 \\
\hline 5,6 e 8 & - & - & 1 & 1,9 \\
\hline 5,7 e 8 & - & - & 1 & 1,9 \\
\hline 5,8 e 9 & - & - & 1 & 1,9 \\
\hline 5 e 10 & 1 & 0,9 & - & - \\
\hline 6 e 7 & 1 & 0,9 & 3 & 5,8 \\
\hline 6,7 e 8 & $1^{*}$ & 0,9 & - & - \\
\hline 7 e 10 & $2^{*}$ & 1,9 & - & - \\
\hline $\begin{array}{l}\text { ao longo da } \\
\text { disciplina }\end{array}$ & - & - & 1 & 1,9 \\
\hline
\end{tabular}

* um semestre a teoria e no outro a prática 
Dos cursos que oferecem a disciplina específica em mais de um semestre, 8 $(50,0 \%)$ dos respondentes justificaram que a teoria e a prática clínica ocorrem em semestres diferentes. Para as demais situações não se obteve informações.

Apresentou-se, inicialmente, no questionário uma pergunta aberta sobre o conteúdo ministrado, mas como no pré-teste algumas respostas foram muito vagas, optou-se por introduzir um check list com os principais temas de CC.

A tabela 19 apresenta os conteúdos listados e a freqüência com que foram mencionados pelos respondentes. Observou-se que independente da carga horária do conteúdo de CC, a maioria dos temas é ministrada por pelo menos $80 \%$ dos cursos.

Temas atuais como cirurgia ambulatorial ou assistência de enfermagem em cirurgias que utilizam novas tecnologias são abordados por cerca de $50 \%$ dos cursos. Se considerarmos apenas os cursos que ministram o conteúdo de $\mathrm{CC}$ em outras disciplinas, a freqüência diminui, tendo-se observado $43,1 \%$ (22) para o tema de avanços tecnológicos e 35,3\% (18) para a cirurgia ambulatorial.

Tabela 19 - Frequência de temas de CC assinalados pelos respondentes. Brasil, 2011.

\begin{tabular}{lll}
\hline \hline Temas de CC & $\mathrm{N}$ & $\%$ \\
\hline \hline Planejamento físico e recursos humanos em CC & 150 & 94,3 \\
Modelo de Enfermagem- SAEP & 135 & 84,9 \\
Assistência de enfermagem no pré, trans e pós-operatório & 156 & 98,7 \\
Riscos físicos, biológicos e psicológicos da equipe cirúrgica & 134 & 84,3 \\
Antissepsia e degermação & 153 & 96,2 \\
Posição cirúrgica & 151 & 95,0 \\
Instrumentação cirúrgica & 94 & 59,1 \\
Hemostasia (sutura e bisturi elétrico) & 140 & 88,1 \\
Anestesia & 149 & 93,7 \\
Monitorização do paciente cirúrgico & 150 & 94,3 \\
Recuperação anestésica & 154 & 96,9 \\
Riscos e controle de infeç̃ão em CC & 150 & 94,3 \\
Assistência ao paciente em cirurgia ambulatorial & 83 & 52,2 \\
Avanços tecnológicos: videocirurgias, robótica, laser e outros & 92 & 57,9 \\
\hline \hline
\end{tabular}




\subsection{CORPO DOCENTE}

Do total de cursos em análise, 158 (99,4\%) informaram o número de docentes. O número de docentes envolvidos na administração do conteúdo de $\mathrm{CC}$, variou de 1 a 6 (Figura 51), média de 2,5 (DP \pm 2,2) e mediana de 2 docentes. Dos cursos, 31,6\% (50) tinham um docente e $29,1 \%$ (46) dois docentes.

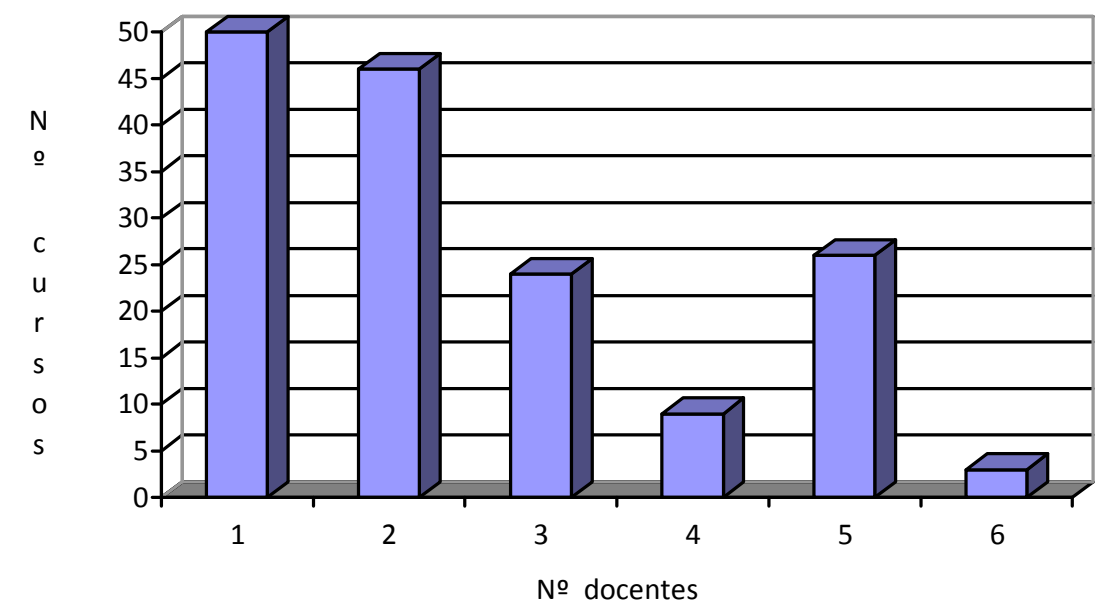

Figura 51 - Distribuição de cursos de enfermagem segundo o número de docentes. Brasil, 2011.

Alguns respondentes caracterizaram a distribuição dos docentes de acordo com as aulas teóricas e teórico-práticas: nove dos cursos com dois docentes disseram que um docente se encarrega do conteúdo teórico e o outro do conteúdo prático. Seis cursos com três docentes informaram que um docente ministra a teoria enquanto dois fazem supervisão de prática. Em um dos cursos com quatro docentes, um se incumbe da parte teórica enquanto os outros três assumem a prática. Dos cursos com cinco docentes, em 23 deles dois docentes são responsáveis pela teoria e três pela prática; um curso mencionou uma relação inversa: três na teoria e dois na prática. Os cursos que não estão estruturados em disciplinas relataram situações diferentes: um deles possui um docente 
na tutoria e outro como facilitador, enquanto no outro curso o aprendizado de $\mathrm{CC}$ fica sob a responsabilidade de um docente de Saúde do Adulto, um docente de Saúde da Mulher e um docente de Farmacologia.

Os cursos sem uma disciplina específica apresentam uma maior proporção de cursos com apenas um docente para ministrar o conteúdo de CC (Tabela 20). Cursos com cinco ou seis docentes estão presentes nos cursos com disciplina específica.

Tabela 20 - Distribuição de cursos segundo ter uma disciplina específica de CC e o número de docentes de CC. Brasil, 2011.

\begin{tabular}{|c|c|c|c|c|c|c|}
\hline \multirow[b]{3}{*}{ № docentes } & \multicolumn{4}{|c|}{ "Disciplina específica } & & \\
\hline & \multicolumn{2}{|c|}{ Sim } & \multicolumn{2}{|c|}{ Não } & \multicolumn{2}{|c|}{ Total } \\
\hline & $\mathrm{N}$ & $\%$ & $\mathrm{~N}$ & $\%$ & $\mathrm{~N}$ & $\%$ \\
\hline 1 & 28 & 26,4 & 22 & 42,3 & 50 & 31,6 \\
\hline 2 & 31 & 29,2 & 15 & 28,8 & 46 & 29,1 \\
\hline 3 & 15 & 14,2 & 9 & 17,4 & 24 & 15,2 \\
\hline 4 & 5 & 4,8 & 4 & 7,7 & 9 & 5,7 \\
\hline 5 & 26 & 24,5 & - & - & 26 & 16,5 \\
\hline 6 & 1 & 0,9 & 2 & 3,8 & 3 & 1,9 \\
\hline Total & 106 & 100 & 52 & 100 & $158 *$ & 100 \\
\hline
\end{tabular}

Proporcionalmente, as escolas de gestão pública possuem mais cursos com um docente $(37,8 \%)$ do que as escolas de gestão privada (Tabela 21$)$. Os cursos com seis docentes estão nas escolas públicas enquanto aqueles com cinco docentes concentramse nas escolas privadas. 
Tabela 21 - Distribuição de cursos segundo o número de docentes de CC e o tipo de gestão das escolas. Brasil, 2011.

\begin{tabular}{|c|c|c|c|c|c|c|}
\hline \multirow[b]{3}{*}{ № docentes } & \multicolumn{4}{|c|}{ Tipo de gestão } & \multirow{2}{*}{\multicolumn{2}{|c|}{ Total }} \\
\hline & \multicolumn{2}{|c|}{ Pública } & \multicolumn{2}{|c|}{ Privada } & & \\
\hline & $\mathrm{N}$ & $\%$ & $\mathrm{~N}$ & $\%$ & $\mathrm{~N}$ & $\%$ \\
\hline 1 & 14 & 37,8 & 36 & 29,8 & 50 & 31,6 \\
\hline 2 & 11 & 29,7 & 35 & 28,9 & 46 & 29,1 \\
\hline 3 & 7 & 18,9 & 17 & 14,0 & 24 & 15,2 \\
\hline 4 & 1 & 2,7 & 8 & 6,7 & 9 & 5,7 \\
\hline 5 & 1 & 2,7 & 25 & 20,6 & 26 & 16,5 \\
\hline 6 & 3 & 8,2 & - & - & 3 & 1,9 \\
\hline Total & 37 & 100 & 121 & 100 & $158^{*}$ & 100 \\
\hline
\end{tabular}

*Um curso não mencionou o número de docentes

Embora em todas as regiões do país haja maior proporção de cursos com um ou dois docentes de $\mathrm{CC}$, a região $\mathrm{NE}$ concentra proporcionalmente o maior quantitativo de cursos com um docente $(45,0 \%)$ (Tabela 22 ). As regiões $\mathrm{N}$ e SE apresentam a maior proporção de cursos com cinco docentes, $16,7 \%$ e $25,9 \%$ respectivamente.

Tabela 22 - Distribuição de cursos segundo o número de docentes de CC e a região das escolas. Brasil, 2011.

\begin{tabular}{|c|c|c|c|c|c|c|c|c|c|c|c|c|}
\hline \multirow{3}{*}{ № de docentes } & \multicolumn{10}{|c|}{ Região } & \multirow{2}{*}{\multicolumn{2}{|c|}{ Total }} \\
\hline & \multicolumn{2}{|c|}{$\mathrm{N}$} & \multicolumn{2}{|c|}{$\mathrm{NE}$} & \multicolumn{2}{|c|}{$\mathrm{CO}$} & \multicolumn{2}{|c|}{ SE } & \multicolumn{2}{|c|}{$S$} & & \\
\hline & $\mathrm{N}$ & $\%$ & $\mathrm{~N}$ & $\%$ & $\mathrm{~N}$ & $\%$ & $\mathrm{~N}$ & $\%$ & $\mathrm{~N}$ & $\%$ & $\mathrm{~N}$ & $\%$ \\
\hline 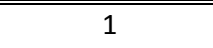 & 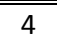 & 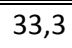 & 9 & 45,0 & $\bar{~} 6$ & 31,7 & 23 & 28,4 & 8 & 30,8 & 250 & 31,6 \\
\hline 2 & 5 & 41,7 & 4 & 20,0 & 7 & 36,8 & 18 & 22,2 & 12 & 46,2 & 46 & 29,1 \\
\hline 3 & - & - & 5 & 25,0 & 2 & 10,5 & 13 & 16,0 & 4 & 15,4 & 24 & 15,2 \\
\hline 4 & 1 & 8,3 & 1 & 5,0 & 2 & 10,5 & 4 & 5,0 & 1 & 3,8 & 9 & 5,7 \\
\hline 5 & 2 & 16,7 & 1 & 5,0 & 2 & 10,5 & 21 & 25,9 & - & - & 26 & 16,5 \\
\hline 6 & - & - & - & - & - & - & 2 & 2,5 & 1 & 3,8 & 3 & 1,9 \\
\hline Total & 12 & 100 & 20 & 100 & 19 & 100 & 81 & 100 & 26 & 100 & $158^{*}$ & 100 \\
\hline
\end{tabular}

*Um curso não mencionou o número de docentes 
$\mathrm{Na}$ análise das medidas de tendência central e de dispersão, apenas se observou uma diferença de média estatisticamente significativa na comparação entre os cursos com disciplina e sem disciplina específica (Quadro 28 ). Com relação à região onde se localiza o curso, a região SE apresentou a maior média (2,9 docentes).

Quadro 28 - Medidas de tendência central e de dispersão para o número de docentes de acordo com presença de disciplina específica, tipo de gestão e região do país. Brasil, 2011.

\begin{tabular}{ccccc}
\hline \hline Variável & Média (DP) & Mediana & Moda & valor de $p^{*}$ \\
\hline \hline Disciplina específica & & & & \\
Sim & $2,7( \pm 1,5)$ & 2 & 2 & 0,0093 \\
Não & $2,1( \pm 1,2)$ & 2 & 1 & \\
\hline Tipo de gestão da escola & & & & \\
Pública & $2,3( \pm 1,5)$ & 2 & 1 & 0,2380 \\
Privada & $2,6( \pm 1,5)$ & 2 & 1 & \\
Norte & & & & \\
Nordeste & $2,3( \pm 1,5)$ & 2 & 2 & \\
Centro-oeste & $2,1( \pm 1,2)$ & 2 & 2 & \\
Sudeste & $2,3( \pm 1,3)$ & 2 & 1 & 0,1653 \\
Sul & $2,9( \pm 1,6)$ & 2 & 2 & \\
\hline \hline
\end{tabular}

*Teste de Kruskall Wallis

Do total de cursos, 155 (97,5\%) forneceram informações sobre a realização de cursos de CC pelos docentes. Destes, 99 (63,9\%) mencionaram a existência de docentes com curso de especialização na área específica.

O número de docentes com curso de especialização em $\mathrm{CC}$ variou de 0 a 6 , com média de 1,7 (DP $\pm 1,8)$ docentes por curso e mediana de um docente (Tabela 23 ). 
Tabela 23 - Distribuição de cursos segundo o número de docentes com curso de especialização em CC. Brasil, 2011.

\begin{tabular}{cccc}
\hline \hline № especialistas em CC & $\mathrm{N}$ & $\%$ & \% acum \\
\hline \hline 0 & 56 & 36,0 & 36,0 \\
1 & 35 & 22,6 & 58,6 \\
2 & 26 & 16,8 & 75,4 \\
3 & 8 & 5,2 & 80,6 \\
4 & 4 & 2,6 & 83,2 \\
5 & 24 & 15,5 & 98,7 \\
6 & 2 & 1,3 & 100 \\
\hline \hline Total & 155 & 100 & \\
\hline \hline
\end{tabular}

Ao se comparar a média de docentes com curso de especialização de acordo com a presença de uma disciplina específica em $\mathrm{CC}$, observou-se que nos cursos com disciplina específica a média de docentes foi de $1,9(\mathrm{DP} \pm 2,0)$ e nos cursos com o conteúdo de CC inserido em outras disciplinas a média foi de 1,0 (DP $\pm 1,5)$, estatisticamente significativa $(\mathrm{p}=0,0084)$. Esta mesma observação, porém comparando os cursos de escolas de gestão privada e pública, não mostrou diferença estatística $(p=0,2522)$.

A média de docentes por região do país é semelhante, com exceção no CO onde a média é mais baixa e no SE mais alta $(\mathrm{p}=0,0255)$ (Quadro 29).

Quadro 29 - Medidas de tendência central e de variabilidade segundo o número de docentes com curso de especialização em CC e a região. Brasil, 2011

\begin{tabular}{ccccc}
\hline \hline Região & Variação & Média (DP) & Mediana & Moda \\
\hline \hline N & $0-5$ & $1,6(\mathrm{DP} \pm 1,6)$ & 1 & 1 \\
$\mathrm{NE}$ & $0-5$ & $1,3(\mathrm{DP} \pm 1,3)$ & 1 & 1 \\
$\mathrm{CO}$ & $0-5$ & $0,8(\mathrm{DP} \pm 1,6)$ & 0 & 0 \\
$\mathrm{SE}$ & $0-6$ & $2,1(\mathrm{DP} \pm 2,0)$ & 1 & 0 \\
$\mathrm{~S}$ & $0-6$ & $1,2(\mathrm{DP} \pm 1,5)$ & 1 & 0 \\
\hline \hline
\end{tabular}


Do total de 158 docentes, 97 (61,4\%) tinham curso de especialização em CC e um $(0,6 \%)$ deles referiu não ter o curso, mas possui o título de especialista pela Sociedade Brasileira de Enfermeiros de CC, Recuperação Anestésica e Esterilização de Material (SOBECC).

Para $53(33,5 \%)$ dos docentes sem curso de especialização em CC, foi relatado que 39 (73,6\%) tinham experiência profissional em bloco cirúrgico, dois $(3,8 \%)$ curso de instrumentação cirúrgica e $12(22,6 \%)$ outros cursos de especialização: três em Enfermagem Médico-Cirúrgica, dois em Unidade de Terapia Intensiva, dois em Administração Hospitalar, um em Enfermagem Cirúrgica, um em Estomaterapia, um em Obstetrícia, um em Estratégia de Saúde da Família, um em Nefrologia.

Alguns cursos detalharam a distribuição de docentes entre a teoria e a prática (Tabela 24). Observa-se nos poucos cursos que ofereceram esta informação, que o modo de condução da disciplina ou do conteúdo é divergente.

Tabela 24 - Frequência de cursos segundo a distribuição entre teoria e prática. Brasil, 2011.

\begin{tabular}{lcc}
\hline \hline \multicolumn{1}{c}{ Distribuição de docentes } & $\begin{array}{c}\text { Total de } \\
\text { docentes }\end{array}$ & № cursos \\
\hline \hline Teoria (1) e prática (1) & 2 & 6 \\
Teoria (1) e prática (2) & 3 & 3 \\
Teoria (3) e prática (2) & 5 & 1 \\
Teoria (2) e prática (3) & 5 & 23 \\
Teoria e prática (2) e docente assistencial(3) & 5 & 1 \\
Teoria (3) supervisor de estágio (2) & 5 & 1 \\
Teoria e Lab (1) e prática (1) & & \\
Teoria e prática (6) & 6 & 1 \\
Teoria (1) e prática & $\ldots$ & 1 \\
Teoria (1) e prática & $\ldots$ & 1 \\
Teoria (1) e prática & $\ldots$ & 1 \\
Teoria (1) e preceptor & $\ldots$ & 1 \\
4 docentes / 50 alunos & $\ldots$ & 1 \\
\hline \hline
\end{tabular}


Com relação à formação strictu sensu a menção foi iniciativa dos respondentes para especificarem a qualificação dos seus docentes. Portanto, não se pode concluir que o número de docentes com pós-graduação strictu sensu sejam apenas os informados. Contou-se 19 (12,0\%) docentes com mestrado e 18 (11,4\%) com doutorado.

Com relação aos docentes com mestrado, estavam distribuídos em 13 (8,1\%) cursos; 11 (57,9\%) em cursos de gestão privada; 15 (78,9\%) em cursos com disciplina específica de CC; dez (52,5\%) na região SE, seis no $\mathrm{NE}(5,3 \%)$, dois $(10,5 \%)$ no S e um $(7,7 \%)$ no $\mathrm{CO}$.

Os doutores estavam alocados em sete $(4,4 \%)$ cursos; $10(55,5 \%)$ em cursos de gestão privada; $15(83,3 \%)$ em disciplinas não específicas de CC; $11(61,1 \%)$ na região SE, seis $(33,3 \%)$ na $\mathrm{CO}$ e um $(5,6 \%)$ no $\mathrm{S}$.

\subsection{DESENVOLVIMENTO DO ENSINO DE CAMPO}

Para as perguntas abertas serão analisados 135 formulários, pois três escolas estenderam suas respostas às outras unidades (24).

Do total de respondentes para as perguntas abertas, $128(94,8 \%)$ informaram como ministram o ensino prático e o conteúdo das respostas foi agrupado nas categorias apresentadas na tabela 25 .

Tabela 25 - Distribuição dos conteúdos das respostas de acordo com as categorias estabelecidas. Brasil, 2011.

\begin{tabular}{lll}
\hline \hline Conteúdo das respostas & N & \% \\
\hline \hline Local de estágio & 58 & 36,0 \\
Estratégia de ensino & 35 & 21,7 \\
Atividades desenvolvidas & 25 & 15,5 \\
Número de alunos/supervisor & 20 & 12,4 \\
Duração & 18 & 11,2 \\
Sem estágio & 5 & 3,2 \\
\hline Total & 161 & 100 \\
\hline \hline
\end{tabular}


Cinco $(3,8 \%)$ cursos não têm ensino de campo, sendo que um deles informou que desenvolvem mesas redondas e trabalhos domiciliares para assimilação do conteúdo teórico prático.

Com relação à categoria local de estágio houve menção de hospitais onde é realizado o estágio ou das unidades utilizadas (Tabela 26).

Tabela 26 - Distribuição dos locais mencionados para desenvolvimento das atividades de campo. Brasil, 2011.

\begin{tabular}{lll}
\hline Locais de prática de campo & N & \% \\
\hline \hline Hospital & 12 \\
CC, RPA e CME & 11 \\
CC & 8 \\
CC e CME & 8 \\
CC, CME e clínica cirúrgica & 4 \\
CC, CC ambulatorial e clínica cirúrgica & 4 \\
CC e RPA & 2 \\
CC, RPA e clínica cirúrgica & 2 \\
CC ambulatorial & 1 \\
RPA e CME & 1 \\
CC e clínica cirúrgica & 1 \\
CC, RPA, clínica cirúrgica e UTI & 1 \\
Enfermaria cirúrgica & 1 \\
Saúde Coletiva, Clínica Cirúrgica, CC & 1 \\
CC, CME, clínica cirúrgica, emergência & 1 \\
\hline \hline Total & 58 \\
\hline \hline RPA - recuperação pós-anestésica
\end{tabular}

Muitos cursos informaram que os alunos fazem um rodízio pelas diferentes unidades com tempos variáveis de estágio. Os respondentes que apenas disseram realizar atividades nos hospitais conveniados $(n=12 ; 9,4 \%)$, não especificaram as unidades utilizadas como campo de prática. As atividades em CME são desenvolvidas por 25 cursos $(18,5 \%)$; o rodízio pela clínica cirúrgica ocorre em 12 cursos $(8,9 \%)$ e o 
CC ambulatorial é utilizado por seis $(4,4 \%)$. Apenas um $(0,7 \%)$ curso não realiza atividades de campo em $\mathrm{CC}$ e um $(0,7 \%)$ outro apenas rodizia os alunos pela recuperação pós-anestésica (RPA).

\subsection{ESTRATÉGIAS PARA O ENSINO PRÁTICO}

As estratégias utilizadas inviabilizaram a categorização do tema. Decidiu-se, então, destacar algumas situações distintas como desenvolvimento de atividades em campo, visitas técnicas, observação, simulação e problematização.

Três $(2,3 \%)$ cursos desenvolvem a prática do ensino apenas com simulação em laboratório de procedimentos de enfermagem (1) ou em sala operatória do campo conveniado (1) e outro apresenta os materiais específicos em sala de aula (1).

Dos cursos, oito $(6,2 \%)$ realizam visitas técnicas às unidades de $\mathrm{CC}$ e $\mathrm{CME}$, sendo que em dois deles há um estágio supervisionado em semestres futuros, em outros dois, após as visitas técnicas os alunos realizam um estágio de observação e, em quatro deles os alunos apenas realizam uma visita técnica. A distribuição dessa forma de ensino de campo ocorre em ambos os cursos, com e sem disciplina específica.

Com relação ao estágio observacional, quatro (2,9\%) cursos utilizam exclusivamente esta estratégia de ensino de campo, porém de diferentes maneiras como se observa nas falas a seguir:

"O campo é no hospital da cidade, o estágio é somente observacional, ocorrendo somente no período de uma semana, passando pelas três areas (CME, Bloco Cirúrgico, RPA). (R-RS.2)

"Os alunos passam no estágio de saúde do adulto no CC para observação apenas” (R-SP.31)

Alguns cursos tem a teoria e o estágio de campo em momentos distintos: 
"O ensino é desenvolvido por meio de aulas teóricas expositivas, os professores levam até os discentes ilustrações, materiais que podem ser levados até a sala de aula, cita exemplos e situações, estudos de caso, mas durante a teoria o aluno não tem uma aproximação prática do conteúdo teórico, ficando isso para o último ano da graduação” (RPR.10)

"No primeiro bimestre há uma concentração de conteúdo teórico e no segundo os alunos vão para prática em Centro Cirúrgico de Hospital conveniado e a prática de instrumentação cirúrgica, bem como CME ocorre em laboratório de perioperatória” (R-PR.4)

Encontraram-se situações em que não foi possível compreender se o aluno desenvolve cuidados de enfermagem no ensino prático:

"O desenvolvimento do campo de ensino se baseia na assimilação teoriaprática com o aluno. Com mesa redonda e trabalhos domiciliares de pesquisa repassados aos alunos pelos professores" (R-MT.2)

"Inicialmente é realizado uma aula teórica para apresentação do campo (conceitos) e os demais dias a teoria é ensinada no próprio campo com discussão de casos e sínteses elaborados pelos próprios alunos. Então o aluno vivencia a prática junto com o paciente” (R-AL.1)

"O ensino é desenvolvido no campo através de uma metodologia problematizadora, com a utilização do portfólio de ensino do aluno e do professor é acompanhado todo seu desenvolvimento em situações da prática / real do CC, através de estratégias e da pesquisa" (R-SC.3)

Alguns associam diversas estratégias em sala de aula, no laboratório de procedimentos, em campo de estágio e atividades interdisciplinares com outras áreas desenvolvendo treinamentos:

"O ensino se subdivide em laboratório e campo de estágio. Em laboratório o professor realize práticas laboratoriais com bonecas e pinças. Muitas vezes utilizam vídeos e simulações. Em estágio o aluno conhece as divisões da área cirúrgica e permanece em cada área para aprender e desenvolver o trabalho da mesma. A participação $e$ observação em cirurgias também é realizada por equipes. Assim conseguem observar o trabalho desenvolvida pelas enfermeiras $e$ instrumentadora" (R-GO.5) 
"Desenvolvemos nossas atividades em nosso hospital escola, trabalhamos com o hospital veterinário e clinica de órteses e próteses da IES no auxilio a treinamentos dos colaboradores no processo de assepsia e esterilização de materiais. Campo prático - estágio” (R-PR.3)

Alguns cursos adotam estilos tradicionais de atividades de campo voltados principalmente para o desenvolvimento de habilidades procedimentais:

"Tanto o ensino clínico quanto o estágio curricular os alunos são acompanhados por um Enfermeiro supervisor de estágio/ensino clínico", (R-MG.3)

"O aluno desenvolve atividades de circulação de sala, instrumentação, procedimentos intra-operatórios de enfermagem, visita pré e pós operatória, recepção de paciente e cuidados na RPA" (R-SP.1)

"O discente inicia o ensino clínico tendo noções de como receber o paciente no CC e encaminhar o mesmo para SO, em um segundo momento receber o paciente na sala, auxiliando a monitorização, indução anestésica, posicionamento e assiste ao procedimento, para ter uma noção do tempo cirúrgico, o próximo passo é ajudar no termino do procedimento (curativo), conversão da anestesia e encaminhamento do paciente para RPA, em um momento, ele receberá o paciente na RPA, monitorizando e realizando o indice de Aldret e escala de Ransay e alta do paciente" (R-SP.3)

"O aluno assume o centro cirúrgico, segundo sua escala, com o professor/preceptor de centro cirúrgico. Posteriormente seu trabalho é analisado e debatido pelos demais professores e gerente de enfermagem do Hospital. É oferecida a atividade profissional não obrigatória em Centro Cirúrgico, extra horário formal do curso, onde a adesão é de dois a três alunos por tarde de prática" (R-RJ.4)

Em alguns cursos, os alunos desenvolvem atividades de observação em sala operatória e cuidados de enfermagem somente na RPA:

"Estágio de observação nas salas cirúrgicas e cuidados integrais na Sala de Recuperação" (R-SC.2)

"Os alunos acompanham o enfermeiro na gestão do CC por um dia; acompanham o circulante de sala cirúrgica e o auxiliar de anestesia por um dia. Ficam na sala de recuperação e prestam cuidados identificando o diagnóstico de enfermagem, monitorando, medicando...” (R-SP.20) 
Entende-se a maior facilidade do aluno em assistir o paciente na RPA, pois esta situação o aproxima das atividades desenvolvidas em unidades de internação, apesar da situação crítica no paciente em recuperação pós-anestésica.

As atividades desenvolvidas pelos alunos foram variadas, com cursos onde os alunos têm oportunidade de vivenciar todas as ações do processo perioperatório e outros em que vivenciam parte dele. A tabela 27 apresenta as principais atividades informadas.

Tabela 27 - Distribuição das atividades desenvolvidas pelos alunos em campo de prática. Brasil, 2011.

\begin{tabular}{|c|c|c|}
\hline Atividades desenvolvidas & $\bar{N}$ & \% \\
\hline Circulação de sala & $\overline{66}$ & \\
\hline Cuidados de enfermagem & 6 & \\
\hline Instrumentação & 6 & \\
\hline Recepção do paciente na SO & 4 & \\
\hline Cuidados na RPA & 4 & \\
\hline Cuidados intra-operatórios & 3 & \\
\hline Atividades de pré-trans-pós & 3 & \\
\hline SAEP & 3 & \\
\hline Visita pré & 2 & \\
\hline Visita pós & 2 & \\
\hline Inespecíficos & 2 & \\
\hline Acompanhamento do processo da admissão à alta & 2 & \\
\hline Preparo do ambiente & 1 & \\
\hline Cuidados pré e pós-operatórios & 1 & \\
\hline Total & 45 & \\
\hline
\end{tabular}

As atividades mais mencionadas foram aquelas relacionadas à sala operatória. Houve pouca menção da realização do SAEP, uma atividade exclusiva do enfermeiro de CC. 
O número de alunos por supervisor de estágio também foi variável, com uma tendência para 5 ou 6, embora tenha-se encontrado cursos que formam grupos de estágio com até 9 alunos (Tabela 28)

Tabela 28 - Distribuição do número de alunos por supervisor de estágio. Brasil, 2011.

\begin{tabular}{cl}
\hline \hline Número de alunos por supervisor & $\mathbf{N}$ \\
\hline \hline 3 & 3 \\
4 & 1 \\
5 & 6 \\
6 & 6 \\
7 & 1 \\
8 & 1 \\
9 & 2 \\
\hline \hline
\end{tabular}

Alguns respondentes caracterizaram a figura do supervisor: docente, enfermeiro institucional, preceptor ou enfermeiro assistencial.

O período de campo de prática abordou diferentes aspectos: a duração em dias ou carga horária, freqüência semanal (Tabela 29).

Tabela 29 - Distribuição dos cursos segundo tempo de estágio. Brasil, 2011.

\begin{tabular}{ll}
\hline \hline Tempo & $\mathbf{N}$ \\
\hline \hline 4 dias em cada setor & 1 \\
4 dias & 1 \\
5 dias & 1 \\
6 dias & 2 \\
7 dias & 3 \\
9 dias & 2 \\
10 dias & 2 \\
12 dias (2 dias/semana) & 1 \\
1 vez/semana & 2 \\
6 h CME e 12h CC & 1 \\
105 h CC e CME & 1 \\
1 dia no 70 sem e 8 dias no 80 sem & 1 \\
\hline \hline
\end{tabular}




\subsection{COMENTÁRIOS SOBRE O CONTEÚDO DA DISCIPLINA}

De todos os respondentes, 84 (62,2\%) fizeram algum tipo de comentário a respeito do conteúdo de CC: 21 (25,0\%) detalharam informações sobre conteúdo, carga horária, objetivos; 16 (19,0\%) emitiram opiniões sobre a carga horária e a densidade do conteúdo; $12(14,2 \%)$ sobre a importância do conteúdo; oito $(9,5 \%)$ sobre a disciplina ser específica ou não; cinco $(6,0 \%)$ (des)vantagens de disciplina (in)específica; quatro $(4,8 \%)$ sobre atualização de conteúdo; quatro $(4,8 \%)$ sobre dificuldades e outros $(n=14$; $16,7 \%)$.

Para este tema optou-se por apresentar as falas mais significativas, pois muitos dos comentários se repetem com informações já descritas.

$\mathrm{O}$ conteúdo de $\mathrm{CC}$ tende a ser denso, porque além dos procedimentos próprios do intra-operatório o processo de enfermagem desenvolvido no centro cirúrgico também apresenta variações daquele que o aluno vivencia nas unidades de internação. Além disso, a carga horária reservada a ele nas matrizes curriculares não têm favorecido os alunos e professores.

"Muito condensado pela importância dada no mercado de trabalho ao enfermeiro de CC e a necessidade deste profissional. Acredito que o conteúdo oferecido, permite que o aluno tenha um conhecimento básico de CC, das técnicas assépticas e da assistência ao paciente crítico" (RSP.1)

"Acredito que o conteúdo de CC deva ser mais abrangente, tem temas atuais que deveríamos abordar mas não temos carga horária, a carga horária é muito pouca. As questões da biossegurança, controle de infecção e gestão" (R-SC.3)

"Percebo que a carga horária é insuficiente e a falta de estágio é no mínimo preocupante diante da evolução tecnológica neste meio, e exigência de adequações ao controle da infecção hospitalar"(R-BA.3)

A distância entre os momentos da teoria e da prática de campo também foi criticada por alguns respondentes: 
"Acho o conteúdo bom, mas poderia ser melhor administrado com uma carga horária maior. $O$ estágio deveria ser no mesmo período da disciplina teórica” (R-GO.7)

“Poderia ter a prática associada a teoria” (R-SP.26)

Enquanto para um dos respondentes a disciplina é complexa para o estudante de enfermagem, outros a vêem como uma oportunidade de utilizar conteúdos previamente oferecidos ao aluno:
"É uma disciplina com conteúdos complexo ao conhecimento do acadêmico" (R-AM.2)

"Trata- se de uma disciplina dinâmica, interativa em que o discente interage com situações de Urgência e Emergência, tendo que assistir o seu cliente como um todo em suas necessidades básicas. Não é apenas o procedimento em si, para acontecer é preciso planejamento" (R-TO.1)

"Deveras importante a vivência desta realidade, principalmente sobre a humanização entre profissionais X clientela X familiares. Oportuniza aprofundamento de conteúdo sobre Controle de Infecção hospitalar, anatomia, entre outros" (R-PR.11)

Um respondente valorizou mencionar a referência básica para o ensino de CC:

"Procuro seguir as práticas da SOBECC em minhas aulas teóricas" (RGO.4)

Dificuldades se apresentam no ensino desse conteúdo por questões de infraestrutura ou pela necessidade de estratégias para motivar os alunos que iniciam a disciplina com ideias pré-concebidas de que não tem afinidade pelo conteúdo de CC:

"Não é um conteúdo elou prática que atraia os nossos alunos. Eles preferem UTI e clínicas" (R-RJ.4)

"Como é uma disciplina muito específica e ministrada ainda no $4^{\circ}$ periodo, percebemos uma dificuldade em compreender a taxonomia cirúrgica, uma necessidade de incentivar os alunos a aplicarem a SAE e não se prender apenas às técnicas cirúrgicas” (R-MG.2) 
"O conteúdo é suficiente, mas a prática é dificultada pela quantidade de professores" (R-GO.2)

"Gostaria da possibilidade de melhorar o campo de estágio para a vivencia na prática” (R-SP.31)

Mas iniciativas não faltam para estimular os alunos a refletirem e a discutirem a prática de enfermagem em centro cirúrgico:

"Durante a prática o aluno é constantemente questionado sobre fatores relacionado ao papel do enfermeiro no controle de infecção, modelos de liderança e estresse dos profissionais de CC, CME e RPA e segurança do paciente" (R-SP.4)

Ser ou não ser uma disciplina específica tem vantagens e desvantagens que somente podem ser percebidas depois de vivenciadas:

"Infelizmente o conteúdo foi perdido quando a disciplina foi incorporada em Saúde do Adulto. Também é preocupante a inviabilização do estágio, especialmente no que se refere a central de material e processo de esterilização" (R-SP.16)

"Em 2010 retornamos com este conteúdo em separado de Reprocessamento de Artigos Hospitalares e de CC” (R-SP.24)

"Deveria ter uma disciplina específica para este conteúdo, pois acredito ser uma área a qual necessita da atuação de enfermeiros, o campo está em constante crescimento pelo desenvolvimento da complexidade das atividades" (R-MG.14)

“Acho que deveria ser uma disciplina separada” (R-DF.1)

"No momento em que estamos implementando esse projeto (pedagógico), percebemos a necessidade de algumas adequações. Considero que seria oportuno a elaboração de uma ementa especifica para a assistência em Enfermagem em Centro Cirúrgico, pois haveria maior agregação dos saberes e proporcionaria ao acadêmico uma visão mais ampla das atribuições do enfermeiro nessa área” (R-MT.1)

Cursos que ofereciam a disciplina no formato de optativa aos alunos, com o tempo a tornaram de caráter obrigatório e outros a fundiram a disciplina de enfermagem cirúrgica: 


\begin{abstract}
"Antes era oferecido como disciplina optativa, atualmente faz parte da matriz como disciplina obrigatória” (R-BA.2)

"Inicialmente possuíamos 2 disciplinas: adulto 2 que abordava conteúdo de enfermagem cirúrgica (internação) e a de CC e CME que abordava exclusivamente o bloco operatório. Em recente reformulação fundimos as duas disciplinas para que houvesse continuidade” (R-MG.)
\end{abstract}

O conteúdo de centro cirúrgico está crescentemente agregando novos conhecimentos e as práticas de enfermagem precisam se adequar ao desenvolvimento de tecnologias utilizadas no procedimento cirúrgico.

“A cada semestre atualizamos o conteúdo, para que possamos oferecer um bom conteúdo da unidade temática Enfermagem em Centro Cirúrgico para os futuros enfermeiros" (R-PA.4)

Inicia-se o século XXI com os cursos envolvidos em suas reformas curriculares, alguns reduzindo a carga horária, outros ampliando-a para se adequar à legislação, e alguns conteúdos, como o de CC, estão sempre em debate para sua extinção ou manutenção dada a característica de especialidade.

"Fico muito feliz com essa busca, se não trabalharmos em conjunto corremos sérios riscos de ver extinta dos programas de ensino a carga horária (já reduzida) especifica de CC. Também para que possamos conscientizar os colegas enfermeiros e docentes da importância do CC no contexto da formação" (R-RS.7)

"É imprescindível para a formação do enfermeiro, e lamentavelmente tenho conhecimento de instituições que não tem a disciplina específica no currículo" (R-SP.5)

Os estudantes gostam muito dos conteúdos e das "Práticas Clínicas e Educativas" de Enf. em CC. Ouve-se que em algumas Faculdades brasileiras o ensino deste conteúdo está sendo retirado do currículo ou perdendo destaque. A posição do corpo docente da Enfermagem da ... é que: "se você não souber a teoria, o como fazer e um pouco das relações que se desenvolvem em um CC, como você poderá ser um Enfermeiro neste ambiente? Aqui no interior não se consegue esperar que um Enfermeiro se desloque a um grande centro para fazer uma especialização nesta área, então acreditamos estar nos adequando a realidade" (R-RS.5) 


\subsection{OPINIÃO SOBRE O CONTEÚDO NA FORMAÇÃO DO ALUNO}

As respostas relativas à pergunta "Qual a sua opinião sobre este conteúdo na formação do aluno? foram 78 (57,8\%). À exceção de quatro respostas, as falas utilizaram os seguintes adjetivos para caracterizar o conteúdo: importante, relevante, imprescindível, necessário, essencial e fundamental.

Nesta análise, independente da freqüência de cada tema, optou-se por ressaltar os aspectos mais debatidos na prática dos docentes de CC.

O conteúdo foi considerado importante para despertar o interesse do aluno para estas áreas e ampliar sua visão sobre o campo de atuação do enfermeiro:

"Importante para despertar nos alunos o interesse por este conteúdo e depois fazer uma Pós Graduação específica” (R-ES.2)

"Importante para a capacitação profissional do enfermeiro e para a orientação vocacional em uma posterior especialização” (R-MT.1)

"Muito importante, pois alem do aprendizado do conteúdo das aulas, observa-se o interesse do aluno no campo profissional especifico em CC e CME” (R-RJ.2)

"Muito relevante eu acredito que o acadêmico deve ter uma visão especifica das áreas hospitalares até para decidir qual pós graduação quer fazer" (R-GO.4)

"Os alunos, a partir da disciplina de CC, mostram maior motivação pela profissão, pois representa sempre uma descoberta, as quais despertam sempre mais curiosidade e assim a descoberta das possibilidades de exercitar uma das especialidades da enfermagem" (R-CE.2 )

O centro cirúrgico, por ser uma área fechada, fica distante do campo de aprendizado do graduando de enfermagem e a oferta deste conteúdo na graduação the permite o acesso a este conhecimento específico e a esta área assistencial dotada de peculiaridades:

"É de suma importância, pois é durante a academia, vivendo as práticas que descobrimos a importância desse aprendizado" (R-GO.3) 
"Conteúdo importante na formação do profissional, pois antes de cursarem a disciplina não valorizam o papel do enfermeiro de Centro Cirúrgico”(R-BA.1)

"É de suma importância por se tratar de um setor fechado de alta complexidade e que atrai a atenção dos alunos pelas suas peculiaridades" (R-AP.1)

Dada às inovações tecnológicas e as peculiaridades do cuidar em $\mathrm{CC}$, as modificações no conteúdo ou nas estratégias de ensino são frequentes:

"É muito conteúdo, mas a cada semestre fazemos algumas modificações (atualização) para que o aluno consiga fazer do conteúdo uma ferramenta de trabalho" (R-PI.3)

O conteúdo de CC é importante para a compreensão do processo saúde doença, pois o tratamento que paciente recebe no $\mathrm{CC}$ faz parte do que Leavell e Clark ${ }^{\mathrm{a}}$ denominaram de prevenção secundária a saúde.

"Fundamental para a compreensão do processo de saúde, da manutenção da higidez do paciente” (R-PR.2)

O conhecimento nesta área auxilia o aluno a compreender o papel do processo de trabalho na prevenção e controle de infecções hospitalares, principalmente, as relacionadas ao sítio cirúrgico. É um conteúdo transversal a outras áreas de conhecimento da enfermagem.

"Conteúdo de extrema importância na formação do enfermeiro. Pode ser o diferencial inclusive para o controle de infecções hospitalares. $O$ enfermeiro de centro cirúrgico precisa ter todo o conhecimento dos riscos (ao paciente), que estão envolvidos em sua atuação" (R-MG.1)

"O conteúdo é adequado na formação do aluno de graduação visto que a interdisciplinaridade esta presente em todos os componentes curriculares" (R-GO.1)

\footnotetext{
${ }^{a}$ Leavell HR, Clark EG. Medicina Preventiva. SP, McGraw-Hill do Brasil, RJ FENAME, 1978
} 
"O conteúdo é de grande importância. Abrange diversos conhecimentos, que mesmo não sendo a opção do alunado para especialização, trarão conhecimentos significativos em procedimentos importantes, como medidas assépticas, controle e medidas de desinfecção e esterilização, prevenção de infecções de sitio cirúrgico, aplicação da SAEP, dentre outras" (R-CE.1)

É interessante como os enfermeiros de regiões com menor número de leitos hospitalares, principalmente cirúrgicos, são capazes de perceber a interdisciplinaridade do conteúdo de CC com o nível de atenção primária a saúde.

"É necessário, pois de alguma forma o enfermeiro terá que informar os pacientes sobre o que ocorre antes, durante e depois de um procedimento cirúrgico, seja numa UBS nos programas de saúde pública, seja no HOSPITAL” (R-AM.1)

Por diversas colocações dos respondentes parece indiscutível a relevância deste conteúdo na formação do graduando em enfermagem:

"O aluno desenvolve senso crítico sobre pontos bastante relevantes no contexto do cuidar e proteger o paciente cirúrgico. Isso é notório quando realizamos discussão dos casos e das situações vividas na prática” (RSP.4)

“É tão importante quanto qualquer outra disciplina da área assistencial” (R-SP.5)

"Considero esses conteúdos muito pertinentes e importantes para a formação do enfermeiro, independente de onde ele venha ou deseje trabalhar" (R-RJ.3)

"Acho indispensável para a formação acadêmica. O centro cirúrgico não pode ser um "limbo", "hiato", na vida do paciente. Muitas complicações seriam evitadas no pós operatório se realmente as intercorrências com o paciente fossem todas registradas" (R-MG.4)

"Faz parte da formação profissional e é fundamental que o acadêmico em formação conheça todas as áreas de atuação do profissional enfermeiro e sua importância ... neste espaço de atuação do enfermeiro" (R-PI.1) 
Um dos respondentes, além de reforçar a relevância do conteúdo de CC, também expressou a necessidade da disciplina ser específica para melhor abordagem do conteúdo:

"É um conteúdo de extrema importância na formação do aluno, por envolver conceitos, técnicas e cuidados próprios deste campo de atuação, e que não poderiam ser abordados de forma satisfatória se fossem diluídos em outras disciplinas" (R-RS.4)

Independente da região onde se localize o curso, parece ser senso comum de que o conteúdo básico de CC é parte essencial da formação generalista do enfermeiro:

"Conteúdos são de grande importância na formação geral do estudante de enfermagem" (R-DF.4)

"Os conteúdos desenvolvidos tanto na teoria quanto na prática da disciplina são imprescindiveis na formação do enfermeiro, mesmo que seja generalista, uma vez que a experiência cirúrgica é vivenciada por pessoas de todas as idades e em todas as especialidades" (R-SP.8)

"Assim como outros conteúdos, a formação do enfermeiro deve ser generalista por isso esta disciplina é de fundamental importância" (R.GO.5 / R49)

"O conteúdo é básico, porém essencial na formação de um enfermeiro com visão generalista” (R-SP.10 / R50)

"Parte importante do currículo de formação generalista" (R-SC.2 / R62)

"O conteúdo abordado é fundamental para a formação de profissionais generalistas. Sabemos que muitos profissionais, em sua trajetória, permeiam por diferentes áreas e especialidades nas instituições de saúde antes de cursarem especializações e os conhecimentos ofertados auxiliam estes profissionais na fundamentação de sua prática profissional" (RRO.1)

"Apesar do entendimento de várias equipes institucionais de ensino superior de que as nossas Diretrizes Curriculares Nacionais apontam para uma formação generalista do enfermeiro, voltada para a assistência básica de saúde, segundo as necessidades de expansão do SUS, e algumas IES terem suprimido a abordagem da enfermagem em centro cirúrgico das suas matrizes curriculares, a equipe de docentes do Curso, 
juntamente com a sua Coordenação, avaliam que os alunos necessitam de uma formação geral que contemple a possibilidade de atuação futura em múltiplos campos da atuação de enfermagem, considerando a capacitação dos mesmos para a assistência cirúrgica de importância prioritária para o seu sucesso na vida profissional futura" (R-PB.1)

Apesar das necessidades de leitos cirúrgicos no país, das longas filas de espera para a realização de cirurgias no âmbito dos hospitais do SUS, ainda na categoria de enfermeiros-docentes há uma falta de reconhecimento da importância deste conteúdo na formação generalista do enfermeiro:

"É imprescindível, mas não é valorizado por todos os docentes de outras áreas: não há informação entre os docentes de que este conhecimento adentra até em saúde pública, nas salas de PS, suturas, pequenas cirurgias, etc." (R-GO.2)

Na luta incessante de manter o conteúdo de CC na grade curricular, há cursos que recorrem a pesquisa para impedir a sua exclusão por ocasião das reformas curriculares.

“...Como ocorreu uma possibilidade do curso excluir essa disciplina do currículo, quando houve uma reestruturação, fizemos uma pesquisa com os acadêmicos (tanto os que cursaram a disciplina de CC, quanto os que não cursaram) e $100 \%$ dos alunos pesquisados avaliaram a disciplina como INDISPENSÁVEL para a formação do enfermeiro” (R-RS.2)

Todo curso de formação profissional deve estar alinhado com as demandas de mercado para preparar o aluno para sua inserção profissional com autonomia e confiança.

"É bastante importante, principalmente para a região Norte, pois os Enfermeiros que desenvolvem suas atividades no interior do Estado, em geral organizam o serviço de Enfermagem em CC e CME” (R-PA.2)

"É indispensável visto que todo o curso forma o aluno generalista, com a disciplina podemos especificar um tópico da profissão onde a oferta de emprego é grande" (R-MG.6 )

"Vital para sua formação, pois é um ambiente com peculiaridades e de dificil permanência do enfermeiro” (R-PR.6) 
“... Numa graduação há necessidade de conhecimentos gerais. Observamos, na nossa cidade, falta de enfermeiros em Centro Cirúrgico” (R-RJ.4)

"Essencial, pois quando o mesmo vai para o mercado de trabalho não sabe qual setor ou área irá desenvolver seu trabalho" (R-MS.1)

"É de suma importância, pois devemos capacitar os discentes para atuarem neste setor que faz parte da estrutura hospitalar, uma vez que o enfermeiro deve ter capacidade e habilidade para poder atuar $e$ gerenciar os serviços e ninguém sabe onde irá atuar" (R-PB.4)

"Como grupo de professores do curso, acreditamos neste conteúdo como muito importante, pois ele contribui para o/a estudante sustentar melhor sua atuação em vários ambientes, principalmente, de alta complexidade. Também acreditamos que este conteúdo ajude nosso egresso a se estabelecer melhor como futuro Enfermeiro de um CC, pois aqui na região não há a opção de especialização na área e estamos muito distantes da capital" (R-RS.5)

Embora se configure o conteúdo de CC como de formação geral e básica, para um dos respondentes ainda há duvidas sobre o que vem a ser "básico":

"O conteúdo ministrado é básico ????????”(R-SP.14)

\subsection{IMPORTÂNCIA DO CONTEÚDO PARA A ATUAÇÃO PROFISSIONAL DO ENFERMEIRO}

Do total de respondentes para as perguntas abertas, $125(92,6 \%)$ emitiram alguma opinião a respeito da importância do conteúdo para a atuação profissional do enfermeiro. Embora algumas respostas abordaram assuntos semelhantes ao da pergunta sobre a importância do conteúdo para a formação do graduando, elas foram consideradas novamente nesta análise, pois foram consideradas importantes.

A análise de conteúdo das respostas permitiu quantificá-las por temas apresentados na tabela 30 . 
Tabela 30 - Distribuição de opiniões emitidas sobre a importância do conteúdo para a atuação do enfermeiro. Brasil, 2011.

\begin{tabular}{lcc}
\hline \hline Tema & N & \% \\
\hline \hline Atuação profissional & 29 & 23,2 \\
Interface com outras áreas & 16 & 12,8 \\
Continuidade dos cuidados & 14 & 11,2 \\
Carga horária pequena & 8 & 6,4 \\
Permite iniciar atuação no CC & 8 & 6,4 \\
Formação generalista & 6 & 4,8 \\
Reconhecer papel do enfermeiro & 6 & 4,8 \\
Visão ampla precisa aprofundar & 5 & 4,0 \\
Demanda de mercado & 4 & 3,2 \\
Outros* & 31 & 23,2 \\
\hline \hline Total & 125 & 100 \\
\hline \hline
\end{tabular}

*Freqüência $\leq 2$

O maior número de falas foi em relação à importância do conteúdo para atuação profissional, pois conhecer todo o processo vivenciado pelo paciente cirúrgico, inclusive suas necessidades de cuidado no intra-opertório, são imprescindíveis para a assistência do paciente cirúrgico em qualquer unidade onde esteja alocado. A seguir apresentam-se falas de diferentes regiões do país evidenciando a importância desse conteúdo para a atuação do enfermeiro em ambientes hospitalares.

"O enfermeiro que atua no contexto hospitalar necessita ter conhecimento desse conteúdo, pois independentemente da unidade que ele atua, ele terá contato com pacientes pré e pós-cirúrgicos” (R-RS.3)

“... o enfermeiro deve ter o conhecimento sobre o procedimento cirúrgico para melhor assistir elou aplicar a SAE no pré- operatório, por exemplo, em clínica cirúrgica e também no pós-operatório, na UTI ou na clínica cirúrgica..." (R-SP.11)

“... mesmo que após formado o egresso do curso não venha atuar dentro de um CC, ele poderá atuar em unidades de pré e pós-operatório ou até mesmo clínica médica, e por possuir estes conhecimentos, melhor assistirá aos pacientes...” (R-BA.5) 
"É fundamental esse conhecimento para o atendimento em clínicas cirúrgicas para a avaliação e preparo pré-operatórios, assistência pósoperatória imediata e mediata" (R-GO.6)

A experiência obtida no CC proporciona ao aluno oportunidades de conhecer diversas tecnologias que vem sendo utilizadas na realização de procedimentos cirúrgicos minimamente invasivos.

“... proporciona conhecimento sobre avanços tecnológicos.”(R-BA.6)

A atuação do enfermeiro em $\mathrm{CC}$ contribui para a redução de riscos e complicações decorrentes dos procedimentos cirúrgicos e, consequentemente, para a melhoria dos indicadores de qualidade assistenciais.

"De grande importância, pois todos os cuidados desenvolvidos pela equipe de enfermagem no $C C$, proporcionam uma diminuição de riscos $e$ complicações para os clientes no trans e pós-operatório, gerando bons indicadores para todo o hospital" (R-PB.5)

Ainda dentro desse tema, alguns respondentes ampliaram a importância desse conteúdo para além do nível hospitalar ou assistencial, como por exemplo, a utilização deste conhecimento para fins de gerenciamento de recursos humanos e materiais:

"Os Enfermeiros são responsáveis pela infra-estrutura, organização e funcionamento do CC e CME nos Hospitais Regionais do Estado do Pará” (R-PA.3)

O número de enfermeiros que atua nos diferentes estabelecimentos de saúde é diferente a depender das políticas de dimensionamento de pessoal, tipo de gestão, filosofia do hospital e disponibilidade do profissional no mercado de trabalho.

"É indispensável, principalmente em cidades com hospitais menores, em que sabemos que não existe um enfermeiro exclusivamente no centro cirúrgico. Geralmente o que acontece é um enfermeiro assumindo a responsabilidade por todos os setores" (R-MG.16)

Dada a política de diminuição do tempo de internação, com o fim de diminuir custos hospitalares e complicações iatrogênicas aos pacientes, é provável que em 
unidades de atenção básica a saúde ou até na assistência domiciliar o profissional de saúde se depare com o atendimento de pacientes em pós-operatório, seja em recuperação, seja com complicações.

"O enfermeiro tanto no contexto hospitalar como da atenção básica necessitam compreender o cuidado da pessoa em situações cirúrgicas, visto o curto período de internação par atos cirúrgicos" (R-SP.9)

A filosofia de cuidado integral ao paciente tem por base a continuidade de cuidados. O enfermeiro não tem como assistir um paciente e a família integralmente da sua admissão a alta e, portanto, depende da interação com seus colegas de outras unidades e de conhecimento sobre todas as etapas do processo de cuidado ao paciente cirúrgico.

"O enfermeiro bem formado poderá contribuir para dar todos os encaminhamentos necessários para que uma cirurgia sejas bem sucedida ou menos traumática para o paciente e sua família” (R-AM.1)

"É de suma importância para a continuidade de sua assistência no contexto hospitalar e comunitário" (R-PR.3)

"Muito importante, pois trata do paciente em um momento especifico, e que muitas vezes estão envolvidos, nesse processo, vários enfermeiros, não somente os do centro cirúrgico" (R-SP.17)

"No contexto hospitalar, o conhecimento sobre o conteúdo em CC facilita a assistência do profissional nos serviços de forma geral, tendo em vista, que este conhecimento pode fornecer uma visão holística do paciente sobre os cuidados com a saúde" (R-PI.2)

"No meu ponto de vista, ter uma boa noção sobre CC facilita a atuação do enfermeiro nos diversos setores hospitalares. O enfermeiro que conhece um tratamento cirúrgico do pré ao pós operatório, certamente terá maior chance de planejar a assistência do cliente" (R-PR10)

Para o tema interface entre as áreas também foram agregadas falas sobre a transversalidade e interdisciplinaridade do conteúdo de centro cirúrgico e também de centro de material e esterilização (CME). Foi através das perguntas abertas que se verificou que em muitos cursos o conteúdo de CME é dado conjuntamente ao de centro 
cirúrgico. As falas a seguir retratam como estes conteúdos específicos são utilizados na assistência ao paciente em outras unidades de cuidado e sua importância m atividades de gerenciamento de enfermagem.

"o conteúdo é transversal, sendo utilizado em diversas áreas/setores hospitalares" (R-RS.9)

"O conteúdo proporciona conhecimentos para fundamentar a assistência de enfermagem em centro cirúrgico, CME, em clínica cirúrgica e para prevenção e controle de infecção hospitalar e em unidades que tenham procedimentos cirúrgicos e exames diagnósticos" (R-RO.1)

"O CC e a CME interferem no dia a dia de todo hospital (taxa de ocupação dos leitos, ritmo de financiamento e atendimento)...” (R-RJ.3)

"Muito importante para o ensino de outras especialidades. O enfermeiro deve compreender que as atividades desenvolvidas no Centro Cirúrgico são fundamentais para a manutenção das atividades em todos os setores do hospital" (R-PR.2)

Foi interessante observar que em diferentes regiões do país se tem a clara compreensão de que o conteúdo de CC e de CME oferece apoio para a assistência em estabelecimentos de saúde que não se configuram em unidades hospitalares, como os serviços de atenção primária a saúde, os ambulatórios especializados e as clínicas particulares.

“... conteúdo contribui para a formação do enfermeiro não só no contexto hospitalar, mas também no contexto de atuação em saúde coletiva, atuando em UBS, AMAS, onde o enfermeiro atua no controle de infecção, limpeza, desinfecção e esterilização de artigos, em pequenos procedimentos cirúrgicos, onde os mesmos princípios podem ser aplicados". (R-SP.15)

"Tanto no contexto hospitalar quanto na atenção primária são importantes. No primeiro caso, conhecer rotinas, processos e o ambiente em si. No segundo, para prover as condições necessárias para o trabalho e orientação pré e acompanhamento pós (operatório), garantindo-se a referência e contra-referência" (R-MG.16) 
"Extremamente importante, não só para a atuação na área hospitalar, mas também em muitas clínicas particulares que oferecem serviços de pequenas cirurgias e exigem conhecimento deste conteúdo” (R-SC.4)

O CC é uma unidade hospitalar que contribui para o aporte financeiro aos hospitais, onde trabalham diversas equipes de médicos especialistas e a sincronia de trabalho no ambiente tem repercussões não somente nas unidades de internação do paciente, mas no agendamento e movimento cirúrgico do hospital.

"As vivencias oportunizadas em $C C$ e $S R$ (recuperação) permitem ao acadêmico identificar a importância que a área representa para o hospital, tanto financeira quanto política e administrativa, também visualizar os conflitos existentes entre as equipes que atuam nesses setor" (R-RS.7)

Os respondentes manifestaram-se em relação à carga horária como insatisfatória para o início da atuação recém formado em $\mathrm{CC}$ e sua importância para o início da vida profissional em centro cirúrgico.

“... entretanto, o conteúdo é denso para pouco tempo de curso” (RMA.1)

“Insuficiente para atuação satisfatória do recém formado” (R-SP.26)

“... sou especialista na área e tenho experiência, porém quando iniciei meu trabalho em Centro Cirúrgico, tinha muitas dúvidas, pois na minha graduação o ensino foi deficitário e mecânico, por isso, acredito que é relevante que a disciplina seja ensinada" (R-PR.4)

Também se comentou a oportunidade de aumento da carga horária com as mudanças curriculares e permitir que o contato com essa área possa oferecer ao aluno mais uma possibilidade de escolha profissional.

“... insuficiente, mas com a nova estrutura curricular, o aluno poderá ter contato com o conteúdo e com isto a oportunidade de ter afinidade com o mesmo, para poder escolhê-lo como especialidade profissional..." (RMG. 14) 
A fala a seguir fala do efeito negativo de um conteúdo reduzido sobre o aluno de graduação, decorrente da diminuição da carga horária no curso do respondente, além da repercussão sobre o mercado de trabalho.

“... esse pouco tempo não mostra para o aluno o dia a dia da prática do enfermeiro nessa unidade deixando-o ainda inseguro para atuar nessa unidade. Acredito que ainda conseguimos nos inserir nas atividades do CC como monitorização dos acidentes, ajuda no posicionamento e na indução anestésica na sala de recuperação porque já faz muito que a docente é a mesma adquirindo confiança da equipe cirúrgica e de enfermagem. $O$ que tenho percebido na prática é pouca opção dos enfermeiros por essa área porque ficam com medo (medo do desconhecido)" (R-SP.20)

Dentro do tema permite iniciar atuação no $\boldsymbol{C}$ destacaram-se falas a respeito do planejamento da assistência perioperatória, o preparo básico para o início profissional e a introdução do aluno ao raciocínio clínico nessa área:

"Imprescindivel para o enfermeiro poder iniciar sua atuação em $C C$. Este conteúdo permite que o enfermeiro adquira conhecimento sobre cirurgias e o impacto do procedimento na recuperação do paciente, de modo que possa fazer o planejamento da assistência..." (R-SP.1)

"Ele tem condições de atuar no cenário cirúrgico, pois ele tem acesso ao básico e muito mais.” (R-PI.3)

"A graduação desenvolve a fundamentação, a pós- graduação a complementação e a prática o aperfeiçoamento. O conteúdo ministrado deverá fundamentar e preparar o pensamento crítico do aluno, bem como prepará- lo para a prática profissional." (R-SP.25)

Algumas falas retomam a questão da formação generalista do enfermeiro, um assunto com amplas interpretações e contradições, e que tem sido utilizado para direcionar as matrizes curriculares.

"Indispensável para a formação do enfermeiro generalista, pois este conteúdo não é especialização, como muitos colegas pensam” (R-RS.2)

"O enfermeiro deve saber atuar em diversas áreas. A medida que o acadêmico alcança o título de enfermeiro está contando para população, 
que está apto a desenvolver qualquer função que se encaixe dentro de nossa profissão” (R-GO.5)

“... os Docentes, o Núcleo Docente estruturante e o Colegiado de Curso avaliam como de importância prioritária as competências desenvolvidas nesta área para a vida profissional dos enfermeiros formados na IES" (R-PB.1)

A inserção do aluno no bloco cirúrgico lhe permite identificar características do papel do enfermeiro neste campo de atuação, sua relação com outros setores hospitalares, além das peculiaridades de um ambiente fechado de atuação.

"Os acadêmicos necessitam de conhecimento que traduzam a atuação de enfermeiros, que compreendam a organização e a função do profissional no setor (CC e CME), e entendam que a eficiência deste não está centralizada em suas atividades como fim, mas também na articulação com outros setores do serviço... Salienta-se a importância da sistematização da assistência de enfermagem como fundamental meio de comunicação com a equipe de enfermagem e equipe multidisciplinar" (RPR.5)

"Apesar da especificidade do Centro Cirúrgico, o aluno precisa conhecer a dinâmica de um Centro Cirúrgico e a atuação do Enfermeiro" (R-MG.4)

"formar profissionais comprometidos com e conhecedores das particularidades de atuação em setores fechados/restritos, com atuação mais especifica quanto ao cuidar do cliente e manusear os materiais e equipamentos especificos ao CC e CME, como também preparar o aluno para a atuação em CCIH, sendo conhecedores de equipamentos de proteção individual’'(R-PB.2)

Embora o conteúdo de CC, se ministrado em uma carga horária condizente, permita ao graduando iniciar sua vida profissional na unidade de $\mathrm{CC}$, a visão é ampla $\mathrm{e}$ requerer que o enfermeiro aprofunde seus conhecimentos depois de formado.

"Com esse conteúdo ele terá uma visão geral, havendo necessidade que aprofundar seus conhecimentos com um curso de especialização ou no dia a dia de atuação profissional nesse setor" (R-SP.3)

"O aluno sai da universidade com uma visão muito ampla da atuação do enfermeiro em CC. Desta forma, ele terá condições de trabalhar 
perfeitamente neste serviço, porém é necessário um aprofundamento sobre CC/SRPA através de especialização ou curso de atualização” (RAL.1)

A demanda de mercado requer que o graduando de enfermagem tenha um conteúdo de $\mathrm{CC}$ na sua formação. A realidade mostra que os enfermeiros são contratados para atuarem nessa área, mesmo sem cursos de especialização na área e esta situação ocorre em qualquer região do país.

"É importante principalmente em, nossa região que é pobre em especializações dentro desta área, logo temos que dar uma formação que possa atender as necessidades do mercado" (R-AP.1)

“...Na nossa região o mercado carece de enfermeiros de CC, principalmente, por que a maioria com o passar do tempo opta por atuar em outra unidade, menos estressante" (R-SC.4)

Empiricamente, se acredita que a maioria dos egressos ao término de sua graduação se insere em cursos de especialização, mas geralmente o que ocorre é o inverso. A partir de sua inserção no mercado de trabalho, o enfermeiro busca o aprofundamento de conhecimento necessário para a sua prática profissional.

"Importantissimo, pois no Vale do Paraíba é usual contratarem recémformados para exercerem suas atividades de imediato em CC e muitos enfermeiros concomitantemente se vêem obrigados a cursarem especialização nessa área" (R-SP.21)

A introdução do aluno nas atividades de bloco cirúrgico the oferece oportunidade de conhecer outros campos de atuação do enfermeiro, além de oferecer a chance de aprofundar seu conhecimento na área durante a disciplina de Estágio Curricular.

"Por ser uma área específica, o aluno que passa pela disciplina já consegue determinar se é uma área de seu agrado para poder atuar como enfermeiro, e por aprender sobre todo processo cirúrgico acaba se tornando um bom enfermeiro assistencial" (R-DF.3)

“... o aluno tem inicialmente a disciplina supervisionada baseado no modelo proposto pelo plano de ensino e depois podem optar no $8^{\circ}$ 
semestre, a disciplina Estagio Curricular, que abrange o SAEP”. (RRS.11)

A autonomia é uma qualidade desejada no enfermeiro e que se conquista com conhecimento, iniciativa e vivências que permitam ao formando reconhecer que o enfermeiro pode tê-la no desempenho de suas funções.

“... Acrescenta e sedimenta no curriculum do enfermeiro conhecimentos específicos do cuidado hospitalar, contribui para a compreensão do processo saúde doença dos clientes com problemas cirúrgicos em suas diversas fases, trabalha os aspectos importantes da liderança, da resolutividade e da autonomia do enfermeiro dentro de um contexto desafiador, conflitante, dinâmico, crítico e avançado aporte tecnológico, desperta para a busca permanente de conhecimento devido às constantes atualizações na área” (R-MG.4)

"As experiências e conteúdos em CC são capazes de desenvolver autonomia ao estudante, capacidade de interação com outros profissionais, habilidade em procedimentos de alta complexidade e rapidez para resolução de problemas da prática. Em nossa experiência, nesse setor os alunos sentem-se inseridos no processo de trabalho e convivem com muitos pacientes em curto espaço de tempo" (R-RJ-9)

As características da atuação da enfermagem no CC permitem que o aluno se insira nas atividades da equipe cirúrgica, considerando suas limitações em termos de habilidades e conhecimento, despertando o sentimento de pertencer a um grupo além de conhecer a complexidade das relações interpessoais em ambientes fechados.

Embora mencionado por apenas um respondente, considerou-se a fala sobre o nível de aprofundamento da disciplina importante, pois provavelmente será o próximo passo para a revitalização e valorização do conteúdo de centro cirúrgico nas grades curriculares.

"São fundamentais para a formação. No entanto, é preciso definir o nível de aprofundamento dos conteúdos e desempenhos de aprendizagem” (RPR.7) 


\subsection{CURSOS DE ESPECIALIZAÇÃO}

De 159 formulários recebidos, $132(83,0 \%)$ tiveram a pergunta sobre realização de curso de especialização respondida. O número de escolas que já ofereceu cursos de especialização foi pequeno $(n=20 ; 15,1 \%)$, mas a resposta sobre o número de especializações realizadas foi de somente 5. A média de cursos de especialização foi de 4,9 (DP \pm 4,3), mediana de 3 (variação de 1 a 14), e moda de 1 curso (Tabela 31 ).

Tabela 31 - Distribuição de escolas que oferecem a especialização em CC, segundo o número de especializações. Brasil, 2011.

\begin{tabular}{|c|c|c|c|}
\hline № especializações de CC & $\mathrm{N}$ & $\%$ & \%acum. \\
\hline 1 & 5 & 33,2 & 33,2 \\
\hline 3 & 3 & 20,0 & 50,0 \\
\hline 5 & 2 & 13,3 & 63,5 \\
\hline 6 & 1 & 6,7 & 70,2 \\
\hline 7 & 1 & 6,7 & 76,9 \\
\hline 9 & 1 & 6,7 & 83,6 \\
\hline 13 & 1 & 6,7 & 90,3 \\
\hline 14 & 1 & 6,7 & 100 \\
\hline Total & 15 & 100 & \\
\hline
\end{tabular}

Das escolas que ministraram cursos de especialização, $11(55,5)$ localizam-se na região $\mathrm{SE}$, quatro $(20,0)$ na região $\mathrm{NE}$, três $(15,0)$ na região $\mathrm{N}$ e duas $(10,0 \%)$ na região S. A oferta do curso de especialização foi mais freqüente nas escolas que oferecem disciplinas específicas de centro cirúrgico $(n=14 ; 70,0 \%)$. Com relação à entidade mantenedora, $12(60,0 \%)$ eram escolas privadas.

Uma escola no estado do Paraná disse que está finalizando o projeto para submetê-lo a apreciação na Pós-Graduação; uma escola no estado do Ceará e outra no Maranhão ofereceram o primeiro curso em 2011; dois cursos, um na Bahia e outro em Santa Catarina, abriram inscrições, mas não obtiveram número de inscritos o suficiente 
Ruth Natalia Teresa Turrini

para ministrar o curso. Um curso no estado de Minas Gerais informou não dispor de recursos humanos para oferecer o curso de especialização.

Três escolas privadas no estado de São Paulo, duas na capital e uma no interior, oferecem cursos de especialização em CC atualmente há pelo menos cinco anos.

As escolas que ofereceram mais cursos localizam-se uma no estado do Paraná e outra no Rio Grande Sul, uma pública e outra privada, respectivamente.

A escola pública, pioneira em cursos de especialização de CC, localizada na região SE (SP) há oito anos não tem oferecido o curso. 
Discussão 


\section{DISCUSSÃO}

A taxa de retorno de questionários no país foi próxima a 20,0\%, semelhante nas regiões do país com exceção do NE em que a taxa foi a metade. De três estados não se obteve um questionário, Sergipe, Rio Grande do Norte e Roraima. Quando se fez o teste de proporção da distribuição de cursos na capital e no interior entre a amostra obtida e o país observou-se que eram semelhantes.

A maioria das instituições participantes era privada, fato esperado pois são em maior número que as públicas. Em torno de $15,0 \%$ dos cursos ainda têm cadastrado no site do MEC uma carga horária inferior a $4.000 \mathrm{~h}$, com maior concentração na região SE e, portanto, ainda precisam se adequar ao parecer CNE/CES n ${ }^{\circ} 213 / 2008^{27}$. A maioria dos cursos tem uma carga horária entre 4.000 e $4.500 \mathrm{~h}$, sendo que nas regiões NE, SE e $\mathrm{S}$ foram observados cursos com mais de $5.500 \mathrm{~h}$.

Pelos relatos obtidos, alguns cursos se beneficiaram da carga horária mínima de 4.000h, pois lhes possibilitou inserir o conteúdo de CC na grade curricular e, a outros, torná-la uma disciplina específica.

A distribuição do conteúdo de CC nas diferentes IES é variada: disciplina específica ou um conteúdo inserido em outras disciplinas e, outras, não oferecem qualquer conteúdo na graduação. No presente estudo, apenas um respondente informou não possuir este conteúdo na grade curricular. Esperava-se que este número fosse maior, mas como cerca de $80,0 \%$ das IES não responderam o questionário existe a possibilidade de que haja maior número de escolas sem o conteúdo na proposta curricular.

Quase $70,0 \%$ dos participantes disseram possuir uma disciplina específica de $\mathrm{CC}$, mas na análise global das respostas, tanto nas fechadas quanto nas abertas, restou a dúvida em relação ao nome da disciplina, se Enfermagem Cirúrgica ou Enfermagem em Centro Cirúrgico. 
Estudo sobre o processo de ensino de enfermagem perioperatória que envolveu dez escolas da região metropolitana de São Paulo identificou que 70,0\% delas tinham uma disciplina própria de enfermagem em $\mathrm{CC}$ e nas demais o conteúdo estava inserido na disciplina Saúde do Adulto. A carga horária teórica em enfermagem em CC variou entre $30 \mathrm{~h}(80 \%)$ e $72 \mathrm{~h}(20 \%)$ e a prática entre $60 \mathrm{~h}(60 \%)$ e $90 \mathrm{~h}(40 \%)^{47}$.

As cargas horárias, teórica e prática, no presente estudo apresentaram maior amplitude para ambas as modalidades, observando-se cursos com zero $(12,1 \%)$ de carga horária prática. Ao se equiparar os dados com os parâmetros do estudo ${ }^{47}$ acima, observou-se com relação a carga horária teórica que $18,9 \%$ apresentam valores $\leq 30 \mathrm{~h}$ e $28,0 \% \geq 72 \mathrm{~h}$. Para a carga prática, identificou-se que $78,0 \%$ têm carga $\leq 60 \mathrm{~h}$ e $8,3 \% \geq$ 90h. Em termos de Brasil, as disparidades são maiores e, além disso, a amostra do estudo nacional é maior.

Quando se analisaram as informações relativas à disciplina específica de $\mathrm{CC}$, as medianas das cargas horárias teóricas e práticas são superiores quando comparadas às medianas do conteúdo ministrado no interior de outra disciplina. Neste grupo, as medianas das cargas horárias teóricas e práticas são quase iguais, enquanto que no conjunto de cursos com conteúdo específico, a mediana da carga horária teórica é um pouco superior à carga horária prática.

Em metade dos cursos, a carga teórica é superior à prática, principalmente nos cursos com disciplina específica de CC. Quando se publicou a Resolução 4/72 ${ }^{23}$ houve uma ampliação da carga teórica, mas as aulas práticas diminuíram para atender ao movimento de intelectualização da profisssão ${ }^{48}$.

Não se pode atribuir que a carga horária prática informada corresponda às atividades clínicas em campo, porque alguns cursos disseram que o valor informado compreende também as atividades em laboratório de enfermagem (LE) e outros consideram a carga horária prática somente como atividades de LE, pois o estágio clínico supervisionado é oferecido em semestres adiante.

Estudo envolvendo seis docentes de escolas públicas de São Paulo, Rio de Janeiro e Rio Grande do Sul (out/88 a abr89) identificou que apenas uma escola de São 
Paulo ministrava o conteúdo de bloco cirúrgico em uma disciplina própria, nas demais o conteúdo estava incluído na disciplina de Enfermagem Cirúrgica. Com relação ao enfoque dado no conteúdo, as escolas de São Paulo e uma do Rio de Janeiro focavam a assistência de enfermagem perioperatória, outra escola do Rio de Janeiro, a ética do enfermeiro e no Rio Grande do Sul obteve-se resposta de apenas uma escola, que mencionou as atividades técnicas: paramentação, instrumentação e tempos cirúrgicos. As cargas teóricas foram bastante diversificadas de $25 \mathrm{~h}$ a $120 \mathrm{~h}$ e a carga prática de $40 \mathrm{~h}$ a $225 \mathrm{~h}^{49}$. Embora este estudo tenha 20 anos, os valores das cargas horárias são tão dispersos quanto aqueles observados no presente estudo nacional.

Muitos respondentes informaram que o conteúdo de CME integra a disciplina e, um deles também inclui o conteúdo de infecção hospitalar. Embora não se tenha colocado na listagem a aula de prevenção e controle de infecção do sítio cirúrgico (ISC) não há como se falar em cuidado perioperatório e segurança do paciente sem abordar aspectos que envolvam a prevenção e o controle de ISC em qualquer atividade ou intervenção no CC.

Nos casos em que o conteúdo de CC é ministrado no interior de outras disciplinas, há variedade na denominação de disciplinas. Quando a denominação indica um aprofundamento de outra ministrada previamente, se poderia facilmente deduzir que o conteúdo de $\mathrm{CC}$ estivesse inserido nela. No entanto, para a maioria delas somente a ementa poderia trazer esta informação. Considerou-se interessante o fato de três cursos oferecem a abordagem do paciente em CC também para crianças e adolescentes e na saúde da mulher. Na prática clínica, a não ser que o hospital seja especializado em pediatria, as crianças e adolescentes são operados no mesmo local dos adultos e os alunos convivem com pacientes de diferentes faixas etárias. Em sala de parto ou nos partos cesárea utilizam-se as técnicas de paramentação, assepsia cirúrgica e instrumentação, quando pertinente, indistintamente. É importante integrar o conteúdo em diferentes momentos ao longo da graduação, sem que se perca a sua identidade.

Alguns respondentes informaram que uma parte do conteúdo é ministrada em disciplinas básicas da enfermagem como Biossegurança, Semiotécnica e Laboratório de 
Enfermagem. Este tipo de abordagem é coerente e moderna, mas deve-se manter a clareza sobre o conteúdo e a carga horária relativos a CC e constar claramente das ementas, constituindo-se inclusive em um facilitador nas situações de transferência de alunos entre escolas ou validação de diplomas estrangeiros.

Os conteúdos menos administrados nas disciplinas foram a instrumentação cirúrgica, cirurgias ambulatoriais e novas tecnologias em CC. Com relação à instrumentação cirúrgica, embora seja uma atribuição da equipe de enfermagem ${ }^{50}$, são poucos os locais em que o aluno tem a oportunidade de instrumentar a cirurgia. Por outro lado, como alguns cursos apresentam uma carga horária baixa, é compreensível que este conteúdo específico não seja oferecido.

A instrumentação não faz parte do conteúdo de $\mathrm{CC}$ em muitos cursos de bacharelado em enfermagem do país, que justificam sua ausência pelo fato de o enfermeiro raramente desenvolver essa atividade e por existirem cursos técnicos preparados para a instrumentação ${ }^{51}$.

Com a prática de instrumentação na graduação não se pretende formar instrumentadores, mas apenas oferecer ao aluno uma oportunidade de integrar a equipe cirúrgica e de assimilar melhor os conceitos de técnica asséptica e campo estéril em cirurgia.

Com relação a conteúdos relacionados aos avanços em cirurgia, também menos ministrados, se adentraria numa especificidade que pode fugir ao escopo da oferta do conteúdo de CC na formação de um enfermeiro generalista. Mas na disponibilidade de carga horária e no caso da prática clínica se realizar em hospitais com CC que utilizam tecnologia de ponta, o conteúdo é pertinente.

A importância da abordagem da cirurgia ambulatorial se pauta na política de redução de tempo de internação do paciente por motivos de custos e para redução do risco de aquisição de uma infecção hospitalar. Apesar de a tendência das últimas duas décadas em ampliar o número de cirurgias ambulatoriais, este aspecto ainda não tem sido amplamente explorado pelos cursos de enfermagem visto que metade dos cursos 
aborda a cirurgia ambulatorial nas aulas, embora discutam a assistência de enfermagem em cirurgias que envolvem novas tecnologias.

No ensino tradicional de CC, o aluno desenvolve em campo as atividades do circulante em SO e na recuperação anestésica atividades de avaliação e cuidado no paciente. Esta forma de ensino permite ao aluno vivenciar o que realmente ocorre com o paciente no CC. Todo este cuidar é feito à luz do processo de enfermagem, mas a sistematização do cuidar foi pouco mencionada nos relatos. Embora assinalado por cerca de $85 \%$ dos respondentes, apenas um deles comentou que os alunos fazem o diagnóstico de enfermagem na recuperação anestésica e dois relataram que os alunos realizam a visita pré-e pós operatória que compõem o SAEP. Assim sendo, não se sabe se o SAEP faz parte do aprendizado em campo de prática para a maioria dos cursos.

$\mathrm{O}$ processo de enfermagem é uma tecnologia de enfermagem, aplicada no perioperatório, pautada na cientificidade, raciocínio clínico e aspectos éticos ${ }^{52}$. Ele constitui o diferencial para o enfermeiro de CC do século XX, pois deu autonomia ao enfermeiro no seu fazer desvinculando-o da imagem de assistente de cirurgião do século XIX. Além disso, é uma tecnologia cuja aplicação permite implementar intervenções que visam a segurança do paciente no processo anestésico-cirúrgico. E, para isso, uma das etapas importantes no SAEP, é a visita perioperatória. Para poder realizá-la o enfermeiro precisa sair do $\mathrm{CC}$ e ir à unidade de internação para realizá-la, mas como muitas vezes no $\mathrm{CC}$ há apenas um enfermeiro ${ }^{53}$ nem sempre o aluno terá oportunidade de observar esta etapa registrada nos instrumentos do SAEP no CC. No entanto, esta atividade pode estar incluída em sua experiência de $\mathrm{CC}$, de acordo com o planejamento do professor, bem como a visita pós-operatória que também se efetua na unidade de internação.

A visita pré-operatória é uma etapa importante do SAEP, pois é neste momento que o aluno poderá avaliar o paciente em busca de pistas para elaborar os diagnósticos de enfermagem para o processo anestésico-cirúrgico, realizar intervenções como, orientação sobre o preparo pré-operatório e estabelecer uma comunicação de apoio para alívio da ansiedade muitas vezes presente antes da cirurgia. Em relatos empíricos, o 
paciente se sente confortável quando é recebido na recepção do $\mathrm{CC}$ pelo mesmo enfermeiro que realizou sua visita pré-operatória. De acordo, com o planejamento do estágio, e se o paciente estiver internado previamente, o aluno também pode vivenciar esta experiência. A dificuldade com o paciente ambulatorial é que a avaliação préoperatória é feita no ambulatório pela enfermeira local e neste caso o aluno ou a enfermeira de $\mathrm{CC}$ terá seu primeiro contato com o paciente ao recebê-lo no CC.

A visita pós-operatória é o momento no qual se pode avaliar a orientação e o preparo que foram dados ao paciente e à família previamente a cirurgia ${ }^{53}$ e também avaliar a qualidade da assistência prestada durante sua permanência na SO e na recuperação anestésica.

Os comentários sobre o conteúdo de $\mathrm{CC}$ versaram sobre a densidade do conteúdo, o pouco tempo para ministrá-lo e os novos temas de interesse de CC que não são abordados pela restrição de carga horária, mas que seriam importantes para atender a demanda de enfermeiros para atuar em CC. Em mais de uma fala se reportaram à necessidade de conteúdos de infecção hospitalar.

Quanto a novas práticas em CC, além das decorrentes das tecnologias introduzidas no procedimento cirúrgico, em 2004 a Joint Comission introduziu o time out para reduzir as ocorrências de paciente errado, procedimento errado e lugar errado. Trata-se de um procedimento formal no qual toda a equipe faz uma pausa para identificar o nome do paciente, procedimento e lateralidade adequados, reserva de hemocomponentes, equipamentos, implantes ou exames radiológicos solicitados, e outras questões relacionadas ao cuidado com o paciente ${ }^{54}$.

Um dos respondentes questionou o qual seria o conteúdo básico de $\mathrm{CC}$ e outro manifestou preocupação em como manter o conteúdo sempre atualizado diante de tantos avanços tecnológicos no tratamento e cuidado do paciente cirúrgico.

Para a realização deste estudo tomou-se como referência o conteúdo de CC ministrado pela EEUSP, até porque ela foi pioneira na disciplina de ECC. Apesar de a diminuição na carga horária que tem sofrido a cada alteração curricular, tem-se procurado manter alguns conteúdos teóricos considerados básicos para a formação 
generalista do enfermeiro, sendo atualizado à medida que novas tecnologias se agregam ao cuidado do paciente cirúrgico. O docente procura inserir em suas aulas o diagnóstico de enfermagem, por enquanto da NANDA (North American Nursing Diagnoses Association $)^{55}$, mas a intenção é introduzir o Perioperative Nursing Data Set (PNDS) ${ }^{56}$. Embora os diagnósticos de enfermagem sejam muito semelhantes aos da NANDA ${ }^{57}$, as intervenções descritas no PNDS são mais voltadas ao cuidar no CC. O PNDS propõe uma linguagem padronizada para descrever a prática da enfermagem perioperatória da pré-admissão até a alta do paciente ${ }^{57}$.

A American Association Colleges of Nursing (AACN) dos Estados Unidos publicou, em 2008, o Essentials of Baccalaureate Education for Professional Nursing Practice, com diretrizes para orientar a revisão do currículo voltado para a formação de enfermeiros para o século $\mathrm{XXI}^{58}$. Propõe uma base liberal para a orientação curricular, mas os itens descritos para definir os objetivos e o perfil do enfermeiro são bem detalhados, reforça a formação de um enfermeiro generalista apto a trabalhar com indivíduos, famílias, grupos, comunidades e população ao longo de todas as fases da vida e em qualquer cenário de atenção à saúde. Recomenda que as oportunidades de aprendizado sejam amplas e profundas para assegurar ao aluno alcance dos objetivos focados nos resultados e que permita agregar conhecimento e habilidades durante sua formação profissional.

Estudo realizado Reino Unido sobre conteúdo de CC, partiu da observação por um determinado período de tempo das atividades de 20 enfermeiros distribuídos em quatro unidades cirúrgicas com as mesmas especialidades e diferentes demandas. Cada enfermeiro era observado por $5 \mathrm{~h}$. As atividades foram listadas e para cada uma delas se identificaram as habilidades e conhecimentos necessários. Os dados obtidos foram comparados ao conteúdo de uma disciplina de CC. Ao final do mapeamento observouse que $95,0 \%$ do conteúdo da disciplina estavam contemplados na lista de atividades observadas. O programa não continha conteúdos de auditoria e de registro eletrônico de enfermagem, além de outros tópicos muito específicos e impraticáveis na formação do aluno. Por outro lado, verificou-se que a aula sobre autoclave rejeitada pelos alunos era 
importante na prática porque havia autoclaves no $\mathrm{CC}$, e o conteúdo sobre transplante poderia ser removido do programa. Algumas situações na equipe cirúrgica também evidenciaram a necessidade do conteúdo de sociologia para atuação em $\mathrm{CC}^{59}$.

Os conteúdos e estratégias também podem ser influenciados pelo conceito que se tem do que é Enfermagem. Estudo ${ }^{60}$ realizado na Suécia envolvendo 27 cursos de graduação em enfermagem se propôs a analisar a grade curricular e os programas de estudo. Foi observado que os programas desenvolviam entre 90 e 145,5 de ECTS (European Credit Transfer and Accumulation System) de conteúdo base da enfermagem (Ciências da Enfermagem ou Ciência do Cuidado) e entre 30 e 67,5 ECTS de conteúdo de Ciências Médicas. Os demais conteúdos, ética e filosofia da vida, saúde pública, ciências sociais e do comportamento, disciplinas optativas, quando presentes, tinham créditos menores. A presença de conteúdos relativos às Ciências Sociais e Comportamentais se verificou em cursos que tinham por base a Ciência da Enfermagem. A disciplina "Cuidado de enfermagem no paciente crítico" apareceu como optativa nos programas em que a base da formação era Ciências da Enfermagem. Outra diferença observada relacionou a distribuição de atividades teóricas e práticas. Quando o programa tinha por foco a Ciência da Enfermagem havia uma distribuição equitativa entre teoria e prática, enquanto aqueles focados na Ciência do Cuidado e nos estudos clínicos (laboratório, exercícios, entre outros) apresentavam blocos distintos de teoria e prática. Com relação à estrutura dos currículos, aqueles com foco na Ciência da Enfermagem utilizaram o código integrado e a estrutura era temática, enquanto na Ciência do Cuidar o código ${ }^{\mathrm{a}}$ integrado revelou-se numa combinação de temas e disciplinas da Ciência do Cuidado. A maioria dos cursos centrados na Ciência da Enfermagem se estruturava no código coleção e no combinado: integrado e coleção. Os

\footnotetext{
${ }^{a}$ A classificação de Bernstein refere-se ao grau de manutenção de fronteiras entre os conteúdos. À organização do conhecimento escolar que envolve alto grau de classificação associa-se um currículo que o autor denomina 'código coleção'; à organização que vise à redução do nível de classificação associa-se um currículo denominado 'código integrado'. Bernstein BA. Estruturação do Discurso Pedagógico: classe, código e controle. Petrópolis: Vozes, 1996.
} 
autores deixam uma indagação: diferenças na terminologia refletem diferenças no conteúdo e em que extensão?

O momento de oferecimento da disciplina também foi diversificado e em alguns cursos ocorre em mais de um semestre. No caso das disciplinas específicas, em metade dos cursos a teoria e a prática são oferecidas em momentos diferentes. Um respondente manifestou desagrado em relação a esta dinâmica. Houve também relatos de respondentes que apenas oferecem o conteúdo teórico de CC.

Concentrar as atividades práticas ao final do curso, opinião pessoal, distancia o aluno da teoria. O objetivo da prática clínica é complementar o aprendizado teórico, para melhorar a assimilação e trazer o conteúdo teórico da abstração para o concreto.

A introdução do aluno no CC não é para dar-lhes a oportunidade de acompanhar determinado procedimento cirúrgico, mas aprender a real dimensão do cuidado ao paciente no $\mathrm{CC}^{61}$. A enfermagem perioperatória oferece uma oportunidade única na compreensão da experiência cirúrgica para o paciente e permite transferir este conhecimento e habilidades para outras ambientes clínicos ${ }^{62}$.

Foi realizado um estudo qualitativo com referencial da hermenêutica para conhecer a opinião de estudantes do terceiro ano que fizeram a disciplina optativa em CC. Os alunos permaneceram duas semanas em campo clínico desenvolvendo conteúdos de enfermagem anestésica, enfermagem intraoperatória e enfermagem pósanestésica. Os alunos relataram que puderam compreender a experiência do paciente no ambiente cirúrgico; como ela está vinculada a assistência de enfermagem no pré e pósoperatório; o cuidado na recuperação anestésica lhes era familiar e o conhecimento obtido nessa área era importante, mesmo que não viessem a exercer a profissão em CC. Alguns alunos sentiram-se sobrecarregados pelas habilidades, conhecimento e tecnologias específicas do ambiente, enquanto outros as acharam repetitivas e monótonas. Apesar de a experiência não foram capazes de captar o papel do enfermeiro perioperatório. Perceberam como os diferentes profissionais se inter-relacionavam, algo que não pode ser observado em atividades em outros campos clínicos ${ }^{63}$. 
Um docente mencionou utilizar como bibliografia as Práticas Recomendadas da SOBECC ${ }^{\text {a }}$, evidenciando a importância que esta sociedade de enfermeiros tem no direcionamento de conteúdos de CC. Empiricamente sabe-se que muitos docentes recomendam esta bibliografia aos seus alunos. Esta publicação feita pela SOBECC e atualizada periodicamente contempla recomendações sobre a assistência perioperatória e sobre o reprocessamento de materiais na $\mathrm{CME}$, com foco na segurança do paciente e qualidade da assistência.

Houve relatos antagônicos sobre a complexidade do conteúdo de $\mathrm{CC}$ ao estudante de enfermagem. $\mathrm{O}$ respondente que falou a favor do conteúdo, comentou a oportunidade de resgatar conteúdos das disciplinas básicas como o de anatomia, conhecimentos sobre biossegurança, infecção hospitalar, emergência. Pode ser que estes docentes vivenciem a disciplina em momentos diferentes da matriz curricular, em um semestre avançado o aluno poderia ter uma maturidade diferente para compreender o conteúdo.

Estudo sobre a percepção dos alunos do último ano a respeito dos estágios supervisionados em curso localizado na região $\mathrm{S}$ do país identificou que o aluno vivencia momentos de sofrimento e angústia ao cuidar de um paciente no hospital sem ter tido um contato prévio, apesar das aulas teóricas ou das atividades em LE. Alguns alunos perceberam o ensino em campo fragmentado, pois cada professor enfocava um aspecto do cuidado, por exemplo, administração, técnicas, processo de enfermagem ${ }^{64}$.

Pelo relato acima, os estágios em campo clínico devem possuir uma duração suficiente para a inserção dos alunos de modo planejado, atribuindo-lhe atividades de complexidade progressiva à medida que se familiariza com o cuidar em determinado cenário. Cabe ao professor desenvolver discussões e reflexões com os estudantes a respeito do cuidado holístico ao cliente e família, agregando os conhecimentos das diversas disciplinas que o aluno frequentou em momentos anteriores. A prática em campo clínico próxima ao conteúdo teórico permite ao aluno que consolide os

\footnotetext{
${ }^{a}$ Sociedade Brasileira de Enfermeiros de Centro Cirúrgico, Recuperação Pós-Anestésica e Centro de Material e Esterilização. Práticas recomendadas - SOBECC. São Paulo: SOBECC; 2007.
} 
conhecimentos para que possa ter mais autonomia e segurança por ocasião do Estágio Curricular Supervisionado no último ano de graduação.

O Estágio Curricular Supervisionado está previsto na $\mathrm{DNC}^{26}$ e deve corresponder a $20,0 \%$ do total da carga do curso para consolidar conhecimentos adquiridos durante o curso e envolve a participação do enfermeiro do campo na supervisão do estudante. Geralmente, a IES define quais serão os cenários de prática. Por exemplo, estudo sobre a disciplina de Estágio Curricular Supervisonado em universidade no interior de Santa Catarina destinava, em 2008, 53,0\% dos espaços a atenção básica, 29,0\% a comunidade e apenas 18,0\% ao hospital ${ }^{65}$.

Alguns cursos utilizam o CC ambulatorial para o campo de prática, o que não compromete o aprendizado básico em CC. Além deste tipo de atendimento ser frequente, os procedimentos realizados são de menor porte, o que pode favorecer o aluno no acompanhamento do paciente da admissão a alta. Como a cirurgia é ambulatorial, os paciente na maioria dos serviços recebem anestesia local e o aluno não tem a experiência da recuperação anestésica em pacientes submetidos a anestesia geral raqui ou peridural.

Embora não se tenha obtido dados publicados da realidade brasileira, estudo realizado no Reino Unido com 718.284 pacientes nos TRE últimos meses de dezembro de 1999, mostrou que o tempo de espera era superior a seis meses nas cirurgias-dia entre 18 a $28 \%$ dos casos e nas cirurgias eletivas de 29 a $40 \%{ }^{66}$. Estes dados indicam que a demanda por cirurgia é elevada em ambas as situações, o aluno pode ter boas oportunidades de aprendizado tanto nas cirurgias eletivas quanto ambulatoriais, apesar de nas cirurgias ambulatoriais não ter a possibilidade de vir a conhecer a dinâmica em casos de cirurgias de urgência ou emergência.

$\mathrm{Na}$ prática docente, observa-se que a carga teórica e prática tendem a ser reduzidas para que se possa oferecer uma experiência clínica ao aluno na cirurgia ambulatorial. Na cirurgia ambulatorial ou com os pacientes de hospital-dia há uma fase pré-operatória de preparo do paciente que envolve uma importante avaliação préoperatória para a detecção de problemas que possam comprometer a segurança do 
paciente no intraoperatório e, ainda, o paciente precisa ser bem orientado, pois ele é o responsável pelo cumprimento desse preparo para a cirurgia. Esta interação com o paciente é feita no ambulatório com certo tempo de antecedência à cirurgia e nos hospitais públicos o tempo de espera pelo procedimento cirúrgico é de meses.

Alguns respondentes referiram utilizar a simulação para as atividades práticas, mas não caracterizaram como são realizadas. Os cursos que apenas utilizam atividades de laboratório ou simulação em sala operatória em ambiente físico real, não oferecem oportunidade ao aluno vivenciar a relação interpessoal com a equipe cirúrgica e conhecer a dinâmica do CC. Em simulação, o aluno aprende as técnicas procedimentais, a circulação de sala e representa o papel de cliente ou familiar ou profissional de acordo com protótipos observados na mídia.

A simulação no cuidado a saúde é uma tentativa para reproduzir aspectos essenciais do cenário clínico, de modo que quando o profissional se depara com um cenário similar na prática em campo clínico, a situação possa ser gerenciada rapidamente e bem sucedida ${ }^{67}$. Quando a simulação tem caráter formativo, como nas atividades de ensino-aprendizagem, o objetivo é melhorar o desempenho do aluno. Neste caso, os alunos recebem um feedback dos professores e de seus colegas, refletem sobre seu conhecimento, habilidades e o pensamento critico relacionado à simulação ${ }^{68}$.

Os simuladores podem ser classificados como de baixa, moderada e alta fidelidade, de acordo com a capacidade de reproduzir sons e imagens. Os simuladores de baixa fidelidade são aqueles estáticos como os manequins utilizados para a prática de punção venosa, passagem de sonda gástrica, entre outros; os de média fidelidade são mais realísticos e permitem auscultar sons respiratórios e cardíacos; os de alta fidelidade são manequins com elevada tecnologia que permitem movimentos, ausculta de sons, emissão de sons vocais e reações funcionais às intervenções dos estudantes ${ }^{69}$. Em termos de Brasil, supõe-se que a maioria dos cursos utilize a simulação em manequins estáticos, pois os simuladores de alta fidelidade envolvem tecnologia sofisticada e custos elevados. 
Embora não se trate de uma situação de $\mathrm{CC}$, estudo ${ }^{70}$ realizado no interior de São Paulo comparou o desempenho dos alunos na avaliação dos olhos considerando duas situações: um grupo teve aula expositiva-dialogada e prática com o uso de simulador e outro aula expositiva-dialogada e prática em laboratório convencional. (Os resultados mostraram que o uso de simulador no ensino da avaliação clínica dos olhos influenciou no desempenho das habilidades práticas dos estudantes de enfermagem.

A simulação de alta fidelidade melhora o aprendizado clínico, oferece oportunidades para o desenvolvimento de habilidades cognitivas e psicomotoras em um ambiente experimental seguro. Estudo ${ }^{71}$ com seis estudantes que tiveram quatro dias de simulação substituídos pela prática clínica no hospital observou melhor desempenho dos alunos envolvidos nas atividades de simulação com melhora nas habilidades reflexivas e psicomotoras, e conseguiram estabelecer uma ponte entre teoria e prática.

Em termos de realidade brasileira poderia se utilizar como estratégia a dramatização. No entanto, a experiência pessoal foi utilizá-la ao final do estágio, onde a partir do que foi vivenciado com o paciente, família e equipe cirúrgica, os alunos reproduziram uma situação similar a real com as atividades da assistência perioperatória em LE, assumindo os diferentes papéis da equipe. Da mesma forma que o descrito na simulação de alta fidelidade, os alunos puderam receber um feedback do professor e dos colegas, com a possibilidade de refletir e rediscutir as ações realizadas fazendo uma ponte entre teoria e prática.

Outras modalidades teórico-práticas foram citadas, como visitas técnicas e estágio de observação. As visitas técnicas que os alunos realizam apenas trazem o conhecimento de como esta estruturada uma unidade de $\mathrm{CC}$ do ponto de vista físico e nem sempre em um primeiro contato o aluno é capaz de identificar que são os elementos da equipe cirúrgica.

Mesmo a realidade americana não é diferente da nossa. Algumas escolas oferecem um conteúdo muito superficial na disciplina de enfermagem cirúrgica e a parte prática se constitui em visitas a unidades de $\mathrm{CC}$. Esta exposição rápida ao $\mathrm{CC}$, ou mesmo quando o estágio se limita a alguns dias de observação, não permite ao aluno se 
envolver nas atividades do ambiente perioperatório ou identificar o papel do enfermeiro na unidade de $\mathrm{CC}^{72}$.

O estágio de observação pode trazer desconforto ao aluno, que deve manter-se distante do campo operatório para evitar contaminações, além do tédio de permanecer horas em pé no canto de uma sala sem participação alguma no processo anestésicocirúrgico. Esse tipo de atividade pode até comprometer a imagem da escola e da disciplina, pois há sempre comentários da equipe "só olhar não se aprende", para desenvolver habilidades é preciso "fazer".

Não é fácil inserir o aluno na SO em parceira com o circulante de sala, pois esta relação depende tanto do interesse e iniciativa do aluno quanto da disponibilidade do circulante em assumir o aluno durante sua jornada de trabalho. Por isso, em alguns cursos o aluno assume a posição de observador em $\mathrm{SO}$, mas na recuperação anestésica tem oportunidade de cuidar do paciente com a supervisão do professor ou do enfermeiro de campo.

Estudo $^{73}$ realizado no Maranhão sobre os fatores que interferem no ensinoaprendizagem no CC com alunos do Estágio Curricular I utilizando um questionário semi-estruturado identificou aspectos de relacionamento interpessoal com a equipe cirúrgica, principalmente com o profissional médico; conflitos observados em SO com a equipe; insegurança diante da equipe com medo de errar e pouca experiência do professor nessa especialidade.

Situações de sofrimento emocional com relação aos conflitos interpessoais em SO são relativamente freqüentes, mas estes momentos devem ser considerados como oportunidade para trabalhar a reação emocional do aluno, pois na vida profissional como enfermeiro ele terá de enfrentar e gerenciar estas situações.

Em decorrência da interpretação das $\mathrm{DNC}^{26}$, observa-se uma tendência na redução dos conteúdos teóricos, para que o aluno aprenda em campo de prática com discussões e sínteses elaboradas pelos alunos. Esta estratégia precisa ser utilizada com cautela, pois para que o aluno participe ativamente das discussões reflexões e avaliações 
críticas é preciso conhecimento. É importante se atentar constantemente que o aluno observa os ambientes de prática com olhar de novato.

Observa-se no desenvolvimento das atividades práticas em campo, um distanciamento entre a teoria e a prática que pode ser amenizado por meio de uma melhor articulação da IES com o serviço de saúde. Mas, para que isto se efetive, é preciso que ambas as partes tenham a mesma visão sobre a proposta e se saiba superar obstáculos como empatia, recursos humanos e materiais, estrutura gerencial do sistema, entre outros.

Para os cursos que forneceram a informação, observou-se que metade deles apresenta grupos de estágio de até cinco alunos, de acordo com a resolução COFEN $371 / 2010^{74}$, onde em seu artigo $2^{\circ}$ e inciso IV recomenda para a assistência intensiva cuidados a pacientes graves, com risco iminente de vida, sujeitos à instabilidade de sinais vitais, que requeiram assistência de Enfermagem e médica permanente e especializada - até cinco alunos por supervisor.

O tempo de duração do estágio, mencionado somente por alguns respondentes, mostrou uma variedade de informações de horas a dias. Pelas informações recebidas metade deles tem até sete dias de estágio. Ao se comparar estas informações relatadas com a mediana das cargas horárias práticas obtidas na disciplina específica de $\mathrm{CC}$ e do conteúdo dentro de outra disciplina, verificou-se que este valor também foi em torno de sete dias.

Uma das escolas em parceira com o hospital oferece oportunidade aos alunos para realizarem estágio extracurricular após terem cursado a disciplina, uma forma dos alunos contornarem o curto tempo de prática, quando se sentem atraídos por esta área de atuação.

Pelo menos no município de São Paulo, há hospitais particulares que oferecem estágio extracurricular para alunos do último ano de graduação. Um relato de experiência a partir da ótica dos enfermeiros que propuseram este programa é a de que esta experiência contribui para o aprendizado do aluno, oferecendo-lhe recursos, oportunidades e infra-estrutura para desenvolver as atividades em bloco cirúrgico sob a 
supervisão dos enfermeiros da unidade, que são responsáveis pelo seu treinamento teórico-prático. Além disso, consideram esta vivência importante para despertar no estagiário o encantamento pelo bloco cirúrgico, apesar do estresse e conflitos entre a equipe multiprofissional, que muitas vezes assustam e afugentam os enfermeiros que desconhecem estas situações comuns no $\mathrm{CC}^{75}$.

Com relação ao número de docentes que ministram a disciplina, metade dos cursos tem até dois docentes e houve predomínio de um docente para a teoria. Muitos cursos, principalmente nas escolas de gestão privada, contratam enfermeiros da prática clínica para supervisionar os alunos em campo hospitalar. Este fato pode ser deduzido quando o respondente informou um docente, mas que no campo de prática a distribuição de alunos é de um supervisor para cada cinco alunos. Nas escolas em que o docente não é contratado para atividades de pesquisa e de pós-graduação, um docente pode ser suficiente para a carga teórica com a vantagem que pode conhecer melhor seu grupo de alunos e acompanhar proximamente o desempenho deles. Os cursos com maior número de docentes foram aqueles que ministram disciplinas específicas.

Estatisticamente, os cursos com disciplina específica de CC apresentaram uma maior média de docentes de CC e também de docentes especialistas em $\mathrm{CC}$, embora não estatisticamente significativo a região SE apresenta quase um docente a mais a que as demais regiões em média.

Apesar de mais da metade dos docentes possuírem um título de especialista em $\mathrm{CC}$, apenas um docente o tinha adquirido por meio da prova de especialista da SOBECC.

Quase $75,0 \%$ dos docentes sem curso de especialização em CC, tinham experiência clínica em bloco cirúrgico. Cerca de $20 \%$ dos docentes eram especialistas em outras áreas de conhecimento.

Dada a disseminação dos cursos de especialização, a necessidade de formação de especialistas para inserção no mercado de trabalho e aos conteúdos superficiais ministrados nos cursos de graduação, há uma busca frenética dos enfermeiros recémgraduados por cursos de especialização, não com o intuito do aperfeiçoamento 
profissional para a melhoria de uma práxis, mas para aumentar as chances de empregabilidade.

A análise do perfil de entrevistados $(n=66)$ para o curso de Especialização em Enfermagem em Centro Cirúrgico, realizado na Escola de Enfermagem da USP em 2003, revelou que $66,7 \%$ não tinham especialização, mas 20,0\% possuíam especialização em Administração Hospitalar, 4,5\% em unidade de terapia intensiva, $3,0 \%$ em cardiologia e os demais em variadas áreas de conhecimento ${ }^{76}$.

Outro levantamento sobre o perfil de enfermeiros $(n=56)$ que atuava em unidades de radiologia intervencionista ou hemodinâmica mostrou que 76,4\% tinham uma especialização, $14,3 \%$ três e $3,6 \%$ duas. Quanto à área de conhecimento, apresentaram maior diversidade que no estudo ${ }^{76}$ anterior: $28,6 \%$ eram especialistas em administração hospitalar, 17,9\% em terapia intensiva e/ou emergência, 7,1\% em cardiologia, 3,6\%, cada, em médico cirúrgica, ortopedia e centro cirúrgico, 1,8\%, cada, em radiologia, nefrologia, obstetrícia, neonatologia, enfermagem do trabalho, estomaterapia, dermatologia, entre outros. Algumas especializações forneciam conhecimentos com uma interface com essas áreas de atuação como terapia intensiva, centro-cirúrgico, cardiologia, mas a maioria não, embora a formação em administração hospitalar seja de interesse para qualquer cenária de atenção a saúde ${ }^{77}$. A diferença pode ser devida ao interstício de cinco anos entre um estudo e outro, pois hoje a diversidade de especializações oferecidas e a oferta de cursos é maior que no passado.

Pelos estudos relatados observa-se que os enfermeiros realizam cursos de especialização, sem uma reflexão prévia sobre a área em que gostariam de atuar.

Cerca de dez por cento dos docentes, respectivamente, eram mestres ou doutores. No entanto, esta pergunta foi mencionada espontaneamente e não se pode tecer conclusões a respeito. A maioria de docentes com título de mestre pertencia ao quadro de pessoal das IES com cursos de disciplina específica e trabalhavam em escolas na região SE. Por outro lado, o maior número de doutores estava vinculado a cursos com conteúdo de $\mathrm{CC}$ incorporado a outras disciplinas. 
Alguns cursos se preocupam com a diversidade de estratégias de ensino. Esta prática traz mais motivação ao aluno e facilita o aprendizado. Um dos cursos utiliza como população alvo para atividades educativas alunos de outras áreas de conhecimento no hospital veterinário e clinica de órteses e próteses da instituição de ensino. São ministrados conteúdos de CC e CME como aulas de assepsia e esterilização de materiais. Esta atividade pode ser uma estratégia motivadora para os alunos perceberem a interdisciplinaridade do conteúdo de CC e CME, além de uma atividade que poderia ser conciliada com o ensino da licenciatura.

A interdisiciplinaridade é uma maneira de articular pessoas e conhecimentos, de modo a perceber o ser humano na sua integralidade ${ }^{78}$. A idéia central do movimento da interdisciplinaridade é superar os limites das disciplinas para que se produzam conhecimentos capazes de interpretar e dar respostas a situações complexas e multifacetadas, bem como acessíveis a mais grupos ou aplicável a vários contextos ${ }^{79}$.

Pode-se discriminar a interdisiciplinaridade em instrumental, conceitual e epistemológica. A forma mais simples, a instrumental, permite que os estudantes de uma disciplina utilizem métodos ou idéias de outra para expandir o conhecimento da disciplina em estudo. A conceitual e a epistemológica são abordagens mais complexas que supõem a construção de um campo de saber novo que não pertence a qualquer disciplina em particular ou a utilização de pressupostos onto-epistemiológicos compartilhados em estudos compostos por estudiosos de diversas disciplinas que produzem teorias que tem aplicação em diferentes áreas, como, por exemplo, enfermagem, educação, antropologia ${ }^{79}$. A interdisciplinaridade na forma instrumental deve ser o primeiro passo na formação do enfermeiro crítico e reflexivo. Independente das particularidades inovadoras dos currículos de cada bacharelado, a própria legislação ${ }^{28}$ já estabelece conteúdos interdisciplinares no currículo de enfermagem. $\mathrm{O}$ desafio está em fazer o aluno trazer para o campo da prática e da reflexão a conexão entre essas diversas disciplinas. Cabe ao professor facilitar ao aluno a integração do conhecimento adquirido nas disciplinas básicas ou próprias da ciência da enfermagem e do cuidar com estratégias de ensino criativas à medida que o curso avança, além de lhe 
proporcionar situações reais ou simuladas para que possa exercitar o uso desses conhecimentos no raciocínio clínico. Depositar sobre o aluno de graduação a responsabilidade sobre a interdisciplinaridade conceitual e epistemológica, sem que tenha vivenciado a instrumental e adquirido conhecimentos específicos do cuidar em enfermagem pode ser temeroso, pois o aluno pode não ter esta maturidade emocional e cognitiva que se acredita que possuam.

No campo da saúde o termo traz consigo a necessidade de incorporar conhecimentos das Ciências Humanas e Sociais, para superar o enfoque biomédico, curativista e fragmentado ao se discutir a problemática na saúde; a busca integrada na prestação de serviços ou na associação docência-serviço ${ }^{80}$.

Quando se fala em interdisciplinaridade nas ações em saúde enfermagem, há um direcionamento para as atividades de promoção a saúde ${ }^{80}$, como se assim não se fragmentasse no processo saúde-doença, o cuidar.

Ao se analisar historicamente a legislação, as resoluções e os pareceres sobre os currículos de enfermagem, nota-se desde o início um conflito entre a formação com foco hospitalar e de saúde pública, expressa em um manifesto das entidades associativas contra os currículos mínimos que não incluíram a disciplina de saúde pública como conteúdo obrigatório, apesar da iniciativa de sua inserção nos currículos estar sediada na própria instituição de ensino superior ${ }^{22}$ p.249.

$\mathrm{O}$ conceito de formação de um enfermeiro generalista poderia ter resolvido o conflito, onde cada IES focaria tanto o hospital quanto a comunidade, mas com cargas horárias distintas, de acordo com sua filosofia do que é ser enfermeiro, sua missão e perfil de morbimortalidade de sua região. Mas a interpretação dos que defendem a priorização da saúde pública é que o termo exclui a especificidade do cuidar de pacientes críticos.

As dificuldades relatadas no oferecimento da disciplina apresentaram dois enfoques: um relacionado à carga horária e recursos humanos e, outro, ao pouco interesse do conteúdo pelo aluno. Segundo um dos respondentes, os alunos têm a 
concepção de que em CC não se presta cuidado ao paciente, e quando se trata de paciente crítico fazem associação apenas com a unidade de terapia intensiva.

Estudo realizado no Reino Unido para avaliar a preferência dos alunos $(\mathrm{n}=455)$ quanto ao cenário de prática utilizando o Clinical Learning Environment Inventory ${ }^{81}$, após a realização da prática no terceiro ano, mostrou que há uma preferência pela experiência em unidade de terapia intensiva, alta dependência e cardiologia, exceto CC. A baixa pontuação a $\mathrm{CC}$, segundo relato de um estudante, foi atribuída a atividade de observação sem que houvesse um contato real com o paciente. Apesar das particularidades não houve diferença estatística ao se comparar ambiente hospitalar e da comunidade $^{82}$.

Houve certo número de docentes ressaltando a necessidade de ser uma disciplina específica de CC. Alguns docentes estão satisfeitos por terem conseguido elevar o conteúdo de $\mathrm{CC}$ ao status de disciplina e outros vislumbram esta possibilidade com o novo projeto pedagógico. Um dos respondentes comentou que, quando o conteúdo é ministrado dentro de outra disciplina, o aluno apresenta maior dificuldade em reconhecer o papel do enfermeiro em CC.

É difícil dizer qual a melhor maneira de inserir o conteúdo na grade curricular, os que a tinham como disciplina optativa a tornaram obrigatória e os que a tinham como disciplina a fundiram com a disciplina de enfermagem cirúrgica. Alguns docentes que estão em reforma curricular vivenciam o medo da exclusão deste conteúdo, pois a maioria dos colegas docentes não a valoriza e outros estão preocupados em ampliar o conteúdo, pois precisam do profissional do mercado de trabalho com uma formação básica para iniciar as atividades em $\mathrm{CC}$, dado que não há oportunidades para que se desloquem aos grandes centros urbanos para realizar uma especialização.

Diante da possibilidade de exclusão do conteúdo da grade curricular, um respondente disse que realizou uma pesquisa com os alunos sobre a importância deste conteúdo na sua formação e com os resultados obtidos, decidiu-se manter o conteúdo na grade curricular. 
Estudo $^{83}$ realizado em uma universidade privada no RS para conhecer as expectativas e as vivências dos acadêmicos de Enfermagem acerca da disciplina de CC evidenciou que os $55,2 \%$ dos alunos que já haviam cursado a disciplina a consideravam importante e $31,1 \%$ essencial para o preparo profissional.

A política voltada para atenção primária não é apenas nacional, o Canadá também vivencia a retirada de determinados conteúdos da grade curricular. O movimento voltado para a formação de um enfermeiro generalista também contribuiu para a retirada de determinados conteúdos dos currículos de graduação em enfermagem ao dar menos foco nas tarefas técnicas e mais na tomada de decisão e habilidades interdisciplinares, trabalho com diversas clientelas, integração com a pesquisa e a ética, com forte enfoque em enfermagem comunitária e na promoção a saúde ${ }^{84}$.

Os docentes reconhecem que a visão dada ao aluno sobre CC na graduação é ampla e que uma vez atuando no bloco cirúrgico devem aprofundar seu conhecimento por meio de um curso de especialização.

O número de cursos de especialização oferecidos foi reduzido e, os ministrados, menor ainda. A maioria desses cursos foi realizada por escolas particulares, localizadas principalmente na região SE. As três escolas que ministram cursos anualmente pelo menos há cinco anos estão no Estado de São Paulo. Dois cursos criaram o projeto para o curso de especialização, mas o número mínimo de inscritos não foi alcançado apesar de a demanda por enfermeiros de CC nesses locais ser grande, segundo os respondentes.

Parece que o país vivencia uma situação semelhante ao que ocorre nos EUA, uma ampla de manda de mercado e poucos enfermeiros interessados nessa área atuação $^{8}$.

Diversas foram as opiniões emitidas sobre a importância no conteúdo de CC na grade curricular dos cursos de bacharelado em enfermagem

Uma questão levantada foi a disponibilidade de emprego na área de $\mathrm{CC}$, a curta permanência de enfermeiros nas unidades de $\mathrm{CC}$ e a necessidade desse conteúdo aos enfermeiros, pois na região $\mathrm{N}$ os enfermeiros do interior do Estado são responsáveis pela organização do CC e da CME. Em muitas regiões do país é um enfermeiro para 
todo hospital e ele precisa ter uma formação básica generalista que lhe dê sustentação para um gerenciamento de enfermagem de qualidade pautado na segurança do paciente.

Pesquisa de opinião com enfermeiros de CC, sobre a importância do conteúdo de enfermagem perioperatória na graduação, mostrou que tanto os enfermeiros que tiveram o conteúdo na grade curricular quanto aqueles que não o tiveram afirmaram que são necessários conhecimentos da disciplina Enfermagem em $\mathrm{CC}$ para atuar no $\mathrm{CC}$ e $100,0 \%$ e $92,0 \%$, respectivamente, disseram que esse conteúdo deve estar no currículo para a formação do enfermeiro ${ }^{85}$. Docentes que iniciaram sua vida profissional em CC valorizam o conteúdo de $\mathrm{CC}$, pois tiveram na graduação um conteúdo insatisfatório em termos de profundidade e de reflexão crítica.

Devido à elevada demanda de profissionais no mercado de trabalho nos Estados Unidos, os serviços de saúde têm contratado enfermeiros sem especialização na área, e desta forma as instituições se deparam com um profissional sem preparo e que por desconhecimento nessa área de atuação também não consegue permanecer no serviço ${ }^{72}$. Em decorrência desta situação, hospitais americanos e a própria AORN têm desenvolvido programas voltados para a enfermagem perioperatória, de modo a preparar os enfermeiros para atuarem no centro cirúrgico. Em particular, o programa da AORN é um curso a distância com 25 módulos e preceptoria clínica ${ }^{86}$.

Um docente manifestou preocupação com o conteúdo deficitário, pois atribui a isto o medo que o enfermeiro recém-graduado tem de trabalhar no bloco operatório.

Uma avaliação sobre o enfermeiro recém-formado observou que sem a oportunidade de obter experiência das habilidades baseadas no contexto, os recémgraduados têm relatado um sentimento de "não se sentirem prontos"

A maioria dos relatos sobre a importância deste conteúdo na formação do enfermeiro relacionou-se à possibilidade de mostrar ao aluno outro campo de atuação e despertar nele o desejo de se especializar na área e permitir que ele reconheça a importância do enfermeiro na unidade de CC. Alguns associaram a questão ao fato do $\mathrm{CC}$ ser uma área fechada sob dois aspectos: um que o aluno teria poucas possibilidades 
de acessar este espaço e outro que o fato de ser uma unidade fechada desperta interesse e curiosidade do aluno.

Alguns relatos versaram sobre a possibilidade de direcionamento profissional que a vivência em $\mathrm{CC}$ pode proporcionar ao aluno. Estudo ${ }^{88}$ para avaliar o quanto o estágio contribui para a escolha profissional realizado com 337 estudantes no norte de Portugal no último ano de formação de diferentes áreas, utilizando a escala "Resultados do Processo de Exploração Vocacional", mostrou que o estágio realmente é uma experiência positiva para o desenvolvimento vocacional dos estudantes, constituindo-se em uma via de articulação entre o espaço formativo e o profissional

Estudo ${ }^{14}$ americano também concluiu que oferecer este conteúdo aos graduandos pode despertar o interesse em vir a cursar uma especialização em CC no futuro. Para contornar a ausência do conteúdo no programa do curso, algumas escolas passaram a oferecem cursos de verão aos estudantes de enfermagem ${ }^{10,12-13}$.

Alguns enfermeiros atrelaram a importância do conteúdo de $\mathrm{CC}$ à compreensão do processo saúde-doença do indivíduo, um fenômeno dinâmico e continuo. Não se pode simplesmente fazer um recorte e remover esta parte do cuidar do processo saúdedoença..

Diz que o enfermeiro deve privilegiar o cuidado integral ao indívíduo, mas se aceita a fragmentação do cuidar quando se retira do aluno a oportunidade de conhecer e exercitar as demandas do cuidar do paciente no intraoperatório e na recuperação anestésica na sua fase de formação. Como orientar o paciente e atender suas necessidades para o momento cirúrgico se o graduando/enfermeiro desconhece o que ocorre nesta unidade fechada e com características peculiares? Como o futuro profissional avaliará e contextualizará determinadas complicações pós-operatórias decorrentes de procedimentos realizados na sala operatória e que envolvem a atenção do enfermeiro?

Um exemplo de como o cuidar no centro cirúrgico integra o conhecimento do aluno pode ser observado no ocorrido na Georgetown University ${ }^{9}$. Após um período de tempo sem o conteúdo de CC na grade curricular, houve uma iniciativa para 
reintroduzir os alunos aos poucos no $\mathrm{CC}$, por meio do acompanhamento de um paciente cirúrgico desde sua internação na clínica cirúrgica até a alta, incluindo o intraoperatório. Os estudantes de enfermagem foram capazes de aplicar o modelo de auto-cuidado da Orem para encontrar as necessidades do paciente cirúrgico na sala operatória, se contrapondo ao motivo de remoção do bloco cirúrgico da grade curricular: a adoção dessa teoria.

Um respondente disse que o conhecimento do cuidado intra-operatório permite ao enfermeiro da clínica cirúrgica ou unidade de terapia intensiva planejar melhor a assistência do paciente, além de contribuir na redução de complicações pós-operatórias.

A técnica asséptica ou o controle de infecção hospitalar apresenta interfaces com outras áreas, como mencionado pelos respondentes, nas unidades que realizam procedimentos cirúrgicos, minimamente invasivos e exames diagnósticos, podendo se configurar como conteúdo interdisciplinar ou transversal. Foi feito um comentário estendendo este conteúdo ao gerenciamento do hospital, pois o fluxo do CC influi na taxa de ocupação, financiamento e atendimento. O aumento no número de clínicas privadas que realizam procedimentos cirúrgicos requer para a organização da unidade cirúrgica e segurança do paciente que o enfermeiro tenha conhecimento nesta área.

Em regiões menos urbanizadas, a atenção primária tem uma importância adicional na atenção a saúde. É interessante verificar como os docentes dessas regiões percebem a importância deste conhecimento na formação do enfermeiro mesmo quando ele atuará na atenção básica para dar conta do sistema de referência contra referência. $\mathrm{O}$ paciente é encaminhado para a cirurgia, mas no pós operatório retorna ao atendimento da atenção primária, e o enfermeiro deve ser capaz de orientá-lo e assisti-lo tanto no preparo pré-operatório quanto no cuidado pós-operatório. Mesmo que se trate de um Programa de Saúde da Família, com a redução do tempo de internação o paciente poderá vir a fazer o pós-operatório no domicílio. Situação comum nas cirurgias ambulatoriais em que o paciente retorna para casa no mesmo dia da cirurgia.

$\mathrm{Na}$ Espanha, desde o ano 2000 diversas cirurgias de pequeno porte (curtagem, criocirurgia, unha encravada, drenagens, suturas, exérese de lesões de pele) têm sido 
realizadas em centros de saúde (Centros de Salud de la Comunidad) O conhecimento das técnicas cirúrgicas nos procedimentos de pequeno porte permite a resolução em loco de problemas que no passado seriam resolvidos somente no ambiente hospitalar. Por isso, o aprendizado e a experiência em cirúrgica devem ser elementos fundamentais para a formação completa do médico de família ${ }^{89}$.

Pelo menos na cidade de São Paulo, há ambulatórios de especialidades no sistema de atenção primária que realizam pequenos procedimentos. Não importa a dimensão da intervenção, o preparo do ambiente cirúrgico requer os mesmo cuidados do hospital para a realização da técnica asséptica. O enfermeiro mesmo atuando neste serviço deveria ter tido na sua formação conteúdos teóricos práticos de $\mathrm{CC}$ e $\mathrm{CME}$, principalmente porque procedimentos mais sofisticados podem vir a ser realizados em unidades de atenção primária como ocorre no Reino Unido ${ }^{90}$.

Para diminuir a lista de espera por procedimentos de correção de hérnia de parede no Reino Unido ${ }^{90}$, em 2005, iniciou-se a realização desse procedimento em um serviço de atenção primária, com a realização de mais de 1.000 procedimentos em três anos. Os procedimentos foram realizados sob anestesia local, sem sedação e não havia infra-estrutura para conversão para anestesia geral. Realizava-se uma avaliação prévia para excluir os pacientes que não atendessem aos critérios para a realização da intervenção em ambiente de atenção primária e solicitava-se assinatura do termo de consentimento. No dia da cirurgia o paciente era recebido pelo enfermeiro que conduzia um protocolo de avaliação, no caso de o paciente apresentar indicações clínicas. A equipe cirúrgica era constituída do cirurgião e de duas enfermeiras, que desempenhavam o papel de assistente e de circulante de sala, respectivamente. $\mathrm{O}$ paciente recebia alta após 30 minutos do procedimento e a noite a enfermeira reavaliava o paciente por contato telefônico. O paciente realizava um retorno em sete dias para remoção do curativo. As complicações foram mínimas, as mais frequentes, recorrência da hérnia $(0,3 \%)$ e hematoma $(0,3 \%)$, sem casos de infecção. Para a realização dos procedimentos foi preciso criar um $\mathrm{CC}$, equipá-lo com desfibrilador e suprimentos para ressuscitação cardiopulmonar, treinar a equipe e padronizar os cuidados para que 
fossem iguais aos dispensados em hospitais, além disso, era preciso contar um médico generalista (general practice) com certa experiência em reparos teciduais.

Diversos respondentes reforçaram a importância do conteúdo de CC na formação do enfermeiro generalista, na fundamentação de sua prática profissional, insistindo que o curso deve preparar o aluno para atuar em diferentes cenários. Consideram que o diploma de generalista traz implícita a mensagem de que o enfermeiro está apto a atuar em qualquer cenário da atenção a saúde.

Mas, o que é ser enfermeiro generalista? É o enfermeiro que teve oportunidades de aprendizado teórico e de desenvolver habilidades técnicas em todos os cenários de cuidado, que o capacite para uma atuação inicial em qualquer estabelecimento ou área da saúde. É o enfermeiro apto a atender demandas do cuidar em qualquer nível de atenção: primária, secundária ou terciária em saúde. Não se pretende negar o caráter de especialidade da enfermagem perioperatória, mas do mesmo modo constituem especialidade a pediatria, saúde mental, terapia intensiva, emergência, entre outras.

Pela tabela 3 observou-se que salvo algumas exceções, o número de enfermeiros com título de especialista em CC é inferior a $0,5 \%$, inclusive nas regiões S e SE onde se localiza a maior oferta de cursos de especialização. Esses dados do Datasus, reforçam o fato de que há muitos enfermeiros atuando em CC sem formação especializada e, portanto, os cursos de graduação tem uma responsabilidade para com a sociedade em formar enfermeiros generalistas com ao menos um conhecimento básico de $\mathrm{CC}$ e de CME. 


\section{Considerações Finais}




\section{CONSIDERAÇÕES FINAIS}

As Diretrizes Nacionais Curriculares ${ }^{26}$ têm seu mérito ao assegurar às instituições de ensino superior a liberdade na composição da carga horária a ser cumprida para a integralização dos currículos e na especificação das unidades de estudo a serem ministradas. Também foi uma proposta interessante ao ser atrelada aos princípios do Sistema Único de Saúde e à prevalência de morbi-mortalidade de cada região.

No entanto, as competências e habilidades propostas são inespecíficas, pois ao mesmo tempo em que privilegiam a liberdade de escolha de conteúdos, também permitem a livre interpretação de quais seriam os melhores conteúdos. Acresce-se o fato de que na tentativa de se adequarem às DNC e, simultaneamente às políticas de saúde $\mathrm{e}$ aos editais de financiamento como o Pró-Saúde, alguns conteúdos, como o de CC, tendem a ser preteridos como de menor valia na formação do enfermeiro.

O Programa Nacional de Reorientação Curricular da Formação Profissional em Saúde (Pró-Saúde) surgiu de uma parceria do Ministério da Saúde com o da Educação em 2005, a partir da Secretaria de Gestão do Trabalho e da Educação Superior (SGTES), da Educação Superior (SESU), com apoio do Instituto Nacional de Estudos e Pesquisa Educacionais Anísio Teixeira (INEP). O projeto, lançado por meio da Portaria Interministerial MS/MEC n $2101^{91}$ reconhece o processo de formação em saúde como um componente para a qualificação da força de trabalho (medicina, enfermagem e odontologia) e para a efetivação da política nacional de saúde. Definiu-se como objetivo incentivar transformações do processo de formação, geração de conhecimentos e prestação de serviços à população, para abordagem integral do processo-saúde doença Neste processo o desafio seria favorecer a articulação entre as instituições formadoras e os serviços de saúde.

$\mathrm{Na}$ leitura de determinados trechos do projeto observam-se propostas que aos sentidos podem parecer contraditórias, como nos parágrafos a seguir: 
"O que se busca é a intervenção no processo formativo para que os programas de graduação possam deslocar o eixo da formação centrado na assistência individual prestada em unidades especializadas - por um outro processo em que a formação esteja sintonizada com as necessidades sociais, calcada na proposta de hierarquização das ações de saúde. Além disso, que essa formação leve em conta as dimensões sociais, econômicas e culturais da população, instrumentalizando os profissionais para a abordagem dos determinantes de ambos os componentes do binômio saúdedoença da população na comunidade e em todos os níveis do sistema." 91 p.19

"É necessária também a reorientação das pesquisas desenvolvidas na área da Saúde, com ênfase na investigação das necessidades da comunidade, organização e financiamento dos serviços de saúde, experimentação de novos modelos de intervenção, avaliação da incorporação de novas tecnologias e desenvolvimento de indicadores que permitam melhor estimativa da resolubilidade da atenção." 91 p.20

"Todos estes encaminhamentos pressupõem a construção efetiva da integração docente assistencial, que envolve tanto a atenção básica quanto os outros níveis de cuidados de saúde, aproveitando amplamente a capacidade instalada da rede de serviços, complementada pela utilização dos hospitais universitários e/ou as unidades assistenciais especializadas dependentes das IES, funcionalmente integradas ao SUS. Isso conduz a uma adequada construção do sistema de referência e contra-referência, essencial para a atenção à saúde com qualidade e resolubilidade. A interação recíproca entre os gestores dos sistemas educacional e do SUS vai permitir a criação das condições reais para o aproveitamento de ambos os sistemas, com melhor qualidade técnica na atenção e no processo de ensino aprendizagem". 91 p.20

O projeto busca direcionar a formação do profissional da saúde para priorizar a atenção primária a saúde, mas simultaneamente preconiza que ela deva ocorrer em todos os níveis de atenção. Deslocar o eixo para a comunidade significa focar na "promoção a saúde", porque a partir do instante que o indivíduo apresenta um problema de saúde, mesmo que atendido na unidade de atenção primária, a intervenção atingirá o indivíduo, salvo as situações que envolvam doenças infecto contagiosas, onde as ações atingirão a comunidade. 
Ao se tomar como referência a teoria do determinismo social ${ }^{92}$ para a compreensão do processo saúde-doença, muito utilizada na saúde coletiva, verifica-se que o adoecimento tem bases sociais e culturais. $\mathrm{O}$ enfermeiro na coletividade faz uso desse referencial para compreender as necessidades de saúde do grupo, mas o alcance de sua intervenção se limita a atividades educativas para a prevenção de doenças e para a promoção a saúde com enfoque na mudança de hábitos de vida. Essas ações, não excluem seu papel no atendimento do indivíduo e família na resolução de problemas de saúde dentro de sua competência.

O texto se reporta à construção do sistema de referência e contra-referência como se o desempenho, sua efetividade e eficiência fossem uma responsabilidade compartilhada com as instituições de ensino. Em parte sim, no que tange a formação do profissional de saúde, pois estará envolvido nesse processo e sua competência influencia a resolução dos problemas de saúde. Mas nesse processo de recuperação da saúde há também um componente sócio-cultural, a co-responsabilidade do cliente no seu auto-cuidado e fatores relacionados ao próprio sistema de saúde. Para dar conta da resolubilidade do sistema de saúde pública, outros cursos de formação profissional deveriam ser envolvidos, como os da área da antropologia, sociologia, economia, administração, ciências sociais, psicologia, nutrição, ecologia, veterinária, engenheiros, entre outros, porque a promoção a saúde envolve muito mais do que o simples cuidado da saúde. Além disso, não é o deslocamento do eixo de atenção a saúde para a comunidade na formação de profissionais que se resolverão as dificuldades do sistema de saúde, principalmente as relacionadas a gestão e ao acesso aos serviços de saúde. Um enfermeiro competente deve ser capaz de atender as necessidades de cuidado do cliente ou saber realizar encaminhamentos quando a questão foge a sua competência, independente do cliente ser o indivíduo ou a comunidade.

A interdisciplinaridade existe e é benéfica para ampliar a compreensão do fenômeno para a solução do problema, mas não transfere ao enfermeiro a responsabilidade por intervenções pertencentes a outras áreas de conhecimento. Esta situação pode ser diversa, caso o enfermeiro ocupe um cargo na hierarquia dos serviços 
de saúde ou na gestão pública que lhe confira autoridade para a tomada de determinadas decisões.

Bagnato e Rodrigues ${ }^{93}$ fazem algumas reflexões importantes a respeito da tendência de adotar currículos demasiadamente liberais, em nome do popular argumento: "formar enfermeiros críticos e reflexivos, desvinculados do conhecimento fragmentado estruturado em disciplinas". Não se deve negligenciar a importância do saber sistematizado, científico e tecnológico porque são nucleares. Da mesma forma, não se pode abrir mão de saberes oriundos das outras áreas do conhecimento que são importantes para o avanço da atenção a saúde, mas é preciso encontrar o ponto de equilíbrio entre a formação técnica e humana para que não se siga o caminho do modismo. Deve-se estar atento às pedagogias tão abertas que não assegurem uma formação consistente apoiada no conhecimento, por privilegiarem o que é valorizado pelo aluno e a não valorização do conhecimento transmitido.

O currículo não deve perder seus conteúdos clássicos, pois é neles que se pauta a ciência do cuidar. $\mathrm{O}$ ensino se transforma historicamente pelo desenvolvimento tecnológico e pelas mudanças sócio-econômico-políticas, sendo assim se verifica a necessidade de seus conteúdos serem adequados para o melhor cuidado dos pacientes nos diferentes momentos de seu processo de saúde-doença.

A necessidade do conteúdo de ECC extrapola a área de $\mathrm{CC}$, os avanços tecnológicos na área de diagnóstico por imagem com a realização de procedimentos minimamente invasivos para diagnóstico ou tratamento, bem como no preparo para determinadas cirúrgicas têm exigido que os enfermeiros que atuam nesse local tenham conhecimento de enfermagem perioperatória e reprocessamento de material.

Não se trata apenas de valorizar o conteúdo de centro cirúrgico nos currículos de graduação, mas sim compreender a repercussão da falta deste conteúdo nos cursos de graduação, inclusive para a adesão aos programas da Aliança Mundial para a Segurança do Paciente. Dada a relevância do tema, em 2009 o Ministério da Saúde em parceria com a Organização Pan-Americana da Saúde da Organização Mundial da Saúde (OPAS/OMS) publicaram o Manual de Implementação de Medidas para o projeto 
Segurança do Paciente: "Cirurgias Seguras Salvam Vidas" de modo a contribuir para a plena percepção do risco ou o reforço, no sentido de uma prática efetiva de medidas preventivas, que potencializam os avanços tecnológicos observados na assistência cirúrgica $^{94}$. Este programa envolve questões da prevenção de ISC, anestesia segura, equipe cirúrgica segura e indicadores de assistência cirúrgica, questões estas abordadas na disciplina de ECC.

Os ataques terrorristas, as guerras, as alterações climáticas e de acomodação geológica tem trazido para o cotidiano do planeta catástrofes de extensa dimensão que requerem hospitais e $\mathrm{CC}$ improvisados para atender os sobreviventes. $\mathrm{O}$ enfermeiro precisa ter um conhecimento mínimo de ambiente de sala operatória e assistência perioperatória para que possa atuar em locais inóspitos sem contribuir com a morbimortalidade pela falta de conhecimento específico mínimo.

Em mundo globalizado, com a liberação de fronteiras se torna mais fácil a migração de trabalhadores e cria-se a necessidade de rever a formação profissional para que se equipare entre os países, sem perder sua identidade própria e para que os diplomas sejam facilmente validados.

O Tratado de Bologna ${ }^{95}$ foi uma iniciativa da União Européia para unificação da educação técnica e superior, de modo a facilitar a migração de profissionais para trabalhar em outros países da comunidade Européia até 2010. Esta reforma foi necessária pela diferença de títulos acadêmicos, estrutura curricular e competências existentes entre os países. A intenção não era de uniformizar os currículos, mas que eles fossem convergentes e compreensíveis para oferecer oportunidades de mobilidade, emprego e colaboração em pesquisa. As universidades deveriam sintonizar seus currículos, sem perder a autonomia e a habilidade de inovação. Um dos focos principais era formar enfermeiros de nível superior, uma vez que em muitos países havia apenas profissionais técnicos. Estabeleceu-se um programa de estudos para o currículo com duração mínima de três ${ }^{96}$.

No Mercosul tem-se discutido a integração educacional do ensino superior com vistas ao desenvolvimento dos Estados Partes (Brasil, Argentina, Uruguai, Paraguai) 
por meio da concretização da produção e socialização de conhecimentos para o desenvolvimento pleno e equilibrado da sociedade. A partir de discussões sobre a integração econômica, estendeu-se a proposta ao setor educacional embora evolua de modo lento. Por meio da Resolução 07/91, o Conselho do Mercado Comum criou a Comissão de Ministros da Educação dos Países Membros do Mercosul para coordenar as políticas educacionais da região com foco no reconhecimento de títulos, na mobilidade estudantil e na cooperação interinstitucional. $\mathrm{O}$ reconhecimento recíproco de títulos de graduação inicialmente focou os cursos de medicina, engenharia e agronomia e posteriormente, definiu-se a inclusão dos cursos de arquitetura, enfermagem, odontologia e veterinária ${ }^{97}$.

Se no país ainda não conseguimos uma compreensão única do que é ser enfermeiro generalista, e quais conteúdos são essenciais para a formação profissional, é de supor que muitos conflitos ainda existirão para uma diretriz de Mercosul sobre a formação do enfermeiro.

O estudo apresentou algumas limitações relativas ao instrumento de coleta. Apesar do pré-teste ter levado a algumas adaptações do questionário, estas não foram suficientes para abarcar a diversidade dos cursos de enfermagem. Uma delas relacionase à compreensão da distinção entre disciplina de Enfermagem em Centro Cirúrgico e disciplina de Enfermagem Cirúrgica, e neste, caso o questionário deveria ter apresentado as duas opções. A denominação das disciplinas, quando o conteúdo é ministrado dentro de outras disciplinas foi muito diferente e sentiu-se falta das ementas da disciplina. Outro ponto pouco claro foi o conceito de carga horária prática, que também necessita de maior cuidado ao se elaborarem perguntas a esse respeito. Apesar desses aspectos, as perguntas abertas trouxeram clareza a algumas dúvidas relacionadas aos dados quantitativos. 


\section{Conclusão}




\section{CONCLUSÃO}

De modo geral, ficou patente nos relatos dos respondentes a importância do conteúdo de CC na formação profissional do enfermeiro generalista. Assim, o discurso político e acadêmico que caracteriza rigidamente os cursos de enfermagem como fragmentados pela manutenção do conteúdo em disciplinas merece reflexão. Mesmo construída em disciplinas, a grade curricular é interdisciplinar e a dificuldade em agregar conteúdos está nos alunos e no professor, pois a interdisciplinaridade e a transversalidade do conteúdo de $\mathrm{CC}$ foi bem contextualizada pelos respondentes.

A contratação de enfermeiros para atuar em CC sem o curso de especialização ainda é a realidade no país. Não se pode conceber que um profissional recém-formado inicie suas atividades em CC sem ter sido exposto a esse ambiente de cuidado na graduação. Alguns cursos de especialização ainda mantêm nos critérios de seleção a experiência prévia nessa unidade, condição esta também relevante para que as discussões sobre a assistência perioperatória e a gestão de CC sejam ricas e se possa formar um enfermeiro especialista de qualidade, reflexivo e comprometido com sua prática.

Os avanços tecnológicos em cirurgia, a complexidade do cuidado e o estado vulnerável do paciente cirúrgico exigem que a atuação do enfermeiro nessas áreas seja respaldada por conhecimentos evidentes de atuação e da concepção de que o nosso alvo é a realização de assistência perioperatória para o sucesso do ato anestésico cirúrgico com segurança.

Embora representando apenas $20,0 \%$ dos cursos de bacharelado ministrados no país, considerou-se que em termos de país obteve-se uma boa representatividade de todas as regiões.

Os cursos com disciplina específica apresentaram maior carga teórica que a prática, enquanto no conteúdo ministrado dentro de outras disciplinas a mediana da carga horária teórica e prática foram quase iguais. Apesar da variabilidade de horas, a 
tendência é a carga prática ser maior nas disciplinas específicas do que na outra situação. Pelas medianas obtidas com relação à carga horária, poderia se estabelecer como diretriz uma carga teórica mínima de $45 \mathrm{~h}$ e carga prática de $35 \mathrm{~h}$, para os cursos que tiverem necessidade de uma referência.

Quase todos os cursos ministram os mesmo conteúdos, mas a diferença nas cargas teóricas indica que em alguns cursos esse conteúdo deva ser muito superficial. Os conteúdos menos abordados foram instrumentação cirúrgica, cirurgia ambulatorial e avanços tecnológicos. Esperava-se que o SAEP fosse abordado em todos os cursos, mas em cerca de $15,0 \%$ deles isto não ocorre.

Salvo algumas exceções, as estratégias de ensino teóricas tendem a ser de aulas expositivas. Modalidades diferentes tendem a utilizadas quando o aluno não tem atividade de campo ou a carga horária prática é muito pequena.

O corpo docente tem poucos títulos acadêmicos, mesmo nas regiões com o maior número de cursos de pós-graduação sensu strictu. Mas, a maioria dos professores tem curso de especialização em CC ou experiência profissional em bloco operatório.

Há uma elevada demanda para enfermeiros de CC no país, com os avanços da tecnologia para procedimentos minimamente invasivos e a expansão no número de clínicas que realizam procedimentos. Tais informações falam a favor da manutenção desse conteúdo nas grades curriculares e com o merecido destaque. São necessárias discussões entre os pares para definir o nível de aprofundamento da disciplina e desempenhos de aprendizagem.

As falas também retratam a solidão dos docentes de $\mathrm{CC}$ nos debates sobre este tema dentro das próprias IES e a necessidade de traçar diretrizes que definam não somente a carga horária, mas qual o conteúdo apropriado para a formação de um enfermeiro generalista com preparo para poder iniciar suas atividades em CC com relativa segurança e estratégias que pudessem melhorar o desempenho do aluno nas atividades clínicas de campo. 
Ruth Natalia Teresa Turrini

Há necessidade de se estabelecer uma rede de discussões, trabalhos e pesquisa para fortalecer o corpo docente e o conteúdo de centro cirúrgico nos cursos de bacharelado em enfermagem. 
Referências 


\section{REFERÊNCIAS}

1. Riley R, Manias E. Foucault could have been an operating room nurse. J Adv Nurs 2002; 39(4):316-24.

2. Hallquist DL. Developments in the RN first assistant role during the Korean War. AORN J 2005; 82(4):644-7.

3. Fairchild SS. Now is the time/future of perioperative nursing. apud Nagle GM. Perioperative nursing. Nurs Clin North Am 2006; 41(2):xi-xv.

4. Fitzwater J. It's time for a return do OR experience. RN 1973; 36(3): 45-7. apud Reynolds A, Sizemore MH. Perioperative clinical experiences: opportunities for baccalaureate nursing students. AORN J 1986; 43(4): 901-6.

5. Williams M. Reflections on a perioperative career: 1970-2008. J Perioper Pract. 2009; 19(3):106-13.

6. Moszczynski A. Before operating room nursing journals: operating room nursing in the pages of the Canadian Nurse 1940-1960. Can Oper Room Nurs J. 2010; 28(3):6-8, 15-7, 23-4.

7. Grundmann BJ, Shetler MG, Casterton SB, Hesterly SC, Minckley BB. Operating room nursing in the basic curriculum: an opinion. Nurs Outlook 1970; 18(1): 44-6.

8. Gentz L. A primer for perioperative education. AORN J. 2004; 80(1):111-3.

9. Armitage PA. Nursing students return to the operating room. AORN J 1980; 31(4): $710,712,714-6$.

10. Beitz JM. Project Alpha: a nursing elective implemented in a general systems theory curriculum. AORN J 1992; 55(5): 1218-30

11. Eakeman F. Nurse educators needed to keep student OR rotation in nursing school curriculum. AORN J 1986; 43(5): 983, 86-7.

12. Gutierrez K, McCormack C, Villaverde M. Perioperative nursing in the college curriculum: a custom fit. AORN J 1989; 49(4): 1052-8, 1060.

13. Tolley RG, Cullen JC, Hoffman ES, Riester SL. Perioperative nursing: designing, implementing a baccalaureate elective. AORN J 1990; 52(1): 105-8. 
14. Clark-Burg K. Future perioperative registered nurses: an insight into a perioperative programme for undergraduate nursing students. J Perioper Pract. 2008; 18(10):432-5.

15. National Student Nurses' Association. NSNA. Expanding Perioperative Nursing Experiences in Undergraduate Nursing Curricula. In: National Student Nurses' Association. Resolutions 2006. p. 19. Available from: http://www.nsna.org/Portals/0/Skins/NSNA/pdf/Resolution\%202006.pdf Acess in 22 fev 2011.

16. Association of periOperative Registered Nurses. AORN Guidance Statement: The value of clinical learning activities in the perioperative setting in undergraduate nursing curricula. AORN J 2007; 86(2): 265-9.

17. Vieira TT, Barros SMPF, Sena SMS, Souza MG. Evolução histórica do currículo da escola de enfermagem da Universidade Federal da Bahia. Rev Baiana Enferm 1975; 1(1):73-89.

18. Renovato RD, Bagnato MHS, Missio L, Bassinello, GAH. As identidades dos enfermeiros em cenários de mudanças curriculares no ensino da enfermagem. Trab Educ Saúde 2009; 7(2): 231-48.

19. Brasil. Lei 775, de 6 de agosto de 1949. Dispõe sobre o ensino de enfermagem no País e dá outras providências. Disponível em: https://www.planalto.gov.br/ccivil_03/leis/1930-1949/1775.htm. Acesso em 20 mar 2012.

20. Brasil. Decreto de 27.246 de 14/11/49. Aprova o regulamento básico para os cursos de enfermagem e de auxiliares de enfermagem. Diário Oficial da União, Brasília, 19 dez 1949. Seção I: 17517.

21. Brasil. Conselho Federal de Educação. Parecer N. ${ }^{\circ}$ 271/62, de 19 de outubro de 1962. Fixa o currículo mínimo do Curso de Enfermagem. Documenta N. ${ }^{\circ} 10$, de dezembro de 1962.

22. Ministério da Saúde. Fundação de Serviços de Saúde Pública. Enfermagem: legislação e assuntos correlatos. $3^{\mathrm{a}}$ ed. Rio de Janeiro; 1974. v.3.

23. Brasil. Conselho Nacional de Educação. Resolução N. ${ }^{\circ}$ 4/72 de 28 de fevereiro de 1972. Currículo mínimo dos Cursos de Enfermagem e Obstetrícia. Diário Oficial da União, Brasília, 26 jul 1972. Seção I. /Documenta N. ${ }^{o}$ 140, de julho de 1972. 
24. Brasil. Ministério da Educação e dos Desportos. Portaria 1.721 de 15 de dezembro de 1994. Fixa os mínimos de conteúdo e duração do curso de graduação em Enfermagem. Diário Oficial da União, Brasília. Seção I: 69-70. Disponível em: http://www.jusbrasil.com.br/diarios/1430852/dou-secao-1-16-12-1994-pg-69/pdf.

Acesso em: 21 mar 2012

25. Brasil. Ministério da Educação. Lei 9.394 de 20/12/94 estabelece as diretrizes e bases da educação nacional. Diário Oficial da União, Brasília, 23 de dezembro de 1994. Seção I: 19801-2.

26. Brasil. Ministério da Educação. Conselho Nacional de Educação. Câmara Superior de Ensino. Parecer CNE/CES 1133 /2001. Diretrizes Curriculares Nacionais dos Cursos de Graduação em Enfermagem, Medicina e Nutrição. Disponível em: http://portal.mec.gov.br/dmdocuments/ces1133.pdf. Acesso em 22 mar 2012.

27. Brasil. Conselho Nacional da Educação. Câmara Superior de Ensino. Parecer CNE/CES n ${ }^{\circ} 213 / 2008$. Dispõe sobre a carga horária mínima e procedimentos relativos à integralização e duração dos cursos de graduação em Biomedicina, Ciências Biológicas, Educação Física, Enfermagem, Farmácia, Fisioterapia, Fonoaudiologia, Nutrição e Terapia Ocupacional, bacharelados, na modalidade presencia. Disponível em: http://portal.mec.gov.br/dmdocuments/pces213_08.pdf. Acesso em 17 mar 2012.

28. Brasil. Conselho Nacional de Educação. Câmara de Educação Superior. Resolução CNE/CES 3/2001. Institui Diretrizes Curriculares Nacionais do Curso de Graduação em Enfermagem. Diário Oficial da União, Brasília, 9 de Novembro de 2001. Seção 1, p. 37.

29. Galleguillos TGB, Oliveira MAC. A gênese e o desenvolvimento histórico do ensino de enfermagem no Brasil. Rev Esc Enferm USP. 2001; 35(1):80-7.

30. Coêlho IM. Graduação: rumos e perspectivas. RAIES Rev Avaliação. 1998; $3(3): 15-21$.

31. Gibertoni G, Salzano SDT, Castellanos BF, Jouglas VMG, Posso MB, Marchetti AM. Plano de ensino de enfermagem em centro cirúrgico. Rev Esc Enferm USP 1973; 7(2): 152-76.

32. Castellanos BEP. Aplicação do processo de enfermagem ao cuidado do paciente na unidade de centro cirúrgico. Rev Esc Enferm USP 1978; 12(3): 170-86.

33. Bianchi ERF, Castellanos BEP, Gatto MAF, Silva A Fator de risco: enfoque na disciplina enfermagem em centro cirúrgico. Rev Esc Enferm USP 1986; 39(2/3): 26-32.

34. Jones JM, Sorell JM. Undergraduate OR experience: are we meeting student's needs? AORN J 1989; 50(2): 316-25. 
35. Reynolds A, Sizemore MH. Perioperative clinical experiences: opportunities for baccalaureate nursing students. AORN J 1986; 43(4): 901-6.

36. Nutting MA. A sound economic basis of schools of nursing. New York, G.P. Putnam's Sons; 1926. p.32

37. Hudson BC. The nursing process record. Nurs Outlook. 1955; 3(4):224-6.

38. Yura H, Walsh MB. The nursing process: assessing, planning, implementing, evaluation. $2^{\text {a }}$ ed. California: Appleton \& Lange; 1973.

39. Graves HH. Can nursing shed bureaucracy? Am J Nurs 1971; 71(3): 491-4

40. Carlson S. A practical approach to the nursing process. Am J Nurs 1972; 72(9): 1589-91.

41. Finch J. Systems analysis: a logical approach to a Professional nursing care. Nurs Forum 1969; 8(21): 177-91.

42. Polacci MM. Process recording by staff nurses. Nurs Outlook. 1963; 11:530-1.

43. Shaw $\mathrm{H}$. What aspects of the nursing process are applicable in theatre nursing and how can they be implements? NAT News 1983; 20(5): 11-13.

44. Porter-O'Grady T, Carter JA. Bringing the nursing process into the OR. AORN J. 1979 Nov;30(5):898-9, 902-3

45. Castellanos BEP, Jouclas VMG. Assistência de enfermagem perioperatória - um modelo conceitual. Rev Esc Enferm USP 1990; 24(3): 359-70.

46. Nagle GM. Perioperative nursing. Nurs Clin North Am 2006; 41(2):xi-xv.

47. Avelar MCQ, Silva A Assistência de enfermagem perioperatória: ensino em cursos de enfermagem. 2005; Rev Esc Enferm USP; 39(1): 46-52

48. Mendes MMR. O ensino de graduação no Brasil entre 1970 e 1994: mudança de paradigma curricular? [Tese] Ribeirão Preto: Escola de Enfermagem, universidade de São Paulo; 1996.

49. Guido LA, Silva MVG. Análise dos programas da disciplina de enfermagem em centro cirúrgico - uma visão das regiões sudeste e sul. In: Anais da III Jornada de Enfermagem em Centro Cirúrgico do Estado de São Paulo. 1989 jul. 3-7; Ribeirão Preto (SP) 
50. Conselho Regional de Enfermagem de São Paulo (COREN-SP). Documentos básicos de enfermagem. Resolução COFEN-214/1998. Dispõe sobre a instrumentação cirúrgica. São Paulo (SP): Escrituras; 2001.

51. Carvalho R, Farah OGD, Galdeano LE. Níveis de ansiedade de alunos de graduação frente à primeira instrumentação cirúrgica. Rev Latinoam Enferm 2004; 12(6): 918-23.

52. Grittem L, Meier MJ, Peres AM. Sistematização da assistência perioperatória: uma pesquisa. Online Braz J Nurs [periódico em internet] 2009; 8(3): Available from http://www.objnursing.uff.br/index.php/nursing/article/viewArticle/j.1676-4285.2009.

53. Fonseca RMP, Peniche APG. Enfermagem em centro cirúrgico: trinta anos após criação do Sistema de Assistência de Enfermagem Perioperatória. Acta Paul Enferm. 2009; 22(4):428-33.

54. Edel EM. Increasing patient safety and surgical team communication by using a count/time out board. AORN J 2010; 92(4): 420-24.

55. North American Nursing Diagnosis Association (NANDA). Diagnósticos de Enfermagem da NANDA: Definições e Classificação. 2005-2006. Porto Alegre (RS): Artmed; 2006.

56. Petersen C. ed. Perioperative Nursing Data Set. $2^{\text {nd }}$ ed. Denver, CO:AORN. Inc; 2007.

57. Viegas LS, Turrini RNT, Cerullo JASB. Na analysis of nursing diangoses for patients undergoing procedures in a Brazilian Interventional Radiology Suite. AORN J 2010; 91: 544-57.

58. American Association Colleges Nursing. (AACN) The Essencials of baccalaureate education for professional nursing practice. Washinton (DC): AACN; 2008. Available from: http://www.aacn.nche.edu/education-respources/BaccEssencials08.pdf [acessado em 24 mar 2012]

59. Tanner J. A practice-based approach to the selection of course content. Nurse Educ Today 2000; 20: 141-6.

60. Öhlén J, Furåker C, Jakobsson E, Bergh I, Hermansson E. Impact of the Bologna process in Bachelor nursing programmes: The Swedish case. Nurse Educ Today 2011; 31: $122-8$.

61. McGarvey H, Chambers M, Boore J. Development and definition of the role of the operating department nurse: a review. J Adv Nurs 2000; 32(5): 1092-100. 
62. McCausland L. A preceptored perioperative elective for baccalaureate nursing students. AORN J 2002; 76(6): 1032,34,36,40.

63. Callaghan A. Student nurses' perceptions of learning in a Perioperative placement. J Adv Nurs 2011; 67(4): 854-64.

64. Higarashi $\mathrm{IH}$, Nale N. O estágio supervisionado de enfermagem em hospitais como espaço d ensino-aprendizagem: uma avaliação. Ciênc Cuid Saúde 2006; 5(supl): 65-70.

65. Colliselli L, Trombini LHT, Leba ME, Relbnitz KS. Estágio curricular supervisionado: diversificando cenários e fortalecendo a interação ensino-serviço. Rev Bras Enferm 2009; 62(6): 932-7.

66. Martin RM, Sterne JA, Gunnell D, Ebrahim S, Davey Smith G, Frankel S. NHS waiting lists and evidence of national or local failure: analysis of health service data. BMJ 2004; 326(7382):1 [ periódico em internet] Available from:

http://www.bmj.com/highwire/filestream/321807/field_highwire_article_pdf/0.pdf

67. Morton PG. Creating a laboratory that simulates the critical care environment. Crit Care Nurs 1996; 16(6): 76-81.

68. Jeffries PR, McNelis AM, Wheeler CA. Simulation as a vehicle for enhancing practice models. Crit Care Clin N Am 2008; 20(4): 471-80.

69. Seropian MA, Brown K, Gavilanes JS, Driggers B. Simulation: not just a manikin. J Nurs Educ 2004; 43(4): 164-9.

70. Teixeira CRS, Kusumota L, Braga FTMM, Gaioso VP, Santos CB, Silva VLS, Carvalho EC. O uso de simulador no ensino de avaliação clínica em enfermagem. Texto \& Contexto Enferm 2011; 20 (esp): 187-93.

71. Ogilvie S, Cragg B, Foulds B. Perceptions of nursing students on the process and outcomes of a simulation experience. Nurse Educ 2011; 36(2): 56-8.

72. Cooper K, Bowers BAORN J. Demystifying the OR for baccalaureate nursing students. AORN J 2006; 84(5):827-36.

73. Silva EL, Leitão GCM. Fatores que interferem no ensino e na aprendizagem no centro cirúrgico. Rev SOBECC 2008; 13(1):32-7. 
74. Conselho Federal de Enfermagem. COFEN. Resolução 371/2010. Dispõe sobre participação do Enfermeiro na supervisão de estágio de estudantes dos diferentes níveis da formação profissional de Enfermagem. Disponível em http://site.portalcofen.gov.br/node/5885. Acesso em 22 mar 2012.

75. Bronzatti JAG, Ponteli SRC, Ferreti HH. Investindo na formação do futuro enfermeiro do bloco operatório. Rev SOBECC 2008; 13(4): 24-9.

76. Turrini RNT, Bianchi ERF, Graziano KU. Especialização em enfermagem em centro cirúrgico da escola de Enfermagem da USP/2003: perfil dos candidatos. Rev SOBECC 2004; 9(2): 24-7.

77. Turrini RNT. Unidades de Radiologia Intervencionista/Hemodinâmica: caracterização do enfermeiro e da estrutura da unidade. Rev Eletr Enf [periódico em internet] 2010; 12(2): Available from: http:// www.ufg.br/revista/v12/n2/v12n2a13.htm Acessado em 22 mar 2012.

78. Gattás MLB, Furegato ARF. A interdisciplinaridade na educação. Rev RENE 2007; 8(1): 85-91.

79. Gastaldo D. Interdisciplinaridade: questões conceituais e aplicadas. (editorial) Texto \& Contexto Enferm 2005; 14(3): 317-8.

80. Meirelles BHS, Erdmann AL. A interdisciplinaridade como construção do conhecimento em saúde e enfermagem. Texto \& Contexto Enferm 2005; 14(3): 411-8.

81. Chan DSK. Validation of the Clinical Learning Inventory. West J Nurs Res 2003; 25:519-32.

82. Murphy F, Rosser M, Bevan R, Warner G, Jordan S. Nursing students' experiences and preferences regarding hospital and community placements. Nurse Educ Pract 2012; in press p1-6. Available from http://sciencedirect.com/science/journal/aip/14715953

83. Borghetti SF, Caregnato RCA. Enfermagem de centro cirúrgico: expectativas versus vivências dos acadêmicos. Rev SOBECC 2011; 16(4): 18-25.

84. Page-Cutrara K. Perioperative nursing education in Canada: current and future perspectives. Can Oper Room Nurs J 2007; 25(1): 10-2,14-5,18-9.

85. Paoli MD, Caregnato RCA, Milão LF. Repensar a disciplina de centro cirúrgico na formação do enfermeiro. Nursing (São Paulo) 2007; 9(106): 136-41.

86. Martin KK. Meeting the challenge of perioperative education. AORN J 2011; 94(4): 377-84. 
87. Ellerton M, Gregor F. A study of trnasition: the new nurse graduate at 3 months. J Cont Educ Nurs 2003; 34(3): 103-8.

88. Vieira DA, Caires S, Coimbra JL. Do ensino superior para o trabalho: contributo dos estágios para a inserção profissional. Rev Brasil Orient Profis 2011; 12(1): 29-36. Disponível em: http://www.pepsic.bvs-psi.org.br/bop. Acesso em 22 mar 2012].

89. Blanco JMA. Pasado, presente y futuro de la cirugía menor en atención primaria. Aten Primaria 2011; 43(2): 58-60.

90. Dhumale R, Tisdale J, Barwell N. Over a thousand ambulatory hernia repairs in a primary care setting. Ann R Coll Surg Engl 2010; 92: 127-30.

91. Brasil. Ministério da Saúde. Ministério da Educação. Pró-Saúde. Programa Nacional de Reorientação da Formação Profissional em Saúde / Ministério da Saúde, Ministério da Educação. Brasília(DF): Editora do Ministério da Saúde; 2007. 78p. Disponível em: http://bvsms.saude.gov.br/bvs/publicacoes/07_0323_M.pdf [acessado em 23 mar 2012]

92. Laurell AC. A saúde doença-como processo social. Rev Latinoam Saúde. São Paulo: Ática; 1983. p.33-58.

93. Bagnato MHS, Rodrigues RM. Diretrizes curriculares da graduação de enfermagem: pensando contextos, mudanças e perspectivas. Rev Bras Enferm 2007; 60(5): 507-12.

94. Organização Mundial da Saúde. Segundo desafio global para a segurança do paciente: Manual - cirurgias seguras salvam vidas (orientações para cirurgia segura da OMS) / Organização Mundial da Saúde. Rio de Janeiro: Organização Pan-Americana da Saúde ; Ministério da Saúde ; Agência Nacional de Vigilância Sanitária, 2009. 29 p.

95. Davies R. The Bologna process: the quiet evolution in nursing higher education. Nurse Education Today 2008; 28: 935-42.

96. Salminen L, Stolt M, Saarikoski M, Suikkala A, Vaartio H, Leino-Kilpi H. Future challenges for nursing education - a European perspective. Nurse Educ Today 2010; 30: 233-8.

97. Cabral GP. Integração educacional no âmbito do ensino superior no Mercosul. In: Anais do XV Congresso Nacional do Conselho Nacional de Pesquisa e Pós-Graduação em Direito; 1996 nov 15-18; Manaus (AM). Disponível em: http://conpedi.org.br/manaus/arquivos/anais/bh/guilherme_perez_cabral.pdf. Acesso em 20 mar 2012. 
Apêndices 


\title{
APÊNDICES
}

\begin{abstract}
APÊNDICE 1

\section{QUESTIONÁRIO}

Este instrumento é parte da pesquisa "Análise do ensino de Enfermagem em Centro Cirúrgico nas escolas de enfermagem do Brasil". Contamos com sua colaboração no preenchimento do questionário e re-envio por e-mail aos pesquisadores (enfcc@usp.br). A pesquisa prescinde de TCLE, pois sua resposta implica em aceite na participação desta pesquisa. Mesmo assim garantimos o anonimato dos informantes e das escolas participantes, bem como a liberdade de retirar sua participação a qualquer instante. Informamos que os dados serão divulgados em eventos e periódicos científicos. Em caso de dúvida, consulte o CEP da EEUSP por e-mail: edipesq@usp.br.
\end{abstract}

Desde já, agradecemos sua colaboração!

Nome da instituição:

Local:

Duração do curso em semestre:

Carga horária do curso:

1. Há uma disciplina específica de enfermagem em centro cirúrgico em seu curso de graduação?

Sim: $\square$ Não:

Se sim, carga horária teórica e carga horária prática

2. Se não, o conteúdo é abordado no interior de outra disciplina?

Sim: $\square$ qual?

Não:

Se sim, carga horária teórica e carga horária prática

Qual a porcentagem desta carga horária $\mathrm{em}$ relação à carga total $\overline{\text { da disciplina? }}$

3. Qual o conteúdo teórico - prático ministrado?

( ) planejamento físico e recursos humanos em centro cirúrgico

( ) modelo do SAEP

( ) assistência de enfermagem nos períodos pré, trans e pós-operatório 
( ) riscos físicos, biológicos e psicológicos da equipe cirúrgica

( ) antissepsia e degermação

( ) posição cirúrgica

( ) instrumentação cirúrgica

( ) hemostasia (sutura e bisturi elétrico)

( ) anestesia

( ) monitorização do paciente cirúrgico

( ) recuperação anestésica

( ) riscos e controle de infecção em centro cirúrgico

( ) assistência ao paciente em cirurgia ambulatorial

( ) avanços tecnológicos no centro cirúrgico: videocirurgias, robótica, laser e outros

4. Como é desenvolvido o ensino de campo?

5. Em que semestre do curso o conteúdo de centro cirúrgico é ministrado?

6. Quantos docentes participam da administração desse conteúdo?

7. Os docentes têm formação específica para ministrar esse conteúdo?

8. Gostaria de fazer algum comentário sobre o conteúdo dessa disciplina?

9. Qual sua opinião sobre este conteúdo na formação do aluno de graduação?

10. Qual sua opinião sobre este conteúdo para a atuação do enfermeiro no contexto hospitalar?

11. Sua escola oferece cursos de Especialização em Enfermagem em Centro Cirúrgico?

Sim:

Não:

12. Quantos cursos de Especialização em Enfermagem em Centro Cirúrgico já foram oferecidos?

13. Quantos atestados de cursos de Especialização em Enfermagem em Centro Cirúrgico foram emitidos?

14. Outros comentários. 


\section{APÊNDICE 2}

\section{CARTA CONVITE}

Escola Prezado Diretor Prof

Vimos por meio desta apresentar o projeto de pesquisa intitulado "Análise do ensino de Enfermagem em Centro Cirúrgico nas escolas de enfermagem do Brasil" em desenvolvimento pelos docentes da Disciplina de Enfermagem em Centro Cirúrgico da Escola de Enfermagem da USP. A pesquisa tem por finalidade conhecer como ocorre o ensino de enfermagem em centro cirúrgico nas escolas de enfermagem no Brasil.

Para tanto elaboramos um instrumento semi-estruturado com perguntas relacionadas ao ensino de enfermagem perioperatória (existência de disciplina específica ou inserção do conteúdo em outra disciplina, conteúdo ministrado, carga horária, corpo docente, importância da disciplina, oferta de cursos de especialização).

O projeto foi submetido ao CEP da EEUSP ((processo $n^{\circ}$ 1018/2011)) e prescinde de Termo de Consentimento Livre e Esclarecido (TCLE), pois o "não preenchimento" do questionário enviado por e-mail será entendido como não interesse em participar da pesquisa. Mesmo sem o TCLE, garantimos o anonimato dos respondentes e da instituição participante, bem como a liberdade de retirar sua participação a qualquer instante. Qualquer dúvida relativa aos quesitos éticos da pesquisa segue o e-mail do CEP da EEUSP: edipesq@usp.br E TELEFONE: 30617548.

Informamos que os dados serão divulgados em periódicos e em seminários de discussão do ensino de enfermagem em centro cirúrgico.

Sua participação é muito importante para o fortalecimento da enfermagem perioperatória.

Agradecemos sua atenção. 